ขึ้
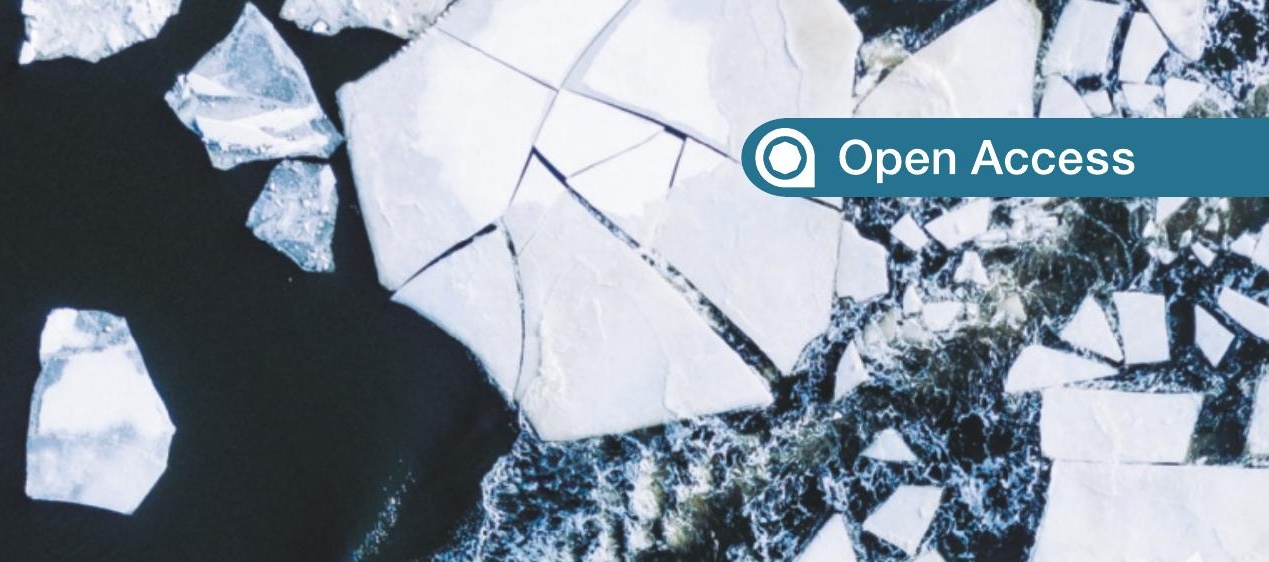

432
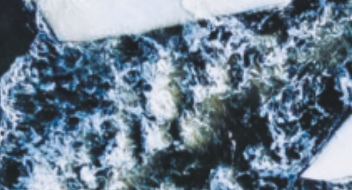

A.tin:
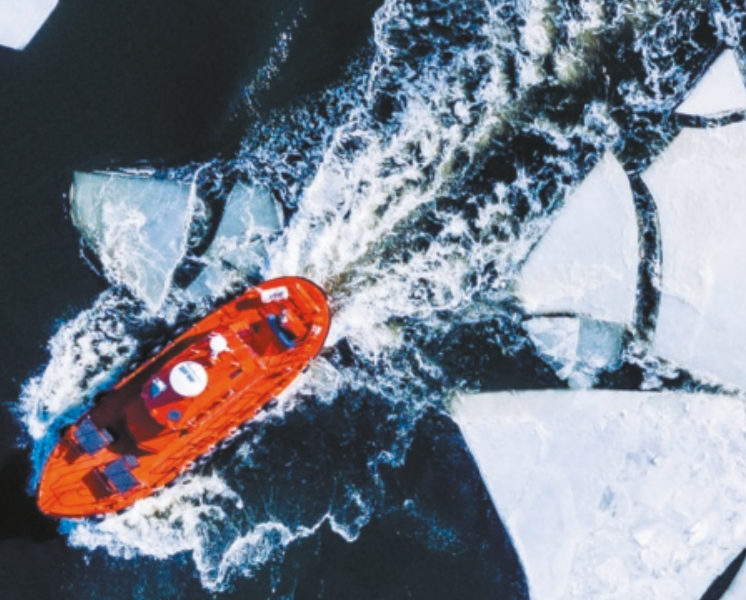
ats 5
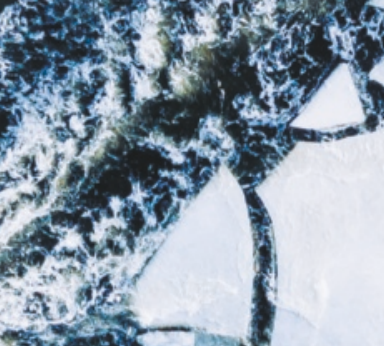

arans

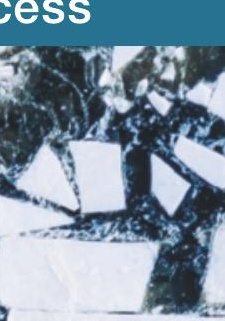




\section{Vulnerability in Scandinavian Art and Culture}


Adriana Margareta Dancus · Mats Hyvönen · Maria Karlsson

Editors

\title{
Vulnerability
}

in Scandinavian Art and Culture

\author{
palgrave \\ macmillan
}


Editors

Adriana Margareta Dancus

University of South-Eastern Norway

Bakkenteigen/Borre, Norway

Maria Karlsson

Uppsala University

Uppsala, Sweden
Mats Hyvönen

Uppsala University

Uppsala, Sweden

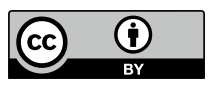

ISBN 978-3-030-37381-8 ISBN 978-3-030-37382-5 (eBook)

https://doi.org/10.1007/978-3-030-37382-5

(C) The Editor(s) (if applicable) and The Author(s) 2020. This book is an open access publication.

Open Access This book is licensed under the terms of the Creative Commons Attribution 4.0 International License (http://creativecommons.org/licenses/by/4.0/), which permits use, sharing, adaptation, distribution and reproduction in any medium or format, as long as you give appropriate credit to the original author(s) and the source, provide a link to the Creative Commons license and indicate if changes were made.

The images or other third party material in this book are included in the book's Creative Commons license, unless indicated otherwise in a credit line to the material. If material is not included in the book's Creative Commons license and your intended use is not permitted by statutory regulation or exceeds the permitted use, you will need to obtain permission directly from the copyright holder.

The use of general descriptive names, registered names, trademarks, service marks, etc. in this publication does not imply, even in the absence of a specific statement, that such names are exempt from the relevant protective laws and regulations and therefore free for general use.

The publisher, the authors and the editors are safe to assume that the advice and information in this book are believed to be true and accurate at the date of publication. Neither the publisher nor the authors or the editors give a warranty, expressed or implied, with respect to the material contained herein or for any errors or omissions that may have been made. The publisher remains neutral with regard to jurisdictional claims in published maps and institutional affiliations.

Cover image: Miemo Penttinen - miemo.net

This Palgrave Macmillan imprint is published by the registered company Springer Nature Switzerland AG

The registered company address is: Gewerbestrasse 11, 6330 Cham, Switzerland 


\section{ACKNOWLEDgements}

This book has developed out of a seminar on vulnerability in Scandinavia organized by Adriana Margareta Dancus in Kristiansand in December 2017. The seminar was funded by the Faculty of Humanities and Education at the University of Agder. We want to thank the University of Agder for their financial support, which allowed researchers across disciplines, university affiliations and national borders to meet and have productive discussions that eventually resulted in the current publication. Our many thanks go also to the interdisciplinary research programme Engaging Vulnerability at Uppsala University. Their generous funding made it possible for the editors to have optimal contact in the last phase of the project and to publish this anthology in Open Access. In addition, the academic libraries connected to the University of South-Eastern Norway and the University of Agder have contributed with funds to enable publication of this book in Open Access. Thank you to all these institutions for supporting the effort of scholars in humanities to make an impact outside their immediate research communities. We are also indebted to the Scandinavian artists that have given permission to publish images of their works: cartoonist Sara Olausson, the theatre group Institutet, and painter, director and pilot Simone Aaberg Kærn. The two blind peer reviewers have provided constructive criticism and insightful comments that have motivated us and helped the editors in making important editorial decisions, for which we are grateful. We also wish to express our deep appreciation to all the contributors to this edited volume, who 
have engaged with vulnerability in such a perceptive and nuanced way, and for an overall excellent collaboration throughout the project. Last, but not least, many thanks to the Palgrave Macmillan team for trusting the project, for optimal communication throughout and for excellent guidance in all phases of the publication process. 


\section{Contents}

1 Mobilizing Vulnerability in Scandinavian Art and Culture

Adriana Margareta Dancus, Mats Hyvönen and Maria Karlsson

Part I Gendered Bodies and Scandinavian Privilege

2 Conditional Vulnerability in the Films of Ruben Östlund

Asbjørn Grønstad

3 The Mother, the Hero, and the Refugee: Gendered Framings of Vulnerability in Margreth Olin's $D e$ andre (2012) and Leo Ajkic's Flukt (2017) Elisabeth Oxfeldt

4 Shared, Shamed and Archived Images of Vulnerable Bodies: On the Nexus of Media, Feminism and Freedom of Speech in Scandinavia

Bodil Marie Stavning Thomsen 
Part II The Vulnerable Subject and the Welfare State

5 Nowhere Home: The Waiting of Vulnerable Child Refugees

Odin Lysaker

6 Vulnerability When Fecundity Fails: Infertility and Assisted Reproductive Technologies in The Bridge Melissa Gjellstad

7 Uses of Vulnerability: Two Eras of Social Commitment in Swedish TV Drama?

Per Vesterlund

Part III Societies of Perfection and Resisting Normalcy

8 Vulnerability and Disability in Contemporary Nordic Literature: Linn Ullmann's Grace and Sofi Oksanen's Baby Jane Jenny Bergenmar

9 Life of a Fatso: Young, Fat and Vulnerable in a Scandinavian Society of Perfection Elise Seip Tønnessen

10 Vulnerable Viewer Positions: Queer Feminist Activists Watching Paradise Hotel Fanny Ambjörnsson and Ingeborg Svensson

Part IV Mobilising the Pain of Others

11 The Art of Begging Adriana Margareta Dancus 
12 Partitioning Vulnerabilities: On the Paradoxes of Participatory Design in the City of Malmö

Erling Björgvinsson and Mahmoud Keshavarz

13 Facing War: On Veterans, Wounds, and Vulnerability in Danish Public Discourse and Contemporary Art Ann-Katrine Schmidt Nielsen

14 The Politics of True Crime: Vulnerability and Documentaries on Murder in Swedish Public Service Radio's P3 Documentary

Mats Hyvönen, Maria Karlsson and Madeleine Eriksson 


\section{Notes ON CONTRibutors}

Fanny Ambjörnsson has a Ph.D. in Social Anthropology and is Associate Professor of Gender Studies in the Department of Ethnology, History of Religion and Gender Studies at Stockholm University. Her research interests include youth studies, queer theory and activism, queer temporality and care work. Among her recent publications is a book on the practice of cleaning, Tid att städa. Om städningens praktik och politik (Ordfront, 2018), an (updated) introduction to queer theory and politics Vad är queer? (Natur \& Kultur, 2016) and "Time to Clean-On Resistance and the Temporality of Cleaning" in Sociologisk Forskning (2019).

Jenny Bergenmar is Associate Professor of Comparative Literature in the Department of Literature, History of Ideas and Religion at the University of Gothenburg. Her research interests include Nordic fin-de-siècle literature, digital humanities, and disability in literature and life writing. She has previously published articles on autism; for example, 'Translation and Untellability. Autistic Subjects in Autobiographical Discourse', LIR Journal 2016, no. 6; and 'Autism and the Question of the Human', Literature and Medicine 2015, no. 1. She is currently working with a citizen humanities project and finishing a book about the European reception of Swedish women writers in the nineteenth century with colleagues at her department.

Erling Björgvinsson is Professor of Design at the School of Design and Crafts, Faculty of Fine Arts, Gothenburg University. A central topic of 
research is participatory politics in design and art-in particular, in relation to urban spaces, and the interaction between public institutions and citizens. He has published in international design and art journals and anthologies, and he is the co-editor of the international art research journal PARSE.

Adriana Margareta Dancus is Associate Professor at the University of South-Eastern Norway. Dancus researches at the crossroads of gender and ethnicity studies, with a focus on contemporary Scandinavian film and literature. Her most recent book, Exposing Vulnerability: Self-Mediation in Scandinavian Films by Women (Intellect Books/University of Chicago Press, 2019), is a cultural and socio-political analysis of contemporary films by Scandinavian women as they use their own experiences with globally relevant issues such as race, gender, mental illness, bullying and the trauma of migration.

Madeleine Eriksson is a Ph.D. candidate in Sociology within the GENPARENT project at the Swedish Institute for Social Research (SOFI). Her research focuses on lesbian couple's transitions from partners to parents. In particular, she is interested in the reasoning and the realization of the division of paid work, housework and care related tasks.

Melissa Gjellstad is Professor and Norwegian Programme Coordinator at the University of North Dakota in Grand Forks. Since 2014, Gjellstad has also spent summers teaching Norwegian literature at the University of Oslo International Summer School. Gjellstad's research interests revolve around gender studies and representations of mothers and fathers in millennial Norwegian literature. Her additional research interests include faculty governance in higher education, and has also translated Norwegian poetry and non-fiction.

Asbjørn Grønstad is Professor of Visual Culture in the Department of Information Science and Media Studies, University of Bergen. He is founding director of the Nomadikon Center for Visual Culture and the author/editor of 10 books, the most recent of which are Film and the Ethical Imagination (Palgrave, 2016) and Invisibility in Visual and Material Culture (co-edited with Øyvind Vågnes; Palgrave, 2019).

Mats Hyvönen is Media Scholar at Uppsala University and coordinator for the Engaging Vulnerability Research Programme. Hyvönen's research interests are mainly in media history, especially the study of the public 
sphere as a vulnerable space, and how the media both resist and facilitate that vulnerability. Recent publications include (as co-editor and contributor) Post-Truth, Fake News: Viral Modernity \& Higher Education (Springer, 2018).

Maria Karlsson is Senior Lecturer in Literary Studies and Rhetoric at the Department of Literature at Uppsala University. She is on the advisory board of the Engaging Vulnerability Research Programme (www. engagingvulnerability.se). Her research interests have mainly been narration in women's fin-de-siécle (nineteenth/twentieth century) fiction, audiences and media dramaturgy. Currently, her work is on begging letters from readers; on provocative art in a context of media and politics, and on vulnerability and the Swedish radio documentary.

Mahmoud Keshavarz is a Postdoctoral Researcher at the Engaging Vulnerability Research Programme, Department of Cultural Anthropology and Ethnology, Uppsala University. His research and publications sit at the intersection of design studies and politics of borders, movement and migration. His work has appeared in various journals and anthologies in English, Swedish and Persian. He is the author of The Design Politics of the Passport: Materiality, Immobility and Dissent (Bloomsbury, 2019), co-founder of the Decolonizing Design Group and, since 2019, co-editor of the journal Design and Culture.

Odin Lysaker is Professor of Ethics at the University of Agder. He holds a Ph.D. in philosophy from the University of Oslo. Although working broadly in the fields of moral philosophy, political philosophy and social philosophy, Lysaker's current main fields of research cover migration and health, democracy, free speech and pluralism, as well as environment and development. Here, he is particularly interested in the experiential and normative role of vulnerability. Lysaker is co-author (with Cindy Horst) of "Miracles in Dark Times: Hannah Arendt and the Refugee as "Vanguard" (Journal of Refugee Studies, 2019).

Ann-Katrine Schmidt Nielsen is a Ph.D. fellow in the Department of Communication and Culture, Aarhus University, Denmark. Her research focuses on the representations of veterans in Danish media, and contemporary art and literature. She is interested in research areas such as hauntology, remilitarization, affect and discourse, and literature and aesthetics. 
Elisabeth Oxfeldt is Professor of Scandinavian Literature at the University of Oslo, Norway. She leads the 'ScanGuilt' project (Scandinavian Narratives of Guilt and Privilege in an Age of Globalization). She is coeditor of, and contributor to, the open access anthologies: Skandinaviske fortellinger om skyld og privilegier $i$ en globaliseringstid (Universitetsforlaget, 2016) and Åne dører mot verden. Norske ungdommers mote med fortellinger om skyld og privilegier (Universitetsforlaget, 2017), as well as the themed journal issues: "The Happiest People on Earth? Scandinavian Narratives of Guilt and Discontent", Scandinavian Studies, 89(4), 2017, "Skyld og skam i Skandinavien", Kultur \& Klasse 125, 2018 (open access), and "Framing Scandinavian Guilt," Journal of Aesthetics and Culture, 2018 (open access).

Ingeborg Svensson has a Ph.D. in Ethnology at the Department of Cultural Anthropology and Ethnology at Uppsala University. Her research interests include queer theory and culture, ritual theory and feminist affect theory. She is co-editor of, and contributor to, the anthology Att känna sig fram. Känslor $i$ humanistisk forskning (2011) and has written on queer mourning and loss in, for example, Liket $i$ garderoben. Bögar, begravningar och 80-talets aidsepidemi (Ordfront, 2013) and "Affirm Survival: On Queer Strategies of Resistance at Queer Funerals", in Queer Futures Reconsidering Ethics, Activism, and the Political (Yekani, Kilian and Michaelis (eds), Ashgate, 2013).

Bodil Marie Stavning Thomsen Professor MSO, School of Communication and Culture, Aarhus University, Denmark. Her research focuses on media, aesthetics and culture with an emphasis on film, new media, haptic space, affective encounters and events. She is head of the research project Affects, Interfaces, Events (2015-2020) and research partner in the Canadian project Immediations (2013-2020). Bodil Marie is editorin-chief of Journal of Aesthetics and Culture. Recent titles include: Lars von Trier's Renewal of Film 1984-2014. Signal, Pixel, Diagram, 2018; "Dreams Rewired", in Icarus Films, 2016; "Interface Screenings", in Transvisuality, 2015; "Affective Attunement in the Field of Catastrophe", in Politics of Affect, 2015; "Signaletic, Haptic and Real-Time Material", in Journal of Aesthetics and Culture, 2012.

Elise Seip Tønnessen is Professor at Department of Nordic and Media Studies, University of Agder. Her research interests span from children's literature and media culture, with a particular emphasis on reception, to 
multimodal literacy. Currently, she is involved in a research project on the use of picture book apps in kindergartens. She has published on reading across the curriculum, on multimodal social semiotics in the classroom, and on children's literature in various media. Recent publications include Møter med barnelitteratur [Encounters with Children's Literature] (Universitetsforlaget, 2018, co-edited with Ruth Seierstad Stokke) and Multimodality and Aesthetics (Routledge, 2018, co-edited with Frida Forsgren).

Per Vesterlund is Senior Lecturer in Cinema Studies/Media Studies at University of Gävle. He gained his Ph.D. at Stockholm University in 2000 with a thesis on the films of Swedish film director Erik 'Hampe' Faustman. Swedish film and media policy, representations of the welfare state, and the use of cinema by the Swedish Labour movement are among his research interests. Latest publications: Schein: En biografi (2018); 'Why not make films for New York?': the interaction between cultural, political and commercial perspectives in Swedish film policy 1963-2013 (co-written with Olof Hedling) in Film Policy in a Globalised Cultural Economy (2018). 


\section{List OF Figures}

Fig. 11.1 Marcela Chereși and Ioan Luca Lăcătuș on display as beggars inside Malmö's Fine Arts Museum (C) Anders Carlsson at Institutet)

Fig. 11.2 Tears falling down Felicia's face. Panel from the graphic short story Felicia (2015) ( Sara Olausson)

Fig. 11.3 Raindrops falling down on Sara. Panel from the graphic short story Sara (2015) (@ Sara Olausson)

Fig. 13.1 By (C) Simone Aaberg Kærn, 2010, coloured pencil on rough paper. The 'soldiers' are wounded Afghans who have been made 'Danish' by changing their eye and hair colour

Fig. 13.2 By (C) Simone Aaberg Kærn, 2010, coloured pencil on rough paper. The 'soldiers' are wounded Afghans who have been made 'Danish' by changing their eye and hair colour 


\title{
Mobilizing Vulnerability in Scandinavian Art and Culture
}

\author{
Adriana Margareta Dancus, Mats Hyö̈nen \\ and Maria Karlsson
}

\section{On Vulnerability}

Vulnerability has become an important paradigm in our times. Today, the notion of vulnerability is used in very different contexts: health, climate and environment, crime, migration, military defence, computing, banking, human rights, urban development, education. It is an inevitable part of embodiment: all human bodies are vulnerable because we are

\author{
A. M. Dancus $(\bowtie)$ \\ Department of Languages and Literature Studies, University of South-Eastern \\ Norway, Bakkenteigen/Borre, Norway \\ e-mail: adriana.m.dancus@usn.no \\ M. Hyvönen · M. Karlsson \\ Uppsala University, Uppsala, Sweden \\ e-mail: mats.hyvonen@antro.uu.se \\ M. Karlsson \\ e-mail: maria.karlsson@littvet.uu.se \\ (C) The Author(s) 2020 \\ A. M. Dancus et al. (eds.), \\ Vulnerability in Scandinavian Art and Culture, \\ https://doi.org/10.1007/978-3-030-37382-5_1
}


dependent on each other and our environment to survive. Vulnerability is also relational and social, manifesting different forms contingent on variables such as gender, race, ethnicity, class, age, able-bodiedness, sexuality, religion, nationality, occupation, historical circumstance, geographic location, and so on.

Scholarship on vulnerability has flourished since 2010, including feminist perspectives that seek to recuperate vulnerability as more than a weakness (Butler 2004, 2009; Butler et al. 2016; Fineman and Grear 2013; Gilson 2014; Mackenzie et al. 2014; Koivunen et al. 2018). Leading feminist thinkers such as Judith Butler point out that vulnerability encompasses many paradoxes and tensions. On the one hand, vulnerability can feed a crisis mentality and legitimize the control of minorities such as women, migrants or LGBTs. On the other hand, vulnerability can become an important source of resistance and social transformation such as, for example, in acts of civil disobedience when unarmed citizens expose their bodies to police and army in a call for justice. Moreover, groups in positions of power commonly project vulnerability onto others, whom they seek to contain and exclude, such as when Norwegian and Swedish authorities launched aggressive assimilation policies meant to 'civilize' the aboriginal Sami at the end of the nineteenth century. The very same groups can, however, also use the language of vulnerability about themselves, for instance when Scandinavians today talk about their own vulnerability to Eastern European citizens begging on the streets of their cities.

In this book, we explore various forms of vulnerability as staged and mediated in contemporary Scandinavian art and culture. Internationally, postwar Scandinavia has been commonly presented as a haven for happy, affluent, equal, progressive, and design-interested people. Since the turn of the millennium, however, factors such as the increased popular appeal of neo-Right parties, terror attacks in all the Scandinavian capitals, significant demographic changes because of immigration, an aging population, environmental disasters, high levels of sick leave and suicidal rates are disrupting this image. In other words, new discourses of Scandinavian vulnerability are developing. These are cultured, speaking of Scandinavia's specificity and uniqueness, but they are also closely embedded in global politics. Contemporary Scandinavian art installations, fiction and documentary films, TV series, literature, design, graphic art, radio podcasts and various campaigns on social media are important arenas for the 
articulation of such emerging discourses on vulnerability. Indeed, as postMarxist theorist and critic Raymond Williams (1977) underlines, art in general and, we should add, social media, are particularly suited to capture social changes before they are rationalized, classified, and institutionalized. From this perspective, paying attention to cultural representations of vulnerability in Scandinavia will necessarily provide important insights into not only how established ideas of what it means to be Scandinavian are currently being renegotiated with new threats, but also opportunities on the horizon. Moreover, as Asbjørn Grønstad explains in his contribution to this book, because fiction harbours the dramatic as part of its core structure, it is well-suited to throw light on the complexities embedded in the condition of vulnerability as discussed by recent vulnerability scholarship. Fiction, then, and also art, can generate a vocabulary that we can use to talk about social change, as well as to obtain a critical understanding of vulnerability across disciplines, across media, across national borders. By bringing attention to examples from Denmark, Norway and Sweden, the chapters in this book consider why and how vulnerability as staged through Scandinavian art and culture matters to more than scholars of Scandinavian film, literature, media and cultural studies.

Engaging vulnerability as a theoretical lens is, in many respects, a risk sport. There are several reasons for this, of which we wish briefly to address four aspects of specific relevance to this anthology: the problem of ontology, the question of privilege, unease with the state, and the challenge of using a concept in motion. First, in the introduction to The Power of Vulnerability. Mobilising Affect in Feminist, Queer and Anti-racist Media Cultures, Koivunen et al. (2018, p. 10) point out that, at the forefront of media theoretical uses of vulnerability, there has been an understanding of vulnerability as an ontological condition shared by all humans. Koivunen et al., as well as other scholars, claim that this penchant to discuss vulnerability as an existential condition has resulted in abstract theorizing that loses sight of the fact that some groups and individuals are more vulnerable than others (Koivunen et al. 2018; Kulick and Rydström 2015). When various forms and degrees of embodied vulnerability are levelled out, specific political claims run the risk of being diluted into ontological arguments (Butler 2016).

In our analyses, the existential dimension of vulnerability is always discussed in relation to the politics of vulnerability. We show how the examples analysed resonate across the political field and how vulnerability is used as a specific political language. In that respect, we attend to 
various forms of vulnerability embodied by groups and individuals that have missed the safety net of the Scandinavian welfare state and fallen between the cracks: Romanian citizens begging on the streets of Scandinavian cities (Dancus), unaccompanied refugee minors (Lysaker and Oxfeldt), individuals who seek help from assisted reproductive technology (Gjellstad), women of whom images of their naked bodies have been shared online without their consent (Thomsen), high school dropouts (Tønnessen), young queers confronting reality TV's fixation with heterosexual coupling (Ambjörnsson and Svensson), individuals who seemingly opt for assisted suicide (Bergenmar), and groups who are positioned and framed as vulnerable in participatory design projects (Björgvinsson and Keshavarz). Provocatively, these lives, experiences and voices are mediated in ways that often block compassion. This is intriguing given the common claim that spectacles of vulnerability call for compassionate responses that erase the power mechanisms that produce vulnerability in the first place. Power, then, is at the forefront of our investigations.

Moreover, we explore the relationship between vulnerability and power by setting the limelight not only on those at the margins, but also on those at the centre. This brings us to the second reason given: why vulnerability as a theoretical lens can be problematic when one loses sight of the fact that those in positions of power also deploy the language of vulnerability about themselves. To address this concern, several of the contributions in this anthology show how vulnerability becomes a particularly productive prism to explore questions of Scandinavian privilege. Vulnerability in such cases is unpleasant and awkward, pointing to random, undeserved, and even repulsive advantages and entitlements. It is the white woman who wants to do good by turning into a global mother of sorts (Oxfeldt), the white man who has an emotional collapse following an initial act of selfishness (Grønstad), the high school dropout coming from a well-off, highly educated family (Tønnessen), companies and institutions empowering themselves instead of the groups with which they collaborate and that they regard as vulnerable (Björgvinsson and Keshavaraz), or the Scandinavian art lover who is uncomfortably confronted with the pain of the Other in the museum's white room (Dancus) and through multi-layered graphic art (Nielsen). The problematic connection between vulnerability and privilege becomes evident, while the ways in which Scandinavian privilege is thematized and staged open up for ethical reflections with regard to whose vulnerability counts and in what situations. 


\section{ON THE STATE}

A third problem we need to address, particularly in the Scandinavian context, is the question of the state and its position with regard to vulnerability. American legal theorist and political philosopher Martha Fineman (2013) advocates that the state should take an active role in addressing social structures and conditions that acerbate individual vulnerability. Fineman's vulnerability thesis thus builds on two pillars: the institutionalization of a responsive state that, in turn, recognizes the subject not as autonomous and invulnerable, as is the case in the neo-liberal discourse, but as inherently vulnerable (Fineman 2013, p. 13). The editors of the volume Vulnerability in Resistance remain sceptical of Fineman's idea because, as they underline, the state has historically functioned as a paternalistic political and social institution (Butler et al. 2016, p. 2).

This unease with the state is intriguing to look at from a Scandinavian perspective. The Scandinavian welfare state can no doubt be referred to as a form of response to vulnerability, both in its original ambition to erase it, and in a certain ethics produced by it over the years; a set of values sometimes referred to as 'Scandinavian exceptionalism' (e.g. Pratt 2008). Despite the high standards of living in the Scandinavian countries, and despite Scandinavia's investment in modernity and values such as equality and solidarity, there have been numerous discussions of its failures. These failures are, at times, framed as a question of institutional vulnerability, such as, for example, in the recent anthology Sustainable Modernity. The Nordic Model and Beyond (Witoszek and Middtun 2018), which discusses the sustainability of the Nordic welfare state in the age of globalization, cultural collisions, digital economy, fragmentation of the work/life division and often intrusive EU regulation. In Scandinavian art, the failures of the welfare state are commonly framed as a critique pointed at its impersonal, inefficient, inhuman, stiff and even discriminating bureaucracies. Moreover, as Per Vesterlund shows in his contribution to this volume, the critique of the welfare state has been more or less constant in Swedish TV drama since the golden age of the Swedish welfare state in the late 1960s, although it was the Scandinavian crime fiction of the 2000s, or what has been labelled 'Scandi crime' or 'Nordic noir', that has made this critique travel far and wide through its international success.

Several chapters in this anthology show how the Scandinavian states fail to be responsive to vulnerability in questions related to fertility and reproduction (Gjellstad), hate porn (Thomsen) or immigration (Oxfeldt, 
Lysaker, Björgvinsson and Keshavarz, Hyvönen et al.). They also make evident the differences between Denmark, Norway and Sweden, and how the various Scandinavian welfare states address vulnerability not as a block but, rather, according to specific national concerns, values and interests. In her analysis of the TV series The Bridge, Gjellstad explicitly reflects on the differences between Denmark and Sweden with regard to assisted reproductive technologies, and how these differences have led to reproductive tourism across the Scandinavian borders. Through an analysis of Simone Kærn's portrait series of wounded Danish politicians and soldiers, Nielsen brings attention to emerging national discourses in Denmark that underline Denmark's role in global politics as a warring coalition partner in the 2000s. This focus on war and Danish casualties stands in contrast to how neighbouring Norway and Sweden, respectively, continue to see themselves as peacemakers and neutral. Also when it comes to policies on immigration and integration, the Scandinavian countries differ a great deal, with Sweden accepting the largest number of immigrants in relation to its population (Karlsdóttir et al. 2018; Hernes et al. 2019). Several of the contributions in this volume indirectly address those differences by explicitly dealing with the cultural and political discourses pertinent in the national contexts from which they write. For example, Oxfeldt analyses two Norwegian documentaries (film and TV) about migrants; Hyvönen et al. use examples of Swedish public service radio podcasts about murders committed by migrants; and Björgvinsson and Keshavarz make their points partly by analysing a participatory design project that included a music grassroots organisation aimed at countering negative images of migrants projected by the mass media.

While all the contributions in the anthology focus on examples taken from the 2000s, they all reflect in various ways the transformations Denmark, Norway and Sweden have undergone since the 1960s. For example, several of the chapters in this book discuss how intensified mediation has impacted the ways in which Scandinavians make sense of their lives. Thomsen points out that freedom of speech has traditionally been highly valued in Scandinavia (freedom of speech has been constitutional in Sweden since 1809, in Norway since 1814, and in Denmark since 1849). She further shows how the advent of the Internet and social media has challenged traditional conceptions of this freedom, not least in connection to hate-speech and fake-news, but also in relation to revenge-porn and cyber bullying. Vesterlund reveals how depictions of the mass media in Swedish TV drama have changed since the 1960s, from the mass media 
being an alienating force to becoming a nostalgic object activating memories from the heyday of the Swedish welfare state project. Further, Ambjörnsson and Svensson show how watching a reality TV format such as Paradise Hotel gives queer feminist activists in the 2000s an opportunity to negotiate their own vulnerabilities while also resisting heteronormativity. Finally, Hyvönen et al. argue that radio documentaries on famous Swedish murders aired by Swedish public service radio channel P3 in the 2000s commonly rely on rhetorical mechanisms that endanger the public service aim of impartiality; for instance, when covering crimes committed by people with an immigrant background, or implicitly suggesting a politics of mobility aimed at women and female children.

It is evidently the case that the Scandinavian welfare states are in motion, incorporating ideas about what the welfare state is, what it does, and what its relation is - or should be-to its subjects. The same is true of the concept of vulnerability, which brings us to the fourth and final point we wish to address when reflecting on the deployment of vulnerability as a theoretical lens. As Koivunen et al. put it, 'the language of vulnerability is clearly in motion', and it is indeed hard to predict 'where the language of vulnerability will go' (Koivunen et al. 2018, p. 20). We find this stimulating and productive, and by no means do we want to fixate on the various meanings and uses of the concept of vulnerability. Instead, our collection of chapters shows how the language of vulnerability goes North, while also acknowledging that it comes from elsewhere and that it is still on the go, and will keep wandering. Moreover, inspired by affect theorists such as Sara Ahmed (2004a, b), this anthology tracks down how vulnerability moves us, not only towards each other, but also against one another. These push-and-pull movements, and the frictions caused by them, are at the heart of this volume. In other words, we show how vulnerability as a lens does something-it mobilizes, puts in motion, is generative, and is not merely referring to passive positions.

\section{Overview OF THE BOOK}

The present volume consists of 13 chapters structured in four parts. Part I, Gendered Bodies and Scandinavian Privilege, contains three chapters that, in different ways and with different examples, analyse vulnerability in relation to Scandinavian privilege and gendered bodies. Although gender equality is one of the most often waved ideals of the Scandinavian welfare state, and indeed realized in many ways, there are still significant 
gender inequalities and issues in Norway, Denmark and Sweden. This can be seen, for example, in relation to the distribution of power positions, salaries, and domestic violence. In particular, the word 'privilege' refers to two things in this part of the volume. First, the privilege to live in a society where you are allowed to address all matters of gender inequality because of the law and a certain ethics. Second, a paradox to the first, the social privilege that comes from being able to perform a specific hegemonic (white) masculinity that is traditionally 'strong', but that is also supportive of the welfare state's gender equality flagships. Examples of this are an active fatherhood and the sharing of household work (Gottzén and Jonsson 2012) or, of course, the privilege that still goes with respectable (white) middle-class femininity (Dahl 2014; Ambjörnsson 2019).

Filmic representation of the vulnerability of masculinity is addressed in Asbjørn Grønstad's chapter on the films of the Swedish director and writer Ruben Östlund. With a particular emphasis on Östlund's 2017 feature The Square, the chapter launches the concept of conditional vulnerability, defined as exposure to contingent forces that may threaten to undermine one's social privilege. Among those is that of middle-class masculinity, which Östlund carefully scrutinizes in The Tourist (2014), where the main character's failure to perform normative masculinity tears him apart. Appraising some of the current research on vulnerability in philosophy and related fields, Grønstad's analysis zeroes in on the ways in which conditions of vulnerability are inscribed into the aesthetic fabric of fictional films.

Privileged femininity, but also a partly marginalized masculinity, is dealt with in Elisabeth Oxfeldt's chapter 'The Mother, the Hero, and the Refugee', which analyses how vulnerability is framed by gender in Margreth Olin's documentary film De andre (Nowhere Home 2012) and the documentary TV series Flukt (NRK 2017) hosted by Leo Ajkic. Both Olin and Ajkic have been particularly strong on the issue of contemporary war refugees. Oxfeldt's focus is on the way Olin and Ajkic relate the vulnerability of the refugee Other to their own. Olin does this especially through the national trauma brought about by the Oslo Massacres $(22$ July 2011), while Ajkic activates his personal memories of fleeing from Bosnia in the late 1990s. In both cases, the child serves as a significant figure of vulnerability. Olin's role as a postnational mother in relation to the child is explored in the chapter, as well as Ajkic's hybrid masculinity.

A privilege taken for granted in Scandinavian feminism is freedom of speech. But how do young women master this in relation to bodily 
exposure on the internet? Bodil Marie Stavning Thomsen's chapter analyses vulnerable bodies in the light of the practice of sharing, shaming and archiving images. Thomsen explores the nexus of media, feminism and freedom of speech, and relates the vulnerability in cyberbullying and hate porn to historical questions on women's liberation movements and the constitutional rights of free speech. Her reading of the interfacial exchanges in the TV series SKAM connects freedom of speech to the ability to master media. Young feminists both argue against sharing of images without consent and acclaim playfulness on the Internet. Thomsen discusses the intensification of affect in interfaces as a folding between feeling the body from within and seeing it from the outside, and thus the consent to have one's image shared on the Internet is key to a freedom of expression in which vulnerability plays a creative role.

In the second part of the book, The Vulnerable Subject and the Welfare State, matters of the vulnerable subject and the welfare state are discussed in connection with examples taken from Scandinavian film and TV. How does the welfare state fail to respond to the call of some of its vulnerable subjects? To what extent should the state respond to individual vulnerability (Fineman 2013, p. 3) and to what extent should it back off, so as not to repeat a history of paternalism and social institutionalization (Butler et al. 2016, p. 2)? The three chapters in this part touch on these questions by discussing the state's responsibility towards unaccompanied minors and people seeking help from assisted reproductive technologies (ART), as well as by flashing up the various interactions between citizens and state bureaucracy from the zenith of the welfare state in the 1960s to an age of accentuated mediation in the 2000s.

The subject of Odin Lysaker's chapter is 'particularly vulnerable' child refugees in the light of UN human rights. Like Oxfeldt, Lysaker also addresses the documentary film Nowhere Home by Margreth Olin, but with a different philosophical purpose. In Lysaker's view, the film primarily illuminates the vulnerabilities and injurabilities of child migrants subjected to prolonged waiting. The unaccompanied minors are only offered temporary residence. Olin's film identifies why they can be characterized as particularly vulnerable by having their childhoods put on hold. Lysaker conceives vulnerability as an existential precondition in terms of something bodily and enabling. Because of their particular vulnerability, prolonged waiting can violate child refugees' inherent dignity, bodily health, life quality and human rights. In light of Olin's documentary, Lysaker 
therefore introduces a 'waiting guarantee', which sets an ethical threshold level regarding such violations of their vulnerability.

While the Scandinavian welfare state fails in its responsibility towards unaccompanied minors, whose childhood is put on hold, it does better when it comes to assisted fertility treatment, even though the LGBT communities have not had the same rights as heterosexuals for a long time. ART transformed the treatment of infertility in Scandinavia and, in the course of a forty-year history, Denmark has become an international leader in the proportion of babies born via ART. Melissa Gjellstad's chapter discusses vulnerability when fecundity fails as depicted in the Danish-Swedish TV series The Bridge (2011-2017). She analyses the fourth season, which includes a subplot of infertility and state responsiveness to the involuntarily childless, the fertile donors, and the donor-conceived children. Gjellstad outlines milestones in the development of medically assisted reproduction in Denmark and Sweden, including policy differences still present in 2019 regarding procedures such as surrogacy. She considers those states in an analysis of The Bridge from the perspective of the relationship between the vulnerable subject and the state.

A historical perspective on the Scandinavian welfare state is also present in Per Vesterlund's comparative analysis between two eras of Swedish TV drama; namely, TV series from the heyday of the Swedish welfare state project in the late 1960s and early 1970s, and TV series from the 2000s. In his chapter, Vesterlund argues that the interplay between vulnerable societies and vulnerable individuals is a key theme in the TV series he analyses. In particular, Vesterlund identifies two thematic clusters that are present in productions from both periods: health care and the mass media. In connection to the latter, Vesterlund argues that media users in the productions from the late 1960s and early 1970s are depicted as vulnerable victims of the effects of mass media while, in the productions of the 2000s, the mass media have become a nostalgic token of a welfare state that no longer exists.

The third part of the book, Societies of Perfection and Resisting Normalcy, presents close readings of literature and analyses of interviews with reality TV viewers. The chapters are interconnected through their investigation of and resistance to normativity and perfection. How is vulnerability distributed and how is it handled from positions (posed as being) on the outside, or in the margins of, normalcy? And furthermore-in societies where the performance of heteronormativity constantly leaks (Butler 1990), and where psychiatric diagnoses of different kinds are 
increasing-can vulnerability be used to include that which has traditionally been regarded as deviances in a wider human spectrum? In the first chapter of the part, Jenny Bergenmar explores how the concept of vulnerability can provide new perspectives on disability by analysing two novels of Nordic literary fiction: Linn Ullmann's Grace (2002) and Sofi Oksanen's Baby Jane (2005). The chapter consists of two parts-the first outlines the relation between vulnerability and disability in key texts in the field of literature and disability, and the second part uses the concept of vulnerability to explore disability in Grace and Baby Jane. The analysis reveals that a focus on vulnerability may help to disrupt the idea of 'the disabled' as a separate group and as a specific theme in literature. An acknowledgement of a shared-albeit not equally distributed-vulnerability may be used to challenge ableism and place disability on a human continuum of abilities.

Also the subsequent chapter in the third part of the book is a close analysis of a Scandinavian novel - this time an example from Young Adult literature: Miss by Synne Sun Løes (2017). In the novel, the main character, Ea, copes with being fat by resisting becoming 'Little Miss Perfect'. Her other position is, however, more destructive - the feeling of being a misfit. Elise Seip Tønnessen analyses Miss from this dual perspective and asks two main questions: what has made this teenager from a welloff family so vulnerable, and how is her resistance expressed? Discussing vulnerability and resistance, Tønnessen explores how Ea positions herself as an outsider through bodily and social protest, which makes her both vulnerable and strong.

In the last chapter of this part, Ambjörnsson and Svensson analyse queer feminist activists watching the reality show Paradise Hotel. Inspired by feminist research's interest in consumers, the reality TV format is seen as centred around intervention, participation and emotionality, rather than merely representation. The viewers' emotional reactions of approaching and distancing themselves from the programme are used to explore ways of handling and managing vulnerability. A specific queer feminist viewing position is localized, where the viewers' feminist identification with female subordination is paired with a camp attitude towards the despised and failed. Thus, through embracing and exposing themselves to the excessive, shameless and often sexist and homophobic representations in the show, they negotiate marginalization, subordination and a longing for inclusion in mainstream society, as well as their own potential middle-class advantage. 
Sara Ahmed's (2004a) thoughts on orientation through emotional reactions are important to the last cluster of chapters in this book, Mobilizing the Pain of Others. In various ways, all four chapters in the fourth part deal with the mobilization of the pain of others. Adriana Margareta Dancus's chapter, 'The Art of Begging', discusses how artists initiate collaborations with migrants from Romania who beg on the streets of Scandinavian cities. It analyses two art projects: a performance for which the theatre group Institutet paid two migrants begging in the Swedish city of Malmö to pose as 'beggars' inside the Malmö Fine Arts Museum, and a multiplatform project led by the cartoonist Sara Olausson in collaboration with Felicia Iosif, a homeless woman in Stockholm. In both projects, vulnerability as a condition commonly projected onto migrants is deployed in a tactical field, with unpredictable changes and results. Dancus shows how the migrants involved in the first project were not merely passive and exposed, but partly active when lending their bodies to artists at Institutet. It also sheds light on how Olausson and Iosif shared vulnerability in ways that provoked angry reactions in a political climate that is increasingly hostile to begging migrants.

Scandinavian participatory design projects also collaborate with vulnerable groups, as is discussed in Björgvinsson and Keshavarz's chapter. The authors start out in the welfare state of the 1970s, and engagement with trade unions, and bring the reader forward to the local communities of today. The claims of participatory design in initiating bottom-up change, democratic engagement and overcoming the vulnerabilities of marginal groups are questioned, and so are the presuppositions in relation to vulnerabilities associated with different groups. The analysis of a participatory design project in Malmö makes clear how the call to, and the process of, participation always happen in an already partitioned world. Participation does not necessarily give equal voices to the parts but, rather, produces new ones, ignores others and lifts up particular parts depending on the power relations. It is shown that participatory methods can generate lessrecognized vulnerabilities and ignore the resistance against uneven participation made by vulnerable groups.

While collaborations with the Other build on direct contact, warfare relies on the opposite: distance. Ann-Katrine Schmidt Nielsen's chapter, 'Facing War: On Veterans, Wounds, and Vulnerability in Danish Public Discourse and Contemporary Art', analyses the two entangled RAMT portrait series by the controversial Danish artist Simone Aaberg Kærn. 
Nielsen places the portraits in a Danish media and political context characterized by a dominant focus on the wounds and scars of Danish veterans, and the effective effacement of the Other, the Afghan, Iraqi, Libyan and other victims of war. The chapter traces the multiple layers of Kærn's portrait series to analyse how they play with the in/visibilities of vulnerable bodies, and how the series may lead us to a haunting encounter with the vulnerable, distant Other of contemporary Danish warfare.

In the final chapter, Hyvönen et al. focus on P3 Documentary, the most popular pod radio format in Sweden with 600,000 listeners (in a country of 10 million people). The majority of the programmes stage crime and are most commonly famous murder cases. Of the murder documentaries, 19 are analysed in relation to the choice of cases; the use of victims, perpetrators, families and experts; the horror genealogy and the increasingly suspense driven and stereotyped dramatic form that has developed over the years. Hyvönen et al. show how listeners are vulnerable to the circulation, invocation and mobilization of emotions in the programmes, and that the format does significant political work. A politics of mobility-aimed mainly at women and children-is distributed, and, in cases involving migrants, the pain of the Other is used in processes of othering that complicate the public service aim of impartiality.

\section{REFERENCES}

Ahmed, S. (2004a). The Cultural Politics of Emotion. Edinburgh: Edinburgh University Press.

Ahmed, S. (2004b). Affective economies. Social Text, 22(2), 117-139.

Ambjörnsson, F. (2019). I en klass för sig: Genus klass och sexualitet bland gymnasietjejer (2nd ed., Doctoral dissertation). Stockholm: Ordfront.

Butler, J. (1990). Gender trouble: Feminism and the subversion of identity. New York: Routledge.

Butler, J. (2004). Precarious Life: The Powers of Mourning and Violence. London and New York: Verso.

Butler, J. (2006). Gender Trouble: Feminism and the Subversion of Identity. London and New York: Routledge.

Butler, J. (2009). Frames of War: When Is Life Grievable?. London and New York: Verso.

Butler, J. (2016). Rethinking vulnerability and resistance. In J. Butler, Z. Gambetti, \& L. Sabsay (Eds.), Vulnerability in Resistance (pp. 12-27). Durham, NC, and London: Duke University Press. 
Butler, J., Gambetti, Z., \& Sabsay, L. (Eds.) (2016). Vulnerability in Resistance. Durham, NC, and London: Duke University Press.

Dahl, U. (2014). Skamgrepp: Femme-inistiska essäer. Stockholm: Leopard.

Fineman, M. A. (2013). Equality, autonomy, and the vulnerable subject in law and politics. In M. A. Fineman \& A. Grear (Eds.), Vulnerability: Reflections on a New Foundation for Law and Politics (pp. 13-28). Farnham: Ashgate.

Fineman, M. A., \& Grear, A. (Eds.). (2013). Vulnerability: Reflections on a New Foundation for Law and Politics. Farnham: Ashgate.

Gilson, E. C. (2014). The Ethics of Vulnerability: A Feminist Analysis of Social Life and Practice. New York: Routledge.

Gottzén, L., \& Jonsson, R. (Eds.). (2012). Andra män: Maskulinitet, jämställdhet och normskapande. Malmö: Gleerups.

Hernes, V., Arendt, J. N., Andersson Joona, P., \& Tronstad, K. R. (2019). Nordic Integration and Settlement Policies for Refugees: A Comparative Analysis of Labour Market Integration Outcomes. Copenhagen: Nordic Council of Ministers/Publication Unit.

Karlsdóttir, A., Norlén, G., Rispling, L., \& Randall, L. (Eds.). (2018). State of the Nordic Region: Immigration and Integration Edition. Copenhagen: Rosendahls.

Koivunen, A., Kyrölä, K., \& Ryberg, I. (Eds.). (2018). The Power of Vulnerability: Mobilising Affect in Feminist Queer and Anti-racist Media Cultures. Manchester: Manchester University Press.

Kulick, D., \& Rydström, J. (2015). Loneliness and Its Opposite: Sex, Disability, and the Ethics of Engagement. Durham, NC, and London: Duke University Press.

Mackenzie, C., Rogers, W., \& Dodds, S. (2014). Vulnerability: New Essays in Ethics and Feminist Philosophy. New York: Oxford University Press.

Pratt, J. (2008). Scandinavian exceptionalism in an era of penal excess: Part I: The nature and roots of Scandinavian exceptionalism. The British Journal of Criminology, 48(2), 119-137.

Williams, R. (1977). Structures of feeling. Marxism and Literature (pp. 128135). Oxford: Oxford University Press.

Witoszek, N., \& Middtun, A. (2018). Sustainable Modernity: The Nordic Model and Beyond. London: Routledge. 
Open Access This chapter is licensed under the terms of the Creative Commons Attribution 4.0 International License (http://creativecommons.org/licenses/ by $/ 4.0 /$ ), which permits use, sharing, adaptation, distribution and reproduction in any medium or format, as long as you give appropriate credit to the original author(s) and the source, provide a link to the Creative Commons license and indicate if changes were made.

The images or other third party material in this chapter are included in the chapter's Creative Commons license, unless indicated otherwise in a credit line to the material. If material is not included in the chapter's Creative Commons license and your intended use is not permitted by statutory regulation or exceeds the permitted use, you will need to obtain permission directly from the copyright holder.

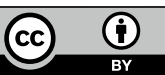


Gendered Bodies and Scandinavian Privilege 


\title{
Conditional Vulnerability in the Films of Ruben Östlund
}

\author{
Asbjørn Grønstad
}

In August, tornadoes caused by the tropical storm Harvey ravage the Houston area. In September, a major earthquake strikes Mexico City. In October, a mass murderer butchers 58 people and injures almost 500 others from his hotel window in Las Vegas. Later the same month, an uncontrollable wildfire in the Santa Rosa area north of San Francisco kills over 40 people and destroys thousands of homes. These disasters, which take place within the span of six to seven weeks in the early fall of 2017, transpire against the backdrop of a rapidly accelerating environmental crisis and-with seemingly mentally ill political leaders in North Korea and the USA - the perhaps most perilous geopolitical condition in recent memory. Rarely has it made more sense to consider one of the most defining circumstances of our lives, both as individuals and as a species. That circumstance is vulnerability.

Cataclysmic events tend to place the condition of being existentially exposed on the agenda, as when Judith Butler wrote about precarious life

\footnotetext{
A. Grønstad ( $\otimes)$

University of Bergen, Bergen, Norway

e-mail: asbjorn.gronstad@uib.no

(C) The Author(s) 2020

A. M. Dancus et al. (eds.),
}

Vulnerability in Scandinavian Art and Culture, https://doi.org/10.1007/978-3-030-37382-5_2 
in the wake of $9 / 11$, and the invasions of Afghanistan and Iraq. In her book from 2004, she relates precariousness to the process of coping with 'a sudden and unprecedented vulnerability' (Butler 2004, p. 42). 'Precarious' as a critical term has also been associated with the work of Bourriaud (2009) and Foster (2009). But however much extreme occurrences serve to emphasize our vulnerability, the condition itself is permanent and universal, although its rate of attrition is, of course, unevenly distributed across the continents. To study states of vulnerability along with their causes and properties is certainly a burning issue for researchers from many fields, from the natural sciences to the humanities, but my main interest in this chapter is, rather, the fictional treatment of the individual's response to the condition of being vulnerable. Building on my previous studies of the complex imbrication of aesthetics and ethics, of how artistic expressions may renew and even transform our ethical insights (cf. Grønstad 2016), I want to turn toward a small group of feature films to see if they may teach us something about dealing with vulnerability that escapes more anthropological approaches.

One of the contemporary filmmakers who have explored what I propose to call the aesthetics of vulnerability most consistently is the Swedish director Ruben Östlund. With a handful of well-received feature films such as Involuntary (2008), Play (2011), Force Majeure (2014) and The Square (2017) to his credit, Östlund has during that time emerged as possibly the foremost chronicler of social unease and moral precarity in Scandinavian cinema. In Involuntary, Östlund examines the psychology of peer pressure; in Play, questions of race, class and political correctness; in Force Majeure, problems of contemporary masculinity; and, finally, in The Square, the delusions and hypocrisy of the art world. What is shared by all his films is an unusual sensitivity to the ways in which everyday life may be upended by unexpected events that pose an existential threat to the characters and their worldviews. In the cinematic universe Östlund constructs, the condition that is most particularly scrutinized is that of exposure; the sense of losing the (cultural as well as material) privilege of protection and finding oneself unshielded from unpleasant and invasive forces from outside. The key post-millennial film to address this issue is arguably Caché (Michael Haneke 2005), in which the comfortable life of a successful television host is made precarious by encroaching circumstances from his own past. What I have elsewhere referred to as Haneke's cinema of intrusion is an important precursor to Östlund's project (Grønstad 2012), which retains elements both of Haneke's style and his themes to forge, on the 
Swedish director's own terms, a cinema of vulnerability specifically situated within a Scandinavian cultural context. This chapter considers the process and experience of vulnerability, and how it is inscribed into the aesthetic fabric of Östlund's films.

Questions of vulnerability are often identified with a set of interrelated concepts such as precariousness, suffering, susceptibility, affectability, dependency and responsibility. Leading scholars in the emergent field of vulnerability studies have grappled with issues such as the ontology of vulnerability (Catriona Mackenzie, Wendy Rogers and Susan Dodds), the vulnerable subject and its potential for replacing the category of the legal actor (Martha Fineman), the idea of a feminine economy that reconstitutes vulnerability as strength (Erinn Gilson drawing on Hélène Cixous), and the relation between vulnerability and resistance (Judith Butler). Most of these approaches also operate within the larger domain of ethics. What I purport to do here is not only to extend the discussion of vulnerability into the realm of aesthetics, but also to put it into contact with a concept that, at first, may seem surprising, perhaps even counterintuitive. That concept is privilege. Disenfranchised groups are obviously vulnerable. If by chance we happen to find ourselves in the midst of a natural disaster such as an earthquake or a tornado, we are also undoubtedly vulnerable.

But vulnerability can also be contingent on forces that are less patently socio-economic, political, or environmental. In cases in which privilege and entitlement are threatened, vulnerability may assume an existential foundation. For some critics, the notion of vulnerability has to be put into quotation marks when it is applied; for instance, in the context of a fear of immigration or feminism (Butler et al. 2016, p. 4). But does this 'performed' sense of vulnerability not deserve to be taken seriously? I would like to suggest that this inauthentic or artificial vulnerability is valuable precisely as an index of the logic of privilege. The loss of privilege is presumably perceived and felt as a real thing, so maybe inauthentic is not the best term from a phenomenological point of view, but this form of vulnerability is nonetheless markedly different from that discussed in the scholarly literature referred to above. Call it conditional vulnerability, a special kind of precarity that ensues from the erosion of advantages that may not have been entirely warranted in the first place. Psychoanalytically inspired feminism, Butler et al. (2016, p. 4) write, has suggested that 'the masculine positions are effectively built through a denial of their own vulnerability. This denial or disavowal requires one to forget one's own vulnerability and project, displace, and localize it elsewhere.' The 
prospect of losing one's privileges does introduce a degree of actually felt vulnerability into the life of the subject, no matter how ideologically odious these privileges are. The privileges of wealth, race and gender work to preclude vulnerability. When they come under threat, the subject is exposed to the same general vulnerability that is a condition of life for the disenfranchised. This exposure could no doubt generate frustration, violence and attempts to project vulnerability onto other people, but it could also, in the best of circumstances, lead to a better acknowledgement of and empathy with the suffering of others. My contention is that aesthetic works, in compressing, narrativizing and fine-tuning experiences of vulnerability, can contribute insights that are beneficial for our ethical reflections on the subject.

While Haneke may have been one of the first filmmakers systematically and unflinchingly to probe the fraught intersection of cultural privilege and vulnerability, Östlund has been the one to take up the mantle in a series of features that, in quite subtle ways, reveal the fear and helplessness that quickly arise when white masculinity comes under siege. Östlund's cinema is also effective in encapsulating the feeling of being exposed, as the sense of a looming and possibly accelerating threat is incorporated into the very style of his films. In Play, for example, the general eschewal of shot-reverse-shot structures and the preference for the use of a zoom lens and long takes that have characters saunter in and out of the frame create an abiding sense of tension and peril. Described by one critic as an aesthetic of detachment that is at once physically calm yet optically nervous (Coldiron 2011), Play is a work that deals with social discomfort and anxiety on both a narrative and a thematic level. Based on allegedly real incidents in Gothenburg, the film depicts the intimidation of two white kids and one Asian by five black adolescents. The latter group has devised an elaborate role-play scheme to divest the former group of their phones, who for fear of appearing politically incorrect get increasingly embroiled in the scam. A controversial feature about the cultural psychology of racial profiling, Play engages with a host of intersecting issues in which vulnerability appears to be a constituent part-identity, immigration, race, class, harassment and manipulation. As I will argue, the film may be read as a story about not only corporeal vulnerability and the threat of imminent violence, but also about the vulnerability that results from having one's cultural privileges suspended, even that of political correctness.

Mobile phones also play a distinguished role in Östlund's next project, his international breakthrough movie Force Majeure. Set in the French 
Alps, the film's narrative charts the dissolution (and possible reconciliation) of a Swedish upper-middle-class family vacationing at the magnificent Les Arcs ski resort. On their second day there, something out of the ordinary takes place. Having lunch at the rooftop restaurant, the family are watching a controlled avalanche gather so much momentum toward the dining area that they mistakenly believe it is going to consume them. Chaos and panic follow. The screen goes momentarily blank from the whiteness of the snow, yet there is no mistaking the instinctive gestures and action of Tomas (Johannes Kuhnke), the family father. Unmindful of the immediate well-being of his wife and children, Tomas grabs his cell phone and gloves and makes a swift escape. The avalanche stops just in time and nobody is injured but its effect will linger on throughout the rest of the film. Later the same day, during dinner with another couple, Tomas's wife Ebba (Lisa Kongsli) shares the story, emphasizing her husband's somewhat less than heroic behaviour during the avalanche. Tomas categorically rejects her version of the events, thus making matters even worse.

Both Play and Force Majeure hone in on the unnerving friction that evolves out of fairly everyday situations, although, in the case of the latter film, the incident that sparks the drama may itself be unusual. The kind of conditional vulnerability Östlund unveils is not straightforwardly covered by the terms introduced by philosophers Catriona Mackenzie and her colleagues $(2014$, p. 4$)$ (inherent, situational, pathogenic), which seem too broad. ${ }^{1}$ Tomas's anguish may appear context-specific on the surface but betrays a deeper sense of cultural conditioning that involves a messy interaction between the norms, expectations, and privileges associated with a particular form of masculinity. Force Majeure also represents an especially salient case of working through vulnerability in visual fiction, as it features one of the most spectacular male breakdowns in all of cinema. Portraying in unsparing detail a despondent trajectory from an initial act of selfishness to a complete emotional collapse, Östlund's film comes across almost as an inversion of the narrative arc of Straw Dogs (1971), Sam Peckinpah's perennially scandalous investigation into the nexus of masculinity and violence. While Dustin Hoffman's character in that film starts off as an emasculated American academic out of his depth in a hardened working-class environment in rural Britain, only to regain a sense of primitive masculinity through a momentous act of violence, Tomas in Force Majeure is an alpha male, privileged in all ways imaginable, who gradually comes apart at the seams in a starkly unflattering manner. 
Ebba's simmering disapproval of her husband's comportment during and after the avalanche is the motor of Östlund's psychodrama, whose unflinching gaze at marital discord owes something not only to Haneke, but also to Ingmar Bergman. As viewers we will never know whether the relationship between Tomas and Ebba was turbulent even before the crisis, but the perfect family façade from the opening scenes seems irreparably damaged not only by Tomas's thoughtlessness/cowardice, but also by his pathetic lies in the aftermath of the event. Even though the film's ambiguous ending may suggest a glimmer of hope for the couple, the relationship Östlund captures with both cynical precision and elements of comedy is one progressively tainted by Ebba's mounting contempt. What the film essentially dissects is how that contempt subtly materializes in the strained interactions between the couple, until it culminates in the scene where Tomas breaks down in front of his family, howling uncontrollably. Rarely has humiliated masculinity been shown in such an uncompromising way on screen. The moment also spells the end of Tomas's state of denial and his entry into a condition of naked vulnerability.

Pivotal as this scene is, it is not the only cinematic figuration of vulnerability in Force Majeure. Östlund takes advantage of the film's setting to compose a series of tableaux that disclose the inconsequentiality of the human against the backdrop of the immense alpine landscape. 'The family are nothing more than ants', one critic observes, 'and it's the little things that collapse the supposed edifices that they construct' (Gnanalingam 2014). Comparing Östlund's visual and thematic orientation to that of Michelangelo Antonioni-an influence seen, for instance, in the former's interest in the nature of existential discontent-the same reviewer notes that it is 'the impassive natural landscapes that dominate the puny human attempts to tame it' (Gnanalingam 2014). Several of the interior scenes are likewise set up to accentuate the potential defencelessness of the family, as in the shot of the four of them sleeping in the same bed, fully clothed and drained after the day's activities. Östlund's handling of film space to convey a sense of uneasiness and apprehension is also reflected in his frequent withholding of reverse shots, as in the scene from The Square in which Michael is waiting in the car near the housing projects and we never see the person who knocks on the window and talks to him.

As an aesthetic medium, cinema is uniquely positioned to address states of vulnerability, among other things because its chief substance is the human body and its interaction with a given environment. Entire genre ecologies are based on the inherent frailty of that body, from disaster 
movies to action spectacles and horror films. Furthermore, the kinds of drama films associated with modernist art cinema and with filmmakers such as Antonioni, Rossellini, Bergman, Ozu, Resnais, Tarkovsky and many others also sometimes act as vehicles for the artistic examination of subjectivity under duress. Contemporary directors such as Haneke and Östlund are, in various ways, indebted to this tradition; but, they also renew it through their more or less implicit yet sustained critique of cultural privilege, currents of entitlement tied to class, gender and ethnicity.

Östlund's acidic art-world satire The Square, his follow-up to Force Majeure, may be read as an enquiry into the ethical ramifications of this sense of privilege, using experiences of vulnerability as a wedge. Again, the spatial dimension is prominent. The eponymous object of the film's title is a small gathering place outside a fictional art museum in Stockholm, described by its plaque as 'a sanctuary of trust and caring' and as a space where everyone has 'equal rights and obligations'. An instance of participatory art that also seems to nod to Nicolas Bourriaud's (2002) notion of relational aesthetics, 'The Square' is designed to be an installation for the cultivation of empathy. But the context for this project is an art establishment infected by a hypocrisy so deep and systemic that it has become virtually second nature. Oblivious to the social affliction around him, Christian (Claes Bang), the museum's arrogant and occasionally clueless director, comes to personify a perspective wherein the best moral intentions have lost any connection to material reality. But Östlund, like Haneke, is not content merely to expose this institutional insincerity; he also wants to see what happens when the infrastructures of respectability and privilege disintegrate, and the ostensibly unassailable become vulnerable just like the rest. There are two events in The Square that, in particular, pursue this objective: the theft of Christian's phone and wallet, and the repercussions his ill-conceived attempt at getting them back will have; and the aggressive disruption of a formal dinner by a performance artist.

What kind of ethics, then, if any, does Östlund's cinema encapsulate? My thesis is that films such as Force Majeure and The Square dramatize and give aesthetic shape to the conceptual transition, promoted by Martha Fineman and Anna Grear (2013, p. 4), from the idea of the legal actor or 'unencumbered self' - 'the rational, property-owning actor at the heart of classic liberalism' - to the idea of the vulnerable subject. Vulnerability is not primarily about emotional or physical distress but about the receptivity for insight. In Erinn C. Gilson's (2014) words, vulnerability is 'an 
experience born of discomfort with the unfamiliar, the uncontrolled, or the unpredictable', but, she adds, 'only through muddling about in this experience do we learn, change, and extend ourselves beyond our current limits' (p. 127). Because fiction, practically by definition, harbours the dramatic as part of its core structure, it is particularly suited to capturing the intricacies of this experience.

Christian in The Square - and, by extension, the social world in which he is enmeshed-perfectly embody this confrontation between the unencumbered self and the vulnerable subject. Prior to the curious events that unfold in the film's narrative, any infringement on the privileges and benefits of this sheltered sphere would be wholly inconceivable to someone like Christian. To rub in the disparity between this sphere and that of sheer precarity found outside the walls of the museum, the film resorts to some rather heavy-handed juxtapositions of cultured affluence and homelessness on the streets of Stockholm. More subtle is the suggestiveness of the film's titular object, the 'installation' that comes to represent 'a sanctuary of trust and caring' in which all have 'equal rights and obligations'. On one level, the square metaphorizes one of the functions that the museum as an institution already has, which is that of a temporary sanctuary and space of escapism from the harsher realities of the world outside (an idea entertained in Jem Cohen's Museum Hours from 2012). ${ }^{2}$ From this point of view, the very notion of such an installation appears disingenuous, more than anything an unnecessary and self-congratulatory gesture whose ethical vacuity is borne out by Christian's less than noble actions, which-contrary to the idealism of his art project-are mostly distrustful and uncaring. It moreover seems unlikely that Östlund would be unaware of Jehane Noujaim's award-winning and critically lauded documentary of the same name, which premiered at Sundance in 2013 and which deals with Tahrir Square and the revolution in Egypt that began in January of 2011. On a different level, then, the square in Östlund's film designates a place where, unlike that of Tahrir, nothing much is really at stake. This troubled and politically charged tension between the warm and fuzzy square of the white, western and predominantly male art world on the one hand and, on the other, the unsafe square in which real struggle takes place could be further contextualized by the colonial histories of the art museum. The first objects in Britain's National Gallery, for instance, were purchased from the collection of John Julius Angerstein, a prominent banker and Caribbean plantation owner (see Conlin 2006). 
But as it turns out, in Östlund's movie the rarefied sanctuary that is the modern art gallery ceases, at least temporarily, to be a safe place for the over-privileged western subject. In the film's set piece, anarchic forces foreign to the habitus of the art world erupt onto the scene of a formal dinner party. As entertainment someone has brought a performance artist who, during a dazzling 11-minute scene, intimidates the gala guests with his progressively antagonistic routine as a deranged chimpanzee. As an introduction, an acousmêtre announces that the partygoers will soon be 'confronted by a wild animal' trained to sense their vulnerability and fear. In comes the grunting, shirtless Oleg, played by American stunt actor Terry Notary, whose act is inspired by the transgressive hardcore rocker GG Allin. At first, Oleg appears a bit apprehensive. Before long he is turning assertive, prowling among the tables on all fours, barking and growling, taunting his chosen victims and chasing the party's alpha male out of the room. Careful to include reaction shots of the befuddled and increasingly disconcerted guests, throughout the elongated and intricate sequence Östlund ups the ante by making Oleg's behaviour progressively more threatening and unpredictable. Twice the guests applaud the performance, most likely as a futile attempt to cut short the show and, along with it, their own dismay. But Oleg continues undeterred. Chasing away a few more guests, he jumps up on a table. The room has gone quiet, and everyone stares at their hands. Perched atop the table, Oleg notices a red-haired woman, whom he proceeds to fondle before abruptly and brutally pulling her off her chair and dragging her across the floor. As what is surely one of the most uncomfortable scenes in all of cinema reaches its climax, Oleg tries to rape the woman but an elderly gentleman intervenes. Finally confronted, Oleg the ape man is attacked by a mob that pummels him relentlessly.

This scene, which took four days to shoot and involved dozens of takes with an ensemble of extras consisting of artists and curators, condenses multiple issues involving white male privilege. First, it divulges the naked vulnerability of cultured and affluent masculinity when faced with unanticipated and erratic forces beyond its horizon of experience. This is a theme with a certain family resemblance to Haneke's Caché, in which the external menace is associated with the subaltern, and to Force Majeure, where a natural phenomenon occasions a psychological collapse on part of the seemingly insusceptible white male. The figure of Oleg the monkey man in a way epitomizes both these senses of intrusion, the culturally Other whose mode of operation causes havoc the repercussions of which 
seem akin to a natural disaster. Second, when the male guests at the gala dinner finally act, their response prompts a breakdown of social convention no less disturbing than Oleg's own behaviour. The enraged men are not content merely to defuse the escalating chaos by subduing Oleg, but keep on hysterically pounding him (the actor broke a toe while shooting the scene). Rarely has the veneer of civilized conduct been shown to be this thin. The conformity that prevents the guests from interceding any sooner seems to be the same conformity that just a little later transforms them into a seething, mad mob. Discussing the scene, the director himself has stated that ' $[t]$ he reason we don't have the ability to take responsibility in situations like that is because we are herd animals and we get scared, and when we get scared we get paralyzed' (Östlund quoted in Yuan 2018). For the kind of masculinity that Christian and his peers represent, it could be argued that the gravest risk, however, is not Oleg's potential for doing violence to their bodies but, rather, his power to elicit precisely those reactions that would undermine their professional identities and self-understanding.

As part of a (gendered) elite for whom there is no contradiction between neglecting the homeless while pursuing a project centred on values such as trust and caring, Christian is obviously a 'modern hypocrite', to borrow the language of one critic, 'idealistic in his words and cynical in his deeds' (Jakobson 2017). This psychological chasm, which has become practically second nature to Christian, propels a failure of personal ethics. That his project 'The Square' is a flagrant example of what the French curator and art critic Nicolas Bourriaud has termed relational art is deeply ironic (Bourriaud 2002), since Christian seems constitutively unable to grasp the nature of the various social and institutional entanglements of which he is a part. The beggars that line the streets of his immediate environs are simply invisible to him, and his poor judgement in dealing with the people he suspects may have stolen his phone and wallet betrays a lack of interpersonal sensitivity. The extent to which Christian seems disconnected both from other people and from the consequences of his own actions is demonstrated in a comically absurd scene in which he insists on disposing of his own used condom after being with the journalist Anne (Elisabeth Moss). Again, Christian indicates through his egotistic behaviour that he is either unaware of or indifferent towards the ways in which his life is entwined with those of others.

By now, it may have become clear that what I refer to above as conditional vulnerability may be a force of productive change in milieus 
such as that depicted in The Square. For Östlund's advantaged white men, the process of having their self-centredness exposed and their privileges challenged results in crises whose attendant new insights could only be attained through becoming vulnerable. While there is a rich tradition in the arts for direct and unswerving portrayals of existential, corporeal vulnerability - from the work of artists such as Hannah Wilke, Felix Gonzales-Torres, Derek Jarman and David Wojnarowicz, to recent projects such as Lata Mani and Nicolás Grandi's The Poetics of Fragility (2016) - Östlund's films zero in on a different form of engaging with vulnerability, one that would seem to prove the validity of Gilson's (2014) thesis that 'being vulnerable, openness to being affected and affecting, is the basic precondition for experience' (p. 14l). But for the kind of ossified masculinity that a character such as Christian signifies, this potential for receptivity needs some sort of catalyst from without, be it a mysterious videotape, an avalanche, or a human ape. If an ethics emerges from the moral laboratories of Haneke and Östlund, it is one closely aligned with what Wendy Brown (1988) once termed 'post-masculinist politics', a rejection of instrumentalist notions of rationality grounded in a pathological need to control and dominate one's environment. The prescience of The Square, made previous to but released stateside just after the \#metoo movement exploded and mere months before the Swedish Nobel Academy scandal broke, finally also relates it to Joanna Zylinska's (2014) critique of stale masculinist positions ill-equipped to handle what she calls a 'post-anthropocentric ethics of expanded obligations' (p. 17). This is an ethics unthinkable without vulnerability.

\section{Notes}

1. In the work of these critics, 'inherent' vulnerability designates a corporeal condition that is universally shared, whereas 'pathogenic' vulnerability extends to subjects that are already disadvantaged due to various disabilities, corporeal as well as mental. 'Situational' vulnerability comes closer to my own term, 'conditional' vulnerability, as it refers to aspects of the subject's social or political environment. I would argue that the term nonetheless is too imprecise for the kind of vulnerability that I try to capture here, which is, first, symbolic more than material and, second, is articulated through aesthetic processes, rather than through the direct experiences of actual subjects. 
2. For an analysis of the depiction of the museum in Cohen's film, see Asbjørn Grønstad, 'Museum movies, documentary space, and the transmedial', in Documenting the Visual Arts, ed. Roger Hallas, 2019.

\section{REFERENCES}

Albertson Fineman, M., \& Grear, A. (2013). Introduction: Vulnerability as heuristic-An invitation to future exploration. In M. Albertson Fineman \& A. Grears (Eds.), Vulnerability: Reflections on a New Ethical Foundation for Law and Politics. Farnham: Ashgate.

Bourriaud, N. (2002). Relational Aesthetics (S. Pleasance \& F. Woods, Trans.). Dijon: Presses du reel.

Bourriaud, N. (2009). The Radicant: No. 17. New York: Sternberg Press.

Brown, W. (1988). Manhood and Politics: A Feminist Reading in Political Theory. Totowa, NJ: Rowman and Littlefield.

Butler, J. (2004). Precarious Life: The Powers of Mourning and Violence. London: Verso.

Butler, J., Gambetti, Z., \& Sabsay, L. (2016). Introduction. In J. Butler, Z. Gambetti, \& L. Sabsay (Eds.), Vulnerability in Resistance. Durham: Duke University Press.

Coldiron, P. (2011, October 15). Play. Slant Magazine. https://www. slantmagazine.com/film/review/play. Accessed 3 November 2017.

Conlin, J. (2006). The Nation's Mantelpiece: A History of the National Gallery. London: Pallas.

Foster, H. (2009, December). Precarious. Artforum, pp. 207-209.

Gilson, E. C. (2014). The Ethics of Vulnerability: A Feminist Analysis of Social Life and Practice. New York: Routledge.

Gnanalingam, B. (2014, August 5). God complex: The reunion, force majeure. The Lumière Reader. http://lumiere.net.nz/index.php/the-reunion-forcemajeure/. Accessed 8 November 2017.

Grønstad, A. (2012). Screening the Unwatchable: Spaces of Negation in Postmillennial Art Cinema. Basingstoke: Palgrave Macmillan.

Grønstad, A. (2016). Film and the Ethical Imagination. Basingstoke: Palgrave Macmillan.

Grønstad, A. (2019). Museum movies, documentary space, and the transmedial. In R. Hallas (Ed.), Documenting the Visual Arts. London: Routledge.

Jakobson, C. (2017). Ruben Östlund's The Square: The art of being human. Fourbythreemagazine. http://www.fourbythreemagazine.com/cannes-filmfestival-2017/ruben-ostlund-the-square. Accessed 9 November 2018.

Mackenzie, C., Rogers, W., \& Dodds, S. (2014). Introduction: What is vulnerability, and why does it matter for moral theory? In C. Mackenzie, W. Rogers, 
\& S. Dodds (Eds.), Vulnerability: New Essays in Ethics and Feminist Philosophy. Oxford: Oxford University Press.

Yuan, J. (2018, 6 November). The Square's monkey-man scene is bonkers. Here's how it was made. Vulture. http://www.vulture.com/2017/11/how-thesquares-bonkers-monkey-man-scene-was-made.html. Accessed 7 May 2018.

Zylinska, J. (2014). Minimal Ethics for the Anthropocene. Ann Arbor: Open University Press.

Open Access This chapter is licensed under the terms of the Creative Commons Attribution 4.0 International License (http://creativecommons.org/licenses/ by $/ 4.0 /)$, which permits use, sharing, adaptation, distribution and reproduction in any medium or format, as long as you give appropriate credit to the original author(s) and the source, provide a link to the Creative Commons license and indicate if changes were made.

The images or other third party material in this chapter are included in the chapter's Creative Commons license, unless indicated otherwise in a credit line to the material. If material is not included in the chapter's Creative Commons license and your intended use is not permitted by statutory regulation or exceeds the permitted use, you will need to obtain permission directly from the copyright holder.

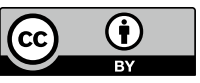




\section{The Mother, the Hero, and the Refugee: Gendered Framings of Vulnerability in Margreth Olin's De andre (2012) and Leo Ajkic's Flukt (2017)}

\section{Elisabeth Oxfeldt}

For more than a decade, and especially in 2015 , the so-called refugee crisis has stirred controversy in Europe, forcing its nations to debate their legal, social and ethical obligations towards non-Europeans fleeing from war and violence. A basic issue becomes one of othering those arriving from outside Europe's borders. They are regarded as different from a national 'us', as they are demonized, victimized and dehumanized. In these debates, the media plays a significant role in framing populations as more or less vulnerable, and as more or less deserving of our humanitarian interest. As Judith Butler (2010) explains in Frames of War, 'such frames structure modes of recognition, especially during times of war', and they are operative 'also in the politics of immigration, according to which certain lives are perceived as lives while others, though apparently living, fail

\footnotetext{
E. Oxfeldt $(\bowtie)$

University of Oslo, Oslo, Norway

e-mail: elisabeth.oxfeldt@iln.uio.no
}

(C) The Author(s) 2020

A. M. Dancus et al. (eds.),

Vulnerability in Scandinavian Art and Culture, https://doi.org/10.1007/978-3-030-37382-5_3 
to assume perceptual form as such' (p. 24). Writing in response to the US media coverage of the 'War on Terror', Butler critiques a dominant discourse of dehumanization that denies the basic vulnerability and interdependency of all human beings. What she calls on is a counter-framing, deconstructing the perceived us-them divide, emphasizing that 'there are no invulnerable bodies'-neither among 'them' nor 'us' (p. 34). As she repeatedly emphasizes: 'We are all precarious lives' (p. 43). ${ }^{1}$ Butler's main questions are clearly relevant for Scandinavia, too. In Norway, global warfare and refugee migration spur ongoing debates on national identity. Who are we in terms of shared values, culture and politics, and what is our connection to, and responsibility towards, those fleeing from war-ridden countries?

Two recent documentary voices, working to deconstruct the us-them divide, have been particularly strong on this issue: those of filmmaker Margreth Olin and TV host Leo Ajkic. While Olin immersed herself in the documentary film project De andre (2012; Nowhere Home), Ajkic hosted the five-part NRK documentary series Flukt (2017; Escape/Fleeing) directed by Lars Petter Gallefoss. Both were highly acclaimed projects. ${ }^{2}$ They exemplify what Butler calls for as 'a move toward the recognition of a generalized condition of precariousness' $(2010$, p. 48). The condition of precariousness is portrayed on three (often overlapping) levels: those of the refugee, the mediator/narrator, and the nation.

The focus of this chapter is on the way in which Olin and Ajkic relate the vulnerability of the refugee Other to their own-Olin especially through the national trauma brought about by the Oslo Massacres (22 July 2011), and Ajkic through his personal memories of fleeing from Bosnia in the late 1990s. A main argument is that they succeed in such mediation by inhabiting seemingly traditional, yet slightly modified and hybrid, gender roles vis-à-vis the refugees they encounter as well as their national audiences.

\section{Gendered Positions}

Gender plays a decisive role in our attitude towards refugees and asylum seekers. In The Cultural Politics of Emotion, Sara Ahmed (2014) writes about the social imaginary as it appears in public discourse on the topic: "The soft national body is a feminised body which is "penetrated" or "invaded" by others' (p. 2). ${ }^{3}$ In line with this dualistically gendered logic, the threatening Other is a male immigrant. In a Norwegian context, 
Marianne Gullestad (2006) finds that in prevailing social imaginaries, 'women and men typically occupy different roles-immigrant women are depicted as victims while immigrant men are depicted as oppressors and potential criminals' (p. 38). Hence, it should come as no surprise that a common way of framing others as vulnerable is by framing them as women and children. According to Butler, "women and children" has a certain salience, makes a certain emotional claim, since both categories designate presumptively innocent populations' $(2010, \mathrm{p} . \mathrm{xxi})$. Olin and Ajkic, however, eschew such stereotypical appeals to innocence and instead maintain a focus on young male asylum seekers. They take the bull by its horns, so to speak, acknowledging that this is the greatest, most threatening, but conversely also most threatened, group of asylum seekers in Norway. ${ }^{4}$ They then proceed to humanize them. They do so in three significant ways: (i) by insisting on the refugees' vulnerability as children-whether this pertains to the metaphorical child within, to childhood memories, or to their current legal status as minors; (ii) by insisting on their great potential as adult human beings to contribute to society at large; and, finally, (iii) by softening up gender stereotypes through their personal mediation of the young men. Olin does this by taking on a maternal role, filtering the young men's misfortune through the compassionate eyes of a mother, while also harnessing more 'masculine' legal and philosophical discourses to her project. Olin, as we shall see, combines the roles of national and global mother into what we may call a postnational mother. ${ }^{5}$ Ajkic, in turn, embodies a version of the new man, who exposes a 'soft', emotional side, and ties this to a hero discourse, urging both men and women, boys and girls, Norwegians and immigrants, to act as everyday heroes. Hence, throughout their documentaries, Olin and Ajkic create counter-discourses and counter-frames to the notion that the nation is simply a feminized body which is dangerously invaded and penetrated by violent males arriving from outside.

\section{The Soft, National Body: Olin's Maternal Framing of De andre}

Throughout her career as a documentary filmmaker, Olin has sought to give voice to social outsiders such as, in the case of De andre, underage asylum seekers in Norway. In her production, she spans Bill Nichol's (2010) division of documentary films into six modes: poetic, expository, observational, participatory, reflexive and performative. De andre draws 
on all these modes, but is first and foremost a participatory documentary, based mainly on her interviews with four male underage asylum seekers whom she maternally refers to as 'my boys'. 6 These are Goli Mohammed Ali (age 18) from Kurdistan, the brothers Husein and Hassan Ali (ages 16 and 17) from Afghanistan, and Khalid Faqiri (age 17) also from Afghanistan. She witnesses their accounts of past traumas and observes current ones as their applications for asylum are rejected. The four young men are then institutionalized in asylum reception centres until their eighteenth birthdays when they can be deported as adults-no longer children. Olin follows their lives over a period of three yearsthrough the aftermath of rejection and deportation.

De andre was made as a response to political changes implemented in 2009 in order to limit immigration. ${ }^{7}$ Previously, lone asylum seekers under the age of 18 whose parents could not be tracked down in the children's home country were given residence permits on humanitarian grounds. But, after the government saw a record-breaking number of lone underage asylum seekers in 2009 , they decided to become more restrictive. Children over 15 who were deemed not to be in need of protection, or not to fulfil the requirements for receiving residence on humanitarian grounds were granted only a temporary residence and had to return 'home' at the age of 18. Olin's clear argument in the film is that Norway is breaking the United Nations' Convention of the Rights of the Child, ratified by Norway in 1991 .

On the one hand, Olin uses the UN Convention of the Rights of the Child to frame her young refugees, and to make a logical argument pertaining to legal guilt expressed through the expository mode of the filmquoting, for instance, several articles from the UN Child Convention. The boys are victims, she shows, and the state is guilty of breaking UN Conventions. On the other hand, she frames her 'boys' to make an affective argument based on feelings of guilt, shame and common precariousness. This affective argument hinges on a humanist understanding that there is no Other, separated clearly from a self. It is an argument expressed both through the film's ambivalent title and through its participatory modethrough Olin's direct involvement with the boys and, especially, through the insertion of a dream sequence tied to the Oslo Massacres in the film's title sequence.

The title sequence constitutes a reconstruction of a dream Olin claims to have had, linking the fate of her asylum seekers to that of the young Norwegians massacred, injured and terrorized on Utøya on 22 July 2011. 
On this date, a lone perpetrator shot dead 69 participants at the annual Labour Party youth (AUF) camp on Utøya after having bombed the government buildings in Oslo, killing 8 people. In all, 77 people died, most of them teenagers. The dream sequence consists of underwater scenes in which we see cropped images of clothed bodies swimming while Olin explains in voice-over that she had a dream about participants at the youth camp trying to save their lives by swimming away from Utøya and being rescued by their families and Norwegian government officials. In the dream, the image of the swimming youth in danger suddenly includes an image of two boat refugees, an 18-year-old girl and a 14-year-old boy, swimming towards the same Norwegian government official. At this point, age becomes a decisive factor. The policeman accepts the 14-yearold boy whereas the 18-year-old girl is denied entry and is told to swim back. 'In my dream they are no longer Norwegian kids. They are the boys from my film. And they're in open sea', says Olin. ${ }^{8}$ We see a man floating on the surface of the ocean, the screen turns black, and the title $D E A N D R E$ appears in white capitals, accompanied by digital foreboding music and Olin's voice: 'I make this film because I'm afraid. I'm not afraid of the others. Of the strangers. I'm afraid of what's happening with us when we no longer are capable of seeing the individual. ${ }^{99}$ Here is Olin's focus on a crisis and vulnerability pertaining to $u s$, our values and our national identity, rather than to a perceived them.

Taking her role as witness to a national trauma one step further in the opening sequence, Olin taps into cultural memories as she inserts black-and-white photographs documenting the devastation and public grief expressed in the aftermath of the Massacres. We thus move from a personal, participatory mode to a more expository film mode as Olin shows us stills commemorating the grief felt after the Oslo Massacres, in particular photographs of flowers placed all over the city and of people in tears. Hence, Olin reminds her viewers of Norwegian values of tolerance and compassion, values that were attacked on 22 July and strongly expressed and reasserted in the following weeks. These are values that Olin wants viewers to keep in mind when watching the film about her refugee boys. Framing the Oslo Massacres as a national moment of grief and vulnerability related to the refugees forced to return 'home' at the age of 18 encourages viewers to expand their circle of concern, to make them see young, male asylum seekers as equally vulnerable, grievable and human. ${ }^{10}$ 
The dream sequence is an example of Olin using and transferring her own trauma to her viewers. Her dream is a result of her having witnessed both the trauma of the boys in her film and the trauma of 22 July as she is about to finish her documentary. In this latter position, she once more emphasizes her maternal role, now through reference to her own child. Towards the end of the film she explains that, after the Oslo Massacre, she walked through the streets with her daughter observing the emptiness, destruction and grief of a nation (captured by the black-andwhite stills). Hence, De andre opens with a title sequence establishing the filmmaker's own, personal sense of vulnerability as well as that of the nation. ${ }^{11}$ The two, in fact, converge and Olin represents and embodies Norway, its institutions, values, memories, traumas and overall spirit. Her daughter, in turn, represents Norway's future. As Susan Moeller (2002) puts it: 'Children are a synecdoche for a country's future, for the political and social well-being of a culture' (p. 39). ${ }^{12}$

A main rhetorical strategy in her film subsequently relies on depicting young male refugees as vulnerable. One way is by having us think of them as children, both legally (they are underage) and emotionally as we are taken back in time and given insight into how traumatized they were as children. The most challenging of the four cases is Goli from Kurdish Iraq who has committed several violent crimes, has been incarcerated in Norway, and is the least desirable type of immigrant (lone young asylum seeker with a criminal record). On the surface, he is much 'tougher' than the film's other young men, whose vulnerability comes across as they express a sense of abandonment through poetry and diaries, as they care for each other, and especially as one of the brothers, Husein from Afghanistan, collapses physically and mentally while his older brother desperately tries to help him. The overt vulnerability calls on the spectators' attention and involvement. Depicting Goli's vulnerability seems more challenging. Yet, Olin captures it by photographing the scars on his body (some self-inflicted, others inflicted by a violent stepfather), by testifying to his childhood miseries (also in Norwegian court), by capturing his childish and playful side, and by illustrating her own willingness to get to know him and take on her maternal role towards him.

As Butler argues, the body is a significant point of departure for understanding people's vulnerability and interconnectedness. The body may appear individual and bounded, but in reality it is 'unbound-in its acting, its receptivity, in its speech, desire, and mobility. It is outside itself, in the world of others, in a space and time it does not control' (Butler 2010, 
p. 52). Goli's body is inscribed with social meaning through his style, expressed through grooming, fitness, posture, body movements, speech and clothing (e.g. piercings, tattoos, black leather jacket, cigarette at hand). As a type, Goli is tough. Yet, through her engagement with Goli, and her focus on his body, its scars, and its movements, Olin reminds us of his vulnerability as well as his inclinations towards change. Butler (2010) insists on the human's constant ability to respond to its surroundings:

As something that, by definition, yields to social crafting and force, the body is vulnerable. It is not, however, a mere surface upon which social meanings are inscribed, but that which suffers, enjoys, and responds to the exteriority of the world, an exteriority that defines its disposition, its passivity and activity. (pp. 33-34)

Framing Goli as a playful individual (joking, laughing, playing with a dog, playing with a ball), Olin shows not only how he suffers, but also how he enjoys life. And prodding him with questions about love, children and family, she succeeds in showing that his hateful disposition is fostered by 'masculine' principles of rendering him passive (in handcuffs, within institution walls), while his loving disposition is fostered by 'feminine' principles urging him, for instance, to consider becoming a father. At the end of the film, Olin steps up her focus on children. She has a final conversation with Goli in which he declares that he has nothing to live for. 'What about love?', she asks, and turns this into a question of parental love: 'You like children. What if you had a child of your own?'13 Goli dismisses her question, and Olin cuts to black-and-white stills documenting the devastation she experienced with her daughter in the streets of Oslo after 22 July. In voice-over she reflects on notions of vulnerability, fear, freedom and interconnectedness:

I've always thought the best thing in humans is to seek freedom. We walked in parades for our freedom. We triumphed over fear. But did we also feel that our freedom depends on other people's freedom? And what will secure our freedom if not the protection of the value of every individual. When we treat children and young people in a way we would never treat our own, one have [sic] to ask if freedom could be limited and only apply to some people. Then what happens to freedom? ${ }^{14}$

We are back to the imagery and questions forwarded in the opening sequence: why do we only care about our own children and youth? In 
order to reinforce this point, Olin turns to the more common trope of the innocent refugee child, juxtaposing images of a young homeless child in Athens having to sleep in public places, with a classic Norwegian lullaby, Margrethe Munthe's 'Dear God, I am well taken care of', sung in a dreary and melancholy manner, emphasizing the discrepancy between the visual and aural imagery. ${ }^{15}$ Hence, the interconnectedness between human beings - and the falseness of the us-them divide-is stressed once more at the end of the film. We have all once been vulnerable children and, although we may come across as distinct, individual adults, living in distinct, individual nations, this is just a façade. War and acts of terror testify to our vulnerability as adults, too, in Norway as elsewhere.

If we return to Ahmed's (2014) statement that, in public discourse, "the soft national body is a feminised body which is "penetrated" or "invaded" by others" (p. 2) we find that in De andre, Olin herself, as narrator, may well be regarded as the embodiment of a soft, national, feminized body. ${ }^{16}$ What she argues, however, is that this body is not threatened by letting Others in, as long as it extends love, compassion and understanding to these Others. The threat to the 'soft' body comes instead from within. It is the part of the national body that lets itself harden, becoming xenophobically inhumane and overly nationalistic/patriotic. Olin's main strategy in getting this point across is precisely her framing of her documentary through the title sequence connecting Norwegian immigration policies with the terror of 22 July. In this case, Norway was not violated by a male foreigner but, instead, by a Norwegian man acting on an anti-humanist, anti-feminist and xenophobic doctrine. Nationalist antihumanism, in other words, is the threat against Norway's soft national body with which we have to reckon. Olin, on the other hand, is an embodiment of the soft nation, emphasizing the strengths, rather than the weaknesses, provided by its vulnerability.

\section{The 'Invading' Other: Ajkic's Hero Framing in Flukt}

While Olin may be regarded as representing the nation's soft, feminized body, Leo Ajkic may be regarded as partly representing the threatening male immigrant. Bosnian-born Ajkic arrived in Norway at the age of 11 (born in 1983) and, to some extent, fits the threatening young male refugee profile, not least by virtue of his appearance. Dark-haired, browneyed, with a trimmed beard and moustache, pierced ears, standing 6 feet 
4 inches tall $(193 \mathrm{~cm})$, speaking a foreign accented Bergen-dialect and usually sporting some kind of street-wear/hip-hop look (hoodies, caps, sneakers), Ajkic can come across as rather intimidating and reminiscent of a stereotypical ex-Yugoslavian 'bad guy'. ${ }^{17}$ In reality, Bosnians are among the most successful immigrant groups in Norway (Dzamarija 2016) and Ajkic, who has studied social anthropology at the University of Bergen, is one of the most popular contributors at the Norwegian Broadcasting Corporation (NRK) where he has hosted programmes since $2010 .{ }^{18} \mathrm{He}$ often takes on mediating roles, negotiating between the Norwegian and the non-Norwegian (cf. Leo \& U-landslaget). In Flukt, Ajkic becomes this type of 'translator-figure', mediating the strengths and vulnerabilities of the refugees he meets, and, by virtue of his own position as a successful refugee immigrant, he reassures the viewer that refugees can be a resource to Norwegian society. Ajkic simultaneously embodies the hybrid role of the refugee, mediator and national body, clearly destabilizing hegemonic us-them dichotomies. Meanwhile, he also destabilizes traditional gender roles, as he is a new man, performing what Demetrakis Demetriou (2001), inspired by Antonio Gramsci and Homi Bhabha, has termed a hybrid masculinity (p. 349). ${ }^{19}$ This, as we shall see, is a position of dominant masculinity that maintains its power, not by simply opposing and negating but, rather, by incorporating, appropriating and negotiating aspects of non-dominant, marginalized masculinities and femininities (Demetriou 2001, p. 348). Ajkic exemplifies what David Sarvan has called a 'new, more feminized and blackened white masculinity', offering 'subject positions that have been marked historically as being both masculine and feminine, white and black' - and native and immigrant, we may add (Sarvan quoted in Demetriou 2001, p. 348). Emotionally, Ajkic performs a masculinity that combines traits of 'sensitive' and 'tough' men (Demetriou 2001, p. 349). Hence, Ajkic, too, ultimately problematizes the dualistic question of a soft, feminine, national body versus a violent foreign male invader.

Flukt was made in response to the refugee crisis, culminating during the fall of 2015 with more than 30,000 people seeking asylum in Norway that year (Østby 2015). A central strategy in the series is the way Ajkic's own refugee experience frames and introduces the five episodes. As a celebrity journalist, Ajkic and his personal history become the centre of attention. Thus, like De andre, Flukt is a participatory documentary based to a great extent on interviews yet, whereas Olin's film borders on 
other modes, especially the observational documentary, Flukt borders primarily on the performative documentary. We watch Ajkic actively engaging with, and reacting to, the situation he is witnessing and documenting.

The first episode begins with Ajkic visiting his childhood apartment building in Mostar, sitting on a windowsill looking down into a courtyard and stating that he remembers 'that day' very well. It was a day of ethnic cleansing when Croatian soldiers came to round up Bosnians. Ajkic's mother was Croat herself and succeeded in lying to the soldiers, maintaining that her (Bosnian) husband was not at home. 'Things could have ended up differently', Ajkic reflects. ${ }^{20}$ Then comes a title sequence used to introduce each of the five episodes: Ajkic explains that he was only seven years old: 'I will never forget what it is like to flee for your life.'21 He walks through the streets in Mostar. This is followed by an aerial shot in which he is standing on the Stari Most Bridge, or 'the old bridge' (Gamlebroen), as he calls it. The perspective is gradually heightened, and Ajkic ends up a disappearing dot in the landscape. We then cut to archival footage of the bridge being blown up by the Croat military during the Civil (Croat-Bosniak) War in 1993. The bridge Ajkic was standing on is the 2004 reconstruction. In voice-over, Ajkic proclaims:

There are more than 65 million refugees in the world today. The number increases by 34000 each day. But I don't want us to see them as only as traumatized people in need. We also have to think that it is 34000 opportunities each day. ${ }^{22}$

What Ajkic captures in this statement is an ethics of vulnerability in which one does not regard vulnerable people in terms of their weaknesses. As Erinn C. Gilson (2013) puts it in The Ethics of Vulnerability:

If we are to respond well to vulnerability, then it is incumbent upon us to reflect on what we mean when we speak of vulnerability and to formulate a more developed account of the concept, namely one that does not rely upon uninterrogated presuppositions linking vulnerability with harm, affliction, and weakness, and thus opposing it to strength, agency, and ability. (p. 128)

After Ajkic's call for us to turn our attention to refugees, and-like Olinregard softness and vulnerability as a strength and refugees as agents, rather than passive victims, the title FLUKT appears in white capital lettering against the back of his dark jacket as he enters that episode's site 
of exploration. We are, in a sense, piggyback-riding on Ajkic, meeting the refugees through a mediator who has personal experience of fleeing from war.

In the first episode, we start out in Beirut, Lebanon, after having seen Ajkic in Mostar. Here, the refugee crisis is quickly framed in terms of the innocent child as Ajkic, who has just brought us close to his own childhood, engages with an 11-year-old boy who, like him, was 7 years old when 'the problems started'-in the boy's case, in Syria. Hence, the link between host and depicted refugee is emphasized. We follow the boy and his family, the Asaad family, consisting of a divorced father, a grandmother and four children, as they apply to become refugees in Norway. They are interviewed by the Norwegian police in a UN reception centre in Beirut-and, after three weeks, they are granted permission to come to Norway. The father's sister and her five children, however, are denied entry. Not only are they left behind, but the sister also has to part with her mother-who is her best friend-not knowing whether she will ever see her again.

At the end of the episode, we return to Ajkic standing on the Stari Most Bridge. He once more takes on a mediating role, explaining that he knows how the sister feels. When he fled from Bosnia, he also had to leave behind his best friend-his grandfather. In preparing for the documentary series, Ajkic went through personal archives he had not looked at for a long time and found a letter he had sent to his grandfather in 1994, a couple of months after arriving in Norway. He translates it into Norwegian and reads: 'Dear Grandfather'. ${ }^{23}$ While Ajkic reads, photos from his childhood are superimposed on the screen. The first one is of Ajkic as a child, standing together with his grandfather in front of the Stari Most Bridge. The end of the letter reads: 'Of all the pictures I have, the very dearest is the one I have of you.' ${ }^{24}$ Ajkic chokes up and has to interrupt his reading: 'Yeah-just wait a minute. ${ }^{, 25} \mathrm{He}$ quickly sniffles and continues: "And when they make a new "Old Bridge" we will take a picture in the same spot. I hope to see you soon. If we have to flee again, we'll do it together. ${ }^{26}$ Through Ajkic's emotional reaction, we get the sense that Ajkic, meanwhile, has lost his grandfather and that the photo serves as a testimony to what once was, but no longer is, and no longer can be.

At the same time, the shedding of tears is 'a classic component' of the celebrity witnessing narrative (Christiansen and Frello 2016, p. 140). The celebrity witness goes on a journey to become acquainted with people in 
need. He or she is positioned as the main protagonist of the travel narrative and 'the celebrity must display some form of genuine emotion and personal attachment to the "suffering other" (Christiansen and Frello 2016, pp. 135, 137). Yet, Ajkic's narrative diverges from such a standard narrative in two significant ways. First, his vulnerability is evoked by a 'suffering other' who is, simultaneously, himself (as a child) and the contemporary refugee. The two are inextricably entwined, as the suffering Other reminds Ajkic of his younger self, and Ajkic conversely sees and understands contemporary refugees through his own memories and experiences. This goes for Ajkic as well as the viewer. Second, the protagonist of celebrity witnessing narratives tends to be gendered as feminine, following a traditional association between femininity, empathy and emotions (Christiansen and Frello 2016, p. 139). Ajkic is male and, as indicated, inhabits that role in terms of hybrid masculinities. Hence, as 'boys don't cry', his teary reaction may be considered particularly strong, even overwhelming, and thus also authentic and convincing. ${ }^{27}$ Ajkic quickly recovers, both by holding back his tears and by addressing his emotionality in a 'masculine' language of English slang. Referring to the episode in retrospect, Ajkic explains that Flukt is the most demanding and important project he has carried out, and that it was impossible to hold back his tears. Yet, he dares to show his vulnerable side: 'I am not embarrassed to show emotions when it's about "real shit"' (Grøtte 2017). ${ }^{28}$ Ajkic, in other words, constructs a hybrid masculinity allowing him to incorporate a female-gendered emotion and its expression-crying-while retaining a 'masculine' distance from femininity by, for instance, discussing it in rough, vulgar terms. ${ }^{29}$

Having finished reading the letter, Ajkic encourages the viewers to be nice to the Syrian refugees arriving in Norway. We see the Asaad family looking happy and hopeful in Norway, and are encouraged to think of them through Ajkic. History repeats itself. Ajkic was once like the Syrian boy arriving in Norway. He is now well-integrated-even a national celebrity. Refugees should be looked on as resources and opportunities, not as threats to a Norwegian way of life. Emphasizing this point of agency and resourcefulness is the fact that the Asaad father immediately starts working in his brother's kebab shop.

Like the photos used by Olin to document the aftermath of 22 July, the photos of the Stari Most Bridge serve to document a national trauma. They are taken at three different moments: (i) when the bridge was more than 400 years old, reminding us of peaceful times before the Yugoslavian 
wars; (ii) when it was blown to pieces in the midst of war; and (iii) when it has been reconstructed after the war. The pictures bring us back and forth in time, testifying to times of peace and war. They trigger Ajkic's memories and emotions, and are a witness to history and History-personal history and world history. The series of photos captures the vulnerable child as well as the strong adult, and shows how the two combine in Ajkic. Places and persons may stand strong, be broken down and end up standing strong again.

Images of Mostar and the Stari Most Bridge reoccur in each episode. In Episode 3, which concerns anti-immigrant movements (in Lebanon, Austria and Greece), Ajkic returns to Mostar to explain how hatred divided the city into three parts. Ajkic felt the division on his own body, as he was previously regarded as 'Yugoslav' but ended up a child of 'mixed' marriage. Again, through Ajkic, us-them dichotomies are shown to be contingent.

For the last episode, Ajkic poses the question of how Norwegians should welcome refugees to their country as he advocates an everydayhero approach. First, he investigates how they are received on Lesbos, stating that 'maybe we Norwegians have something to learn'. ${ }^{30}$ The choice of pronoun interestingly reinforces Ajkic's own status as a Norwegian in this series. ${ }^{31}$ In the last part of Episode 5, we return to the Asaad family and their arrival in Søgne, close to Kristiansand. The children run out to play on an outdoor playground. This serves as yet another segue to Ajkic's childhood. He states that he recognizes their childhood happiness: 'Once I was the new boy in the foreign country.' 32 Again, photos from Ajkic's childhood are superimposed on the screen. 'But the war stayed with me. What you have experienced stays with you. It's not always easy to fit in. ${ }^{33}$ We cut to live footage of Ajkic from behind as he enters a pedestrian tunnel. In voice-over he continues: 'When I came to Norway, I was restless. I did something stupid and ended up in a bit of trouble. I even had the police arriving at my parents' door. To be honest, things could have gone wrong with me. ${ }^{34}$ We are reminded that Ajkic relates to young, criminal, immigrant boys. In the next shot, Ajkic is filmed front-on emerging from the tunnel. The architectural symbolism provided by the tunnel is as heavy as that of the bridges (especially the Stari Most Bridge). Ajkic has been through dark times, but has re-emerged into the light. 'But the people one meets on one's way can change everything', says Ajkic, inviting us to hear more about his arrival in Løvstakken, Bergen, and to reflect on this statement, and how it may involve you as a viewer and 
fellow Norwegian. ${ }^{35}$ A Norwegian took on the role of an everyday hero and helped Ajkic.

When Ajkic was twelve, he met Yngve Træland who was working for the county to integrate young immigrants, 'people like me', as he says. ${ }^{36}$ Træland took the kids on trips and vacations, and involved them in making radio programmes. In his archives, Ajkic has a cassette with a young Leo interviewing another boy on the radio. Ajkic listens and concludes that this turned out to be the first step on a path he had no idea he would take: 'And things have ended up pretty well for me.' 37 This the viewer can attest to, and Ajkic's story is used to encourage people to be everyday heroes.

And, as Ajkic points out, the role of an everyday hero is limited by neither gender nor age: 'Everyday heroes do not have to be adult men who work for the county; an everyday hero can also be a 10-year-old girl. ${ }^{38}$ The next shot shows one of the Asaad girls who has befriended a 10-year-old blond Norwegian girl who 'welcomes her new Syrian neighbours'. ${ }^{39}$ Ajkic returns to visit the Asaad family after they have lived in Søgne for half a year. The children confirm that they are well-integrated and have new friends. Ajkic then reflects on his documentary project overall, reminding us of all the refugees he has met during each episode in Africa and Europe, and on the Mediterranean Sea. 'For me, it's been a great journey. I have met amazing people who can become an opportunity for Norway. If they are given the chance. ${ }^{40}$ Again, Ajkic encourages the viewer to regard refugees as opportunities, not just as liabilities, and we are reminded of the role we play as hosts in a host country: 'Then you have to welcome them.' Cause you cannot create world peace or get rid of poverty. But you can say "welcome". 41 While Olin expresses abstract philosophical humanist ideas in her voice-overs, Ajkic brings them down to earth. As a translator figure, he seeks to affect his listeners by speaking in plain language, in pragmatic terms about what the ordinary person is able to do for a good cause-for people who can do something for Norway. Olin, by contrast, remains the maternal, overtly moralizing figure, educating her viewers through more philosophical questions such as the: 'Then what happens to freedom?'

A final shot shows the Asaad family from behind-the father in the middle with two children on each side, all holding hands and walking on a paved path-walking away from the camera and towards the rest of their lives in Norway. Again, images of paths are used literally and metaphorically - with bridges, tunnels and open roads constantly reminding us of 
people moving through life phases, encountering other people and other cultures. The strong father is in the middle, once more reinforcing the image of a new man, in this case a divorced man serving a dual caretaker role, rather than an image of a threatening male immigrant. The path is paved, metaphorically speaking, by everyday heroes inclined to help each other.

\section{Feminist Alternatives to the White Man's Burden}

The refugee 'crisis' has brought on new discourses of Scandinavian vulnerability, as many fear the violent and criminal consequences of especially young, male refugees gaining access to the country. Olin and Ajkic present counter-discourses that involve Norway losing sight of its own identity based on humanist and humanitarian values: Norway being vulnerable to internal right-wing terrorism, and Norway missing out on the opportunities provided by hard-working and innovative immigrants. In terms of gender, Olin comes across as a postnational maternal figure who is able to see, depict and remind us of the vulnerable child that still resides inside the tough-looking young man. She is also able to safeguard national values in a globalized world, tending to the future of her own child as well as that of refugees. Ajkic, on the other hand, reveals the vulnerability of the child he once was. He is an object of fascination as he, himself, could have been the threatening, criminal, male immigrant in Norway but, instead, ends up an exemplar refugee and celebrity mediator between 'us' and 'them'-a dichotomy he nonetheless destabilizes as he personally figures as 'Yugoslav', 'a son of a mixed (Croat-Bosnian) marriage', 'Bosnian', and 'Norwegian'. Overall, Ajkic serves as a reminder of how we may be overly focused on the negative aspects of vulnerability-focused both on our own helplessness as a national body opening up to refugees, and on the refugee as a weak, suffering Other. In both cases, Ajkic urges us to think not in terms of helpless passivity but, instead, in terms of strength, agency, and ability, to use Gilson's words (2013, p. 128).

Rhetorically, Olin appeals to her audiences primarily on a political level, demanding compliance with human rights laws. Her point of departure is more abstract, legal and philosophical, presented in a classic humanitarian discourse. Emotionally, she nevertheless also appeals to our sense of compassion by emphasizing the vulnerability of both refugee Others and ourselves, ultimately framing current refugees in terms of how they could have been our own children. Ajkic, on the other hand, appeals to 
his viewer in a more quotidian way, asking him or her to act as an everyday hero-someone willing to step in and help another person when he or she needs it. His appeal is rooted in the personalized idea that current refugees could have been (and once were) him. Both mediators use their personas in gendered ways - as mother (the nation's mother, a global mother) and as everyday, new-man hero-to destabilize common perceptions of an ethnic and cultural self and Other. This, in part, allows them to speak from a non-dominant Norwegian position, deconstructing ethnic dichotomies. In the end, both Olin and Ajkic represent alternatives to the imperialist trope of the white man carrying his burden of civilization. Each, in his or her own way, represents a new man and a new maternal figure, and each emphasizes what Butler (2010) refers to as 'the recognition of shared precariousness' (p. 28).

\section{Notes}

1. Butler further distinguishes between 'precariousness' understood as a general threat to the safety of all lives and 'precarity' as a structurally determined precariousness, rendering certain groups of people more vulnerable than others. Both terms are relevant for a discussion of refugees; in this chapter, I focus on 'precariousness' and 'vulnerability', and use them synonymously.

2. De andre was awarded best documentary at the 2012 Bergen International Film Festival, the 2013 Amanda Awards and the 2013 Documentary festival in Volda. The film is also used for pedagogical purposes in schools (cf. Dokka, n.d.). Flukt won the 'Gullruten' ('Golden Screen') for best documentary series of the year, while Ajkic also won the 'Gullruten' for best male host as well as Fritt Ords Honnørpris 2017, for having used his own background as a refugee to provide insight into the lives and dreams of refugees in Europe and Norway. In 2019, he won the Jonas Prize, awarded to people who have contributed to creating a more tolerant society in which human variety and individual difference is considered an enrichment, rather than a problem. The jury especially emphasized his work with the two documentary series Flukt (2017; Escape/Fleeing) and Uro (2019; Unrest/Worry).

3. This trope is well-known from postcolonial theory where nations (a people, their nature, and spirit) are imagined as women, while nations as states are imagined as masculine institutions in charge of order and protection, such as the military (cf. Nagel 1998).

4. Lone, minor asylum seekers tend to be regarded as violent and criminal. In an article on Olin's De andre, Anne Marte Blindheim recognizes this 
point: 'The lone, minor asylum seekers constitute a grey mass of youth, largely boys. Usually they are mentioned in the same breath as drug selling and knife stabbing' (Blindheim 2012; my translation).

5. I use the term 'postnational' to indicate a situation of globalization in which nation states and national identities lose their importance relative to transnational and global entities. The prefix indicates that our understanding of the national-while still meaningful-is under pressure and is being renegotiated.

6. 'gutta mine'. Throughout this article, I use the English subtitles on the DVD for English translations of De andre.

7. To give an indication of the refugee situation in Norway: De andre premiered in 2012. Between 1990 and 2011, Norway registered 110,000 immigrants living in Norway as refugees. Of these, 67,000 had sought asylum (Dzamarija 2013, p. 22). Until 2012 (having started in 2003), Iraqis constituted the largest refugee group in Norway. In 2012, the largest refugee group arriving in Norway was from Somalia; out of 9800 people seeking asylum in 2012, 2200 were from Somalia, 1200 from Eritrea, and 990 from Afghanistan (UDI, n.d., pp. 1, 5). Jumping ahead in time to the most recent available statistics: as of 1 January $2015,188,100$ people with a refugee background were registered as living in Norway. They comprised $3.6 \%$ of the total population (Østby 2015). In total, the three largest refugee immigrant groups were still from Somalia $(26,100$ people), Iraq $(20,600$ people $)$ and Eritrea (14,100 people). Yet, the fastest growing group compared to previous years consisted of Syrians (Østby 2015). In 2014, 2000 Syrian refugees arrived in Norway compared to 800 in 2013 (Østby 2015). De andre captures a moment in time when Iraqis comprised the largest refugee group in Norway. The first person we meet in the film is Goli from Kurdistan as he is deported to Iraq.

8. 'I drømmen er det ikke lenger norsk ungdom. Det er guttene i filmen min. Og de er i åpent hav.'

9. 'Jeg lager denne filmen fordi jeg er redd. Jeg er ikke redd for de andre. For de fremmede. Jeg er redd for det som skjer med oss når vi ikke lenger er i stand til å se det enkelte menneske.'

10. Butler (2010) coins the adjectives 'grievable' and 'ungrievable' to discuss how we mourn the loss of lives among people with whom we identify, while we seem unaffected by the death of others; for example, civilians dying in countries against which the USA has waged war.

11. Here, traditional boundaries between the individual, communicative and cultural memory are collapsed (Assmann 2010). Although this may be understood in terms of a personal trauma on the one hand, and contemporary mediatization on the other, the immediate effect of this collapse among critics was a sense of discomfort directed at Olin as a filmmaker. For further analysis, see Oxfeldt (2019). 
12. Olin uses her daughter in a similar way to point to the future in her documentary Ungdommens råskap (2004; Raw Youth).

13. 'Kjærlighet, da? [...] Du liker jo barn. Tenk om du hadde et barn som var ditt.'

14. 'Jeg har alltid tenkt at det beste i mennesket er å søke frihet. Vi gikk i tog for vår frihet. Vi vant over frykten. Men kjente vi også da at vår frihet er avhengig av andres frihet? Og hva skal sikre friheten om det ikke er beskyttelse av hvert enkelt menneskes verdi. Når vi behandler andres barn og ungdommer slik vi aldri ville behandlet våre egne, da er det grunn til å spørre om friheten kan begrenses til å gjelde bare noen. Hva skjer med friheten da?'

15. 'Kjære Gud jeg hard et godt' (my English translation). The shameinducing juxtaposition of the genre of the lullaby and imagery of refugee children is similarly used by Henrik Nordbrandt in his poem 'Vuggevise' (Lullaby), inspired by Alan Kurdi's death (Nordbrandt 2015).

16. This resonates with her overall film oeuvre: Olin's breakthrough documentary film was Kroppen $\min (2002 ; M y$ Body), depicting the vulnerability of her body (and her relationship to it).

17. This is a common stereotype used in Scandinavian films; for example, the Serbian drug lord Milo in Nicolas Winding Refn's Pusher trilogy (Philipsen 2013).

18. Approximately 14,000 people fled to Norway from Bosnia-Herzegovina in the 1990s. Measured in terms of education and employment, Bosnian immigrants are exceptionally well integrated (Dzamarija 2016). They have the greatest percentage (over $40 \%$ ) of young people enrolled in higher education. The number is greater than for any other immigrant group in Norway and for the Norwegian average in general (Østby 2015).

19. In his discussion of hybrid masculinities, Demetriou aligns himself with David Sarvan as well as Brian Donovan (Demetriou 2001, pp. 348-349).

20. 'Det kunne gått annerledes.' All translations into English from Flukt are my own.

21. 'Jeg kommer aldri til å glemme hvordan det er å flykte for livet.'

22. 'Det er over 65 millioner på flukt i verden i dag. Tallet øker med 34000 hver eneste dag. Men jeg vil ikke vi skal se dem bare som traumatiserte mennesker i nød. Vi må også tenke at det er 34000 muligheter hver dag.'

23. 'Kjære bestefar.'

24. 'Av alle bildene jeg har, så er mitt aller kjæreste det jeg har av deg.'

25. 'Yeah-bare vent litt.'

26. 'Og når de lager en ny "gamlebro", skal vi ta bilde samme sted. Jeg håper vi sees snart. Hvis vi må flykte igjen, gjør vi det sammen.'

27. 'Boys don't cry' may be explained by the fact that in some cultures, including Western cultures, women are expected to show vulnerability expressed through emotions of fear, shame, embarrassment, distress, sadness and so 
on, whereas men are 'expected to express anger, an emotion associated with a superior social status' (Vermot 2015, p. 149). Or, as Alan Petersen (2004, p. 5) puts it, 'acting "emotionally", "lovingly", "passively", "sensitively", and so on, is strongly associated with being "feminine", while acting "rationally", "distantly", "assertively", "insensitively", and so on tends to be associated with being "masculine".

28. 'Jeg er ikke flau over å vise følelser når det handler om "ekte shit”.'

29. Michael Messner from a similar feminist perspective analyses powerful, American men shedding a tear in public (Messner 1993).

30. 'Kanskje vi nordmenn har noe å lære.'

31. Ajkic's in-between status as Bosnian-Norwegian manifests in his changing use of pronouns. Sometimes, as here, he includes himself among Norwegians and says 'we'. Other times, such as when he published a New Year's speech on NRK Ytring in 2016, he addresses Norwegians through the second person plural pronoun: 'Now it's the time of year when the king and the prime minister give their new year's speeches, so I figured that I, too, would use the occasion to say some words. But I won't speak of how nice Norway is and how great you Norwegians are. You already know that I like you' (Nå er det den tiden på året da kongen og statsministeren holder nyttårstale, så jeg tenkte jeg skulle benytte anledningen til å si noen ord, jeg også. Men jeg skal ikke snakke om hvor fint Norge er og hvor fete dere nordmenn er. Dere vet jo at jeg liker dere) (Ajkic 2016). In a similar New Year's speech at the end of 2018, he acknowledges that many are afraid of people like him, immigrants, but ends up using the pronoun 'we', stating that 'we' disagree on many things in this country, but that 'we' nevertheless seem to agree on the most important things, like wanting to take care of each other and the welfare state (Ajkic 2018).

32. 'En gang var jeg den nye gutten i det fremmede landet.'

33. 'Men krigen ble med meg. Det du har opplevd, blir med deg. Det er ikke alltid lett å passe inn.'

34. 'Da jeg kom til Norge, var jeg rastløs. Jeg gjorde noe tull og havnet litt i trøbbel. Fikk til og med politiet på døren til foreldrene mine. For å være xrlig kunne det gått galt med meg.'

35. 'Men folkene man treffer på veien, kan endre alt.'

36. 'sånne som meg'.

37. 'Og det har gått ganske bra med meg.'

38. 'Hverdagshelter trenger ikke være voksne menn som jobber i kommunen. En hverdagshelt kan også være en ti år gammel jente.'

39. 'som tar godt imot sin nye syriske nabo'.

40. 'For min del har det vært en flott reise. Jeg har møtt fantastiske folk som kan bli en mulighet for Norge. Hvis de făr sjansen.'

41. 'Da må du ønske dem velkommen. For du klarer ikke å skape fred i verden eller å avskaffe fattigdom. Men du klarer å si "velkommen".' 


\section{REFERENCES}

Ahmed, S. (2014). The Cultural Politics of Emotion. Edinburgh: Edinburgh University Press.

Ajkic, L. (2016, December 30). Nytårstale fra en flyktning. NRK Ytring. https://www.nrk.no/ytring/nyttarstale-fra-en-flyktning-1.13286465. Accessed 30 November 2018.

Ajkic, L. (2018, December 31). Nyttårstale fra en som lytter. NRK Ytring. https://www.nrk.no/ytring/nyttarstale-fra-en-som-lytter-1.14350186.

Accessed 8 January 2019.

Assmann, J. (2010). Communicative and cultural memory. In A. Erll \& A. Nünning (Eds.), A Companion to Cultural Memory Studies. Berlin: De Gruyter.

Blindheim, A. M. (2012, October 27). De etthundreogførti andre. Dagbladet. Butler, J. (2010 [2009]). Frames of War: When Is Life Grievable? London: Verso. Christiansen, L. B., \& Frello, B. (2016). Celebrity witnessing: Shifting the emotional address in narratives of development aid. European Journal of Cultural Studies, 19(2), 134-149.

Demetriou, D. Z. (2001). Connell's concept of hegemonic masculinity: A critique. Theory and Society, 30, 337-361.

Dokka, I. (n.d.) Filmstudieark. De andre. Film og Kino. https://www.filmweb. no/skolekino/incoming/article1071958.ece. Accessed 7 December 2018.

Dzamarija, M. T. (2013). Innvandringsgrunn 1990-2011, hva vet vi og hvordan kan statistikken utnyttes? Rapporter 34. SSB/Statistics Norway. https:// www.ssb.no/befolkning/artikler-og-publikasjoner/_attachment/135482?_ts= 140 bf5cf4f8. Accessed 8 January 2019.

Dzamarija, M. T. (2016, December 14). Bosniere-Integreringsvinnerne? Samfunnsspeilet. https://www.ssb.no/befolkning/artikler-og-publikasjoner/ bosniere-integreringsvinnerne. Accessed 8 January 2019.

Gallefoss, L. P. (Director). (2017). Flukt. Norway: Pandora Film.

Gilson, E. C. (2013). The Ethics of Vulnerability: A Feminist Analysis of Social Life and Practice. New York and London: Routledge.

Grøtte, M. (2017, January 17). Leo Ajkic om tårene i 'Flukt': Ikke flau over å vise følelser. $V G$ https://www.vg.no/rampelys/tv/i/82112/leo-ajkic-omtaarene-i-flukt-ikke-flau-over-aa-vise-foelelser. Accessed 30 November 2018.

Gullestad, M. (2006). Plausible Prejudice. Oslo: Universitetsforlaget.

Messner, M. A. (1993). 'Changing men' and feminist politics in the United States. Theory and Society, 22, 723-737.

Moeller, S. D. (2002). A hierarchy of innocence: The media's use of children in the telling of international news. Press/Politics, 7(1), 36-56.

Nagel, J. (1998). Masculinity and nationalism: Gender and sexuality in the making of nations. Ethnic and Racial Studies, 21(2), 242-269. 
Nichols, B. (2010). Introduction to Documentary. Bloomington: Indiana University Press.

Nordbrandt, H. (2015, September 9). Vuggevise. Politiken.

Olin, M. (Director). (2012). De andre. Norway: Speranza Film.

Østby, L. (2015, December 18). Flyktninger i Norge. Statistics Norway. https://www.ssb.no/befolkning/artikler-og-publikasjoner/flyktninger-inorge. Accessed 12 December 2018.

Oxfeldt, E. (2019). Memories of crisis and guilt: the Oslo Massacres (22 July 2011 ) and Margreth Olin's De andre (Nowhere Home, 2012). In A. Drost, O. Sasunkevich, J. Schiedermair, \& B. Törnquist-Plewa (Eds.), Collapse of Memory: Memory of Collapse-Narrating Past, Presence and Future about Periods of Crisis (pp. 27-41). Göttingen: Vandenhoeck \& Ruprecht.

Petersen, A. (2004). Engendering Emotions. Basingstoke: Palgrave Macmillan.

Philipsen, H. (2013). Har vi set en rigtig negermand i dansk film? Om fremstilling af fremmedhed i fiktionsspillefilm. In S. Frank \& M. Ü. Necef (Eds.), Indvandreren $i$ dansk film og litteratur (pp. 162-197). Hellerup: Spring.

UDI. (n.d.). Migrasjon 2012. Fakta og analyse. https://www.udi.no/ globalassets/global/aarsrapporter_i/aarsrapport-2012.pdf. Accessed 12 December 2018.

Vermot, C. (2015). Guilt: A gendered bond within the transnational family. Emotion, Space and Society, 16, 138-146.

Open Access This chapter is licensed under the terms of the Creative Commons Attribution 4.0 International License (http://creativecommons.org/licenses/ by $/ 4.0 /)$, which permits use, sharing, adaptation, distribution and reproduction in any medium or format, as long as you give appropriate credit to the original author(s) and the source, provide a link to the Creative Commons license and indicate if changes were made.

The images or other third party material in this chapter are included in the chapter's Creative Commons license, unless indicated otherwise in a credit line to the material. If material is not included in the chapter's Creative Commons license and your intended use is not permitted by statutory regulation or exceeds the permitted use, you will need to obtain permission directly from the copyright holder.

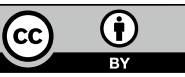




\section{Shared, Shamed and Archived Images of Vulnerable Bodies: On the Nexus of Media, Feminism and Freedom of Speech in Scandinavia}

\section{Bodil Marie Stavning Thomsen}

In recent years, the easy sharing facilities provided by social media have been much debated in Scandinavia in relation to the vulnerability of individuals whose images are shared (with or without consent) on platforms such as Facebook, Messenger, Twitter, Snapchat or other more or less closed web fora. ${ }^{l}$ While sharing between individuals is often done with consent, distributions to a wider group is generally done without consent. This vulnerability on the Internet, identified in words such as 'cyberbullying', 'hate crimes' and 'hate porn', is a real player among youngsters, who hold the opinion that freedom of speech is a democratic right in the Scandinavian welfare states, but who are not entirely familiar with the rules of ownership and copyright issues connected to older media and art forms.

B. M. S. Thomsen $(\bowtie)$

Department of Scandinavian Studies, Aarhus University, Aarhus, Denmark e-mail: bodilmarie@cc.au.dk

(C) The Author(s) 2020

A. M. Dancus et al. (eds.),

Vulnerability in Scandinavian Art and Culture, https://doi.org/10.1007/978-3-030-37382-5_4 
The task of this chapter is to take a closer look at the vulnerability involved in self-exposure on the Internet in relation to questions on women's liberation movements and the constitutional rights of free speech in Scandinavia. ${ }^{2}$ The chapter will focus on cases and discussions related to Danish culture except for the analytical exploration of the Norwegian TV series $S K A M$, which was highly popular in Denmark with 3 viewers out of 10 in 2016 (Eskesen 2016). The guiding research agenda sets off from the thesis that freedom of speech is closely intertwined with one's access to and mastery of media and, consequently, that one of the central issues of the Feminist movement in Scandinavia-whether or not one should have access to the copyright of one's own image-is central to this. Danish Feminist Emma Holten's point-that young women must have the right to give or deny consent to the circulation of their 'own image'-is included in the chapter, as well as the stance taken by her and other young Scandinavian Feminists that women's liberation has to be negotiated through the conditions of contemporary media (Dich 2017). Feminists of today demonstrate both obvious objections to sharing their images without consent, as well as affective forms of playfulness on the Internet. It is my point that the latter displays mastery of the medium, and that it is through the ability to administer and master a medium that the 'freedom of speech' is negotiated in our Scandinavian culture-today as well as in the past. To my mind, freedom of speech should, today, include not just spoken and written expression, but also the consent or non-consent of individuals whose images are exposed, shared or shamed as content; for example, becoming vulnerable body-objects. The idea of copyright may be too narrow and not easy employable in such issues, since ownership concerning images has generally been attributed to the subject of the act (the painter, the photographer) and not to the 'object' portrayed or exposed.

The crux of the matter is that the sharing of images today is done through interfaces through which the issue of ownership of content is blurred. According to Anna Munster's definition, interfaces accentuate the intensity of a folded relation between sensing your own body (from the inside) while, at the same time, mapping it (from the outside) (cf. Munster 2006, p. 142). So, simultaneous with the 'so-called' content, the involvement in a folded relation between inside and outside in the very act of chatting or image-sharing, for example, brings affect-relations to the fore. ${ }^{3}$ Thus, a traditional conception of being either the subject of ownership (or of perception), or an object of ownership (or perception) 
is blurred. The chapter will take its point of departure in a short close study of the affectively felt role of interfaces in the Norwegian TV series $S K A M$. It clearly illustrates how issues of sexual freedom and expression of individuality are closely linked to interfacial mediations of affects. These can-as will be shown - be both studied in the narrative or thematic distribution of how bodies act and relate, and as forces of affect that highlight the signaletic materiality of interface relations.

The term 'the signaletic material' that I will use throughout the chapter refers to Gilles Deleuze's definition in Cinema 2: The Time-Image (Deleuze 1989), where he underlined that the inclusion of movement (from film media and onwards to electronic media) should entail a theoretical move from sign to signal. The accent on meaning-making, representation and narration as a 'piece of information' should be switched to an interest in the medium as message, as 'source of information' (Deleuze 1989 , p. 269; cf. Thomsen 2012, 2018). In this chapter, I propose to look at real-time text messages and image messages on social media platforms as something that brace and support-for better or for worse-a folded relationship to one's own body in a folded intensity to the signaletic material of the interface. Nothing is stable in interfaces. But, as in all relations-mediated or not-we can focus on establishing what Brian Massumi terms 'a thinking-feeling of what happens' that can make us 'see potential' and 'a life dynamic, [where] we virtually live relation' (cf. Massumi 2011, p. 43). Even though it can certainly be an experience of vulnerability to share content on the Internet, it is important to notice that negotiations and fixations of meaning most often happen in social and cultural contexts. The channel for this negotiation is often the amount of 'likes' or 'sharings'; that is, the level of algorithmic data measurement that has become a new filtering mechanism in media for accessing the level of cultural meaning.

The chapter will conclude by taking a closer look at the 'immediate' level of the signaletic material and the interfacial fold that escapes classical aesthetic studies of meaning and reproduction. The 'immediation' is precisely described by Alanna Thain (in relation to cinema) as a 'suspendedness' or 'du-pli-cation, the felt folding of the world'. She continues with a characterization of David Lynch's film Inland Empire: 'This suspendedness is neither displacement nor alienation, but an infidelity to the self, understood here as the "crime of time" (Thain 2017, p. 12). Lynch famously explores this 'crime of time' in Inland Empire by making specific use of the recording facilities of video (the rewind and recording-erasing 
procedure, especially), and thus the signaletic material or the interlacement of past and future representations of a body, for example, can be immediately 'felt' in the perception of the film. The signaletic materiality is easily graspable when thinking of the grainy salt-and-pepper electronic structure of video that is also an important ingredient to affect in many of Lars von Trier's films (cf. Thomsen 2018). In the following short study of two significant episodes of SKAM, it is my intention to highlight how the interface is explored as the explicit 'content' between actors, screens and situations - thus becoming a 'felt' signaletic material to the viewer. That the series explicitly explores the idea of shame and shaming amongst youngsters (between the ages of 16 and 19) in Norwegian High Schools, where identities are vulnerable and objects to cultural negotiation, makes the series a clear-cut case for studying affect. The series can be seen as an exploration of the affective intensities of interfaces in relation to the vulnerability of youngsters who need to master not only their social and cultural identity offline, but also their online identity, which includes fashioning and controlling one's 'own image'.

\section{The Sharing of Shame in SKAM}

The Norwegian TV series SKAM (Shame) comprises four seasons with 43 episodes, written and directed by Julie Andem, and originally broadcast in Norway 2015-2017.4 Its huge success in Scandinavia was certainly due to the integration of interface screens such as mobile phones and computers in the narration. Nevertheless, this has not been studied nearly as much as the representational content; that is, the description of sexuality, ethnicity, shame, or the slang used between the youngsters (cf. Stage 2017; Christensen 2017; Hougaard et al. 2017). Whereas the studies by Anne Jerslev (2017) and Vilde Sundet (2017) also highlight the series' creation of immediacy and hypermediacy, and erasure of bounds between fiction and reality, due to the use of digital media platforms and real time, Krüger and Rustad (2017) and Rustad (2018) focus on the series as producing 'a digital space for interaction and experimentation' (Krüger and Rustad 2017). Meanwhile, the following will focus especially on the use of interfaces in SKAM, and explore the intensification of affect relations involving bodies and technology alike. In recognizing this level, it raises other, broader questions: 'What do interfaces do?'; 'What proportion do interfaces comprise in shaming or in vulnerability?' In the summary that 
follows, I have used italics to accentuate when interfaces are key to a narrational unfolding.

I will focus on season II, episodes 9, 10 and 11, where Noora as the main protagonist negotiates her relation to William, whom she dates on and off. The focus of the three episodes is whether or not William's brother, Nicolai (Nico), has doped and raped her, and afterwards shared his photo of her naked body online. This narrative thread initiates episode 9, when Noora wakes up after a party, naked and lying in the same bed as Nico and another girl, sleeping behind him. She quickly dresses, collects her purse and cell phone, and flees the scene. The following evening at her place, she searches the Internet for information on alcohol-related doping and rape in trying to figure out, why she remembers nothing about the party. She also searches for Nico's contact information and texts him asking what happened at the party. Meanwhile, she does not respond to Williams many text messages and calls on her cell phone, as well as at her door. On Monday morning, William contacts Noora at school, only to be let down again. For the entire week she checks for messages from Nico. At the end of the week, he texts her, assuring her that nothing happened at the party. Immediately after she finds William, and they reconcile with a kiss. William tells her that Nico is a psychopath who would do anything and everything to ruin their love. William has to leave straight away, and Nico texts her again saying that he now remembers how willing she was and that she acted like a whore. An image follows of her naked body in the bed. She takes a close look (as does the viewer) and freezes. In episode 10, she wakes up in her own bed, thoughtful. William texts her, wanting to spend time with her. She lies and texts back that she is sick. She texts Nico again, asking what happened last Friday. He immediately texts back, wanting to meet up with her. William enters her room and, under pressure, she tells him a white lie but a true story about her deadline for an article about Norwegian Constitution Day, 17 May. He calms her and, while she falls into a deep sleep, he writes the article for her at her computer, making sure to shut down the announcements of messages coming in. The next day, he wakes her up and drives her to her friend Eva's place to celebrate Norwegian Constitution Day with her friends. Here, Eva reads aloud Noora's (i.e. William's) article from her iPad. It connects the freedom of the welfare state of Norway with youngsters' intensive use of social media, and their constitutional rights and responsibilities to society. Her reading leaves Noora crying at the end. Confronted with the attentive care of her friends, she blurts out that Nico may have raped her. The 
group of girls forces her into action and escort her to the doctor, who examines her and views the photo on her cell phone. Two days later, she meets up with Nico at a restaurant and confronts him with the fact that producing, keeping and sharing sexualised images of children is a criminal offence in Norway, carrying sentences of up to three years in prison. She also quotes the criminal law on serving alcohol to underage persons. She points out that, according to both laws, she is considered underage or a child, and underlines the words 'without consent' ('uten mitt samtykke'). Even though cornered, he threatens her, but she leaves the restaurant, having shown him that she recorded their conversation on her cell phone. A few days later, a text message from Nico makes it clear to her that he has given William the impression that she had a one-night stand with Nico about which she remembers nothing. William furiously approaches her, as her lack of memory makes it impossible for her either to confirm or deny Nico's claim. In episode 11 , Noora finally plucks up courage to approach the girl, Mari, who shared the bed with Nico and herself after the party. Mari makes it evident that Nico did not rape her, and Noora is convinced when Mari gives her more background information about Nico and William's family. In the long reconciliation scene between William and Noora that follows, numerous text messages are exchanged back and forth and, at last, she succeeds in making William interrupt his planned flight to London. The essential information to the viewer, however, is that Noora has reported Nico to the police for having an image of her naked body in his possession without her consent.

When watching these episodes, it becomes clear how all interface screens and functions serve the purpose of bringing key messages to the fore to the TV viewer, who experiences the real-time level of online discourse as though present (cf. Jerslev 2017; Krüger and Rustad 2017; Sundet 2017). The beeping and texting sounds, as well as the close-ups of message content, function as mimetic traces to the affective level of online devices familiar to the viewer. Along with this, Noora often checks her smart phone waiting for messages that just as often arrive unexpectedly. Thus, narrational time is folded into the flow, the overload or the interrupting forces of interface sounds and images. Another level of affect is due to the fact that Noora, in the first part of the italicised interfacial situations, - before confessing to her friends - is mostly portrayed as a vulnerable body in pyjamas suffering from eating disorders. That she has stopped eating after the party is stressed several times, and this alludes to the general depiction of her as fragile and vulnerable throughout the 
series. For the key speech at the 17 May celebrations, about constitutional rights intertwined with youngster's responsibilities in relation to the time and energy used online, Noora wears a very short and slim-fitting white dress that makes her look both underaged and anorectic. On their way to the doctor's practice and to display modesty, three of the girls wear full-length national dress as typically worn by Norwegians on May 17. The group appears determined, almost revolutionary, when dragging the vulnerable Noora along in their midst. In this scene Noora presents the group as well as the doctor to Nico's apparent intimate photo of her that-without this action-might have developed into shameful online content, if shared by Nico to his friends. In the last part of the italicised situations, Noora wears normal clothing. In demonstrating to Nico that she recorded him threatening her, the series points out that, by framing him, she masters her online and offline existence.

All of the above follows a classical narrative reading of relations and actions. In the next section, I will focus on Noora's change of bodily expression from affectionately kissing William to her frozen posture at the sight of Nico's photo-which presents her as a slut-at the end of episode 9. The reason for focusing on this scene is that the felt intensity experienced with William does not correspond with Nico's interfacial sharing of her body as seen from the outside. She cannot remember and, in a sense, was 'not there'; thus, 'she' is not in the picture-neither as 'feeling' nor as 'image'. She did not take part in the interfacial folding even though she was 'there'. The result is devastating: at the beginning of episode 10, she seeks isolation, escapes her closest friends, and her line of flight is already designated: to become an anorectic body. The negative affective state she is left in, confronted with Nico's framing of her, is the reverse of the affects of joy she just experienced with William. The power to act and to extend this power to grow as a person cuts into an immediate level of sensation (including the viewers') that, on a narrative level, is closely related to Noora's paranoid or anxious handling both of text messages and of personal approaches. The episodes taken together clearly demonstrate that affects influence a body's power to act-along with its image affections and ideas - and its capabilities of becoming either joyful or sad, as explained by Deleuze in his reading of Baruch Spinoza's Ethics:

The passage to a greater perfection, or the increase of the power of acting, is called an affect, or feeling, of joy; the passage to a lesser perfection or the diminution of the power of acting is called sadness. Thus the power of 
acting varies according to external causes for the same capacity for being affected. The feeling affect (joy or sadness) follows from the image affection or idea that it presupposes (the idea of the body that agrees with ours or does not agree); and when the affect comes back upon the idea from which it follows, the joy becomes love, and the sadness, hatred. In this way the different series of affections and affects continually fulfil, but under variable conditions, the capacity for being affected. (Deleuze 1988, p. 50)

In this way, the three episodes of SKAM II dig into the vulnerability of youngsters in relation to the affective intensity of interfaces, when hindered in mastering and accessing their 'own image'. In interfaces, affect arises not only in encounters with other bodies, things or experiences. The very folding experience of interfaces includes recognition or misrecognition of (our own) images as well. So, as shown, Noora's demand for 'consent' if Nico shares a picture of her questions ideas of both ownership and copyright, as well as classical ideas of freedom of speech. When speaking from the position of the objectified, she is within her rights to ask 'whose ownership?' and 'whose freedom of speech?', since Nico's ownership of the photographic 'content' that portrays her as a slut limits her freedom of speech. As photograph and 'owner' of the copyright according to classical laws of distribution, he has the advantage of mastering her access to both the interpretation of her image and her access to its interpretation. She is not on equal terms with him.

The question of copyright to one's own image or text is also dealt with in the three episodes, if William's point of view is included. To him, the question of whether or not Noora loves him is tightly keyed to the question of whether she is trustworthy and true (to him). In other words: is she the right object of his desire, and can he 'own' her? While Noora deals with the exploration of the affects of sadness in starving, and her friends call for medical and legal assistance, William helps her by making her rest and by finishing her article before the deadline. He steps in but, due to her lie, he acts on false premises. She is not able to confess to him that Nico has diminished her power to act. To William, she has to keep her body an object of desire in order to affect joyful passions in him.

The important breakthrough of her fences-and the ability of her friends to help her out-stems from the mixed affects running through her body, when Eva unexpectedly reads her 'supposed' article. The content of the article brings together constitutional rights and responsibilities in relation to social media and the freedom of the welfare state. 
This makes her shameful in relation to William: she is both ashamed and touched by his unselfish act of writing, and thus 'falsely' giving her the copyright. The 'expressionist' side of Noora's pretence of ownership, when Eve ceremoniously reads her 'false' article, makes her shameful in another way. She has not deserved the admiration of her friends. On the level of content, what matters in her affects toward William is that she cannot return his gift of love (his renunciation of ownership) since she, herself, has no copyright to her own body-image and thus cannot access the bodily affects of joy that might give her a power to act. On the level of expression, the whole situation becomes insincere, since her power to act has been diminished. Thus, confronted with the pathetic register of the text in relation to the false copyright, she has to uncover both her friends' idea of her being a virgin and her disguised secret of being robbed of the copyright to her own (shared) image. This episode makes it clear that, on an affective level of experience, losing copyright to one's online image can be just as strongly felt as encountering bodily affects offline. This register of affect can easily be dismissed, if we only attend to the discursive level of narration. At the end, Noora takes control over the interfacial 'signaletic material' of her body-image, through which she also come to master her anorectic body and her needs. She learns how to respond to the constitutional rights and responsibilities into which both her offline body and online body are affectively enfolded. As pointed out earlier, the central expression 'without consent' is clearly presented in these three episodes as a necessary amendment to the constitutional freedom of expression as celebrated on Norwegian Constitution Day.

It is fascinating that the above episodes of SKAM concerning shaming on the Internet refer directly to the constitutional rights in the Scandinavian welfare state of Norway. With the above affect-relational reading in mind, the following section will take a closer look at the historical intertwinement of sexual liberation and freedom of speech in Denmark. I will start with a short retrospective on the time after World War II when attention was paid to both the rise of the second Feminist movement and the mediation of bodies in the public domain of pornography. 


\section{Freedom of Speech, Sexual Freedom and Vulnerable Bodies}

The postwar era in the Scandinavian welfare states is often seen as synonymous with an increase of wealth and leisure time, identified, among other ways, in modern housing, and modern furniture and design. In Denmark, democratic ideas of an equal and free way of living freed from repression were developed in the cultural radical movement 'Kulturradikalismen' of the 1920s and 1930s. ${ }^{5}$ Amongst its proponents were Otto Gelsted, Hartvig Frisch and Poul Henningsen, who were working for an emancipated culture in the fields of literature, theatre, design and architecture. Their ideas were on par with the 1930s Sex and Society movement, that (inspired by Wilhelm Reich) believed that repression and powers of war on a societal level were directly related to the individual's lack of sexual freedom (and orgasm). Therefore, they argued, women's access to abortion and contraception was key to sexual freedom and the liberation of society. In the 1950s and 1960s, this general belief had impacted both the Cultural Radicals and Danish society at large, where illegal abortions became a growing problem among young, independent women, who saw marriage as paternalistic rescue from pregnancy.

Books with pornographic content were liberated from censorship in 1967. The trial case in 1965 concerned a Danish translation of John Cleland's Fanny Hill (1748), which was later published with a foreword by Poul Henningsen. Subsequently, Denmark became the first country to allow pornographic images and films in 1969, followed by Sweden. Both nations became huge distributors of pornographic content. It is often forgotten that the free mediation of pornography in magazines and films, which often trademarked fair-haired, sexually liberated Scandinavians, was closely related to both an easy availability of the contraception pill (in 1966) and the legalisation of abortion before the 12th week of pregnancy (in Denmark in 1973). At the beginning of the 1970s, everything was ready for the young generation's sexual experimentation, followed by the second wave of Feminism's claims for equal opportunities for men and women.

The historical convergence of free distribution of sexual content and sexual liberation (from motherhood) in Denmark can, in this way, be interpreted in continuation of the struggle for freedom of speech. Today, with a hitherto unseen global scale of mediated freedom to both display 
and distribute sexual content online, it becomes imperative also to question whose freedom of speech we are protecting, if we cannot protect online body-objects from endless display or archival presence. Negotiation of 'whose body should be displayed how by whom' has become an identity-political issue globally. The mastery of online mediation, distribution and the conditions for freedom of speech (and sexuality) are a central issue to the fourth Feminist movements in Scandinavia for a reason: the vulnerability of real bodies is at stake. ${ }^{6}$ The claim, that the freedom of being creatively involved in online expressions of any kind-with consent-is key to Feminist issues. It shows that the fight for equal access to freedom of speech and alternative ways of thinking and feeling the body and its potential in body-images always has to respond to contemporary forms of mediation.

\section{Private Content and Copyright, Public Concerns and Public Service}

In Scandinavia, personal media such as smart phones are everywhere, ${ }^{7}$ and free wi-fi has almost become a human right, categorized within the same claims to infrastructural equality as access to water and electricity in public spaces. ${ }^{8}$ Our global media culture with its $24 / 7$ news feed and real-time communication has become an appreciated value as well as a problem, since the sharing of 'content' and comments, rarely allows the offended to counteract, as illustrated in the three episodes of SKAM II. It is noteworthy that so-called 'revenge-porn', where 'private' images shared between friends or lovers are later distributed to a wider audience, are often defended by the former friend or partner with reference to a 'change' in this relationship. Thus, the changed status of a relation seems also to change the status of the photograph-from being a private token of trust or love to becoming an object 'owned' by the perpetrator. This ownership justifies its being 'traded' or shared with a wider public, even though it is widely known that once something is shared online it cannot be deleted. Furthermore, the signaletic material of the Internet does indeed create immediation in the sense elucidated above by Alanna Thain (2017) — as a 'suspendedness' or 'du-pli-cation' (p. 12). So, seeing oneself as a pixelated (maybe even manipulated) image on the Internet surely can occasion feelings of suspendedness, or intensify affect reactions due to the folding operation of the interface. When shared and archived, an image or video taken without consent from the portrayed, has the risk of 
becoming a haunting object with no date of expiration-just as in Lynch's film Inland Empire. Thus, the feeling of suspendedness or du-pli-cation is strengthened in being deprived ownership to one's 'own' image.

The vulnerability of knowing that nothing can be erased becomes critical, especially to youngsters, who negotiate both identity and sexual orientation online. Joyful 'sharing' and interfacing as an intensification of affect is attractive, and even a necessary dimension of online existence, if youngsters want to be on a par with, and maybe even master, social media platforms (cf. Kofoed and Ringrose 2012). This field challenges the grey zone between 'public' and 'private', and connects to endless discussions on how, for example, images of naked bodies should be negotiated in a 'public' domain. In Denmark, the case of revenge-porn has in recent years been discussed in parliament, where more than one hearing on the subject has been held, since these assaults have violated individuals who are literally unable to defend themselves against new sharing of content. Violations in the form of cyber-bullying have especially become widespread amongst peer groups in upper secondary schools and it has become clear, on a state level, that these new forms of crime and violations of 'private' content demands a higher level of police awareness than has hitherto been offered. ${ }^{9}$

This said, it is important to stress that, even though people still use the terms 'private' and 'public' as though the boundary between them is as clear as it was in the nineteenth century, the terms should be set in inverted commas as above, since they have become almost obsolete. The sharing, the 'likes' and other emoji's should, in light of McLuhan's wellknown phrase 'the medium is the message' (introduction in McLuhan 1964), be considered the message or 'content' of contemporary media. This overall message of the media has indeed changed or overruled 'content' in the sense that, in general, our culture follows the medium as source of information (Deleuze 1989, p. 269). If a post (of content), for example on Facebook, is shared enough times, it attracts more sharing, more likes and, ultimately, the number of sharings itself will (as a so-called 'vox-pop') become a 'public concern' (and thus new content) in the news feed of TV and print media. Numbers of online likes and sharings are messages with impact on our behaviour and our values, as well as on political opinions over time. ${ }^{10}$

Besides illustrating McLuhan's point, this example also shows that realtime distribution and speed is favoured over considerations of censorship or copyright, known from the printed press with clear political stances 
shared by their readers. A conflict concerning the democratic right to 'free speech' can be traced here. Whereas the slower distribution of the printed press allowed for the censorship of offensive content in 'public' domain, Nordic television channels (DR, Denmark; NRK, Norway; and SVT, Sweden) have an obligation to bring (independent news and a wide range of original, challenging and relevant public service content that reflects the cultural and societal values of each Nordic country'. ${ }^{11}$ The point here is that citizens pay a licence fee for being informed as democratic citizens; with regard to the 'free speech' content-or, as argued above, since Internet information has become the new meaning-no one knows how copyright of 'private content' could be secured when shared, or how the messages of vox-pop could be administered or limited.

\section{The Vulnerable 'Body' Speaks Back}

As argued, global sharing of offending, fake or 'private' content (images, videos, opinions and remarks) notably affects public opinion, and is again echoed on social media. This (re)action mode rarely allows victims to counteract, since 'vulnerability' is connected to the medium-to the sharing and distribution - that becomes the message. This is the signaletic material of the Internet media that overshadows meaning in the form of signs. Therefore, cleansing the wound of the deed by removing 'content' can never remove the vulnerability (of bodies) shared online. That you are seen and victimized by others, often with delayed knowledge of this offence, is especially hard when images and videos of so-called 'private content' are shared in closed web forums, hosted in foreign countries safe from police investigation. The distribution is endless, ${ }^{12}$ and the production of value (formerly connected to a sign or a commodity) is unknown to the person whose image has become the carrier of the signaletic material. This vulnerability has been noticed by the Danish Institute for Human Rights Report. In Human Rights in Denmark: Status 2016-17 (Christoffersen et al. 2017), in the section 'Gender Equality', it says:

In 2016, revenge porn assumed a prominent place on the political agenda. The debate and subsequent cases indicate that sharing compromising photos without consent is a more widespread problem than previously assumed. A study carried out by the market research institute YouGov in 2016 for DR showed that up to four out of ten young persons between 
15 and 30 years old have sent or shared nude photos of themselves, while more than half have received a nude photo of another person. The number of police reports has grown significantly from 2011 to 2016, and the police have had difficulties investigating and prosecuting offenders, e.g. because the offenders use foreign file-sharing services. (Christoffersen et al. 2017, p. 46)

Besides this, new voices are heard in the Danish culture. Among these, is Danish feminist Emma Holten, who raised the issue of the (copy)right to one's own image. She became an activist in 2011, when she found images of her naked body exposed on the German TV channel, RTL. The channel, infamously known for its soft porn programming, had hacked the images of Holten from her e-mail and Facebook account without her consent. ${ }^{13}$ They were self-portraits sent to her boyfriend three years earlier. Her most important activist step was to amend the word 'revengeporn' to 'porn-without-consent', and to publish the project 'Consent' (Danish: 'Samtykke', cf. Holten 2017). ${ }^{14}$ In this publication, she acted as a model for photographer Cecilie Bødker. Together, they aimed to explore whether a woman's body (in this case, topless portraits) could be portrayed, freed from the 'male gaze' (cf. Mulvey 1975). Holten also discussed the fact that she, herself, had been the model as well as the photographer of the images she sent to her (former) lover as a gift. ${ }^{15}$ After the production of 'Consent', she became a global spokeswoman for online vulnerability worldwide. ${ }^{16}$ In the context of this chapter, it is noteworthy that, even though Holten generally condemns online distribution without consent, she underlines the importance of not avoiding online exposure. She supports the need, especially for youngsters, to 'perform gender' on social media.

Social media were indeed also key to the global \#Metoo manifestation of sharing experiences of sexual harassment in 2017. ${ }^{17}$ These accounts have radically changed the attitude towards vulnerability online as well as offline. For, contrary to what comprises the case of the web fora in sharing porn-without-consent, these accounts are in accordance with the quantifiable element of the Internet. They cannot be explained away simply due to their numbers, and individuals cannot be objectified and categorized since she or he is notoriously one of many. Contrary to this, the 'content' of porn-without-consent is kept in secret and obscure web groups. ${ }^{18} \mathrm{In}$ this sense, the successful action of \#Metoo and the feminist claim of freedom of speech online and offline ${ }^{19}$ has a basic likeness with the second 
Feminist wave of the 1970s. The public gathering made a difference then just as the public sharing of accounts makes a difference today-purely by the power of quantity.

\section{Constructing a Bioethical Meta-Body Online}

Notwithstanding this, questions on the ethics of self in relation to blogging, sharing and the distribution of selfies online is often debated. Inspired by Foucault, Joanna Zylinska proposes the term 'bioethics' for the necessary narcissism in 'becoming and self-creation' involved in the use of online media (Zylinska 2013). Whereas Foucault is positively interested in the auto-poetic practice connected with notebooks as both a means for recollection and memory and as a way to create a logos bioéthikos' or an ethos of life, Zylinska draws a wider conclusion of bodily becoming within networks, data and electricity:

diaries, blogs and online profiles are not just commentaries on someone's life, already lived to this point, but also somehow more 'real' outside its narrative; rather, they are materializations of it. Digital writing and linking is therefore a form not only of cultural but also of corporeal production; it literally produces the body by temporarily stabilizing it as a node in the network of forces and relations: between multiple servers and computers, flows of data, users' eyes, fingers and sensations, particles of electricity and so on. (Zylinska 2013, p. 99)

If sharing of content is seen as a bioethical production of (in)dividual bodies closely connected to online and interface technology, it becomes apparent that the Scandinavian fourth wave of Feminism is negotiating bioethical meta-bodies online. The second wave of Feminism's negotiations of the right to control one's own body in terms of sexuality, appearance and reproduction were likewise technologically embedded in the electronic hype of the day. Global connectivity was performed via electronic music, live-concerts, video-art and real-time transmissions on TV. This technological backdrop was just as substantial to the 1970s claims for new democratic forms of freedom of speech as contemporary media are today. ${ }^{20}$

The outspoken demands of visibility on the Internet put forward by women from the fourth Feminist wave should not be termed 'narcissism' in the negative sense. ${ }^{21}$ Rather, as Erinn C. Gilson indicates (Gilson 
2014 , p. 127), ethical concerns in relation to affective experiences of vulnerability should embrace that 'vulnerability is the necessary condition of creative, critical, and novel becomings' (p. 149). As already mentioned in relation to affect, becoming is key to the understanding of change. All events and affectively felt encounters (negative and positive) carry the potential of twisting, deforming or creatively changing the conditions of what Gilson (with Gilbert Simondon) terms 'collective individuation', meaning that changes in culture on individual as well as collective levels of transformation have to pass through social and technological networks of their time (cf. Gilson 2014, p. 139). The point is that the same vulnerability that, on an individual level, might affect sadness otherwise could inspire change and even joy in the perspective of collective individuation. In the above reading of $S K A M$ dealing with individual exposure to shame, it is shown that bioethical changes can happen, if encapsulated, individual affects are collectively individuated by way of a media technologic response.

The production of meta-bodies needs the operation of interfaces, as indicated by Zylinska. Returning to Anna Munster's (2006) definition of interfacing as affectively felt in the passage 'between sensing and rendering' (p. 142), alterity becomes central to bioethical becoming:

Affect arises relationally and is produced out of the difference between being in the body and representing/mapping the body from the outside. Affect sustains the singularity of sensing and of representing as a differential experience of embodiment, one in which alterity has a place. And in any interface between bodies and technology we will always encounter this difference. (Munster 2006, p. 142)

According to this, affect is experienced as micro-perceptions in the informatics of rendering, felt as 'at once strangely distant or removed and immediately intimate' (Munster 2006, p. 142) Interfaces (re)construct and deconstruct meta-bodies, and this is vulnerable per se, since we will always-like Noora in $S K A M$ - explore a certain amount of affect and alterity in the passage between feeling the body from the inside and mapping it from the outside (Munster 2006, p. 142) ${ }^{22}$ We tend to forget the interfacial micro-perceptions experienced in vibration, electric stimuli of sounds and pixels operating directly on a sensational level of perception. With Brian Massumi, those experiences could be termed 'non-sensuous 
perception' (Massumi 2011, p. 23), since we do not distinguish between body and matter:

We do not see the electrons traveling down our optic nerve. We see what our body makes of their activity. We take their activity into our own, producing an event of seeing - certainly a novelty for an electron. In the arcing of the event toward the production of its novel outcome, physical matter, life matter in general, and human life-matter are actively indistinguishable. (Massumi 2011, p. 27)

Massumi stresses that non-sensuous perception includes things that we do not see but that we nevertheless experience without knowing. This affective perception takes part in becoming, in the unfolding of future events. If our focus were more on micro-perceptions and bioethical becoming or collective individuation in the signaletic material of interfaces, the energy and joy experienced online may actually be seen and read.

\section{CONCLUSION}

This chapter has dealt with the bioethical composition of online metabodies. The questions 'What do interfaces do?' and 'What proportion do interfaces comprise in shaming or in vulnerability?' raised at the beginning of this chapter were studied through three episodes of $S K A M$. The question of shame in the series in relation to Noora's 'meta-body' was read through the theory of affect and in seeing interfaces as a folding operation of intensity between sensing and rendering. In reading the microperceptual plane of the signaletic material, it became evident that 'shame' not only signifies vulnerability in terms of social and sexual marginalisation, it also gives expression to vulnerability as connected to the bioethical affects and non-sensuous perceptions of interfaces. As such, bioethical affective events can be considered the 'name of the game' of SKAM. In all episodes, the alerts of instant messaging or the ringtones interrupt the narration and function as intervening paths or refrains to the actions or exchanges taking place. They function as distractions, as in real life, but they are also cued into an overall exploration of meta-bodily reconstruction and deconstruction of online existence. Zooming into a microperceptual level of affective involvement gives the viewer an opportunity to feel an interfacial fold-even on TV. Thus, even though freedom of speech is clearly the theme on a narrational level of content, the right 
to one's own (meta-)bodily expressions is felt as an extra-narrational signaletic material by way of affective involvement.

The double agency of playing a meta-bodily game and defending the freedom of speech has been key to the exploration of how access to and control of media has always been closely intertwined with questions on women's liberation in the Scandinavian welfare states. The chapter concludes that anyone whose image is portrayed or shared by others should give or deny consent to this. This amendment of the freedom of speech so highly valued in Scandinavia would be a first move towards giving a type of copyright protection to the object of sharing in contemporary media. A next step would be to limit the machinic access to our data. The chapter thus raises the question of how we, the users, could obstruct and prohibit our data from being used or archived for purposes of control and forms of surveillance without our consent. In continuation of this, the chapter also questions copyright as a law of ownership afforded to whomsoever possesses the content or data.

\section{Notes}

1. In the following, 'vulnerability' is used in a broad sense to characterize the exposure ensuing from becoming an (often unaware) object of shared intimate content (often, images of bodies). When a shared content reaches a wider public, such exposure is felt as a shaming of the actual physical body. Here, this exposure to vulnerability is explored in relation to the theory of affect following Brian Massumi's definition in "The Autonomy of Affect" (Massumi 2002, p. 23).

2. Sweden was the first country worldwide to introduce freedom of print in 1766, and Denmark and Norway followed in 1770. Even though often restricted during those first years and an object of dispute since then, the freedom of speech has been constitutional in Sweden since 1809, in Norway since 1814, and in Denmark since 1849. The protected right of a minority or an individual to criticize the state without repercussions (if defamation of individuals or violence is not exerted) has been an acclaimed value ever since. Recently, freedom of speech has been much debated, especially in Denmark, as a reaction to the so-called Muhammed Crisis that began in 2004, when a newspaper, Jyllands-Posten, asked a group of cartoonists to draw Muhammed. This, in order to test whether selfimposed censorship - on whether or not Muhammed could be depicted publicly — was the 'order the day' in Denmark. When one of the cartoonists portrayed Muhammed with a bomb in his turban and the prime minister refused to apologise for this, since it was subject to the freedom of 
speech of the press, it caused an intense reaction in Arab countries as well as in Denmark (cf. Stage 2011).

3. In the following, I will rely on Brian Massumi's definition of affect (Massumi 2002) that, again, refers to Gilles Deleuze's definition (in its difference from affections - one body to another) phrased as: 'affect refers to the passage from one state to another, taking into account the correlative variation of the affecting bodies' (Deleuze 1988, p. 49). He expands on Spinoza's definition: 'By affect I understand affections of the body by which the body's power of acting is increased or diminished, aided or restrained' (Spinoza 1677, III, p. 3; Deleuze 1988, p. 49). In both Spinoza and Deleuze, affects between bodies (and between bodies, things and events) can entail fast or slow transitions to other states. Thus, the term 'affect' is closely related to change as a becoming of events that virtually influences the actual.

4. SKAM was produced by NRK, the Norwegian public service TV channel, aimed at a primary group of viewers aged 15-17. Julie Andem started with researching the interests of this age group in Norway. Actors were selected among 1200 candidates with no former training, and Andem worked with the 9 main actors throughout all seasons, so that they had a voice in forming their characters and in the development of the series. The announcement of the series took place as Instagram posts fictionally created by Internet producer Mari Magnus as though by the actors. The audience could follow a Facebook or SMS chat between characters as well, and thus the announcement was shared by youngsters themselves-as in a relation between friends. Each episode premiered online, and ongoing feedback was likewise received on social media. After each premiere, episodes were broadcast on TV.

5. This movement must again be seen in continuation of the 1890's modern breakthrough in literature and art in Scandinavia. In Denmark, Georg Brandes was the gatekeeper of this international orientation, which deliberately kept women writers and artists back (cf. Dahlerup 1983). However, Thit Jensen's radical claims for women's access to contraception as intertwined with liberation (and unburdened motherhood) must be remembered.

6. The Feminist movement is often described as coming in waves, the first wave (USA from 1848, UK in the 1850s, Germany and Scandinavia in the 1870s) fought for equal rights and culminated in the right to vote for women. The second wave (the 1970s in the western world) fought against stereotypical roles in society and for women's right to their own bodies; the right to abortion; and the right to women's conditions of life represented in culture, art, and (his)tory. The third wave (in the 1990s) was concerned with the differentiation and the performance of gender in society, a main concern being how women's rights—regardless of religion, 
nationality, colour and sexual orientation-were still structurally restrained by patriarchy. The fourth wave (from the 2010s) is especially concerned with the bullying and harassment of women in the so-called 'slutshaming' and 'revenge porn' on the Internet. The global manifestation of women's unequal conditions in professional contexts had a huge manifestation in \#Metoo in 2017 and, in this sense, the fourth wave is still vibrant worldwide today.

7. Smart phones were marketed by Apple in January 2007 and, in October 2008, Apple had sold 4.7 million iPhones, which amounts to $13 \%$ of the global market. As early as 2008 in Denmark, 99\% of teenagers between 16 and 19 years, 98\% of adults between 20 and 39 years, 94\% of adults between 40 and 59 , and $82 \%$ of adults between 60 and 74 years used mobile phones for private communication (cf. Helles 2009, p. 84). After Apple's launch of iPads in January 2010, the percentage of other uses of screened communication has probably increased (cf. https://www.thegua rdian.com/technology/2012/jan/24/smartphones-timeline).

8. According to EU kids online, Denmark is one of the leading countries when it comes to time spent on online media by children aged 9-16, since free access is the norm (cf. http://www.lse.ac.uk/media-and-comm unications/research/research-projects/eu-kids-online).

9. In September 2018, a suspended sentence of 40 days handed down to a 20-year old boy sharing a sex video in which a 15-year-old girl had intercourse with several 15-year-old boys was sent to trial at the highest court in Denmark. This case is only one of those in the so-called 'Umbrella-case', which related to a case from 2015 in which more than 1000 youngsters had shared this video that, in some cases, had been edited so that one could not identify the girl as sexually underage. The problem is that, if the girl's face is visible, the court has to pass sentence on this case as a case of paedophilia.

10. Recently, the Cambridge Analytica scandal, where 87 million Facebook users' data were used in political campaigns and 'fake news' by way of socalled 'micro-targeting' and 'psychographic analysis' has made the public become more aware of algorithmic traces and measuring. Unable to access our own data, we are contributing to big data assemblages that can be measured, analysed and traded. Our 'likes' draw graphs or direct imprints to inform our individual (cf. Deleuze 1992) 'personality styles', and even changes in style can be followed over time.

11. Citation from the Nordic Council of Ministers, 2015: https://danskeme dier.dk/marked-og-okonomi/nordiske-ministre-vil-fremtidssikre-public-se rvice/ (accessed 12 September 2018).

12. The Danish Facebook group Offentimentum is an example of a closed forum with the purpose of distributing offensive material-and this very 
criterion seems to exceed the threshold of what is offensive. The physical harassment and bullying that one could often find in a classroom has, so to speak, moved to a virtual classroom. Due to a coordinated harassment, the site was closed by Facebook on the 11 September 2017, only to be reopened in another version 24 hours later. Before its closure, the site had 105,000 members (cf. https://www.skivefolkeblad.dk/articl e/20170912/RITZAUINDLAND/309129892) (accessed 12 September 2018).

13. Later, in 2016, she received compensation from RTL for the lack of consent on her part. Since the hacking happened much later, the case underscored that violation can happen at all times in the sharing process.

14. It contained an article and a catalogue, and was published in the feminist magazine Friktion, 1 September 2014, edited by Emma Holten (a section can be read here: https://friktionmagasin.dk/samtykke-14841780be52) (accessed 13 May 2019).

15. Her method, in this sense, mirrors the method of American photo artist Cindy Sherman, who acts as both model and photographer in order to underline the composed and objectifying operations of photographs and photography. With smart phones, this method is now available to anyone.

16. Cf. The Guardian, TED talks and so on. On 12 November 2017, Emma Holten announced her withdrawal from public exposure in the Danish television show, 'Vi ses hos Clement', DR2.

17. The hashtag was initiated by Tarana Burk in 2010 and got a major impact when singer and actor Alyssa Milano made an act of sexual harassment public on Twitter in October 2017, following the charges made against Harvey Weinstein.

18. The latter mentioned practice is in line with patriarchal traditions of menexchanging-women in order to sustain power (over women). In this practice, women are reduced to tokens of value; for example, the meaning of beauty.

19. In an interview, Holten mentioned the importance of the Internet for her generation of feminists, especially because of the ability to share experiences with other women (Kaasgaard 2016).

20. In this line of reasoning, the formation of democracy in western societies followed the rise of the printing press and new readers, who read papers and novels in their native language. Thus, once locally distributed newspapers were established according to the political parties representing farmers and workers, democracy flourished-and, eventually, also women and servants were allowed to vote. The right for women to be nominated and to vote at elections was decided in Denmark in 1915. In Finland, this right was obtained in 1906; in Norway, in 1913; Swedish women had to wait till 1919-1921. 
21. Nonetheless, some Danish feminists of this older generation have widely attacked the new feminist movement of being too narcissistic and of accentuating the female (often part-naked) body too much in public spaces. As a reaction to one of these-Mette Fugl's attack-some of the new feminists responded that they want to fight for the ownership of their own body, which also includes taking ownership of their beauty-power (cf. http://politiken.dk/debat/debatindlaeg/art5780289/Derfor-er-vi-af $\mathrm{kl} \% \mathrm{C} 3 \%$ A6dte).

22. In an article on the built-in operation of 'slutting' individuals on Web 2.0, Wendy Chun and Sarah Friedland (2015) argue that the Internet is promiscuous, and that this vulnerability should be embraced.

\section{REFERENCES}

Christensen, C. L. (2017). Er web- og tv-serien SKAM en serie om skam? Nordisk Tidsskrift for Informationsvidenskab Og Kulturformidling, 6(2), 7-12.

Christoffersen, J., Holck, L., Dyrborg, U., Emil Kiørboe, E., \& Christoffer Badse, C. (Eds.). (2017). Human Rights in Denmark: Status 2016-17. Copenhagen: The Danish Institute for Human Rights. https://www.humanr ights.dk/sites/humanrights.dk/files/media/dokumenter/udgivelser/status / dihr_status_2016-17_uk.pdf. Accessed 12 September 2017.

Chun, W. H. K., \& Friedland, S. (2015). Habits of leaking: Of sluts and network cards. Differences: A Journal of Feminist Cultural Studies, 26(2), 1-28.

Dahlerup, P. (1983). Det moderne gennembruds kvinder. København: Gyldendal. Deleuze, G. (1988). Spinoza: Practical Philosophy. San Francisco: City Light Books.

Deleuze, G. (1989). Cinema 2: The Time-Image. Minneapolis: University of Minnesota Press.

Deleuze, G. (1992). Postscript on the societies of control. October, 59(Winter), 3-7.

Dich, K. (2017, October 17). Ny nordisk feminisme. Hvordan har feminismen det i Skandinavien i dag? Vagant. http://www.vagant.no/ny-nordisk-femin isme/. Accessed 12 September 2018.

Eskesen, A. H. (2016, October 20). Knap 3 ud af 10 'Skam'-seere er fra Danmark. DR. https://www.dr.dk/nyheder/kultur/knap-3-ud-af-10-skamseere-er-fra-danmark. Accessed 12 November 2018.

Gilson, E. C. (2014). The Ethics of Vulnerability: A Feminist Analysis of Social Life and Practice. New York and London: Routledge.

Helles, R. (2009). Personlige medier $i$ hverdagslivet (Doctoral dissertation). København: Det humanistiske Fakultet, Københavns Universitet. 
Holten, E. (2017, September 1). Samtykke. Friktion Magasin for køn, krop og kultur. https://friktionmagasin.dk/samtykke-14841780be52. Accessed 12 November 2018.

Hougaard, T. T., Andersen, E. M., \& Rathje, M. (2017). SKAM-i sproget og i interaktionen. Dansk Noter, 3. Afdeling for Nordisk, Institut for kommunikation og kultur, Aarhus Universitet.

Jerslev, A. (2017). SKAMs 'lige her' og 'lige nu': om SKAM og nærvær. Nordisk Tidsskrift for Informationsvidenskab Og Kulturformidling, 6(2), 75-81.

Kaasgaard, S. (2016, May 2). Emma Holten om hævnporno: 'Jeg har fundet mig i alt for meget pis'. Eurowoman. https://www.alt.dk/artikler/emma-ho lten-jeg-har-fundet-mig-i-alt-for-meget-pis. Accessed 12 November 2018.

Kofoed, J., \& Ringrose, J. (2012). Travelling and sticky affects: Exploring teens and sexualized cyberbullying through a Butlerian-Deleuzian-Guattarian lens. Discourse: Studies in the Cultural Politics of Education, 33(1), 5-20.

Krüger, S., \& Rustad, G. C. (2017). Coping with shame in a media-saturated society: Norwegian web-series Skam as transitional object. Television and New Media, 20(1), 72-95.

Massumi, B. (2002). Parables for the Virtual: Movement, Affect, Sensation. Durham and London: Duke University Press.

Massumi, B. (2011). Semblance and Event: Activist Philosophy and the Occurrent Arts. Cambridge, MA, and London, UK: MIT Press.

McLuhan, M. (1964). Understanding Media: The Extensions of Man. New York: Mentor.

Mulvey, L. (1975). Visual pleasure and narrative cinema. Screen, 16(3), 6-18.

Munster, A. (2006). Materializing New Media: Embodiment in Information Aesthetics. Hanover and London: University Press of New England.

Rustad, G. C. (2018). Skam (NRK, 2015-2017) and the rhythms of reception. Critical Studies in Television: The International Journal of Television Studies, 13(4), 505-509.

Spinoza, B. (2010 [1677]). Ethics. Hertfordshire: Wordsworth Editions.

Stage, C. (2011). Tegningekrisen-som mediebegivenhed og danskbedskamp. Aarhus: Aarhus Universitetsforlag.

Stage, C. (2017). Om skammen i Skam-og de eksistentielle medier. Dansk Noter, 3. Afdeling for Nordisk, Institut for kommunikation og kultur, Aarhus Universitet.

Sundet, V. S. (2017). Det er bare du som kan føle det du føler-emosjonell investering og engasjement i nettdramaet SKAM. 16:9. Filmtidsskrift. Aarhus.

Thain, A. (2017). Bodies in Suspense: Time and Affect in Cinema. Minneapolis: University of Minnesota Press.

Thomsen, B. M. S. (2012). Signaletic, haptic and real-time material. Journal of Aesthetics and Culture, 4(1). https://www.tandfonline.com/doi/full/10. $3402 /$ jac.v4i0.18148. 
Thomsen, B. M. S. (2018). Lars Von Trier's Renewal of Film 1984-2014: Signal, Pixel, Diagram. Aarhus: Aarhus University Press.

Zylinska, J. (2013). The culture of blogging: At the crossroads of narcissism and ethics. In N. Couldry, M. Madianou, \& A. Pinchevski (Eds.), Ethics of Media (pp. 91-105). Basingstoke, UK, and New York: Palgrave Macmillan.

Open Access This chapter is licensed under the terms of the Creative Commons Attribution 4.0 International License (http://creativecommons.org/licenses/by $/ 4.0 /)$, which permits use, sharing, adaptation, distribution and reproduction in any medium or format, as long as you give appropriate credit to the original author(s) and the source, provide a link to the Creative Commons license and indicate if changes were made.

The images or other third party material in this chapter are included in the chapter's Creative Commons license, unless indicated otherwise in a credit line to the material. If material is not included in the chapter's Creative Commons license and your intended use is not permitted by statutory regulation or exceeds the permitted use, you will need to obtain permission directly from the copyright holder.

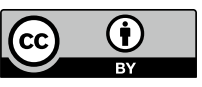


The Vulnerable Subject and the Welfare State 


\section{Nowhere Home: The Waiting of Vulnerable Child Refugees}

\section{Odin Lysaker}

\section{INTRODUCTION}

In her 2012 documentary Nowhere Home, filmmaker Margreth Olin sheds light on the vulnerabilities of child migrants subjected to prolonged waiting. The documentary shows unaccompanied minors being offered only temporary residence. Echoing the UNHCR's vocabulary, Olin illustrates why these irregular migrants can be characterized as 'particularly vulnerable'. However, the nature of vulnerability is contested. In the following, I therefore ask what is an adequate understanding of the concept of vulnerability.

Due to child refugees' particular vulnerability, prolonged waiting can violate their bodily health and life quality, as well as their inherent dignity and human rights. Within the context of moral philosophy, I introduce what I term a waiting guarantee. This principle sets an ethical threshold level regarding the violation of child refugees' vulnerability. Furthermore, it stresses the impacts of child refugees' prolonged waiting. Consequently,

O. Lysaker $(\bowtie)$

University of Agder, Kristiansand, Norway

e-mail: odin.lysaker@uia.no

(C) The Author(s) 2020

A. M. Dancus et al. (eds.),

Vulnerability in Scandinavian Art and Culture, https://doi.org/10.1007/978-3-030-37382-5_5 
the principle states that it is morally unacceptable if prolonged waiting puts child refugees' childhood on hold. Illustrated through minors' life histories in Olin's documentary, I claim that we should approach the issue of child refugees' long-term waiting through the lens of the waiting guarantee. Thus, vulnerability is accounted as something enabling.

I begin by defining the concept of vulnerability as grounded in humans' existential precondition against the horizon of Martha A. Fineman and other feminist outlooks. Then, inspired by Hannah Arendt, I shed light on the implications of falling out of time concerning time as a normative resource and a scarce good. To conclude, drawing on Martha C. Nussbaum, I present the waiting guarantee.

\section{Vulnerability as a Human Condition}

In Nowhere Home, Olin mirrors the UNHCR, since the child migrants depicted in her documentary can be described as particularly vulnerable. Vulnerability is a key concept within migration discourse (Crock and Bhabha 2007, p. 22; Bhabha 2016, p. 22; Silas 2018, p. 178; Kulu-Glasgow et al. 2019). Nonetheless, this concept is disputed. I suggest that we perceive vulnerability as an embodied human condition.

\section{Child Refugees-The 'Most Vulnevable'}

The UNHCR ascribes vulnerability to different groups, such as refugees, stateless people and asylum seekers, who are viewed as the 'most vulnerable groups [...] in the world' (UNHCR 2016, my italics). However, 'within this group, there are people who are even more vulnerable'; for instance, children, the elderly, disabled and ill people (UNHCR 2016, my italics). Legally, in accordance with the UN 1989 Child Convention, all humans under 18 years old are recognized as children. The UNHCR claims that child refugees in terms of unaccompanied children are 'particularly vulnerable' (UNHCR 1998, my italics), based on the fact that unaccompanied minors are often separated from their parents, guardians, or caregivers (UNHCR 1999). The younger these children are (i.e. 6-9 years of age), the more vulnerable they become if they suffer from traumatic experiences (Sourander 1998).

The UN 1951 Refugee Convention and its 1967 Protocol also count refugees as some of 'the most vulnerable people in the world' (UNHCR 1951, my italics). This is due to refugees' 'well-founded fear of being 
persecuted' by their own country. Such vulnerability exposes them to mis-recognition of their identities based on, inter alia, race, religion and nationality, as well as political and social membership. This violates refugees' human dignity, since the UN 1951 Refugee Convention is grounded in the UN 1948 Universal Human Rights Declaration, chiefly Article 14, which is based on the moral idea of the 'recognition of the inherent dignity' stated in both the Preamble and Article 1. Humans' dignity is the moral heart of human rights (Habermas 2010). Therefore, refugees' vulnerability in general, and child refugees' special vulnerability in particular, should be morally protected through recognizing their dignity.

\section{Refugee Patients}

'I had enough of this life', Husein tells Olin. He and his brother Hassan, both minors that have fled Afghanistan, have struggled for years to make the Norwegian government recognize Husein's very poor health situation. In fact, Husein can be described as a refugee patient, since he feels like he '[j] ust [has] to wait all the time, and never gain control of [his] life because of what [he has] experienced'.

Within the migration discourse, the term 'refugee patient' comprises at least three aspects (Varvin 2008). First, refugee patients' human dignity and human rights are violated due to, for instance, torture and sexual abuse (Sourander 1998).

Second, refugee patients experience various forms of loss, such as loss of parents or other caregivers; loss of a place of belonging; or loss of mental and physical capabilities due to, for example, traumatization and posttraumatic stress disorder (PTSD). Refugee patients are sometimes already suffering from pre-migration traumatic experiences (e.g. forced to hide, beatings, torture, imprisonment and lack of water or food). Moreover, traumas can appear during the flight (e.g. loss of hope and prospects of a good life, uncertainty and mental pain). Moreover, refugee patients can suffer from stressors in the sense of post-migration traumas (e.g. ongoing temporary protection, anxiety, fear of being repatriated, poor access to health care, delays in processing applications, loneliness, boredom, depression, isolation and suicide, as well as worries about their family at home, disqualification from work, financial difficulties, loss of identity, competence and social roles) (Carswell et al. 2009; Miller and Rasmussen 2010; Li et al. 2016). Such post-migration problems can be related to 
'adverse childhood experience'. Children may experience negative events during their upbringing, which are traumatizing due to the children being exposed to severe events both inside and outside the family (e.g. loss of caregivers in early childhood, or being physically, sexually, emotionally, or verbally abused by caregivers) (Cassidy and Mohr 2001). Additionally, by affecting the mental health and life quality of particularly vulnerable child refugees, adverse childhood experiences can influence, and even affect, their lifespan (Anda et al. 2006). The latter is important in light of the consequences regarding child refugees having their childhood put on hold. These kinds of experiences of traumas before, during and/or after the flight reduce the child refugees' functioning and coping with their own vulnerability (Jensen et al. 2015). Even so, such trauma may cause problems regarding the child refugees' later capacity for development throughout their life course. Thus, recognition as love, respect and esteem, as well as persons' basic need for positive self-development concerning self-confidence, self-respect and self-esteem, are at stake (Honneth 1995). As a result, refugee patients often experience both multiple and prolonged traumatic events. This kind of trauma undermines their bodily (i.e. mental and physical) health.

Third, refugee patients are characterized by resilience in connection to being capable of living through, as well as tackling, various kinds of major stress over a longer time period of prolonged waiting, even though they are suffering from traumas (Varvin 2008; Fazel et al. 2012). Stable environments within which the refugee patient can be offered treatment, rehabilitation and development must be created (Varvin 2008). Consequently, the particularly vulnerable group of minor refugee patients should be recognized so as to develop the capacity to reflect on and relate to their own experiences, emotions and thoughts. Resilience also concerns re-establishing and cultivating close and stable relationships based on basic mutual recognition, such as love and care (ibid.; Honneth 1995). Here, positive effects can be achieved concerning their bodily health if they receive a permanent residence permit (Silove et al. 2007). However, many refugees are subjected to long-term waiting for the result of the government's process, which may take months, years, or sometimes even decades (Jakobsen et al. 2017, p. 2; Parekh 2017). 


\section{Vulnerability as an Existential Precondition}

It is worth conceiving the concept of 'particularly vulnerable' child refugees in light of the philosophical discourse about vulnerability. Roughly, vulnerability can be accounted for in two ways (Mackenzie et al. 2014 , pp. 4-7; Mackenzie 2017, p. 85). First, vulnerability is considered as 'the contingent and relational susceptibility of particular persons or groups to threats to their interests'. Second, vulnerability refers to 'the universal capacity to suffer', which is 'inherent to human embodiment' (Mackenzie 2017, p. 85; see Fineman 2008, p. 9; Mackenzie et al. 2014, pp. 1-2, 4, 7; Ferrarese 2017, p. 77).

Surely, between these two outlooks, it can be argued that the former is the more relevant to child refugees, since this interest-based vulnerability' is sensitive to contingent contexts within which some members of this group have a 'diminished capacity to safeguard their interests relative to others' while being subjected to, inter alia, prolonged waiting. The group of particularly vulnerable child refugees is 'especially susceptible to wrongful harms', which are due to various inequalities (e.g. resources and power) (Mackenzie 2017, p. 85).

However, morally speaking, I adopt the latter 'suffering-based vulnerability', which more adequately captures the situation of child refugees potentially becoming refugee patients. Here, traumatization, for example, requires focusing more on bodily experiences, including the subjective suffering of child refugees exposed to prolonged waiting. Equally, to highlight the life histories in Olin's documentary, the 'suffering-based vulnerability' is more relevant, since these minor migrants biographically reveal experiencing bodily harms (e.g. traumatization).

Such vulnerability is ontological; namely, grounded in certain existential preconditions (Nussbaum 2006, p. 160; Fineman 2008, pp. 1-2, fn. 25 at 9, 12; 2010, p. 28; Lysaker 2013; Mackenzie 2014, pp. 33, 34, 36, 38; Mackenzie et al. 2014, pp. 1-2, 4, 7; Ferrarese 2018, pp. 27-29). Thus, vulnerability is situated in 'a universal, inevitable, enduring aspect of the human condition' (Fineman 2008, pp. 1, 8; see 1, 12; Mackenzie et al. 2014, pp. 4, 5, 8). Put differently, vulnerability is a '[g]eneral shared feature [...] of human life' (Nussbaum 2013, p. 401, my italics; see Nussbaum 2006, pp. 43, 87-88, 160, 221, 237, 278). Subsequently, it is something non-optional and thus irremovable (Lysaker 2013), which means that, as bodily beings, humans 'cannot nor would $[. .$.$] want to$ 
fully eradicate our vulnerability to others' (Petherbridge 2016, p. 598, my italics).

Humans' vulnerability is also related to 'two forms of individual differences'. First, vulnerability is linked to 'physical' variations (e.g. mental, emotional, sensual, intellectual and other contrasts in human embodiment). Such variations can be further linked to the fact that '[all] [h] uman beings are in general disabled' (Nussbaum 2004, p. 306, my italics). This implies different ways in which each human being is 'mortal, weak-eyed, weak-kneed, with terrible backs and necks, short memories and so forth' (ibid.). Such 'general disability' can be viewed in light of what I term humans' 'existential life graph' (Lysaker 2015; see Mackenzie et al. 2014, p. 1; Ferrarese 2018 , p. 33). Our lives always already fluctuate, by which I mean that throughout one's life course humans' shared vulnerability can occur to a lesser or greater extent, as well as for a shorter or longer period of time (Nussbaum 2006, p. 101).

Second, our vulnerability is connected to 'social' variations (e.g. constructed on the basis that individuals are institutionally situated within the context of complex and overlapping webs of relationships) (Fineman 2013 , p. 21). Then, vulnerability is contingent on the social environment within which the person exists, such as birth, upbringing, development, adulthood and illness (Nussbaum 2006, pp. 87, 111, 120, 125, 129, 132, $143,160,221)$. However, contextually, vulnerability also signifies something non-contingent, such as ageing, health reduction, protracted illness, old age and one's own death (ibid., pp. 111, 120, 123, 125, 143). In turn, this 'requires forms of social action and cooperation' through recognition as love, respect and esteem (Honneth 1995; Anderson and Honneth 2005; Petherbridge 2016, p. 598) to have this social dimension surrounding one's vulnerability safeguarded.

Vulnerability is further grounded in basic needs (e.g. food, water, health, sanitation, shelter, clothing and education) (Fineman 2008, p. 10; Mackenzie et al. 2014, p. 1; Ferrarese 2017, p. 77). These bodily needs are extended through all periods of a person's life course. To exist at all, as well as to develop our life in accordance with our capabilities, these needs must be met. If not, due to our vulnerability, we may be exposed to various forms of suffering; for example, physical illness, injury and mortality (Mackenzie et al. 2014, p. 1). Thus, in light of vulnerability creating basic needs, we should, as needy and suffering creatures, be provided with capabilities for developing an undistorted and positive self-relation (Honneth 1995; Petherbridge 2016, p. 598; Schweiger and Graf 2017, p. 245). 
Our bodily vulnerability, as based on humans' fundamental needs, creates 'a [basic] form of interdependence that attends to the subject in her [bodily] needfulness' (Petherbridge 2016, p. 598; see Fineman 2010, pp. 21-22; Mackenzie et al. 2014, p. 1). This dependency is 'unavoidable and inevitable', as well as 'developmental and biological' (ibid., p. 23). Irrespective of age, it makes us needy vis-à-vis others (Honneth 1995; Mackenzie et al. 2014, pp. 1, 4; Ferrarese 2017, p. 77). Still, such dependency is 'episodic and as shifting in degree over the lifetime of an individual' (Fineman 2008, p. 12; 2010, p. 25).

Vulnerability is also connected to human affections. We are emotionally and psychologically vulnerable to others (e.g. loss, mourning and grief) (Mackenzie et al. 2014, pp. 1, 7). Building on this, humans' fundamental 'openness' vis-à-vis the 'richness of sensuality and sensual encounters with [oneself] the other and with the world' (Petherbridge 2016, p. 598).

It is significant, therefore, to disconnect vulnerability from such negative associations as helplessness and passivity (Mackenzie 2014, p. 33; Fineman 2008 , p. 8 ). Rather, we should recognize that vulnerability contains a productive potentiality; namely, that 'vulnerability can have positive manifestations and value, enabling the development of empathy, compassion, and community' (Gilson 2013, p. 8, my italics; see Fineman 2008, p. 11; Petherbridge 2016, p. 598; Ferrarese 2018, p. 30). In turn, our vulnerability enables humans to act and interact (Ferrarese 2018, p. 30) in terms of 'affective activity' (Ferrarese 2018, p. 38). This is related to 'relational autonomy' (Mackenzie 2014, p. 33; Ferrarese 2018, p. 30). Such an approach to autonomy is 'premised on recognition of human vulnerability' (Mackenzie et al. 2014, p. 16). Here, the so-called 'autonomy myth'-namely, the imaginary that humans are self-sufficient, independent, and rational (Fineman 2008; Mackenzie 2014, p. 33) -is criticized.

In view of suffering-based vulnerability, then, the UNHCR's as well as Olin's description of child refugees as particularly vulnerable relates to a basic, inherent and bodily vulnerability, shared universally and expressed uniquely by all humans.

\section{Vulnerable to Moral Injury}

Ethically, child refugees' particular vulnerability can be conceptualized in view of being 'vulnerable to moral injury' (Honneth 1995, p 48; see Butler 2004, p. 20). Specifically, it is an affinity between one's subjective experience of embodied vulnerability, on the one hand, and human 
dignity, on the other. When individuals mutually perceive each other as 'morally vulnerable persons', they recognize each other concerning their 'fundamental claims to [bodily] integrity' (Honneth 1995, p. 48). Consequently, 'the specific vulnerability of humans result[s] from the internal interdependence [grounded in] [...] recognition' (ibid., p. 131, my italics). Thus, each person shares a basic need for recognition, which is due to our specific embodied vulnerability that can be exposed to 'injury' through others' mis-recognition (ibid.; see Butler 2004, p. 20; 2010, p. 2). If so, to have one's bodily vulnerability injured can 'bring the identity of the person as a whole to the point of collapse' (ibid., p. 132, my italics; see pp. 133, 135).

In the case of child refugees, being vulnerable to moral injury indicates having one's particular vulnerability mis-recognized in the shape of violations of the person's bodily integrity and human dignity. Accordingly, child refugees' development through a wide range of processes consisting of socialization, internalization and individuation ideally leads to an undistorted and positive self-realization: 'Without the assumption of a certain measure of self-confidence, of legally enshrined autonomy and of a belief in one's ability, it is impossible to imagine a successful process of self-realization' (Honneth 2001, p. 50, my italics). Such mutual relationships of recognition as love, respect and esteem are necessary components, therefore, if children, hereunder child refugees, are to achieve a successful self-realization. If not, they would suffer from misdevelopment: '[I]n order to be able to acquire an undistorted relation-to-self, human subjects always need-over and above the experience of affectionate care and legal recognition-a form of social esteem that allows them to relate positively to their concrete traits and abilities' (Honneth 1995, p. 121, my italics). Here, humans' basic undistorted self-relations include self-confidence, self-respect and self-esteem. These dimensions represent ways to safeguard that humans, including child refugees, to the greatest extent possible, are capable of relating to themselves, to others, as well as to the wider world in an undistorted, positive and successful manner.

It is thus important to avoid 'autonomy gaps' (Anderson 2017); namely, the discrepancy between a cultural expectation that people, on a societal and institutional level, become autonomous, on the one hand, and what I above term as humans' 'existential life graph', on the other. Autonomy gaps are thus undermined, by, for instance, harming individuals with respect to their actual capabilities for societal participation on a par with each other. Moreover, such autonomy gaps cause emotional 
harm because of the bodily stress people experience due to powerlessness, while not being able to continue with the expectations of being autonomous.

Therefore, since human dignity is ontologically grounded in our bodily vulnerability, autonomy gaps can even degrade human dignity. In turn, it is important to supplement our story about humans as autonomous by showing the ways in which we are vulnerable and dependent. To the extent to which child refugees are often more vulnerable than others, they are also more exposed to these autonomy gaps and ways in which could result in mis-recognition of their dignity.

However, through recognition children develop skills to tackle their embodied vulnerability and injurability on the basis of 'agentic resources' (Anderson 2017). Through such developmental capacities and processes, children undergo a transition from being totally dependent on others (e.g. their parents) to learning how to become increasingly mature and independent. Hence, children and their childhoods are 'never on hold', since 'developmental needs do not wait for an emergency phase of a refugee situation to end' (Sourander 1998, my italics; see Graf and Schweiger 2017; Schweiger and Graf 2017). Still, traumas before, during and/or after they flee can 'harm children's physical, intellectual, psychological, cultural and social development' (Sourander 1998), which is due to disruption, uprooting and insecurity of forced displacement and prolonged waiting. Against this horizon, vulnerability is 'inherent' by being ontologically conditioned through embodied developmental capabilities, as well as 'situational' by being practised as well as hindered within concrete life forms (Mackenzie 2017, p. 89).

In light of the significant role of recognition concerning child refugees' particular vulnerability, mis-recognition can incorporate structural 'patterns of humiliation and denigration' (Anderson and Honneth 2005, pp. 135-136). Subsequently, this makes children 'less able to be self-determining' concerning the care for undistorted and negative self-realization related to their agentic resources in a developmental life stage that are crucial for every child (ibid., pp. 135-136; Anderson 2017; Schweiger and Graf 2017, p. 247). 


\section{Falling Out of Time}

'Are you lonely?', Olin asks Goli, a Kurdish migrant minor, who was recently deported from Norway. 'Yes', he answers. Then Goli adds: 'Sometimes I don't give a fuck, but not always.' In Olin's documentary, Goli's everyday life can be described as falling out of time, since he is sent back and forth between Norway and Greece.

Due to protracted refugee situations and other forms of prolonged waiting, particularly vulnerable child refugees and other migration minors are mis-recognized if they fall out of time. This means an exclusion from a normal, expectable lifecycle in terms of socially shared scripts of life pathways and life courses, including expectations about the timing and sequencing of role transitions (Settersten and Hagestad 1996; Hagestad and Dykstra 2016). Subsequently, refugee minors' life course is put on hold regarding temporally conditioned everyday life practices of childhood (e.g. eating, being cared for, playing, or attending school). Furthermore, falling out of time implies that normal expectancies about a healthy body, predictable linear time and expected durations are no longer conformed to the normal timetable scripts (Hagestad 1996).

\section{Protracted Refugee Situations}

'Nobody wants to do die, but I risk it. I have waited too long', Goli answers in response to Olin expressing her worry when he is about to travel in a boat bringing irregular migrants to Europe. Olin continues by saying that '[ $t]$ here's a possibility of it's not going to be $[\ldots]$ a suicide trip'.

By introducing the concept of protracted refugee situations, the UNHCR seeks durable solutions to the current global challenge of forced displacement, such as in Goli's case. The term is defined as a situation in which refugees, including children, find themselves in a 'long-lasting and intractable state of limbo' (UNHCR 2004, my italics). Moreover, the term is defined as situations lasting at least 5 years, with no prospects of durable solutions. However, according to the UNHCR's figures, globally many protracted refugees experience this situation far longer than 5 years, and it can last an estimated 26 years on average (UNHCR 2015). Additionally, according to the UNHCR (2009), 23 of the 32 protracted refugee situations have lasted for more than 20 years. Even so, in some cases protracted refugee situations continue for generations. 
Subsequently, many children are born and raised, and in some cases even become adults and elderly, while waiting for a durable solution regarding their uncertain future.

These refugees' lives 'may not be at risk, but their basic, rights [e.g. human rights and human dignity] and essential economic, social and psychological needs remain unfulfilled after years in exile' (UNHCR 2004, my italics). Additionally, refugees in this limbo situation are 'often unable to break free from enforced reliance on external assistance' (ibid., my italics), which continues to harm their bodily vulnerability.

As particularly vulnerable, children experiencing protracted refugee situations fall out of time by being mis-recognized through lacking love, respect and esteem, as well as self-confidence, self-respect and self-esteem. Accordingly, while living in a limbo situation, it is highly challenging to restore normalcy, stability, predictability and resilience, and hence avoid becoming, inter alia, refugee patients.

\section{Time as a Normative Resource}

Time, as well as falling out of time, is an existential matter if one's childhood is put on hold in terms of being excluded from a normal, stable and predictable lifecycle. To avoid this fate thus involves being recognized regarding everyday life routines (e.g. caring, eating, playing).

What Arendt $(1958$, p. 8$)$ conceptualizes as the human condition of natality-namely, temporality in terms of, for example, birth, life-course, action-considers time as existential; namely, a given and non-optional condition of human existence. Given that every human is ontologically a temporal being (Horst and Lysaker 2020). Although Arendt connects time to the human condition of mortality, being temporal also denotes unexpected and unpredicted action and interaction. Hence, temporality not only produces an inherent existential vulnerability of fragility or even mortality, but also generates what Arendt describes as the hopes and miracles of 'new beginnings' (Arendt 1958, pp. 9, 246-247) in capacity of thinking, judging and acting within spaces of appearance (ibid., pp. 5, 7, 198-199). Thus, prior to the human condition of plurality, meaning the diversity of unique identities, we must recognize each human's temporally preconditioned existence. This is partly what is at stake if someone, such as particularly vulnerable child refugees, falls out of time. 


\section{Time as a Scarce Good}

Humans as temporal beings infers that time is a scarce good, too. This is due to the ontological fact that we have more or less of it, and sometimes we have very little, almost no, time. Moreover, since our temporally preconditioned life course can be over any minute, this turns humans into a particularly vulnerable creature. Therefore, to have one's years with human dignity and life quality reduced-for instance, due to prolonged waiting - is both psychologically and relationally harmful.

Today, according to the UN's World Population Prospects 2015 Revision, the global average life expectancy at birth is around 71.5 years across gender. Nonetheless, humans' existential life graph and time as a scarce good demonstrate that not every individual has the opportunity to conduct their life in accordance with this average; that is, in line with time as a normative resource. Rather, a long, healthy life with quality and dignity can suddenly-such as when Goli risks his life to return to Norway while experiencing prolonged waiting - be undermined and eventually over.

This existential account of time resonates with Nussbaum's concept of human capabilities, which refers to 'what people are actually able to do and to be' (Nussbaum 2006, p. 70). The first, and most basic, capability is 'life' itself: 'Being able to live to the end of a human life of normal length [i.e. average life expectancy]; not dying prematurely, or before one's life is so reduced as to be not worth living' (Nussbaum 2006, p. 76, my italics). Furthermore, Nussbaum talks about 'functioning': '[capabilities] [...] use[...] the idea of a threshold level of each capability' (ibid., p. 71, original italics), 'beneath which it is held that truly human functioning is not available' (ibid., my italics). Accordingly, to live one's life in harmony with capabilities and functionally, each human being should be able to live to the end of a human life of average expectancy.

\section{WAiting Guarantee}

To find ways in which to avoid prolonged waiting in the case of Husein, Goli and other particularly vulnerable child refugees, we need to explore how ethically to limit such long-term limbo situations, too. 


\section{Ethics of the Temporary}

In light of an ethics of the temporary, which I relate to my own moral principle of a waiting guarantee, the problem of prolonged waiting is described as follows: 'far from being temporary, [forced] displacement [e.g. child refugees] ought to be rigorous ethical consideration'. Thus, we have to take a closer look at the 'the moral dimension of how [forced] displaced are treated between the time of their exile and when [if ever] they are finally able to find a permanent durable solution' (Parekh 2017, p. 3, my italics).

Along these lines, there are at least two reasons why the global situation of prolonged waiting should be criticized. First, empirically, ' $[\mathrm{t}]$ his period of time [e.g. prolonged waiting time or protracted refugee situation] is ever growing, and more and more people spend their lives' in such a situation (Parekh 2017, p. 3, my italics). The UNHCR (2015) documents that the global number of forced displaced people had reached 65.3 million. Here, more than $50 \%$ - that is, over 32 million-are children. Simultaneously, forced displaced minors are particularly vulnerable. Consequently, forced displacement is viewed by the UNHCR as one of the major humanitarian and developmental problems facing the world today. Relatedly, the UNHCR defines around 12 million out of the total of 65 million (i.e. nearly $20 \%$ ) as existing in protracted refugee situations.

Second, normatively, '[f]or the vast majority of people, [...] a [prolonged waiting] time [is] characterized by confinement and human rights violations' (Parekh 2017, p. 3, my italics). Accordingly, to the extent which human rights' moral core is the recognition of persons' inherent dignity (Habermas 2010), these human rights violations simultaneously disrespect their dignity. Against this backdrop, related to, for instance, refugee patients, it can be further claimed that prolonged waiting 'should [morally] not be the accepted norm'. Instead, child refugees and others subjected to forced displacement ought to be morally treated 'as fully human and with [morally] dignity' (ibid., my italics).

An adequate way in which to avoid child refugees' prolonged waiting, then, entails 'a morally acceptable way to house refugees [e.g. child refugees] and allow them to live with [inherent moral] dignity [even] while they are waiting to be resettled or to return to their home countries' (ibid., p. 137, my italics). Consequently, existing in a particular vulnerable life situation, which is exactly what child migrants such as Husein 
and Goli do, this should be taken into closer consideration. If so, accepting the mis-recognition of this groups' particular embodied vulnerability equals morally ignoring these refugees' very human condition as temporal beings, on the basis of which they belong to humanity and thus should have their dignity recognized.

\section{Embodied Human Dignity}

Dignity seems to be the overarching theme of Nowhere Home. During the documentary, Olin states that 'every human being must be a goal in itself'. However, Goli and other child migrants have their dignity misrecognized and apparently have no hope of regaining it.

To support Olin's claim, we thus have to address the concept of human dignity in a relevant manner, since this is the moral threshold level above which this group of refugees should live, even if-or, exactly when-they are exposed to prolonged waiting. Here, in line with Nussbaum's picture of human capabilities, inherent dignity can be approached from exactly the perspective of a moral threshold. What Nussbaum describes as 'life' itself, and the way in which it resonates with the Arendtian term 'natality', serves as an existential precondition for all the other capabilities: without existence in terms of human life in the first place, we cannot develop ourselves along the lines of the other capabilities (bodily health, senses, imagination, thought, emotions, practical reason, affiliation and so on).

Furthermore, this threshold identifies the fundamental requirements for living 'a life worthy of human dignity' (Nussbaum 2006, p. 70), which implies a 'fully human living' (ibid., p. 279) throughout a person's entire lifespan. To exist beneath this level, then, suggests that humans' embodied dignity is mis-recognized concerning the basic need for recognition in terms of love, respect and esteem, as well as positive self-development regarding self-confidence, self-respect and self-esteem (Honneth 1995).

One way in which my ethics of waiting can be normatively justified is to reject all prolonged waiting that exceeds the UNHCR's limit of 5 years of protracted refugee situations. Moreover, in accordance with the Arendtian idea of time as a human condition, as well as a normative resource and a scarce good, it can be argued that, as soon as the capability to live one's lifespan in accordance with one's inherent dignity and human rights, as well as bodily health and life quality (Turner 2006, p. 25) is undermined due to prolonged waiting, this situation is morally unacceptable. 
In Nussbaum, dignity is related precisely to both humans' temporality and embodiment. Temporally, since our capabilities are grounded in the very basic one, 'life' itself, it follows that the other capabilities should existentially and morally protect the ability to live to the end of a normal human lifespan. Moreover, to the extent to which this basic capability of life itself serves as the moral basis on which one should be able to live a life worthy of human dignity, the other capabilities should be achieved for 'each and every person, treating each as an end and none as a mere tool of the ends of others'. Hence, to have one's life course put on hold-as in the case of particularly vulnerable child refugees' prolonged waiting-is a way in which to have one's ontologically grounded and bodily appearing capability of life, and thus one's inherent dignity, mis-recognized. To Nussbaum, therefore, the very basic capability of life itself establishes 'a bare minimum of what respect for human dignity requires' (Nussbaum 2006, p. 70, my italics; see pp. 74, 180, 274, 278). In short, it expresses the moral grounding of humans' temporal life worthy of dignity.

Regarding embodiment, Nussbaum holds that the inherent moral worth of each person is primarily grounded in given and shared bodily ways in which humans exist and thus should be protected by others. Accordingly, dignity is something that 'inheres in the animal body' (Nussbaum 2006, p. 87) and 'bodily need[s]', including the need for recognition as care (ibid., p. 160). This central role of the body is also visible with regard to several other capabilities that safeguard 'truly human' life, such as 'bodily health' and 'bodily integrity' (ibid., p. 76). Here, the human body enables the realization of these capabilities through such capacities as the sense apparatus, the nervous system and our emotional life.

Nussbaum also argues that humans' inner worth 'could not be posed by a being who was not mortal and vulnerable' (Nussbaum 2006, p. 132, my italics; see pp. 87-88). Against this background, she argues that 'bodily need, including the need for care, is a feature of both of our rationality and our sociability' (ibid., p. 160, my italics). To care for others not only presupposes our own emotional and sensual empathy, but also that others are receptive addressees regarding such recognitive caregiving.

This idea of dignity is explicitly related to children, which can be linked to the issue of child refugees. To live a dignified life indicates to Nussbaum that others should treat each person through '[g]ood care'. This denotes that due to their 'acute or asymmetrical dependency' and 'primary needs', to respect children's dignity requires a special 'focus[...] on [the] support for capabilities of life, health, and bodily integrity' (Nussbaum 2006, 
p. 168). Hence, I not only take humans in general, but also, particularly, vulnerable child refugees as a group that requires special protection in light of the capabilities. Capability-based needs should, then, be normatively justified as children's 'special priority'. Such a moral priority, echoing the UNHCR's account of child refugees as particularly vulnerable, is based on what Nussbaum describes as 'the special pulnerability of children' (Dixon and Nussbaum 2012, p. 549, my italics; see Benporath 2003; Mullin 2014; Macleod 2017; Schweiger and Graf 2017).

Accordingly, she introduces a 'vulnerability principle', which holds that 'an important component to [the capabilities approach] [...] [is that] it recognizes human frailty and vulnerability as central parts of the [Arendtian] buman condition for adults as well as for children' (Dixon and Nussbaum 2012 , p. 584 , my italics). So, children's special vulnerability regarding, for instance, physical, emotional and cognitive maturity through recognitive and hence positive, undistorted self-development, can be safeguarded to a greater extent than is currently the case (ibid., p. 574). If so, the transnational situation of child refugees-particularly their prolonged waiting — would most certainly be improved.

\section{Towards a Waiting Guarantee}

The ethical guideline I wish to propose can be stated thus: it is morally unacceptable if prolonged waiting puts child refugees' childhood on hold. An important aspect of this waiting guarantee is the way in which it requires being more aware concerning the difference between 'misrecognition' and 'non-recognition' (Lysaker 2013). Recognition as love, respect and esteem are basic bodily and relational needs that are ontologically shared by all humans. However, in cases in which people lack such recognition, it occurs in at least two ways. With mis-recognition, I mean when humans in general, and child refugees in particular, are capable of struggling to regain their recognition after being humiliated. Hence, such cases are 'ordinary' in the sense that the very struggle may take a while to succeed, but without lasting too long as for the mis-recognized person to yet again being recognized.

Non-recognition, however, undermines even the person's very capacity to struggle for recognition after being mis-recognized in terms of traumatization or dehumanization. For instance, in cases in which child refugees are exposed to prolonged waiting, as well as traumatization before, under and/or after the flight, the implication of this can be that the children's 
prolonged waiting is even further prolonged due to the traumatizations as non-recognition. Then, these two forms of recognitive negation are ways in which to identify the moral threshold level in Nussbaum, beneath which the dignity of child refugees is turned into the situations in which these children cannot regain their recognized life form due to severe bodily health issues stemming from their prolonged waiting.

To prevent not only what I describe as mis-recognition, but also nonrecognition, it is relevant to relate Nussbaum's 'vulnerability principle' in the case of children-including child refugees-to the UN 1989 Child Convention. Here, Article 3 declares the following moral principle: 'In all actions concerning children, whether undertaken by public or private social welfare institutions, courts of law, administrative authorities or legislative bodies, the best interests of the child shall be a primary consideration' (UN 1989, my italics). So, if the best interests of the child shall be safeguarded, particularly the vulnerable group of child refugees should not be exposed to prolonged waiting in terms of non-recognition, including its costs concerning reduced bodily health and life quality, as well as violated inherent dignity and human rights.

\section{CONCLUSION}

In Nowhere Home, we are told the life histories of child migrants such as Husein, Hassan and Goli. Starting from brief examples from the documentary, I have explored the dynamics between vulnerability, child refugees and prolonged waiting. I have underscored how various exclusion mechanisms mis-recognize this group of irregular migrants' inherent dignity, bodily health, life quality and human rights.

Accordingly, particularly vulnerable child refugees should not have their childhood put on hold due to prolonged waiting. Instead, the ethical demand of Olin's documentary, as I see it, concerns recognizing child refugees' basic capabilities to live above the threshold level concerning the vulnerable and injurable nature of their embodied dignity.

Acknowledgements I would like to thank Serena Parekh, John Christman, Synnøve Bendixsen, Line Indrevoll Stänicke, Zemir Popovac and Hilde Lidén, as well as the editors for their comments. Earlier versions of this chapter were presented in 2018 at the conferences Philosophy and Social Science in Prague, and Refugees and Minority Rights: Acceptable and Unacceptable Criteria for Accepting/Rejecting Refugees in a Non-Ideal World at the University of Tromsø; as 
well as at the workshop Reason and Affect in Divided Societies: The Nordic Case at the Uppsala University, and in 2017 at the Centre for Women's and Gender Research at the University of Bergen. I would like to thank the audiences at these events for their feedback. The chapter is published as part of the research project WAIT (Waiting for an Uncertain Future: The Temporalities of Irregular Migration), which is funded by the Research Council of Norway.

\section{REFERENCES}

Anda, R. F., Felitti, V. J., Bremner, J. D., Walker, J. D., Whitfield, C., Perry, B. D., et al. (2006). The enduring effects of abuse and related adverse experiences in childhood. European Archives of Psychiatry and Clinical Neuroscience, 256(3), 174-186.

Anderson, J. (2017). Ordinary vulnerability, institutional androgyny, and gender justice. In C. Straehle (Ed.), Vulnerability, Autonomy, and Applied Ethics. London: Routledge.

Anderson, J., \& Honneth, A. (2005). Autonomy, vulnerability, recognition, and justice. In J. Christman \& J. Anderson (Eds.), Autonomy and the Challenges to Liberalism. Cambridge: Cambridge University Press.

Arendt, H. (1958). The Human Condition. Chicago: University of Chicago Press.

Benporath, S. R. (2003). Autonomy and vulnerability: On just relations between adults and children. Journal of Philosophy of Education, 37(1), 127-145.

Bhabha, J. (2016). Child Migration and Human Rights in a Global Age. Princeton: Princeton University Press.

Butler, J. (2004). Precarious Life: The Power of Mourning and Violence. London: Verso.

Butler, J. (2010). Frames of War: When Is Life Grievable? London: Verso.

Carswell, K., Blackburn, P., \& Barker, C. (2009). The relationship between trauma, post-migration problems and the psychological well-being of refugees and asylum seekers. International Journal of Social Psychiatry, 57(2), 107-119.

Cassidy, J., \& Mohr, J. J. (2001). Unsolvable fear, trauma, and psychopathology: Theory, research, and clinical considerations related to disorganized attachment across the life span. Clinical Psychology, 8(3), 275-298.

Crock, M., \& Bhabha, J. (Eds.). (2007). Seeking Asylum Alone. Sydney: Themis Press.

Dixon, R., \& Nussbaum, M. C. (2012). Children's rights and a capabilities approach: The question of special priority. Cornell Law Review, 97(3), 549-594. 
Fazel, M., Reed, R. V., Panter-Brick, C., \& Stein, A. (2012). Mental health of displaced and refugee children resettled in high income countries. The Lancet, 379(9812), 266-282.

Ferrarese, E. (2017). The vulnerable and the political: On the seeming impossibility of thinking vulnerability and the political together and its consequences. In E. Ferrarese (Ed.), The Politics of Vulnerability. London: Routledge.

Ferrarese, E. (2018). Vulnerability and Critical Theory. Leiden: Brill.

Fineman, M. A. (2008). The vulnerable subject: Anchoring equality in the human condition. Yale Journal of Law and Feminism, 20(1), 1-23.

Fineman, M. A. (2010). The vulnerable subject and the responsive state. Emory Law Journal, 60(2), 251-275.

Fineman, M. A. (2013). Equality, autonomy, and the vulnerable subject in law and politics. In M. A. Fineman \& A. Grear (Eds.), Vulnerability: Reflections on a New Ethical Foundation for Law and Politics. London: Routledge.

Gilson, E. (2013). The Ethics of Vulnerability: A Feminist Analysis of Social Life and Practice. London: Routledge.

Graf, G., \& Schweiger, G. (2017). Ethics and the Endangerment of Children's Bodies. Basingstoke: Palgrave Macmillan.

Habermas, J. (2010). The concept of human dignity and the realistic utopia of human rights. Metaphilosophy, 41(4), 464-480.

Hagestad, G. O. (1996). On-time, off-time, out of time? Reflections on continuity and discontinuity from an illness process. In V. L. Bengtson (Ed.), Adulthood and Aging. New York: Springer.

Hagestad, G. O., \& Dykstra, P. (2016). Structuration of the life course: Some neglected aspects. In M. J. Shanahan, J. T. Mortimer, \& M. Kirkpatrick Johnson et al. (Eds.), Handbook of the Life Course (Vol. 2). New York: Springer.

Honneth, A. (1995). The Struggle for Recognition: The Moral Grammar of Social Conflicts. Cambridge: MIT Press.

Honneth, A. (2001). Recognition or redistribution? Changing perspectives on the moral order of society. Theory, Culture, and Society, 18(2-3), 43-55.

Horst, C., \& Lysaker, O. (2020, forthcoming). Miracles in Dark Times: Hannah Arendt and the Refugee as 'Vanguard'. Journal of Refugee Studies.

Jakobsen, M., Meyer DeMott, M. A., Wentzel-Larsen, T., \& Heir, T. (2017). The impact of the asylum process on mental health: A longitudinal study of unaccompanied refugee minors in Norway. British Medical Journal Open, $7(6), 1-8$.

Jensen, T. K., Fjermestad, K. W., Granly, L., \& Wilhelmsen, N. H. (2015). Stressful life experiences and mental health problems among unaccompanied asylum-seeking children. Clinical Child Psychology and Psychiatry, 20(1), 106-116.

Kulu-Glasgow, I., Smit, M., \& Sirkeci, I. (Eds.). (2019). Unaccompanied Children: From Migration to Integration. London: Transnational Press. 
Li, S. S., Liddell, B. J., \& Nickerson, A. (2016). The relationship between post-migration stress and psychological disorders in refugees and asylum seekers. Disaster Psychiatry, 18(82), 81-90.

Lysaker, O. (2013). Menneskeverdets politikk: Anerkjennelse av kroppslig krenkbarhet. Oslo: Abstrakt.

Lysaker, O. (2015). Å leve et menneskeverdig liv: Martha Nussbaums globale helseetikk. Nordic Journal of Applied Ethics, 9(2), 53-70.

Mackenzie, C. (2014). The importance of relational autonomy and capabilities for an ethics of vulnerability. In C. Mackenzie, W. Rogers, \& S. Dodds (Eds.), Vulnerability: New Essays in Ethics and Feminist Philosophy. Oxford: Oxford University Press.

Mackenzie, C. (2017). Vulnerability, needs, and moral obligation. In C. Straehle (Ed.), Vulnerability, Autonomy, and Applied Ethics. London: Routledge.

Mackenzie, C., et al. (2014). Introduction: What is vulnerability and why does it matter for moral theory? In C. Mackenzie, W. Rogers, \& S. Dodds (Eds.), Vulnerability: New Essays in Ethics and Feminist Philosophy. Oxford: Oxford University Press.

Macleod, C. (2017). Doctrinal vulnerability and the authority of children's voices. In C. Straehle (Ed.), Vulnerability, Autonomy and Applied Ethics. New York: Routledge.

Miller, K. E., \& Rasmussen, A. (2010). War exposure, daily stressors, and mental health in conflict and post-conflict settings: Bridging the divide between trauma-focused and psychosocial frameworks. Social Science and Medicine, $70(1), 7-16$.

Mullin, A. (2014). Children, vulnerability, and emotional harm. In C. Mackenzie, W. Rogers, \& S. Dodds (Eds.), Vulnerability: New Essays in Ethics and Feminist Philosophy. Oxford: Oxford University Press.

Nussbaum, M. C. (2004). Hiding from Humanity: Disgust, Shame, and the Law. Princeton: Princeton University Press.

Nussbaum, M. C. (2006). Frontiers of Justice: Disability, Nationality, Species Membership. Cambridge, MA: Harvard University Press.

Nussbaum, M. C. (2013). Political Emotions: Why Love Matters for Justice. Cambridge, MA: Belknap Press.

Parekh, S. (2017). Refugees and the Ethics of Forced Displacement. New York: Routledge.

Petherbridge, D. (2016). What's critical about vulnerability? Rethinking interdependence, recognition, and power. Hypatia, 31(3), 589-604.

Schweiger, G., \& Graf, G. (2017). Ethics and the dynamic of vulnerability of children. Les Ateliers de L'éthique, 12(2-3), 243-261.

Settersten, R. A., Jr., \& Hagestad, G. O. (1996). What's the latest? Cultural age deadlines for family transitions. The Gerontologist, 36(2), 178-188. 
Silas, W. A. (2018). A desired composition: Regulating vulnerability through immigration law. In M. A. Fineman \& J. W. Fineman (Eds.), Vulnerability and the Legal Organization of Work. New York: Routledge.

Silove, D., Steel, Z., Susljik, I., Frommer, N., Loneragan, C., Chey, T., et al. (2007). The impact of the refugee decision on the trajectory of ptsd, anxiety, and depressive symptoms among asylum seekers. American Journal of Disaster Medicine, 2(6), 321-329.

Sourander, A. (1998). Behaviour problems and traumatic events of unaccompanied refugee minors. Child Abuse and Neglect, 22(7), 719-727.

Turner, B. S. (2006). Vulnerability and Human Rights. University Park, PA: Penn State University Press.

UN. (1989). The Convention on the Rights of the Child. http://www.ohchr.org/ EN/ProfessionalInterest/Pages/CRC.aspx. Accessed 18 January 2019.

UNHCR. (1951). The 1951 Convention and Its 1967 Protocol: Relating to the Status of Refugees. https://www.unhcr.org/4ec262df9.pdf. Accessed 31 May 2019.

UNHCR. (1998). Refugee Children: Guidelines on Protection and Care. http:// www.unhcr.org/3b84c6c67.pdf. Accessed 18 January 2019.

UNHCR. (1999). Protecting Refugees: A Field Guide for NGOs. UNHCR: Geneva. https://www.unhcr.org/3d4a5b634.pdf. Accessed 31 May 2019.

UNHCR. (2004). Protracted Refugee Situations. Standing Committee, 30th Meeting, 10 June. https://www.unhcr.org/40c982172.pdf. Accessed 31 May 2019.

UNHCR. (2009). Conclusion on Protracted Refugee Situations, No. 109 (LXI). Executive Committee 61st Session. https://www.unhcr.org/excom/exconc/ 4b332bca9/conclusion-protracted-refugee-situations.html. Accessed 31 May 2019.

UNHCR. (2015). UNHCR Global Trends 2015. https://www.unhcr.org/ 576408cd7.pdf. Accessed 18 February 2020.

UNHCR. (2016). Caring for the Vulnerable. Helping Those with Special Needs. http://www.unhcr.org/ceu/96-enwhat-we-docaring-for-the-vulnerable-html. html. Accessed 18 January 2019.

Varvin, S. (2008). Flyktningpasienten. Oslo: Universitetsforlaget. 
Open Access This chapter is licensed under the terms of the Creative Commons Attribution 4.0 International License (http://creativecommons.org/licenses/ by $/ 4.0 /$ ), which permits use, sharing, adaptation, distribution and reproduction in any medium or format, as long as you give appropriate credit to the original author(s) and the source, provide a link to the Creative Commons license and indicate if changes were made.

The images or other third party material in this chapter are included in the chapter's Creative Commons license, unless indicated otherwise in a credit line to the material. If material is not included in the chapter's Creative Commons license and your intended use is not permitted by statutory regulation or exceeds the permitted use, you will need to obtain permission directly from the copyright holder.

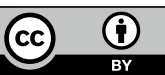




\title{
Vulnerability When Fecundity Fails: Infertility and Assisted Reproductive Technologies in The Bridge
}

\author{
Melissa Gjellstad
}

Citizens' vulnerability with reproduction and the state's responsiveness to vulnerability comes under investigation in season III of Bron/Broen (The Bridge) from 2015, a Nordic noir television serial that teams up two detectives, one Danish and one Swedish, to solve crimes that have impacted both countries and the cities of either Copenhagen or Malmö. The collaboration engages the greater metro area of the Øresund region, linked since July 2000 by the titular bridge, which the criminals and the police traverse at a dizzying pace. Written by Hans Rosenfeldt and co-created by Rosenfeldt, Måns Mårlind and Björn Stein, the Danish/Swedish co-production of The Bridge ran for four seasons from 2011 to $2018 .^{\text {l }}$ It quickly became a domestic and international success; by 2018 , it had been aired in 188 countries and remade in other

M. Gjellstad (凶)

Department of Modern and Classical Languages and Literatures, University of North Dakota, Grand Forks, ND, USA

e-mail: melissa.gjellstad@und.edu

(C) The Author(s) 2020

A. M. Dancus et al. (eds.),

Vulnerability in Scandinavian Art and Culture, https://doi.org/10.1007/978-3-030-37382-5_6 
nations with unique border relationships such as Austria/Germany, Estonia/Russia, France/UK and Mexico/USA, with another remake under way in Malaysia/Singapore (Chawla 2018). In seasons I and II, Martin Rohde (Kim Bodnia) from Copenhagen is paired with Saga Norén (Sofia Helin) from Malmö, while seasons III and IV bring Henrik Sabroe (Thure Lindhardt) from Copenhagen to be Saga's new work colleague. ${ }^{2}$

Much has been, and can be, said about the complex primary characters Saga, Morten and Henrik, fallible and fascinating as they are; however, this article focuses not on the main detective heroes but, rather, on the secondary characters woven into the DNA of season III of the series. By my reading, one critical subplot of the third season concerns infertility, including the ways in which individuals counter this life crisis to form families with assisted reproductive technologies (ART), the inconsistencies in ART governance across the Øresund, and the consequences for donorconceived children. Perpetrators, victims and innocent bystanders wind up caught in the helix of reproduction that revolves around the larger plot arc. The Bridge critiques the Danish and Swedish welfare states, and assesses how they handle the embodied vulnerability of aspiring parents' infertility and reproduction now (in the 2010s) and in the early years of ART (in the 1980s), and of the emerging donor-conceived citizenry as they mature as vulnerable subjects.

The case on which Saga and Henrik professionally collaborate has them investigating a series of gruesome murders where the killer arranges the victims' bodies as performative art exhibits that cluster around a loosely defined theme of the family. The wealthy Holst couple, Freddie (Nicolas Bro) and Åsa (Anna Björk), own an art collection that links to the victims' death vignettes. The Holsts also await their firstborn son from secret surrogate mother Jeanette (Sarah-Sofie Boussnina). Saga and Henrik solve the complex puzzle and catch the killer Emil Larsson (Adam Palsson), whose victims are individuals who represent the institutional injustices he suffered as a child. ${ }^{3}$ A donor-conceived child who became a ward of the Swedish welfare state, Emil has learned that Freddie Holst was the anonymous donor of the sperm his mother received at the fertility clinic.

Thus, this infertility subplot of season III of The Bridge presents a myriad of vulnerable subject positions that, viewed together, critique the efficacy of the responsive welfare state in a cross-border comparison. Because it exists in the transnational region of the Øresund, the series levels criticism at the policy gaps between neighbouring welfare states that breed reproductive tourism and political tension in this imagined space. Success 
stories of ART in the early 1980s launched the Nordic countries on a trajectory that has transformed medically assisted reproduction and substantially reduced barriers to parenthood for involuntarily childless citizens. A woman in Sweden in September 1982 gave birth to a baby girl who was the first Nordic in vitro fertilization (IVF) baby, four years after the birth of Louise Brown in the UK. A woman in Denmark followed suit in 1983, when Troels Renard Østbjerg became Denmark's first IVF baby. By 2017, Denmark led European counterparts with a solid margin as the country initiating the largest number of ART cycles in Europe-followed by Belgium, Iceland, Sweden, and Slovenia-according to a study by sociologists Patrick Präg and Melinda C. Mills (2017). ${ }^{4}$ National legislation governing ART varies widely across the globe; Präg and Mills (2017, p. 305) attribute the national variation in Europe most generally to the cost of procedures, the extent of health care coverage for treatments, and the cultural beliefs regarding pregnancy and parenting, although multiple factors are at play.

Governance controls the regulation of and access to ART, and policy discrepancies challenge the claims of equality for health care surrounding infertility. Regulatory differences within the Nordic states have decreased over time as new amendments modify existing laws to keep pace with cultural change around medically assisted reproduction. Historically, Denmark has been most inclusive in ensuring that the broadest swathe of citizens has affordable access to ART. In the words of biomedical researchers Sebastian Mohr and Lene Koch (2016), 'IVF transformed Denmark: the use of reproductive biomedicine became normalized to the degree that access to reproductive health services is not regarded just as an individual matter, but a collective responsibility' (p. 94). Danes have complete health care coverage for ART treatments with national health insurance for single women, cohabiting couples, and married couples of any sexual orientation (Präg and Mills 2017 , p. 297). ${ }^{5}$ Sweden only permitted lesbian and single women access to ART in 2016, although it had been legal in Denmark since 2007. Cross-border reproductive care (CBRC), or reproductive tourism, emerged as a logical response to inaccessible and unaffordable ART treatments at home. People who are involuntarily childless and have sufficient resources travel to another country where their desired ART is attainable. Denmark became an ART destination for Scandinavians and many others, and The Bridge incorporates this reality, showing the strengths and weaknesses of their system. 
I investigate infertility and ART in Denmark and Sweden in the secondary characters from The Bridge in conversation with Martha Fineman's (2013) vulnerability thesis and Rachel Anne Fenton's (2013) vulnerability study of the inadequacy of the UK health care system to serve infertile citizens. There are many elements of medically assisted reproduction not addressed in the Scandinavian TV serial, but concerns surrounding sperm and egg donation, anonymity, surrogacy, and donorconceived origins emerge in the plot and the film narratology. Among the spectrum of secondary characters are the infertile mothers-to-be (Helle Anker, Anna-Maria Larsson, and Åsa Holst) who need donor gametes, the fertile donors (Jeanette, and Freddie Holst) who provide donor gametes and bodies, and the donor-conceived children (Morten Anker, Emil Larsson, Jan Fredrik Holst) who result from the successful ART treatments. The responsive Nordic welfare state has treated citizens differently, overlooking the vulnerability of some of the people in these intentional families; The Bridge magnifies those shortcomings for the involuntarily childless in a subplot that reveals the privileges of the partnered and fertile.

\section{EMBODIED VULNERABILITY OF THE INFERTILE IN ØRESUND}

American feminist legal scholar Martha Fineman (2013) theorizes that humans are vulnerable, and that the institutions humans create in response to those vulnerabilities mirror the universal condition of dependency: 'I set out an alternative vision for justice by developing the concepts of vulnerability and resilience and articulating an argument for a responsive state-a state built around the recognition of the vulnerable subject' (Fineman 2013, p. 13). Charting an alternate course for legal equality, Fineman advocates for a vulnerability analysis that necessitates a recalibration based on our understanding of the fact that, "vulnerability is a universal and constant aspect of the human condition. Dependency and vulnerability are not deviant, but natural and inevitable' (Fineman 2013 , p. 17). All citizens are equally vulnerable, despite possible status as protected classes, as Fineman believes that identity characteristics often limit state action to help citizens for they become stigmatized and serve as 'proxies for problems such as poverty or the failure of public educational systems' (Fineman 2013, p. 15). As a way to correct gendered inequities of care, Fineman uses 'dependency' to rebalance engrained divisions of labour within the traditional family structure and the state's system of 
institutions that ameliorate those caregiving burdens for individuals. Vulnerability can vary, depending on the quantity of resources available to the individual, but individuals never become invulnerable in Fineman's framework.

In recognizing the dependency of the vulnerable subject, Fineman's concept makes individual need visible as a core responsibility of good governance at every administrative level. To serve the vulnerable subject adequately, Fineman calls for a 'responsive state', which she defines as:

a state that recognizes that it and the institutions it brings into being through law are the means and mechanisms whereby individuals accumulate the resilience or resources that they need to confront the social, material, and practical implications of vulnerability. As such, a responsive state also recognizes that it has a responsibility to monitor the activities of its institutions to ensure that they function in an appropriate, egalitarian manner. This progression from vulnerability to state responsiveness incorporates the realities of human dependency. (Fineman 2013, p. 19)

Fineman's responsive state shares many commonalities with the 'cradle to grave' Scandinavian welfare states designed to respond to human vulnerability, including infertility. States' nimbleness and willingness to adapt to changing technologies and social realities clearly varies. Whether or not the growing pressures on the welfare state allow it to maintain the same degree of responsiveness for which Fineman advocates is another question.

British feminist legal scholar Rachel Anne Fenton (2013) operationalizes Fineman's vulnerability framework for reproductive medicine in an analysis of the UK health care system's legislative treatment of the infertile, and finds that the state is inadequate and unresponsive in 'addressing the embodied vulnerability of the infertile — an inadequacy exacerbating conditions of privilege and disadvantage' (Fenton 2013, p. 126). Fenton claims that equality in reproductive health care is illusory, and regards the $\mathrm{UK}$ as unresponsive to infertility. The analytical framework established by Fineman (2013) and Fenton (2013) around family, gender and equality in reproductive legislation and policy construct a productive platform from which to launch an analysis of The Bridge, and the responsiveness of the Danish and Swedish states to embodied vulnerabilities dealing with fertility. 
To reproduce is to be vulnerable, Fenton (2013) argues, and thus one of the essential elements of human existence is universal; everyone is vulnerable to the embodied human condition of infertility, or the inability to reproduce. Fenton acknowledges that infertility, for some, is a major life crisis, and that most individuals encounter complexity surrounding the desire and ability to reproduce. The state also has a stake in individuals' decisions to reproduce and regenerate society; therefore, it is the state's duty to be responsive and to allow all its vulnerable citizens to realize their full potential. For many individuals, realizing that full potential means to become a parent. ${ }^{6}$

While there are consequences at home, Fenton maintains that 'unethical legislative behaviour and the evasion of responsibility to provide genuine equality of access by a nation-state' to ART and fertility treatments also have global ramifications (Fenton 2013, p. 126). Research on CBRC makes evident that some restrictive laws feed market forces that allow only the privileged actors agency in their reproductive choices as resistance against vulnerability. Those citizens with less privilege and fewer resources are excluded. Fenton argues that state behaviours and policies that intensify discrimination ostensibly absolve states from responsibility for the involuntarily childless. Knowing treatments abroad may be more affordable, states may justify their inaction as the best choice for the privileged able to access CBRC - a practice Fenton labels as a highly problematic ethical subversion. Policy on gamete donations may leave the next generation of donor-conceived children unduly vulnerable. Fenton's charge applies to the CBRC between Denmark and Sweden regarding 'the use of anonymous sperm donation abroad which flies in the face of a nationally recognised principle of biological truth - of the possibility for a child to know its genetic origins' (Fenton 2013, p. 143). Even well-intentioned responsive states that provide some degree of resilience against vulnerability in the welfare system may not be suitably equipped for dealing with the growing numbers of donor-conceived children's families, child care, and educational needs.

Attention to these international ART issues has emerged concurrently with the genesis of the Øresund region, so it is fitting that this season's plot interlaces the topics. Pei-Sze Chow (2016) reads The Bridge as a product of the 10-plus year investment to generate a unified imagined community of 'Øresund' that linked Sweden and Denmark, and as a critique of the regional social fusion created by the fluid borders between nations (Chow 2016, p. 37). Chow builds on Andrew Nestingen's claim 
that the crime fiction genre uses lawlessness as a catalyst for a debate on domestic national character and transnational diplomatic relations. The detectives' mobility traversing the borders resembles a sewing motion that stitches together the region that 'crime then seeks to tear apart' (Chow 2016 , p. 46). Chow argues that The Bridge is unique because it concentrates those tensions on one region and international metro area that comes into being as the detectives cross borders, both literal and figurative. The concentrated visual space of Øresund is 'the landscape of a transnational metropolis, portrayed as a paradoxically fractured yet seamless urban space that must be traversed to stop the perpetrators' (Chow 2016, pp. 43-44). The literal cross-fertilization of citizens of both nations fits Chow's imagery.

The transnational imaginary pairs well, Chow argues, with the multiple subordinate storylines that the TV serial format enables. One season contains 10 episodes, presenting innumerable opportunities for subplots and supporting characters to enter and exit the story while the primary characters encounter, uncover and solve pieces of the larger plot of the crime narrative. Viewers then see:

a multiplicity and simultaneity of perspectives - subjective experiences of the region through each of these minor characters who typically come from diverse social groups and whose depictions are emphatic comments on topical welfare-state issues pertinent to modern day Denmark and Sweden. [...] Underneath the crime narrative lies a more complex social mapping and characterization of the Øresund. (Chow 2016, p. 46)

Chow's iteration of the formal conventions for The Bridge enables an inclusivity of perspectives on ART and a social mapping of welfare state shortcomings surrounding infertility by portraying examples of vulnerable citizens with varying needs and resources. To more fully unpack infertility narratives in The Bridge within this vulnerability framework, it is productive to consider the history of ART in Denmark and Sweden. The narrative time of the TV serial is roughly the time of production, but the show embeds some of the pre-series action back in the early years of Swedish and Danish fertility treatments and legislation to inform and exacerbate contemporary consequences. 


\section{ART History-Swedish and Danish State Provisions}

Unresolved tensions in the governance of and access to some variants of ART in the Øresund region percolate through the surface of Scandinavian communities, despite many scholars' insistence on the public unanimity around medically assisted reproduction. Sweden receives praise from pioneering scholars within the field of reproductive medicine in an article on the legal aspects of the early history of ART (Cohen et al. 2005). The authors stress the innovative research in Sweden and the public-private collaboration in reproductive medicine as elements of their laudatory beginnings. Advocating early for ART, the first private fertility clinic opened in Stockholm in 1984, two years after Swedish physician Lars Hamberger assisted the birth of the first Nordic IVF baby in Göteborg (Cohen et al. 2005, p. 456). Legislation struggled to keep pace with the medical advancements but, again, Cohen et al. (2005) recognize the Nordic states for creating laws regulating reproductive medicine as it developed. Even though ART legislation can be hailed as 'a novel phenomenon' by many, Präg and Mills (2017, p. 295) caution that 'there is a long history of government interference in the reproductive realm'. Norway and Sweden began passing legislation in the late 1980s, and Iceland and Denmark followed suit in the late 1990s. ${ }^{7}$ The earliest laws tended to be the most restrictive, and there was great variation in ART access and availability between the Nordic states. Cohen et al. state that a noteworthy feature of the Swedish law prohibited anonymity for sperm donors, making it the first country in the world to legislate such provisions (Cohen et al. 2005, p. 455). This no doubt influenced CBRC in the Øresund region, as evidenced in one of The Bridge storylines.

Writing this early history after the first twenty years of ART, Cohen et al. compared numbers of ART treatment cycles in their 2005 data set and found that the Scandinavian states had nearly triple the number of fertility treatment cycles compared to the USA and UK that same year. The researchers attributed the extraordinarily high numbers to 'relatively high reimbursement levels in the Nordic countries and a high public acceptance of the technique' due to health care benefits in the welfare state and the demonstrated safety of ART treatments (Cohen et al. 2005, p. 456). The collective belief and trust in ART permeated Scandinavian societies, despite national variation in access and regulation. This growing trust is echoed in the Präg and Mills (2017) research into IVF in European states from 2017, as well; together, these two studies suggest a 
respectable degree of responsiveness in Nordic states to citizens' vulnerabilities compared to European peers.

While Sweden may enjoy early praise, Denmark surged ahead as a global leader in ART. In a 2016 article on the history of IVF in Denmark, Mohr and Koch argue IVF transformed Denmark from 'a society concerned about the social consequences of reproductive technologies to a moral collective characterized by a joined sense of responsibility for Denmark's procreative future' (Mohr and Koch 2016, p. 88). Echoing Fineman (2013) and Fenton (2013) in the way they frame infertility issues for vulnerable subjects and a responsive state, Mohr and Koch (2016) argue that the acceptance of IVF in Denmark was about more than medical procedures helping involuntarily childless individuals, for it became a 'technology of social contract' that created 'a space of possibility' for negotiations between the state, its institutions and its citizens to construct a unified 'pursuit of procreative futures' (Mohr and Koch 2016, p. 89). Mohr and Koch claim that IVF has become a normalized part of Danish life now, given the relatively high number of children born following ART procedures (8\% per year in 2016 in Denmark), allowing citizens to establish families 'whose mode of creation and existence is rarely questioned by either political or media representatives' (Mohr and Koch 2016, p. 89). Danes expect the collective-state and society - to ensure national reproductive futures.

It did not start that way, according to Mohr and Koch. Danes initially regarded IVF with suspicion because of the unfamiliar medical procedures, the reproductive control and the way in which it disrupted established heteronormative family models:

When IVF was introduced, there was harsh opposition to it and a rejection of non-traditional families; once approved, it gained swift acceptance, but non-traditional families still met disapproval; and today, IVF is accessible to (almost) everyone, helping to create all kinds of non-traditional families, with Statistics Denmark currently registering 37 different family types. Thus whereas in the 1970s and 1980s IVF was too controversial to be offered outside of heterosexual coupledom, today IVF marks Denmark as a reproductive collective. (Mohr and Koch 2016, p. 95)

For Mohr and Koch, the societal concerns that dominated the early days of the 1980s were of a medical nature, ensuring that the science was sound. Societal norms and beliefs had changed by the 1990s, and they 
argue the focus of the debate had shifted to the state's regulation of access to ART as an equality project. ${ }^{8}$ The overtones to Fineman (2013) and Fenton's (2013) work ring clear. Humans are vulnerable and, around the millennium shift, the responsive Danish state recognized that it must build resilience to serve the citizens equitably and to allow anyone to become a parent.

Denmark's reputation as a 'reproductive collective' is growing, for ART treatments and for gamete donation. Mohr and Koch (2016) reported 21 public and private fertility clinics, and four sperm banks in Denmark. This includes Cryos International, one of the world's largest sperm banks, which began in 1981 as Ole Schou's dream; it eventually opened in Aarhus in 1987 and now has international offices (Petroff 2015). Men's sperm donation is a profitable business, regulated and routine, and the donors receive modest financial compensation. ${ }^{9}$ Stine Willum Adrian and Charlotte Kroløkke (2018) in their study of the reproductive pathways in and out of Denmark attest that, within the industry, Denmark has the reputation of being a fertility nexus due to the leading role the country has played in the development of the industry, and due to the high rate of children born with ART treatments. Compared to difficulties recruiting donors and prolonged waits to procure donor sperm in Sweden and Norway, Adrian and Kroløkke (2018) confirm that 'in Denmark, donated sperm has become an export commodity, enabling the recruitment of both anonymous and non-anonymous donors' (p. 6). Women's egg donation is not a routine procedure and does not have a comparable societal acceptance. Legal since 2006 in Denmark, egg donors cannot receive compensation given laws that prevent the commercialization of these gametes. ${ }^{10}$ Adrian advocates equity but states that societal views on gamete donation perceive egg cells as 'gifts', while sperm cells 'move around anyway' (Bajekal 2019, p. 6). The dissimilar treatment of female donors to their male counterparts leads Mohr and Koch (2016, p. 90) to ascribe a gendered legislation to Denmark's gamete donation laws.

As with egg donation, surrogacy remains one of the most contested variants of ART in Denmark and in many other nations. ${ }^{11}$ Traditional altruistic surrogacy is legal for Danish citizens in Denmark. Gestational commercial surrogacy is prohibited, and excessive compensation can impede legal adoption and transfer of parental rights. The policy environment is currently extremely dynamic in Denmark and in Sweden, and this 
controversial issue is a moving target in both countries. The Swedish parliament advised against surrogacy in 2016 , based on a report compiled by Eva Wendel Rosenberg (SVT Nyheter 2016), and in opposition to recommendations from the Swedish National Council on Medical Ethics (The Local 2016): the debate rages on concerning whether or not to allow altruistic surrogacy there (Everingham 2017). The Swedish Green Party advocated for reinvestigating the ban at their May 2019 party convention, yet the culture remains in flux, as demonstrated by the societal debate and the unwillingness to change policy (Aftonbladet 2019).

Discrepancies in fertility legislation in Denmark and Sweden, both historical and current, force involuntarily childless citizens to cross borders fluidly in their search for the combination of laws and services that fit their individual needs. The Swedish state's responsibility is negated by the existence of the transnational Øresund region that enables easy movement to Denmark, and thus minimizes issues with reproductive tourism for Scandinavian citizens. Quoting a Swedish couple they interviewed during their research on ART in Denmark, Adrian and Kroløkke (2018) write that in their 'imagination, they are just going to a different town, which makes their negotiation of ethical, legal, and national boundaries appear unproblematic' (p. 12). The Bridge portrays this international reproductive tourism and calls attention to the ways Denmark and Sweden perpetuate privilege and disadvantage in reproductive medicine.

\section{THE BRIDGE-INVOLUNTARILY Childless Women Become Mothers}

Women's embodied vulnerability as involuntarily childless citizens of Denmark and Sweden in the early days of ART plays out in The Bridge in the characters of Danish Helle Anker and Swedish Anna-Maria Larsson, while the contemporary situation emerges in Swedish Åsa Holst. Their individual stories portray access to ART, CBRC, surrogacy and the efficacy of the responsive welfare state given ART legislation. Glimpses of their reproductive histories emerge as clues in the 10 episodes of season III. In episode 1, Helle is found dead and Anna-Maria has already died; their ART events precede the narrative time of the series and set the stage for Åsa's narrative. These two women presumably identified as cisgender heterosexuals needing donor sperm to become pregnant when they conceived, and different paths led them to the same donor sample. 
It is no surprise that Helle Anker, a pioneering founder of a fertility clinic, would take advantage of the clinic's services; living in a heteronormative marriage, the treatments could be kept secret with no visible societal consequences. Helle Anker was married to Willy in the 1980s, so her use of anonymous donor sperm was uncontroversial and the heterosexual couple's authority as parents to their son Morten (Asbjørn Krogh Nissen) was unquestioned, as Mohr and Koch argue such treatments were in Denmark. 'Positioning donor insemination as an intervention that subscribed to the traditional kinship model, rather than disturbing it, thus secured medical authority over its administration' (Mohr and Koch 2016, p. 91). As the first murder victim in episode 1, Helle's death leaves behind her grieving wife Natalie (Marall Nasiri) and two sons. Given that she was in a same-sex marriage in 2015 , her second son was presumably a donorconceived child, although the show never clarified the biological origins of the younger son. At the time Helle and Natalie conceived, single and partnered lesbian women would have had equal access to ART treatments and health care coverage in Denmark, theoretically making both of Helle's family constructions equally accepted. However, the TV serial narrative casts doubt on the level of acceptance in practice given the turmoil around Helle's family. Helle apparently told Morten his genetic origins, and he pursued and learned the identity of his donor. Helle appears not to have shared that information with her wife, who misinterprets Morten's reaction at Helle's death to 'tell his father' the news.

In contrast to Helle's unquestioned access to ART, Anna-Maria Larsson would have been denied ART treatments for infertility as a single woman living in the late 1980s in Sweden. Sweden's initial restrictive legislation prohibiting single women's access to ART passed a decade before similar legislation in Denmark. 'During this period (1986-1997) of legal regulatory void, [Danish] clinics were free to offer treatment to anyone, including lesbian and single women (later excluded from treatment by the fertilization law)' (Mohr and Koch 2016, p. 92). Anna-Maria circumvented restrictive Swedish law by traveling to Denmark in order to conceive with ART in an early example of CBRC in Øresund. The label 'reproductive tourism' may have been more palatable in that pre-bridge era, when travellers relied exclusively on ferries to carry cars and passengers internationally across the sound. Travel was not difficult, but not as simple as in the post-bridge era. Anna-Maria's marital status is never confirmed, but her son Emil remembers the fantasy-laden stories she told him about his father. Anna-Maria took her reproductive secrets with her 
to the grave, in spite of the regulated Swedish state system. ${ }^{12}$ Recalling that Swedish law required a known sperm donor, Anna-Maria's choice to pursue CBRC and a donor in Denmark plausibly excluded her and Emil from the IVF statistics in the Swedish system, a factor that may have thwarted the state's ability to address the vulnerabilities of mother and son appropriately. Only the mother's code-protected file at the fertility clinic existed as evidence to confirm these ART treatments and trace the donor identity, which became a hurdle for Saga and Henrik's investigation.

Unlike the fecundity of the 1980s ART histories of Helle and AnnaMaria, Åsa Holst is infertile and she counters her involuntarily childlessness in 2015 by procuring a donor egg and a surrogate womb. A Swedish citizen, Åsa is married to Danish entrepreneur Freddie Holst and the two reside in Denmark. Egg donation would have been legal in both countries when Åsa needed the state to support her health care needs, but surrogacy was not legal in Sweden. The couple's marital status and primary residence outside of Copenhagen eliminated the need for CBRC for the Holsts due to the fluidity of the Øresund region. Åsa apparently identifies as cisgender heterosexual who is married to a fertile Danish man who can provide sperm for the surrogate, thus ensuring the required biological link to one parent, for only traditional altruistic surrogacy was legal in Denmark for Danish citizens at the time. Åsa's embodied vulnerabilities centre around guilt and anxiety at her infertility, rather than the responsive state's inability to address her desire to be a mother; once again, the Danish state (and not the Swedish state) had the necessary institutions in place to conceive and bear the child, thereby successfully fulfilling the Holsts' reproductive dreams.

The visible consequences of surrogacy loom large in the narrative. Åsa performs her pregnancy in public by wearing a prosthetic belly, fearing that people will question her claim to the baby that will be their longawaited heir. Despite Mohr and Koch's insistence that Danish society was completely at ease with ART and non-traditional family forms by this time, Åsa's behaviour displays suspicion of public opinion in a society ill at ease with the purported insignificance of a child's genetic origins. It may also reinforce pressures to be a mother and conform to underlying ideals for women to reproduce. Åsa's confidence in her glowingly pregnant body at the gala opening of their art collection exists as a jarring contrast to her personal feelings of insecurity around the surrogacy arrangement, which is revealed in the marital conflict that erupts when the couple returns home and the belly comes off. Åsa harbours fears that 
Freddie will love the surrogate Jeanette more because she was 'woman enough' to bear him a son. Viewers learn Åsa was not planning to meet the surrogate, which speaks to her discomfort with the process, so things became more complicated for Åsa when Jeanette moves into their guesthouse in the final weeks of the pregnancy. The surrogate transforms from an abstract idea to a real person carrying their child, and the daily visual reminder of the other woman's pregnant, fertile body provokes Åsa and infers her physical shortcomings as an infertile woman.

Without a biological link between mother and child, Åsa doubts her ability to bond with her baby and worries that Freddie will always have a better relationship as father to their son because of their shared genetic connection. Åsa admits to Jeanette that she has pretended to be pregnant so that 'no one will doubt that it is my child' (The Bridge 2015, episode 7). Access, cost and laws regulating surrogacy are irrelevant to Åsa, but the inability to establish genuine parent-child bonds terrifies her. The discrepancy between Freddie and Åsa's views on surrogacy emerges in a night-time bedroom confrontation (The Bridge 2015, episode 7).

Freddie: But Åsa, she is pregnant with our son.

Asa: But it doesn't feel that way. It doesn't feel like mine.

Freddie: We wanted a baby, right? But we could not make one.

Asa: I cannot have a child. It is yours and hers. I have nothing to do with it. That's why I didn't want her living here, to see her. If the child had just arrived, then-but when I see you two together...

Freddie: Åsa, look at it this way. We rent her body for nine months. And then the child is yours. And then we will never see her again.

Unable to look at his face, Åsa stares at Freddie's back during this confession, and Freddie does not turn to look at her. The camera allows the audience full access to the faces, body language and emotions of both characters during the exchange. Freddie turns to her for his final line, which the camera observes from the hallway, and Åsa nods her silent agreement to his proposition. ${ }^{13}$ His reduction of the surrogate here to a 'rental womb' stands in sharp contrast to the care he demonstrates for Jeanette's personal welfare, hinting at the individual conflicts each parentto-be wrestles with internally, and the tensions and competing beliefs about surrogacy between husband and wife that may have historical roots in ART governance in Denmark. 
In sum, the Danish health care providers, and thus the welfare state, supported all three women to become mothers by providing resilience strategies to overcome their involuntarily childless states, regardless of their marital status and physical needs. Helle and Anna-Maria learned they were fertile and that their physical bodies were not the root of their embodied vulnerability; Åsa had unexplained infertility so she pursued an egg donor and surrogate. The Swedish state failed to support AnnaMaria's journey to single parenthood when she had not conformed to the traditional kinship model of heteronormative marriage and would not have supported Åsa's surrogacy option. The narrative makes no connection between Anna-Maria's death and her ART utilization, but Åsa suffers for her choices. Helle dies as a victim punished for embracing and enabling the reproductive technologies that made her and countless other involuntarily childless women like her into mothers.

\section{The BRIDGe-Surrogacy AND DONOR Gametes to COUNTER INFERTILITy}

Donors face a different set of challenges than people with fertility issues; The Bridge portrays one female and one male character to tease out these complexities, and how the state generates resilience for their vulnerability. Women's embodied vulnerability as egg donors and surrogate mothers are contested positions in Danish and Swedish society, as previously mentioned. No details are given of Jeanette's recruitment as a surrogate or her ART treatments, which makes it difficult to analyse how responsive the Danish state has been to her. The surrogacy narrative, as all the other ART treatments in the TV serial, exists exclusively in Denmark. Jeanette presumably identifies as a cisgender heterosexual in a cohabitating relationship; economic incentives appear to have motivated her choice to carry the Holsts' child.

The Bridge accentuates the worst fears of domestic surrogacy in Danish society - that it could physically or psychologically harm the surrogate and that it could become commercialized, and thereby a legal form of human trafficking. Jeanette's character has no last name, another sign of her status as a body for hire. Recall that traditional altruistic surrogacy is legal in Denmark, meaning the Holsts' child was presumably conceived with Jeanette's egg and Freddie's sperm by IUI or IVF. In the legal arrangement on paper, Jeanette will receive no compensation beyond her expenses. Off the record, Freddie compensates Jeanette handsomely, with 
a lump sum for her boyfriend Marc (Michael Slebsager) to keep his distance and the deed to a rural farmhouse Jeanette dreams of moving to after the birth, in addition to a pre-arranged sum of half million kroner after the birth (The Bridge 2015, episode 7). Although she infrequently entertains notions of keeping the baby, remembering the promised financial compensation at delivery helps Jeanette keep her eye on the prize. Jeanette rarely thinks of herself as 'mother' to the baby she carries yet, as she observes Åsa and Freddie's marital tensions escalate, she doubts that Åsa will love the baby because the child has half of her genes. In a call to Marc, Jeanette uncharacteristically calls the baby 'my child' and Marc refutes her claim to ownership. Freddie generally calculates the financial risk and investment with the surrogacy, much as in the aforementioned conversation with Åsa. When Freddie therefore calls her 'the best gift' because she will enable him to become a father, Jeanette coldly responds that this act is a 'business deal' without emotions (The Bridge 2015, episode 7).

The surrogacy arrangement ends, Jeanette lives, and so does baby Jan Fredrik. Freddie and Åsa visit Jeanette in the hospital with their son, but she refuses to see the baby or speak with Freddie at the final transaction. The Bridge hardly advocates for surrogacy, as it illustrates manipulation of state legislation, as Fenton (2013) argues, that amplifies citizens' privilege and disadvantage. The Holsts' extensive wealth signals that anything can be procured for a price, even in Denmark with its progressive regulations and a state responsive to fertility needs. ${ }^{14}$ Their wealth clearly sets them well above the average Danish couple, and thus their extortion of a woman from a lower socioeconomic class as egg donor and surrogate feels suspect. Given the trauma of the final episodes, Jeanette seems unlikely to repeat her altruistic act at any price.

Men's embodied vulnerability as sperm donors is uncontested in society, reminiscent of the commonness of the process Adrian and Kroløkke (2018) cite. The Danish state appears adept at addressing the vulnerabilities of male sperm donors during the donation process. Freddie serves both roles as donor and intended father; his attitude toward both roles could not be more dissimilar. Identifying as a cisgender heterosexual then and now, Freddie is as fertile in the 2010s as he was in the 1980s when he first donated sperm. The difference is that Freddie Holst now wants a biological son as an heir to his fortune, and he has gone to great lengths to facilitate the surrogacy. The unborn child is invaluable to him, and Freddie does everything in his power to love and navigate his wife Åsa's 
emotional behaviour and to keep their surrogate Jeanette safe. Arguably the most privileged character, Freddie reaps the benefits of the welfare state; he encounters complexities to become a parent, but the combined status of his citizenship and his financial resources ensure that he can fulfil his desire to be a parent.

Freddie has no memory of having donated sperm in his past, and is equally clueless that he was the anonymous sperm donor that both Helle and Anna-Maria chose at the fertility clinic in the 1980s. This intriguing twist juxtaposes the value of his donated sperm and the biological link to his genetic offspring; he chooses when and which children to claim. Freddie suffers consequences as an early promoter of ART, not for the challenges he faced to give gametes, but for the nonchalance associated with his individual decision. Perpetrator Emil is not a mirror or spokesperson for any one Øresund society, but his perspective does question the attitudes to donated gametes and the donor-conceived children they produce. Freddie manipulates the Danish regulations for surrogacy arrangements, but that is a secondary issue for the perpetrator. Like Helle, Freddie was to become a victim punished for aiding others' intentional family formations.

\section{THE BRIDGE-DONOR-CONCEIVED Children AND Resilience}

Departing from the concerns of the involuntarily childless and the fertile donors, this vulnerability analysis of The Bridge turns, in closing, to the needs of the donor-conceived children. As previously stated, there are three featured characters-all males-born to parents requiring some form of reproductive medicine to bear children: Morten, Emil and Jan Fredrik. While I read the primary focus of the infertility subplot to rest with the parents' generation, the revelation that Emil is the killer reinforces the idea that the donor-conceived children also require attention and equitable treatment. Both wrestling with mental health issues, Morten and Emil's unfulfilled needs as adults contribute to their instability and outreach to donor Freddie as a 'father' figure. These identity characteristics appear to stigmatize these children, and in The Bridge they are portrayed as proxies for systematic inequities of care. The narrative hints that life for donor-conceived children was riskier than for those who could trace their biological roots, secure in identity and genetic lineage. 
Morten Anker is an Afghanistan war veteran suffering from PTSD. Portrayed as a substance-dependent recluse, his mental struggles back in the relative safety of Denmark stem from war trauma and an unexplained military punishment linked to sexual deviancy while on tour. From Helle's fertility clinic code, Morten has learned the donor's identity, discovered his genetic half-siblings and contacted them to reveal the truth of their origins. He elevates Freddie to a father figure in his mind, and visits the Holsts' house in a failed attempt to meet him. Morten reportedly references 'his brother' in his dying breath, which confounds the detectives until they confirm the shared sperm donor.

Emil Larsson, orphaned at the age of five when his mother died, grew up feeling powerless and manipulated by the system. A foster child that fell through the cracks of the responsive Swedish welfare state, Emil was allegedly abused in the home of his foster parents Filip and Inger Jonsson, confirmed as a victim of sexual abuse by a teacher at school and misunderstood as a ward of the state (The Bridge 2015, episode 8). As an adult, Emil becomes the puppeteer controlling the elaborate murder plan and composing the post-murder scenes. Emil calls Freddie Holst and Helle Anker his 'creators' and his stated motive for revenge against all his victims is not to punish but to 'right a wrong' done to him, to 'create beauty', and to bring 'justice' to a tainted past (The Bridge 2015, episode 10). Like Morten, he values biological connection to the extent that 'donor' equates to 'father' in his mind.

Jan Fredrik lives, but there is no sign during the final surrogacy transaction that Åsa and Freddie will share his origin story, or allow Jeanette to be part of their lives. If, indeed, Danish and Swedish societies are becoming increasingly comfortable with the medical, legal and social aspects of ART for involuntarily childless adults, then The Bridge contests that the conditions for their donor-conceived children are as equitable. Societal change and state attention to these citizens have not kept pace, leaving protective welfare state institutions unsafe in the world of the TV serial. This could be a trait of the Scandinavian crime fiction genre, demonstrating the general demise of the welfare state following the tradition in Swedish crime fiction since Sjöwall and Wahlöö, or it could be a projection that donor-conceived children's vulnerabilities remain underserved. Secrecy around ART and stigmatization of reproductive medicine does not build resilience for citizens, and one could argue that The Bridge subplot leaves donor-conceived children in jeopardy of uncertain futures. 


\section{CONCLUSION}

Fineman (2013) states that all humans are vulnerable and the responsive state helps to build resilience for its citizens; while the Scandinavian welfare states agree in principle, infertility and reproductive medicine show the treatment is unequal. Fenton (2013) argues that the state, vested in the reproductive futures of its people, addresses inequities by providing necessary fertility treatments to those wanting to be parents. Season III of The Bridge shows reproductive vulnerability in its cast of characters, and portrays the Øresund welfare states today as largely responsive to those needs. The Danish state, then and now, has been quite responsive in the field of reproductive medicine, while the Swedish state has had room for improvement to match the resiliency to infertility offered across the sound. Given the growing trend of fertility postponement across Europe and in many other countries, policies ensuring equity of access to ART will help individuals address infertility and aid nations trying to increase fertility rates. Even today, some policy differences in access to and regulation of infertility provisions in health care services and insurance policies threaten vulnerable citizens' fundamental rights in the Øresund region and propagate $\mathrm{CBRC}$, the consequences of which are mitigated by the imagined space of the transnational region. The infertility subplot of The Bridge portrays how state health care legislation and systems-and, ergo, states themselves-perpetuate privilege and disadvantage in ART, further exacerbating the vulnerabilities of involuntarily childless individuals, fertile egg and sperm donors and surrogates, and donor-conceived children. While many point to Denmark and Sweden as exemplary models for current ART policy and practice, historical inequities surrounding the stigmatization of infertility exist and persist in some iterations today. Season III of The Bridge continues the crime fiction tradition of finding holes in the safety nets constructed by responsive Scandinavian welfare states to aid their vulnerable citizens.

\section{Notes}

1. Henrik Georgsson and Rumle Hammerich directed season III.

2. Acclimatizing to a new partner at the start of the third season, Saga begins a relationship with Henrik at the office and later at home. Saga's estranged parents make contact with her, her dearest friend and remaining family members die, and her colleagues question her credibility following an investigation by her new interim boss. Henrik secretly abuses substances to 
cope with the loss of his missing wife and daughters, and he hallucinates their presence in the family home, which he has kept unchanged since their departure six years ago. Saga and Henrik grow increasingly reliant on each other as the season evolves, with some unexpected twists. Seasons III and IV raise the stakes on the parenting narrative for Saga and Henrik, infusing their lives with intriguing parallel problems that fall outside the scope of this article.

3. Mimicking works of art, his performative display ART-related installations' of the victims could be read as a poor pun on the medical reproductive subtext.

4. This includes in vitro fertilization (IVF), intracytoplasmic sperm injection (ICSI), frozen embryo replacement (FER), preimplantation genetic diagnosis and screening (PGD), egg donation (ED), and frozen oocyte replacement (FOR). Intrauterine insemination (IUI) is another ART option.

5. Mohr and Koch (2016) specify that the provision of three cycles of 'IVF treatments are covered by the tax-financed Danish public health service for all involuntarily childless women residing in Denmark up to the age of 40' but prohibits ART treatments for women over 45 (p. 89).

6. The state's interest in its citizens' fertility gained media attention in Norway in January 2019 when Prime Minister Erna Solberg addressed the nation's reproductive futures. In her New Year's speech, Prime Minister Solberg reminded Norwegians that every woman needs to have more than two children in order to maintain the national population and carry the increasingly heavy welfare state into the future. By Fineman's metrics, the speech may be read as a conscientious leader monitoring outcomes and shortfalls of the system. Solberg's speech hints at the challenges of infertility without mentioning ART. Veiling ARTs as 'conceived with help from the health care system' was, by my reading, a missed opportunity to recognize the vital role of reproductive medicine as a resource for the involuntarily childless (www.dagbladet.no/video/YUHktnmOJgE). Solberg's call to have more babies is also an intriguing epilogue to a piece of failed ART legislation from May 2018 to bring gender equity to egg donation. Norwegian laws are generally more conservative than their Nordic neighbours; there is not equity of access for all, so those involuntarily childless with sufficient resources must travel abroad to seek CBRC.

7. Cohen et al. (2005) site the years as Norway-1987 (revised 1994); Sweden-1988; Iceland-1996; Denmark-1997; and Finland-no laws in 2005, when the article was published, but 2006 appears to be the first law on ART in Finland (www.finlex.fi/en/laki/kaannokset/2006/ en20061237.pdf). 
8. Referencing Lone Schmidt's (2006) research on infertile Danish couples, Mohr and Koch (2016) state 'IVF makes infertility and childlessness legitimate subject positions in a society which perceives having children as an important rite of passage into adulthood. The central role of IVF is thus to give people hope that they too may join a collective invested in the common good of having children' (p. 93).

9. In Denmark, sperm donors in 2019 received between US\$40-75 per donation, primarily for their 'time and inconvenience' (Bajekal 2019, pp. 5-6).

10. Egg donation remains illegal in Norway and became legal in Sweden in 2003. Embryo donation and double donation of egg and sperm became legal in Sweden in January 2019 (www.kunskapsguiden.se/barn-ochunga/Teman/Samtal-med-barn-om-deras-genetiska-ursprung/Sidor/

Fakta-och-regelverk.aspx) Denmark legalized double donation in 2018 (Folketinget 2017, www.ft.dk/samling/20171/lovforslag/160/index. htm).

11. Traditional surrogacy means the impregnated woman is the genetic donor of the egg that has been fertilized by sperm procured from a donor or a donating father. Gestational surrogacy involves double donation requiring both gametes; the fertilized embryo, conceived by donor egg and donor sperm with no genetic connection to the surrogate mother, is transferred to the body of the surrogate, often called the 'gestational carrier'. When the pregnant woman receives no compensation for her labour beyond expenses incurred during pregnancy, the surrogacy is labelled altruistic or non-commercial. In commercial surrogacy, the pregnant woman receives compensation for her expenses plus an additional fee for giving birth.

12. Cohen et al. (2005) admire the ability of the Swedish state to conduct longitudinal studies of donor children and their medical risks due to the data gathered on citizens in national health registers and ART treatments (p. 457).

13. Mohr and Koch (2016) reported that Danish law previously banned surrogacy for 'egg donors are not recognized as mothers, while surrogates, on the other hand, are considered to be mothers in so far as they have given birth, no matter what the genetic connection between them and the newborn' (p. 90).

14. Some Danes and many Swedes rely on CBRC in countries with more permissive surrogacy laws such as Russia, India and the United States. 


\section{REFERENCES}

Adrian, S. W., \& Kroløkke, C. (2018). Passport to parenthood: Reproductive pathways in and out of Denmark. NORA-Journal of Feminist and Gender Research, 26(2), 112-128.

Aftonbladet. (2019, April 29). MP måste säga ja til värdmödraskap. https:// www.aftonbladet.se/debatt/a/zGlBd4/mp-maste-saga-ja-till-vardmodraskap. Accessed 6 June 2019.

Bajekal, N. (2019, January 3). Why so many women travel to Denmark for fertility treatments. Time. http://time.com/5491636/denmark-ivf-storkklinikfertility/. Accessed 29 May 2019.

Chawla, A. (2018, July 10). Swedish-Danish crime series The Bridge remains inimitable (despite multiple remakes). Scroll.in. https://scroll.in/reel/ 885882 /swedish-danish-crime-series-the-bridge-remains-inimitable-despitemultiple-remakes. Accessed 29 May 2019.

Chow, P.-S. (2016). Traversing the Øresund: The transnational urban region in Bron/Broen. In J. Andersson \& L. Webb (Eds.), Global Cinematic Cities: New Landscapes of Film and Media (pp. 36-58). New York: Columbia University Press.

Cohen, J., Trounson, A., Dawson, K., Jones, H., Hazekamp, J., Nygren, K.-G., et al. (2005). The early days of IVF outside the UK. Human Reproduction Update, 11(5), 439-460.

Dagbladet. (2019, January 1). Solbergs nyttårstale: Norge trenger flere barn. https://www.dagbladet.no/video/YUHktnmOJgE. Accessed 6 June 2019.

Danish Surrogacy Law. OVU Fertility Network. (2019). https://ovu.com/ blog/surrogacy-law-andorra-austria-belgium-bosnia-and-herzegovina-croatiacyprus-denmark-1144. Accessed 6 June 2019.

Everingham, S. (2017, September 4). Scandinavian attitudes to surrogacyPublic policy should catch up. BioNews. https://www.bionews.org.uk/page_ 96161. Accessed 6 June 2019.

Fenton, R. A. (2013). Assisted reproductive technology provision and the vulnerability thesis: From the UK to the global market. In M. A. Fineman \& A. Grear (Eds.), Vulnerability: Reflections on a New Ethical Foundation for Law \& Politics (pp. 125-146). Ashgate: Routledge.

Fineman, M. A. (2013). Equality, autonomy, and the vulnerable subject in law and politics. In M. A. Fineman \& A. Grear (Eds.), Vulnerability: Reflections on a New Ethical Foundation for Law \& Politics (pp. 13-27). Ashgate: Routledge.

Finnish Act on of Parliament on Assisted Fertility Treatments (1237/2006). https://www.finlex.fi/en/laki/kaannokset/2006/en20061237.pdf. Accessed 6 June 2019.

Folketinget. (2017, December). L 60 Forslag til lov om xndring af lov om assisteret reproduction i forbindelse med behandling, diagnostic og forskning 
m.v. og sundhedsloven. https://www.ft.dk/samling/20171/lovforslag/160/ index.htm.

Georgsson, H., \& Hammerich, R. (Directors). (2015). Bron/Broen [Television series]. Stockholm and Copenhagen: SVT and DR.

The Local. (2016, February 24). Swedes told they shouldn't use surrogate mothers. https://www.thelocal.se/20160224/women-in-sweden-told-theyshouldnt-become-surrogate-mums. Accessed 20 June 2019.

Mohr, S., \& Koch, L. (2016). Transforming social contracts: The social and cultural history of IVF in Denmark. Reproductive BioMedicine and Society, 2, $88-96$.

Petroff, A. (2015, October 21). Sperm specialist: How one clinic is satisfying global demand. CNN Business. https://money.cnn.com/2015/10/21/ smallbusiness/sperm-bank-shortage-cryos-denmark/index.html. Accessed 6 June 2019.

Präg, P., \& Mills, M. C. (2017). Assisted reproductive technology in Europe: Usage and regulation in the context of cross-border reproductive care. In M. Kreyenfeld \& D. Konietzka (Eds.), Childlessness in Europe: Contexts, Causes, and Consequences (pp. 289-309). Cham: Springer Nature.

Schmidt, L. (2006). Infertility and assisted reproduction in Denmark: Epidemiology and psychosocial consequences. Danish Medical Bulletin, 53(4), 390-417. SVT Nyheter. (2016, February 24). Utredare säger nej till surrogatmödraskap. https://www.svt.se/nyheter/inrikes/svt-avslojar-utredare-sager-nej-tillsurrogatmoderskap. Accessed 20 June 2019.

Open Access This chapter is licensed under the terms of the Creative Commons Attribution 4.0 International License (http://creativecommons.org/licenses/ by $/ 4.0 /)$, which permits use, sharing, adaptation, distribution and reproduction in any medium or format, as long as you give appropriate credit to the original author(s) and the source, provide a link to the Creative Commons license and indicate if changes were made.

The images or other third party material in this chapter are included in the chapter's Creative Commons license, unless indicated otherwise in a credit line to the material. If material is not included in the chapter's Creative Commons license and your intended use is not permitted by statutory regulation or exceeds the permitted use, you will need to obtain permission directly from the copyright holder.

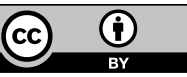




\title{
Uses of Vulnerability: Two Eras of Social Commitment in Swedish TV Drama?
}

\author{
Per Vesterlund
}

Nordic noir begins in misery. Dark moods and dramatic tensions are no unexpected points of departure for films made in criminal genres, but the combination of gloominess with acts of excessive violence in contemporary Scandinavian crime fiction is generally regarded as characteristic of the genre (Bergman 2014; Hansen and Waade 2017; Peacock 2014). Several examples can illustrate this tendency. Each one of the four seasons of the Swedish/Danish series Bron/Broen (The Bridge 2011-2018) not only starts with extraordinary cases of murder, they also all begin in despair. With the grey fog of Öresund and the black Nordic winter night as key components of the setting, the visual design of the series matches the darkness of the stories told. Similar aesthetic and narrative strategies can be found in other films and series of the genre. Swedish Arne Dabl: En midsommarnattsdröm (2011-2015), Danish Forbrydelsen (The Killing 2007-2012) or the adaptations of Stieg Larssons Millenium triology (2009) are all well-known examples.

P. Vesterlund $(\triangle)$

Department of Humanities, University of Gävle, Gävle, Sweden

e-mail: per.vesterlund@hig.se

(C) The Author(s) 2020

A. M. Dancus et al. (eds.),

Vulnerability in Scandinavian Art and Culture, https://doi.org/10.1007/978-3-030-37382-5_7 
The reception of The Bridge has been examined by TV scholar Annette Hill (2018) who, in a study based on interviews with viewers, concludes that the series engage audiences emotionally. The main character, police officer Saga Norén (Sofia Helin), seems to be the focus of the emotional engagement. Norén, a kind of an anti-hero with a non-disclosed diagnosis somewhere on the Asperger's spectrum, is repeatedly put in situations where she is exposed to either social or physical threats (Hill 2018, p. 280). This exposure of the protagonist is regarded as a main facet of the engagement in what one of the informants in Hill's study calls 'a story of vulnerability' (p. 282).

The Swedish TV film Berndt \& Anita from 1969 ends in misery, as well. Even if the film starts as an everyday love story-even though realistic and free of romantic illusions - the young suburban housewife Anita ends up isolated with a small child in the brand new apartment with her husband Berndt. In the final scene, the camera catches her on the way to the balcony while the baby is crying loudly and incessantly behind the closed door to the bedroom. Through the eyes of Anita, we see several images of identical five-floor dwellings. A non-diegetic male voice-over asks in an official neutral tone, like that of a journalist, 'Is it Berndt's fault'? Anita answers 'I don't know'. The voice-over returns: 'Is it your fault'? Again, Anita replies that she doesn't know, while walking into the bedroom where the baby is still crying. She bends down over the baby's bed. The last shot of the film is a long close-up of Anita's neck, while the crying from the baby suddenly stops. A common interpretation by Swedish journalists of this open ending was that it was supposed to indicate that the character Anita intentionally suffocated her baby (Sjögren 1969).

Berndt \& Anita is, in many ways, an emblematic case of Swedish TV drama of its time. It is an early work of writer Bengt Bratt who, for a period lasting for more than four decades, wrote significant TV plays and series such as Friställd [Laid Off] (1969), Hem till byn [Home to the Village] (1971-2006) and Gyllene àr [Golden Years] (1975). Further, Berndt o Anita is a social drama made in a semi-documentary style, relying on aesthetic values of authenticity. As with many other Swedish TV productions of its time, the film was heavily debated in the press after it premiered on 17 December 1969, causing intense discussions on the situation of housewives and young mothers (Vinterhed 1969).

Social commitment and an aesthetics of realism have long since been facets commonly associated with Swedish TV fiction. 'Scandi crime' or 
'Nordic noir' are the key examples, with the genre often described as mirroring a welfare state in decay (Brodén 2008; Hansen and Waade 2017). If the Scandinavian welfare state is in crisis in the twenty-first century, the example of Berndt \& Anita from 1969 could be regarded as surprising, since it was produced at a time when the Swedish model supposedly was at its peak. The fact that there were numerous other TV productions with similar trends to that of Berndt of Anita produced around 1970 makes the case even more intriguing.

While serial murders or organized crime are recurrent symptoms of social despair in the televisual fiction of the 2010s, the crime in Berndt of Anita from 1969 is of another kind. The unplanned desperate action of a tired lonely woman is, by definition, an unpremeditated crime, and stands in sharp contrast to the highly conceived criminal actions taking place in series such as The Bridge. The unanswered questions of guilt $t$ the end of Bengt Bratt's film provide us with a possible vantage point to a study of changing patterns in the representation of social problems in Swedish TV drama. My intention is not to give an answer to the question but, rather, to examine the explicit or implicit answers given in this film, as well as in other productions. The explicit manner in which the question of guilt is posed at the end of Berndt o Anita is rare, but the willingness to use narrative to present societal problems is a common trait in Swedish TV drama.

The welfare state may have been a societal project based on social safety, but films such as Berndt and Anita depict life in Sweden of the late 1960s as an existence characterized by displeasure and despair. If vulnerability - in this case, the powerless position of a married woman such as Anita; in other cases, the uncertain positions of factory workers or small farmers-is to be seen as explicit in these depictions of the shortcomings of central functions in the welfare state, there is also an implicit thematic cluster of more subtle signs of insecurity than material, economic or legal ones. These signs can be identified visually, when we see a long close-up of Anita's hand drifting aimless on the surface of the concrete wall outside her balcony, as though to emphasize her helplessness. It can also be identified in narrative traits such as the recurrent interrogating non-diegetic voice-over. Berndt and Anita is one of many stories from its time that seems to pose vulnerability as a collective state of being, where Anita's tragedy is the tragedy of a society, as much as the story of an exposed individual. The welfare state and its inhabitants are thus both exponents of vulnerability. Individuals are represented as vulnerable beings in a vulnerable society. 


\section{Past ANd Present}

There are various intertwined historical perspectives behind the aims of this article. One of them is found on a textual level and concerns the audiovisual representation of societal needs in Sweden in the heyday of the welfare state. Another perspective relates to the institutional contexts where these representations were produced, perceived and talked about. The Swedish welfare state may have reached its peak during the 1960s and 1970s, but TV drama was yet in its beginnings and the discursive activity surrounding the productions in public life can be assumed as formative.

This article is written within an ongoing research project on Swedish TV drama during the period 1967-1975. Even if the main focus is consequently directed towards this period, there are also reasons to widen the historical perspectives, since the representation of welfare matters in Swedish audiovisual fiction is interesting from other historical strands than the actual projection of social themes during the glory days of folkhemmet, a concept introduced by the Social Democratic party in the late 1920s that has for decades been synonymous with the Swedish welfare project. The very memory of these years constitutes one such perspective. Since the early 2000s, there have been numerous Swedish films and TV dramas set in the years around 1970. ${ }^{1}$ This audiovisual memory-making consists of nostalgic as well as dystopic strategies in the picturing of the past. The lost welfare state is sometimes portrayed as an innocent idyll, but is at other times also characterized by paranoia, despair, or sheer boredom. This intense wave of representations of the near Swedish past during recent decades is paralleled by an even more intense wave of representations of contemporary Swedish society, often connecting it to popular genres such as crime, or fantasy. In particular, the crime genre in Sweden (and Scandinavia) of the 2000s has generally been presumed to mirror a welfare state in decay (Hansen and Waade 2017 , pp. 13, 82, 284). Given this widespread notion of contemporary Nordic noir or Scandicrime as a genre of social commitment, a comparison with the tradition of social commitment in Swedish TV drama seems relevant. The televisual critique of the Swedish welfare state is, however, just as apparent in documentary as it is in fiction. Factual TV genres have, during recent decades, been a main national venue for public critical investigations of social institutions, abuse of power, or other societal questions. Headlines such as Uppdrag granskning [Mission: Investigate] or Dokument inifran [Domestic documents] hide series of more or less 
prestigious TV journalism, documentaries and debates on subjects such as schools, health care, police work or social welfare.

Thus, with the assumption of the 1960s and 1970s as the golden age of the Swedish welfare state in mind, this chapter compares two eras of Swedish TV from the perspective of vulnerability. On the one hand, I will give a few examples from various genres in the 2000s and 2010s (crime, drama, documentary) and, on the other, from social drama from the period 1967-1975.

\section{The Insufficient Welfare}

'Despite the intense reform work undertaken during recent years, poverty and social needs are found in the midst of the welfare state. We do not know enough about these problems' (Persson 1967, p. 7, my translation). In the preface of the book Den ofürdiga välfärden [The Insufficient Welfare] (Inghe and Inghe 1967), Yngve Persson, Chair of the Board of Social Information (Rådet för social information) in Sweden underlined the need for knowledge of the social problems in the otherwise successful Swedish welfare system. The book contained a study made by two sociologists-Gunnar Inghe and Maj-Britt Inghe-who, chapter by chapter, discussed different areas of contemporary Swedish society. Health care, social assistance, general health insurance, access to comfortable dwellings and the regulation of working life were all important components in the general policy of welfare. Gunnar and Maj-Britt Inghe revealed severe shortcomings in all these areas. They focused particularly on the outcasts of the welfare state, as well as on how class structures remained largely unchanged at a time when social and economic egalitarian ambitions had dominated public political discourse in Swedish society for at least a decade.

Den ofürdiga välfürden was heavily debated during the spring of 1967. 2 The book raised questions on how well the welfare systems really worked, and why there has been no awareness the problems inherent in welfare institutions. There were also doubts raised as to whether these problems were really as hidden and undetected as many considered them to be. The book quickly became a bestseller and its arguments permeated public opinion. ${ }^{3}$

With the general awareness of contemporary changes in the Scandinavian welfare systems of today, it is easy to neglect the constancy with which critical and unsympathetic views of the workings of the welfare state 
paralleled the prosperous development of social reforms. Not surprisingly, such critiques were often of conservative or liberal origin. In such cases, arguments were formulated against equality reforms that appeared to be too far-reaching, or against systems of benefits and subsidies that supposedly made the workers and the Swedish industry less efficient (Dagens Nyheter 1965, 16 December; Svenska Dagbladet 1966, 24 May). But critiques of the welfare state were also articulated from the Left; focusing on the insufficiency of benefits and subsidies, misuse of power in public administration, or too generous compromises with capitalistic interests. Den ofärdiga välfärden is but one example of the latter. It was also an example of how paperback books came to be an important arena for intense Swedish public debate on social matters during the 1960s and 1970s (Hyvönen 2015). But debates on dysfunctions in the welfare state were spread across all existing forms of media. With the heightened status of the profession of journalism, consolidated when journalism was included in Swedish higher education in 1967, the importance of news genres in printed press, radio and TV as means of social critique increased (Gardeström 2016). The investigating reporter came to be a hero in the realm of critical societal commentary, as now was also the documentary filmmaker. The factuality of what film theorist Bill Nichols (1991) has called 'the discourses of sobriety' went hand-in-hand with social commitment and a rising awareness of the subjectivity that was implied in the political cause with which the filmmaker interfered in the world.

Correspondingly, such dark pictures of the welfare state were also apparent in different genres of literature and in fiction over a wide range of media platforms. In Swedish poetry, there was already long-established opposition to the reign of rational reason in the welfare state. Poets such as Gunnar Ekelöf, or the writers engaged in the periodical Metarmofos in the 1950s, are good examples (Tenngart 2010). Critical attitudes to the rationality of Swedish society-or ongoing poverty and equality-are found in numerous Swedish novels from the 1940s and onwards (Nilsson 2003; Ingvarsson 2003; Liljestrand 2009). ${ }^{4}$ In film fiction, the popular genre of delinquent youth revealed and reflected on-or exploited-social problems, as did social melodramas on topics such as abortion, divorce, or prostitution (Bengtsson 1998; Björklund 2013). These trends were also apparent with acclaimed auteurs such as the Left-oriented Erik 'Hampe' Faustman, or even Ingmar Bergman (Vesterlund 1999).

In this chapter, I investigate how such critical strands on the welfare state also came to be-and have further been-visualized in Swedish 
televisual fiction. In Swedish television, however, until the late 1960s, the drama department had mainly been focusing on classics or, to some extent, acclaimed contemporary international modernism (Dyfverman 2004). This was an aesthetic strategy that would change drastically from 1967 onwards. Two different historical contexts are highlighted through a number of cases of films and serial drama from Swedish television. The first context is that of the late 1960s and the early 1970s. Following immediately after the release of the book by Inghe and Inghe (1967), this is a period during which the production of Swedish TV drama went through radical change. The socially committed TV theatre played a central part in this aesthetic and institutional makeover of Swedish TV fiction. The second context is contemporary, where genres such as crime fiction, documentary and historical drama exemplify how the welfare state still can serve as both a thematic motif and as a frame of interpretation, two qualities that do not always coincide.

\section{A New Strategy-a Drama of Vulnerability}

With overt influences from recent developments of semi-documentary narration in international-in the main, European-TV drama, Swedish public service TV (Sveriges Radio) radically changed the drama production policies in the late 1960s. In August 1967, the head of the drama department at Sveriges Radio, Henrik Dyfverman, officially declared the direction of the new policy: the repertoire of the forthcoming 1967/1968 season would be 'considerably Swedish' and 'oriented towards society' (Holm 1967). Several of the twenty new plays written for Swedish TV were, according to Dyfverman, made with the aim of causing widespread public debate. Topics such as problems in schools, the rapid depopulation of the countryside, or the misuse of power from the national security police were all examples of problem areas expected to raise serious discussion.

This was a common trend at the time in several European countries; for example, in Finland (Koivunen 2014). The ambition was to produce TV fiction relating to social commitment in the wake of the contemporary wave of realistic and radical TV drama. The main inspiration was British, with the BBC institution The Wednesday Play (1964-1970) and directors such as Ken Loach as major influences. The strategy was, on the one hand, explicitly introduced as an ambition to affect national public opinion and increase awareness of social matters. On the other hand, it 
is not far-fetched to propose that the strategy also served to gain prestige for the drama department, as a way to demonstrate an awareness of contemporary aesthetical and political tendencies in filmmaking for TV.

Where British examples, such as the pivotal film Cathy Come Home (1966), often dealt with poverty, instead, Swedish social drama focused on how the efficiency and bureaucracy of the rapidly changing welfare state - and of the capitalist society - led to alienation and despair. Depictions of dysfunctions related to societal institutions and legislations such as schools, hospitals, agricultural politics and abortion dominated, whereas representations of sheer material poverty were rare. A preliminary observation is that the problems of the Swedish welfare state in these films and series were considered as being primarily irrevelant, caused by conditions in the capitalistic and technocratic system held up by the welfare politics. In the films directed by the prolific filmmaker Ken Loach, a key figure in the British wave of social TV drama, there was a recurrent focus on the working class (Cooke 2003). In Swedish social drama, the settings were just as often portraying a middle-class environment. The protagonists could just as well be artists, teachers, psychologists, or architects as sailors, farmers, or industrial workers. Furthermore, the material conditions (or life style) in the different social groups seem to have differed surprisingly little, at least according to the iconography and mise-en-scène of the TV films.

This chapter gives examples of how vulnerability was constructed and depicted in the visual and narrative representations of social problems in a welfare state such as that of Sweden, where the social standard seems to have be fairly equal, at least compared to the conditions in contemporary British society from where aesthetic and thematic inspiration came. Another aim is to investigate how TV drama was conceptualized at a time when the boundaries between the (more or less) institutionalized narrative modes of theatre and film were as yet unclear in the still new medium of television. The Swedish example of socially committed drama is an isolated national case, but so are most contemporary examples during this period when national public service broadcasting dominated European television. What makes the Swedish example interesting is the frequency at which the films were produced and broadcast. A single TV channel had an average programming time of five or six hours per day, so one or two domestically produced theatre productions each week comprised a vast part of Swedish TV content (Schyller 1996; Edin 2000). Even more striking is the impact of the radical TV theatre on the media. Particularly 
after the introduction of a second channel (TV2) in December 1969, domestic TV drama received considerable attention in the press. Almost each new serial or film generated intense debate. Primarily, it was subject matter - the societal institution criticized in the drama in question-that was discussed, but sometimes aesthetic questions also provided the focus of attention (Vesterlund 1999). Debates were not only spontaneous, but also arranged by the media. A typical set-up was that, having been aired, a TV play was followed by a studio debate, often screened live, in which experts and concerned citizens participated. In the daily press, this was usually followed by articles from experts and opinions from the man in the street. Sometimes journalists organized panels of farmers, nurses, teachers, pupils or athletes-whichever group was affected by the social problem with which the film or series in question had dealt-to discuss their opinions: these panels were supposed to consider how well the fiction had presented their reality.

\section{Pictures of Health Care in the Welfare State}

There are many possible vantage points from which to analyse these programmes. An examination of the interplay between the vulnerability of institutions/society and the vulnerability of individuals/citizens is one approach, actualized by the focus on dysfunctional institutions and misuse of power. Numerous other thematic angles are possible. The representation of place and space is one such motif (Hedling et al. 2010); another is the body, which is a recurrent site for the visualizations of vulnerability. A regular motif in Swedish TV fiction from the late 1960s and onwards is the representation of illness and health care.

In Body Trauma TV: The New Hospital Drama, Jason Jacobs (2003) describes three developmental stages in the televisual hospital drama: the paternal, the era of conflict, and the apocalyptic. Jacobs explains the three stages as successive ways to approach questions on health care and medical science, but also (and perhaps as much) to approach questions on life and death, and also to deal with a societal context. Where the paternal pattern contains the traditional serials with the doctor as a (more or less) unquestioned hero, the subsequent pattern in the era of conflict-beginning in the late 1970s-describes different ways to question paternal authorities (Jacobs' example is the American war comedy M.A.S.H., 1972-1983) to reach more modern, equal, or even efficient medical care. In the apocalyptic stage-established in the very late twentieth century-the modern 
discourse is no longer a given value. Organizational as well as scientific matters are put under question. Doctors and other members of the professional collective at hospitals, and at other institutions connected to health care, are portrayed as haunted with stress or anxiety. Health care as well as medical science is thus contextualized, and the questioning stance is related to conditions in the surrounding society.

Before the premiere of the mini-series Jourhavande [On Duty] on 17 March, 1974, the national morning paper Dagens Nybeter (1974, 18 March) wrote that the TV drama (of which there were three episodes) would focus on many current problems in hospitals such as euthanasia, alternative medical treatment, or conflicts between professionals. On the day after the first episode was broadcast, the TV critic in the same paper, Rune Johansson (1974), was struck by a drama that illustrated the bureaucratization and rationalizations that now were turning Swedish health care into mistreatment. The writer of the serial-Gustav Sandgren (1926-2016) —was no part of the Left-wing movement that has been seen as the dominant force in the social problem oriented TV drama of the 1970s. He was a journalist and writer of prose fiction (often with historical motifs) frequently touching on religious or existential themes. The director, though-Jackie Söderman-was more involved in the Leftist discourses of the times through numerous productions from the Gothenburg TV theatre, where a great deal of the TV fiction for TV2 was made.

Jourhavande was a bleak and gloomy drama where numerous characters acted out problems of a personal and structural nature. For example, there were doctors with drinking problems brought about by the high pressure and demands of the economic systems that threatened the quality of health care. The serial described a dysfunctional national health care where patients were subject to inhuman conditions, but also a working environment where hierarchical structures and a lack of ethical discussion lead to impoverishment at a psychological level. As a nurse in the second episode comments, referring to an unpopular psychiatrist, when talking to a patient: 'It might not be her fault, it might rather be the whole system here' (my translation). This concept of 'the system' is of interest since it is an established popular Leftist (structural/paranoic) cliché in the public life of the Swedish 1970s. This connects the series to the introductory case Berndt \& Anita, where the question of guilt-articulated by the non-diegetic voice-over-is implicitly understood as an impersonal instance. The protagonists have no real responsibility for the tragedy at hand. No answer is given, but it is implied that the sequence of events is 
caused by power structures. Whether these powers are to be understood as western capitalism or the technocratic modern welfare state is not clear, but to posit the mutual workings of these two forces as an explanation of contemporary social problems was a common analysis of the time.

The theme of euthanasia is represented through the story of middleaged male patient Leif, suffering from the late stages of polio, who is in a respirator and unable to move or communicate. The paralyzed body of the polio patient became a departure point for a discussion of the value of a life that did not simply reflect the theme of the series, but also led to a major debate in the newspapers on euthanasia, as well as on the quality of medical treatments of severely neurologically damaged patients. Professionals were asked if Jourhavande really provided an accurate picture of the state of Swedish hospitals. In the closing minute of the third episode of Jourbavande, someone-we just see a hand-disconnects the respirator cable, making both a striking end to the thematic cluster of the question of life and death, and providing a cliffhanger for the second season of the series. The cliffhanger received the greatest attention in the tabloids, where the question of who pulled out the cable made headline news. The media coverage of Jourhavande witnesses the impact of a serial such as this in the Swedish mid-1970s, but it also contributes to the theme of societal guilt. The headline 'Who Killed Leif in TV?' in the tabloid Expressen (1974, 4 April) is not only a commentary on an unresolved narrative; it also implicitly refers to the wider discussion on matters of life and death in Swedish health care.

Almost without exception, other examples of series dealing with medical matters during these years highlighted the problems in Swedish health care. The most famous example is Babels hus [House of Babel] from 1981, a mini-series about the last moths in the life of Primus Svensson (played by well-known Swedish actor Carl Gustav Lindstedt). He will never recover from his illness and, during his time in the big industrial hospital, he is repeatedly stricken by new bodily disorders until eventually he dies of a pancreas tumour. Babels hus is a pivotal example of how the content in TV drama was followed by intense debate (Vesterlund 2017).

Jason Jacobs' three stages are chronologically reversed in Sweden. Even if Jourhavande can be seen as a conflict drama contemporary with Jacobs category, Babels hus and the later melodrama/feel-good success Skärgårdsdoktorn (1996-2003) both breaks Jacobs' succession, placing the apocalyptic era before the paternal. Another reverse angle comes in the 2010s with crime fictions such as Bron or Arne Dabl in which the 
viewers witness a health care system that seems to always succeed in its medical tasks. From having been seen as a distressing and frightening location that represented the shortcomings of modernity, the hospital serves nowadays (perhaps, somewhat paradoxically, together with the police service) as one of the safest spaces in society-at least, in the world of Nordic noir.

Two examples can briefly illustrate this point. When, in episode 2 of season II of Bron (2013), the two main characters (police officers Saga Norén and Martin Rohde) are suspected of being infected with an unknown contagious disease, they are put in quarantine. Apart from the fact they both, almost immediately, are found not to be infected-thus encountering efficient and well-functioning medical care-the interiors of the hospital cease to appear in the dark shades of grey that characterize the mise-en-scène of the episode (and of the series as a whole). The scenes in the hospital are dominated by light colours (mostly white), and shot in a calm style with no strange angles or distinctive movements in the camera work. At the end of the second and last episode of Arne Dabl: En midsommarnattsdröm (2015), a hospital again provides the location. Here, the killer has been badly hurt and is interrogated in his hospital bed. The episode is otherwise dominated by sharp contrasts between foreground and background but, in the hospital scene, the space is depicted with a less dramatic mise-en-scéne and lighting.

\section{Visualized Media in the Welfare State}

In the 10-episode series Friställd [Laid Off] (1969), written by Bengt Bratt and directed by Jackie Söderman, we follow the main protagonist, Robert (Lars Green), following the shutdown of his machine at the factory where he used to work. Robert is an angry young man and, as such, a contrast to his fellow workers, who have less engagement in critical perspectives regarding the power structures of capitalism and government. Robert spends large parts of his days reading and thinking. In one scene, we see him on a couch holding the book Indoktrineringen $i$ Sverige [Indoctrination in Sweden] written by poet and critic Göran Palm. The same book also figures in the two-episode TV film, Tretton dagar [Thirteen Days] (1970), written by Lennart F. Johansson and directed by Keve Hjelm. This film is about a working-class family in a mediumsized Swedish city; one of two young brothers, Göran (Göran Stangerz), 
wants to break out of what he conceives as a trap. The work at the factory and the bleak everyday routines are nodes in a pointless striving for what would - at best-make it possible for the family to embrace a petitbourgeois life style. With support from Palm's book, he explains to his mother how indoctrinated they all are, and he also uses this insight to defend his betrayal of his girlfriend, whom he leaves. He does not want to be a part of the system.

Indoktrineringen i Sverige makes brief appearances in other films from the early 1970s, in the cinema as well as on TV, but Friställd and Tretton dagar are perhaps the most intriguing examples, since they pose two different uses of the book and the concept of indoctrination. On the one hand, it is a tool of emancipation, as is the case in Friställd. But the awareness of (supposed) ideological effects of media and culture can also break the community of the working-class milieu and-for better or worsebecome an unintended disruptive force in a painful societal change. This happens in Tretton dagar, where the outsider Göran is an ambiguous protagonist who seems to use his desire to break out in a way that appears to be more selfish than emancipatory. The film ends with him being beaten up by his older brother who sticks to the family, interestingly played by the same Lars Green that plays Robert in Friställd.

Göran Palm's book played an important role in Sweden by the end of the 1960s. Deliberately released directly in inexpensive paperback-it was Palm's intension to reach a wide audience-in 1968, it became a surprising bestseller. In the book, Palm discussed how school, an import from American TV fiction, press and commercial cinema presented anew values of the capitalistic system and thus kept society-and citizens-in a state of false consciousness (Hyvönen 2015). According to Palm, indoctrination was at work in all kinds of communicative arenas. Even in apparently innocent items such as weekly magazines, comic strips or fairy tales, delusions would arise and sneak into the 'Swedish Cinderella-souls' (Palm 1968 , p. 180). A crucial institution was the family, according to Palm 'the core cell of indoctrination' (p. 212). Children indoctrinated their parents, but parents also indoctrinated their children. The most vulnerable victim of indoctrination was the housewife, uneducated and inexperienced, and thus an easy pray for misbeliefs and myths spread by the media apparatus.

The term 'indoctrination' became widespread as a key concept in the public debate on media, culture and ideology, and was often used in the press in writings on the new Swedish TV drama. One example is how the short film Men vi har ju nästan allting [But we already have everything] 
(1971), about a woman shopping in a supermarket, is presented as a piece of de-indoctrination (Dagens Nyheter 1971, 9 June). Another case is a review of three films by British writer Colin Weiland, all aired in August 1971, where the headline reads 'Indoctrination and its victims' (Jahnsson 1971).

The visualisation of indoctrination in the actual TV-dramas was dominated by people watching television. There are numerous scenes with families, couples or lonely housewives in front of TV sets. From the soundthe screen is rarely in view-it can be gathered that the protagonists are often watching American fiction, or news. The standard visual solution is a static camera frontal shot of a married couple looking forward (at the camera, and the viewer) with indifferent expressions. There are also lonely women filling their suburban loneliness with daytime TV-actually a non-existent phenomenon in Sweden at the time, except for educational programmes-or easy-listening music on the transistor radio. The most striking example of this theme is the initial example, Berndt \& Anita (1969), where the isolated mother Anita (Margita Ahlin) goes out of her mind in an everyday inferno where only the cries from her baby and 'The Girl from Ipanema' on the radio breaks the silent soundtrack. Examples of media users enjoying the output from TV or radio, or becoming emancipated by the content of mass media are non-existent. Even when a serious discussion programme with a focus on the situation of the disabled is watched by the protagonists-in the film Eva \& Bengt (1970)—the use of TV leads to despair. After watching the programme, the woman kills her husband, who suffers from severe paralysis following a car accident. It may be a mercy killing, perhaps a way to get out of a hopeless situation. It is an open-ended film.

The recurrent motif of alienating mass media of different kinds implies a conception of media as a mighty power. There seems to be few highlighted examples such as these of protagonists using traditional mediaTV, press, radio - in newer Swedish TV fiction portraying contemporary life. The communication technology preferred in the crime genre comprises (unsurprisingly) different kinds of social media and devices such as mobile phones or computers. But neither traditional media nor new media are depicted in melodramas with a contemporary setting to invoke the alienated media usage in the way that seems to have been so frequent in the 1960s or 1970s. 
When it comes to the nostalgia of the welfare state, on the other hand, the use of TV is a recurrent sign of times past. The memory of experiencing the heyday of folkhemmet, is often also the memory of experiencing media. In the family melodrama/feel-good series Vår tid är nu [Our Time is Now] (2017-2018), the introduction of television is a crucial signifier of Swedish modernity. TV forms communities where people watch and enjoy programmes together, but it is also an arena for the two major protagonists, Nina and Calle, when they appear in a cooking show produced for the new medium. This is also the case in a very down-beat series such as Jonas Gardell's family drama mini-series De dagar som blommorna blommar [The Days the Flowers Bloom] (2019), where the memories of TV and the collective watching of the world cup slalom (as most Swedes did in the late 1970s) is a marker of time that bears no obvious traces of alienation. Neither does the media use in feel-good mini-series Systrar 1968 [Sisters 1968] (2018) reflect the pessimism of Göran Palm at the time. Set in the same year as the release of Indoktrineringen $i$ Sverige, this series shows no pessimism regarding the power of the media. The female protagonist, Karin (Mikaela Knapp), meets surprisingly few obstacles in her efforts as a revelatory journalist, and the various women around her can easily cast aside their delusions when confronted with the writings of feminist pioneer Betty Friedan. Here, media is in no way an alienating evil; rather, it is a tool of emancipation. When the radio is turned on, news from Vietnam is read to engage listeners. No sentimental mainstream music is heard.

There is a striking contrast between the assumptions of indoctrination in the late 1960s and the contemporary fictive representations of the same indoctrination and alienation, on the one hand, and the retrospective nostalgic idyll of media use in the 1960s, on the other. In the 1960s, the supposed vulnerability of media usage was signified in an iconography of alienation, built around TV sets and transistors. In the 2000s, the same analogous media devices signify the innocence of the past.

And when computers occur in Swedish TV films from the early 1970s, they are the most excessive signs of not only contemporary technocracy, but also of an unhuman future to come. In Babels hus [House of Babel, 1981], a rather late example of the social TV drama series but one of the most successful with audiences as well as with critics, new technology and health care are tied together in iconography and narration (Vesterlund 2017). This is a story of an elderly man who arrives at a huge industrial hospital after suffering from a myocardial infarction. Through the six 
episodes of the series he is transported between different units of the hospitals, never to return home. Computers and new medical technology are no obvious blessings to mankind. Rather, the large and efficient hospital is posed as dangerous and inhuman. Recurrent close-ups of computer screens or advanced medical machinery serve as signs of alienation. The only sympathetic character in the hospital is the hospital librarian, who seems to represent human values in an uncanny new time. The books he offers to the patients serve as an appropriate alternative to the TV and radio that is otherwise routinely provided to patients. But he also stands for an old world-perhaps a better world. Babels hus is a striking case of how nostalgia was introduced in Swedish social TV drama in the early 1980s. The paradise lost here is that of the 1930s, when the protagonist was a young man.

\section{EPILOGUE}

The Scandinavian crime fiction of today is widely recognized as depicting the disruption of the welfare state; Swedish TV drama of the 1960s and 1970s seems to have been just as critical of contemporary society as the Nordic noir genre is generally assumed to be. There are several potential aspects of vulnerability at stake that are interrelated in different ways. The representation of vulnerable individuals is constantly related to representations of a general societal vulnerability. The key institutions of the welfare state, such as public schools or hospitals, were regularly focused on in the1960s and 1970s. The example of health care, which is discussed as a recurrent motif in the productions from both periods, is of particular interest, since it is given different narrative functions. In the films and series from the earlier period, a hospital is, almost by definition, a dysfunctional symptom of large-scale technocracy. In productions from recent years, health care institutions are, irrespective of size, mostly used as secure zones in a world characterized by insecurity.

In Nordic noir there is but one societal institution that is consequently highlighted: the police. The genre rarely has any critical stances against the workings of this service. So, where does the social criticism appear? The representation of the Scandinavian landscape has repeatedly been highlighted as a main feature of Nordic noir. When, in Locating Nordic Noir: From Beck to The Bridge, Kim Toft Hansen and Anne Margit Waade $(2017$, p. 86 ) bring up 'the references to the melancholic mood in 
quite a few recent works on Nordic crime fiction', they can offer a number of examples of scholarly work on the genre. It is not only landscape, but also actual geography that seems to be at the core of Nordic noir. Slavoj Žižek (n.d.) has discussed how the 'specific locale' of a story's setting constitutes an important signification of the geographic particularity in the narrations of the twenty-first century. The cosmopolitism of modernism has given way to the individual experience of globalism, where specific provincial roots in certain geographic places are as substantial as the unspecific anonymous city or landscape. Žižek (n.d.) finds one 'exemplary case of the fate of the detective novel in our era of global capitalism' in the books and films of Henning Mankell, where the small Swedish city of Ystad is the (local) setting of (global) drama.

A crucial function of melancholy in the Scandinavian countries is thus - at least, so it seems in writings on Nordic noir - to highlight the demise of the welfare state. Interestingly, the very same Ystad that Žižek highlights as an open space of despair is the setting of recent feel-good nostalgia film Systrar 1968 (2018). Here, Ystad is the ultimate peaceful rural town. Although it is haunted by sexism and conservatism, the radical feminist forces from the urban world of Stockholm are able to reveal its dirty business. Here, the locale is the setting of a utopia that was never at hand, not even in the TV drama of 1968.

The Swedish TV drama of the late 1960s and early 1970s was also characterized by an emphasis on the local. Since the 1910s, the production of Swedish fiction film had been heavily dominated by Stockholm. With the expansion of the output of TV drama, Sveriges Radio also decentralized the production to Gothenburg, Malmö and Luleå, which could be a reason for an increasing representation of countryside Sweden in its fiction output. Films and serials were shot on location in towns such as Västerås, Göteborg, Luleå and Malmö. The difference here from the contemporary genres was that the places are almost without exception anonymous. The 'specific locale' of the 2000s was thus preceded by unspecific locales that avoided particularity in order to highlight the general shortcomings of Swedish modernity. The places were thus not important per se; their value was to serve as authentic examples.

A final point to make is that the TV drama of the 1960s was entangled with a number of other genres in different media. Novels and theatre plays were adapted to TV, film directors switched between the two media and, in the press, TV drama became a recurrent topic for new stories on 
the shortcoming of welfare institutions. Especially after the introduction of channel TV2 in December 1969, the domestic TV drama received a privileged place in the press. Almost each new socially oriented series or film caused a serious debate either through questions on the functions of the welfare state, or cases of its shortcomings. TV drama was established as a didactic institution, taking a leading role in the education of the inhabitants of folkhemmet as an alternative to the indoctrination that included both high art and commercial culture. Another thematic cluster discussed in this chapter is the representation of media, with media users depicted as vulnerable victims of the effects of the mass media and ideology of the earlier period. A third aspect of vulnerability is thus the vulnerable viewer/media user. This media user was not only depicted in the productions, but was also an ideal recipient of the films and series. One pivotal aim of the new strategy from 1967, and the intense production of social TV drama to come, was to provide an alternative to the commercial media genres. Films such as Berndt \& Anita or Friställd were, of course, not included in the conception of indoctrinating media. The social drama was supposed to be an emancipating instance in the welfare state. In the productions of the 2000s, the function of represented media has changed; representations of media usage are now a somewhat nostalgic token in the depictions of the lost welfare state of the past.

\section{Notes}

1. It is difficult to specify a number of films or TV productions depicting the 1960s and 1970s, but at least 28 feature films (drama and documentaries) produced since 1999 focus on the period. During the same period (1999-2018), at least 21 TV productions-including series, feature films and documentaries-were mainly set in the 1960s, 1970s, or 1980s.

2. Examples are to be found in the major daily newspaper Dagens Nyheter (1967, 4 March; 1967, 31 March; 1967, 14 April; 1967, 20 April), or in Svenska Dagbladet (1967, 19 January).

3. Svenska Dagbladet (1967, 15 April). The book takes fourth place on the best-selling list of 'other literature' (annan litteratur), behind the memoires of Bertrand Russell and an Agatha Christie mystery story.

4. Examples are to be found in books by such politically, aesthetically and historically diverse writers as Vilhelm Moberg, Ivar-Lo Johansson, or P. C. Jersild. 


\section{REFERENCES}

Allister Diesen, T., Farzaneh, L., \& Klänge, P. (Directors). (2015). Arne Dahl一En midsommarnattsdröm [Television film].

Asphaug, M., Lind Lagerlöf, D., Petri, K., \& Petrelius, R. (Directors). (1997-2002). Skärgårdsdoktorn [Television series]. Sveriges Television.

Bengtsson, B. (1998). Ungdom i fara: ungdomsproblem i spensk spelfilm 1942-62 (Doctoral dissertation). Stockholms universitet, Stockholm.

Bergman, K. (2014). Swedish Crime Fiction: The Making of Nordic Noir. London: Mimesis International.

Björklund, E. (2013). The most delicate subject: A history of sex education films in Sweden (Doctoral dissertation). Lund University, Lund.

Bratt, B. (Writer). (1971-2006). Hem till byn [Television series]. Sveriges Television.

Brodén, D. (2008). Folkhemmets skuggbilder: en kulturanalytisk genrestudie av svensk kriminalfiktion i film och TV (Doctoral dissertation). Göteborg: Ekholm \& Tegebjer.

Cooke, L. (2003). British Television Drama: A History. London: BFI Publishing. Cornell, J. (1981). Babels hus [Television series]. Sveriges Television.

Cornell, J. (Director). (1981). Babels hus [Television film]. Sveriges Television.

Dagens debatt. (1966, May 24). Svenska Dagbladet.

Dahl, C. (Director). (1970). Eva \& Bengt [Short film].

Diesen, T. A. (Director). (2015). En midsommarnattsdröm [Television film]. Sveriges Television.

Dyfverman, M. (2004). Den första TV-teatern 1954-1969. Örebro: Blå Bergen.

Edin, A. (2000). Den föreställda publiken: programpolitik, publikbilder och tilltalsformer $i$ svensh public service-television (Doctoral dissertation). Stockholm: Brutus Östlings bokförlag Symposion.

Eriksson, J. (1967, 31 March). Den svenska fattigdomens betydelse. Dagens Nyheter.

Gardeström, E. (2016). Educating journalists: The who, when, how, and why of early journalism programmes in the Nordic countries. In G. Nygren, J. F. Hovden, \& H. Zilliacus-Tikkanen (Eds.), Becoming a Journalist: Journalism Education in the Nordic Countries. Nordicom: Göteborg.

Georgsson, H., Hammerich, R., Sieling, C., Arnfred, M., Windfeld, K., \& Siwe, L. (2011-2018). Bron [Television series]. Sveriges Television/DR.

Hamrell, H. (Director). (2011). Arne Dabl: Misterioso [Television film].

Hamrell, H. (Director). (2017-2018). Vår tid är $n u$ [Television series]. Jarowski. Sveriges Television.

Hansen, K. T., \& Waade, A. M. (2017). Locating Nordic Noir: From Beck to The Bridge. Basingstoke: Palgrave Macmillan.

Hedling, E., Hedling, O., \& Jönsson, M. (Eds.). (2010). Regional Aesthetics: Locating Swedish Media. Stockholm: Kungliga biblioteket. 
Hill, A. (2018). Saga's story: Emotional engagement in the production and reception of The Bridge. In K. Toft Hansen, S. Peacock, \& S. Turnbull (Eds.), European Television Crime Drama and Beyond (pp. 269-284). Basingstoke: Palgrave Macmillan.

Hjelm, K. (Director). (1970). Tretton dagar [Television series]. Sveriges Radio.

Hjulström, L. (Director). (1969). Berndt \& Anita [Television film]. Sveriges Television.

Hjulström, L. (Director). (1975). Gyllene àr [Television series]. Sveriges Television.

Holm, A. (1967, 24 August). TV-teatern satsar på svensk dramatik: Visar tjugo nya pjäser. Dagens Nyheter.

Humle, K. (Director). (1968). Systrar 1968 [Television series]. Sveriges Television.

Hyvönen, M. (2015). Mediekritik i pocketformat: massmedieproblem i debattböcker 1965 till 1975. In M. Hyvönen, P. Snickars, \& P. Vesterlund (Eds.), Massmedieproblem: Mediestudiets formering. Lund: Mediehistoriskt arkiv.

Ickevåld-Ett vidgat försvar. (1967, 14 April). Dagens Nyheter.

Inghe, G., \& Inghe, M.-B. (1967). Den ofürdiga välfürden. Stockholm: Tidens. Ingvarsson, J. (2003). En besynnerlig gemenskap: teknologins gestalter i svensk prosa 1965-70 (Doctoral dissertation). Göteborg: Göteborgs universitet.

Inte blott hälsan tiger still: Den svenska nöden kartlagd. (1967, 19 January). Svenska Dagbladet.

Jacobs, J. (2003). Body Trauma TV: The New Hospital Dramas. London: British Film Institute.

Jahnsson, B. (1971, 26 August). Indoktrineringen och dess offer. Dagens Nybeter.

Johansson, R. (1974, 18 March). Dödshjälp på sjukhus. Dagens Nyheter.

Kajser, S. (Director). (2019). De dagar som blommorna blommar [Television series]. Sveriges Television.

Klänge, P. (Director). (2015). Arne Dabl: Efterskalv [Television film].

Koivunen, A. (2014). Hela folkets teater: televisionsteatrarna i Finland från 1960-talet till 1980-talet. In J. Wiio (Ed.), Den finska televisionens milstolpar: Program och programplanering under fem årtionden. Nordicom: Göteborg.

Koivunen, A., Kyrölä, K., \& Ryberg, I. (Eds.). (2018). The Power of Vulnerability: Mobilising Affect in Feminist, Queer and Anti-Racist Media Cultures. Manchester: Manchester University Press.

Kris i åldringsvården. (1967, 4 March). Dagens Nyheter.

Liljestrand, J. (2009). Mobergland: Personligt och politiskt $i$ Vilbelm Mobergs utvandrarserie. Stockholm: Ordfront.

Loach, K. (Director). (1966). Cathy Come Home [Television film].

Låglönesöl. (1965, 16 December). Dagens Nyheter.

Löfgren, L. (Director). (1968). Exercis [Television film]. Sveriges Radio. 
Masserat, M. (Director). (2012). Arne Dabl: Ont Blod [Television film].

Meurling, P. (1967, 20 April). Pensionär utan pension. Dagens Nyheter.

Nichols, B. (1991). Representing Reality: Issues and Concepts in Documentary. Bloomington: Indiana University Press.

Nilsson, M. (2003). Den moderne Ivar Lo-Johansson: modernisering, modernitet och modernism i statarromanerna (Doctoral dissertation). Hedemora: Gidlund.

Ohlsson, N., \& Ohlsson, M. (Directors). (2012). Arne Dabl: Europa Blues [Television film].

Olzon, S. (Director). (1971). Men vi har ju nästan allting [Television film].

Palm, G. (1968). Indoktrineringen i Sverige. Stockholm: PAN/Norstedts.

Peacock, S. (2014). Swedish Crime Fiction: Novel, Film, Television. Manchester: Manchester University Press.

Persson, Y. (1967). Preface. In G. Inghe \& M. B. Inghe (Eds.), Den ofürdiga välfürden. Stockholm: Tidens förlag.

Rosenfeldt, H. (2011-2018). Bron [Television series]. Sveriges Television.

Schyller, I. (1996). Radio- och TV-utbudet 1925-1994. Stockholm: Stiftelsen Etermedierna i Sverige.

Sjögren, M. (1969, December 18). 'Autentiskt' TV-spel. Svenska Dagbladet.

Söderman, J. (Director). (1969). Friställd [Television film]. Sveriges Radio.

Söderman, J. (Director). (1974-1975). Jourhavande [Television series]. Sveriges Television.

Sveistrup, S. (Creator). (2007-2012). Forbrydelsen [Television series]. Danmarks Radio m.fl.

Television, med reservation för ändringar. (1971, 9 June). Dagens Nyheter.

Tenngart, P. (2010). Romantik i välfärdsstaten: Metamorfosförfattarna och den svenska samtiden (p. 2010). Lund: Elleströms.

Turner, Bryan S. (2006). Vulnerability and Human Rights. University Park: Pennsylvania State University Press.

Vad Sverige läser. (1967, 15 April). Svenska Dagbladet.

Vesterlund, P. (1999). Den glömde mannen: Erik 'Hampe' Faustmans filmer (Doctoral dissertation). Stockholm: Stockholms universitet.

Vesterlund, P. (2017). ...'men visst kände vi igen oss'-iakttagelser av svensk TV-dramatik och samhällsliv under 1970- och 1980-talet. In U. Serrander \& P. Thalén (Eds.), Kunskap, Motstånd, Möjlighet: Humanistisk forskning idag. Molin \& Sorgenfrei: Stockholm.

Vinterhed, K. (1969, 18 December). Fyra mammor om Anita: visst känner man igen sig. Moderslyckan bara en myt. Dagens Nybeter.

Žižek, S. (n.d.). Henning Mankell, the Artist of the Parallax View. http://ww w.lacan.com/zizekmankell.htm. Accessed 15 February 2019. 
Open Access This chapter is licensed under the terms of the Creative Commons Attribution 4.0 International License (http://creativecommons.org/licenses/by $/ 4.0 /$ ), which permits use, sharing, adaptation, distribution and reproduction in any medium or format, as long as you give appropriate credit to the original author(s) and the source, provide a link to the Creative Commons license and indicate if changes were made.

The images or other third party material in this chapter are included in the chapter's Creative Commons license, unless indicated otherwise in a credit line to the material. If material is not included in the chapter's Creative Commons license and your intended use is not permitted by statutory regulation or exceeds the permitted use, you will need to obtain permission directly from the copyright holder.

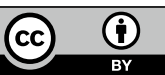


Societies of Perfection and Resisting Normalcy 


\title{
Vulnerability and Disability in Contemporary Nordic Literature: Linn Ullmann's Grace and Sofi Oksanen's Baby Jane
}

\author{
Jenny Bergenmar
}

\section{INTRODUCTION}

What is the relation between vulnerability and disability, when viewing these states as concepts and as conditions for human life? Many thinkers describe vulnerability as an inescapable situation for all that is living. 'As embodied species, we share a common vulnerability emerging from the condition of living in bodies and in time', Marianne Hirsch summarizes (2016, p. 80). All humans are vulnerable as infants, small children and in old age because we have not yet acquired-or lost-various abilities. Anyone is vulnerable to threats against health and able-bodiedness, at any time. That is to say, anyone can become disabled in the course of life as a result of injury or illness. However, to say that disability is a part of the human condition may not be as easily accepted as the idea of a shared

\section{J. Bergenmar $(\bowtie)$}

Department of Literature, History of Ideas and Religion, University of Gothenburg, Gothenburg, Sweden e-mail: jenny.bergenmar@lir.gu.se

(C) The Author(s) 2020

A. M. Dancus et al. (eds.),

Vulnerability in Scandinavian Art and Culture, https://doi.org/10.1007/978-3-030-37382-5_8 
vulnerability. Disabled people are often regarded as a special group with special needs. If the norm is the autonomous, independent individual, people who have difficulty fulfilling-or who are not deemed to fulfilthis ideal are considered to be deviations from the norm.

Another complication is that disability theory and activism have a tradition of focusing on independence and autonomy as rights for the disabled. Vulnerability - in the sense of our mutual dependency on each othermay therefore not be readily accepted as a politically viable concept by disability activists and scholars (Knight 2014, p. 22). However, even if vulnerability is conceived of as a common condition for all humans, it is important to acknowledge that vulnerability is not the same for all. As Hirsch puts it, 'But, importantly, vulnerability is also socially, politically, and economically created and differentially imposed' (2016, p. 80).

Here, she touches on the unequal distribution of vulnerability, which causes some groups of people to be more exposed to threats to their lives, health and subjectivity than others. As Don Kulick and Jens Rydström point out, we 'are not all equally captured in prognosis or equally impacted by regimes of debility' $(2015$, p. 272). Similarly, Jasbir Puar (2017) points out that the idea that we will all be disabled if we live long enough is not true in a global context. The distribution of risk-or, more concretely, 'where we live, what resources we have, what traumas we have endured, what color our skin is, what access we have to clean water, air, and decent food, what type of health care we have, what kind of work we do' (p. xiv)—involves factors that may prevent people from even reaching old age. The unequal distribution of vulnerability evidently has social and economic consequences. Judith Butler describes precarity as 'indissociable from that dimension of politics that addresses the organization and protection of bodily needs' $(2015$, p. 119). In the present work, I understand precarity as the heightened economic and social insecurity experienced by different groups in capitalist society.

In contemporary fiction, disability is both conspicuous and made invisible. There are fictional stories that are explicitly 'about' disability, or that have characters with various diagnoses, such as the autism-spectrum detective Saga Norén in the TV series Bron/Broen. Disability is often used as a device to promote a certain kind of suspense or drama. Saga Norén's autism spectrum condition allows for a Sherlock-like attention to detail and superior logic, as well as for a drama about social isolation that aligns with the series' gloomy, cold and violent Scandinavian cityscape. However, as Michael Bérubé (2016) has pointed out, disability does not always 
present itself as such: 'disability and ideas about disability can be and have been put to use in fictional narratives in ways that go far beyond any specific rendering of any disabled character or characters' (p. 2). He takes his cue from Lennard J. Davis who, as early as 1995, showed in Enforcing Normalcy (1995) that the concept of disability is fundamental to a critical understanding of almost any literary work.

Davis and Bérubé support this point with examples that are mainly taken from English-language fiction; however, in contemporary Scandinavian fiction, Sofi Oksanen's Norma (2015) may be mentioned. This novel is about a girl (Norma) whose hair grows a metre a day; Norma's hair has other unusual qualities, such as the ability to sense the intentions and moods of those around her, and the ability to affect her own mood. The novel combines magical realism with a harsh critique of the exploitation of women's bodies, by making Norma's hair a product on a market. In fact, Norma's extraordinary abilities can also be regarded as disabilities: they must be hidden, which means that she is more or less imprisoned in her apartment. Her hair is a stigma, and a part of her body to which she must adapt, whether she wants to or not. As Bérubé has argued, 'disability in the relation between text and reader need not involve any character with disabilities at all. It can involve ideas about disability, and ideas about the stigma associated with disability' (2016, p. 19). Disability may, then, be a relevant perspective for texts that mainly appear to represent other challenges to physical, mental or cognitive abilities, such as illness or ageing.

In a Nordic context, few attempts have been made to analyse the representation of disability in literary fiction. Indeed, judging from the critical reception of Nordic literature and the general lack of research on Nordic fiction and disability, it seems as though disability is primarily considered as an aspect of texts only if it is clearly announced as a central theme, or is an important part of the portrayal of a character. One well-known example is the hacker heroine Lisbeth Salander of Stieg Larsson's The Millenium Trilogy, whose diagnosis of Asperger Syndrome has been analysed as a literary trope (Ma 2014) and in a neurodiversity context (Freeman Loftis 2015, pp. 130-150). However, even in this case, in which disability is clearly foregrounded, research has mainly focused on other aspects. For example, in an anthology of Swedish gender studies on The Millenium Trilogy, only one of the eight articles makes any mention of her autism-spectrum condition. When it is brought up, it is described as 
a problematic literary device, which makes Salander a stereotypical 'geek girl' (Fahlgren 2013, p. 93).

In this article, the concept of vulnerability will be used to shed light on how disability is narrated in two contemporary literary texts from the Nordic countries in which disability is not explicit: Sofi Oksanen's Baby Jane (2005), a feminist love story about a lesbian couple whose relationship breaks up when one of the women gradually loses her independence due to depression and severe anxiety; and Linn Ullmann's Nåde (2002 [Grace 2005]) about ageing, illness and the gradual loss of different abilities that threaten the sense of self of a middle-aged man. Neither Oksansen's nor Ullmann's novels have been read as texts employing disability as a way to discuss existential or social conditions, but both narrate different kinds of vulnerability. Ullmann's text is about illness, death and remembering the life that has passed. Oksanen's novel has mainly attracted attention for its critique of the patriarchal capitalist society, which makes women's bodies products on a market.

This article can only begin to answer the more overarching question about the role and function of disability in contemporary Nordic fiction. Its primary aim is to use the concept of vulnerability to explore aspects of able-bodiedness and disability in these two texts. A focus on vulnerability may help to disrupt the boundaries of 'the disabled'—both as a group and as a specific theme in literature-and, instead, foreground the idea that humans are only temporarily able-bodied (Knight 2014, p. 25) and that disability is a consequence of normalcy. An acknowledgement of shared vulnerability may thus be used to challenge ableism and place disability on a human continuum of abilities and disabilities.

\section{DisABILITY, VulNerability AND Literature: AN OVERVIEW}

Since the emergence of what Tom Shakespeare has called 'Cultural Disability Studies' (2013, p. 47) in the 1990s, disability discourse and representation have become the centre of attention after a strong focus on material and social relations in the disability studies of the 1980s and 1990s. Rosemarie Garland-Thomson's seminal Extraordinary Bodies: Figuring Physical Disability in American Culture and Literature (1997) was an important part of this development. The underlying assumption in Garland-Thomson's work is that there is a continuity of language 
and material conditions: cultural representations of disability have consequences for the identity of real people. Through the concept of 'normate', Garland-Thomson also zoomed in on the social construction of normality. 'The term normate usefully designates the social figure through which people can represent themselves as definite human beings' $(2017 / 1997$, p. 8). Instead of just scrutinizing representations of disabled characters, this concept switches the focus to the norms that are producing the separation of 'non-disabled' and 'disabled'-that is, to ableist norms, which are often activated in the attitudes of the non-disabled towards others. In her typology of disability representations, drawing from photographs and advertisements picturing disabled people, Garland-Thomson identified four types of visual rhetoric: the wondrous, the sentimental, the exotic and the realistic (2002). In many cases, I argue, these four types can also be applied to literature.

Another influential contribution in this field is David T. Mitchell and Sharon L. Snyder's Narrative Prosthesis. Disability and the Dependencies of Discourse (2000). The concept of 'narrative prosthesis' refers to the use of disability in fiction in a way that supports and stabilizes normality and the social and moral order. In this case, disability is not represented in its own right but is, rather, used as a function to relieve the discomfort of the divergent or abnormal. Disability as narrative prosthesis is typically manifested through stereotypical notions of pity, or by the recovery from or overcoming of disability, thereby restoring a state of normalcy.

In Aesthetic Nervousness: Disability and the Crisis of Representations (2007), Ato Quayson relies on the earlier contributions of GarlandThomson and those of Mitchell and Snyder. His study has been influential in its further explorations of the relation between the normate and fictional disabled characters. This relation, according to Quayson (2007), produces an 'aesthetic nervousness': 'dominant protocols of representation within the literary text are short-circuited in relation to disability' (p. 15), he claims, drawing from Mitchell and Snyder's idea of disability as a 'textual obstacle' (2000, p. 50). Quayson proposes a typology of disability representation in nine categories, arguing that, in comparison with visual representation, literary works demand a more subtle and fine-tuned typology (2007, p. 215), because of the interconnectedness of different levels of the text. Disability is thus not just an ethical or political aspect of the text, but also an aesthetic aspect that may 'lead to a complete revaluation of critical emphasis' of the canon (2007, p. 27). Like Quayson, 
Michael Bérubé argues in The Secret Lives of Stories that disability in literary texts is not just about representation. Rather, it functions in the form of 'narrative deployments of disability' that are active in various narrative strategies: temporality, motifs and narrative self-awareness (Bérubé 2016 , p. 3). The notion that disability may not always be about disabled characters, or be a manifest representation of disability is crucial for this chapter.

How, then, do vulnerability and disability intersect in literature? Garland-Thomson's Extraordinary Bodies was published well before vulnerability became more commonly theorized; nevertheless, she touches on the subject. In discussing Captain Ahab in Moby Dick, she points out that his physical difference, which carries an implication of vulnerability, is in conflict with the ideas of autonomy and self-determination that are present in the novel. 'Ahab, along with other disabled figures, poses the troubling question of whether any person is independent of physical limitations, immune to external forces, and without need of assistance or care from others' $(2017 / 1997$, pp. 45-46). The images of disabled women in Uncle Tom's Cabin are 'icons of vulnerability' that elicit the reader's sympathy and indignation, Garland-Thomson argues (2017/1997, p. 82). Though the disabled women only play minor roles in the narrative, the characters are important for the novel's rhetorical impact on the reader.

Interestingly, neither Quayson nor Bérubé considers vulnerability in relation to disability in a theoretical sense in their more recent contributions. However, in his study on ethics and life writing, Vulnerable Subjects (2004), G. Thomas Couser uses the concept of vulnerability both to describe the vulnerability to harm of the physically or cognitively impaired subject, and to express that subject's vulnerability to misrepresentation in other people's narratives - such as those written by family members and physicians (2004, pp. x-xii). Evidently, there are ethical questions pertaining to biographical narratives about people with disabilities who are unable to give their consent or respond to the narratives, such as in the case of dementia or intellectual impairments, that set these narratives apart from autobiographies written by disabled people themselves. Fiction presents another case, which lacks the truth-claim of biography and autobiography, but involves similar ethical questions in relation to disability representation. Thus, 'people with disabilities are also vulnerable to involuntary and prejudicial representation in diverse media', Couser (2009, p. 17) points out. 
In Embodying the Monster. Encounters with the Vulnerable Self (2002), Margrit Shildrick reads the monster in western thought as a difference we want to project onto others, since it undermines the idea of self-sufficiency and challenges standards of normality. The monster can be seen as vulnerable as a consequence of the deviation from bodily normality but, above all, it 'threatens to expose the vulnerability at the heart of the ideal model of body/self' (Shildrick 2002, p. 54). Shildrick's main goal is to deconstruct the phantasy of the autonomous subject of modernity, and to argue for an embodied ethics that is able to accept or even embrace difference, rather than effacing it. Therefore, disability plays a secondary part, as it is only one kind of monstrosity among others, such as cyborgs and mythological creatures.

In a wider context, disability and vulnerability have been discussed in conjunction-for example, in relation to citizenship. In her article 'Disability and Vulnerability', Jackie Leach Scully compares the consequences of two different notions of vulnerability: vulnerability as a feature of human ontology, and vulnerability as something pertaining to certain groups that risk being subject to harm more than others (2013, p. 206). The former notion risks overlooking the fact that particular circumstances may make some individuals or groups more vulnerable than others, while the latter reinforces a dichotomy between the 'normal' and 'vulnerable others', among whom disabled people are likely to be placed (Scully 2013, p. 206). Arguing that a 'high proportion of the vulnerabilities commonly associated with disability are $[\ldots]$ contingent rather than inherent, because they are secondary to a particular social response to impairment' (2013, p. 209), Scully challenges the idea that vulnerability is a kind of 'autonomy deficit' (2013, p. 212) from which disabled people suffer. Besides the shared vulnerability of our bodies, the social dependencies that all humans rely on in families and in societies constitute a different kind of ontological vulnerability, one that relies not on the body, but on social relations. This is in line with Butler's view that vulnerability exceeds injurability (Butler 2009, pp. 54-62) and that, in addition to our injurable bodies, vulnerability has to do with a radical dependence on others (Butler 2009, pp. 19-20).

In this chapter, I will rely on previous research on disability in literature, while simultaneously drawing on the discussion about disability and vulnerability in other fields. More precisely, I will use disability as a critical position that reveals the vulnerability of fictional subjects in general, 
rather than only those who are explicitly narrated as disabled. An important question to be considered from an interdisciplinary perspective is $w h y$, and perhaps also how, disability in fictional literature matters. In the introduction to their study about disability and sexuality, Loneliness and Its Opposites (2015), Kulick and Rydström juxtapose the work of 'professors of literature' focusing on 'representation' (p. 10) with disability studies dealing with actual people; for example, through interviews (a method employed by Kulick and Rydström themselves).

Departing from the contributions to the understanding of disability in the previously discussed research, I would argue that the separation between textual disability studies and disability studies that engage with policy and lived experience is unfortunate. In the words of GarlandThomson, 'representation informs the identity - and often the fate-of real people with extraordinary bodies' (2017/1997, p. 15). Quayson also argues that the study of disability in fictional literature is not merely a question of aesthetics: the representation of disability 'transcends the literary domain and refuses to be assimilated to it' $(2007$, p. 19). Narratives are powerful instruments for the consolidation of the normate, as well as being places where the normate can be challenged.

\section{BABY JaNe: VulNerability, Precarity AND Dependence}

Finnish-Estonian author Sofi Oksanen had her international breakthrough with Purge (2008), which won the Nordic Council Literature Prize in 2010. It was her third novel after Stalin's Cows (2003) and Baby Jane (2005). ${ }^{l}$ Oksanen often writes about political and patriarchal oppression. Both Stalin's Cows and Purge are about the history of Estonia under Soviet occupation; however, the scene is changed in Baby Jane. This is a love story set in modern Helsinki between Piki, 'the coolest dyke in Helsinki', and a young woman who is the narrating ' $I$ '.

The novel is divided into five parts, all narrating different stages in the relationship between the narrator and Piki, although not in chronological order. In part I of the novel, the meeting with Piki is described. Part II narrates life after the break-up with Piki, as the narrator tries to adapt to a heterosexual middle-class life with her boyfriend Joonatan. Part III introduces Bossa, Piki's ex-girlfriend, who also functions as her personal assistant, doing the shopping for her food and the washing-up. In part IV, the relationship between the narrator and Piki deteriorates due to 
Piki's poor health and the narrator's jealousy of Bossa, resulting in the narrator stabbing Piki and injuring her badly. This is also the cause for the break-up that was narrated in part II. Part V describes how Piki's health deteriorates even more. She does not leave her home and is completely dependent on Bossa, who only brings her food occasionally. Piki asks the narrator to assist her suicide. The last pages make it clear that Piki was ultimately killed by Bossa with a blow to the head, but that the narrator has been convicted and is in prison for Piki's murder. This is the place and point in time from which the narrator tells her story.

In the first pages, the narrator describes her first impressions of Piki with amazement and awe. Piki is older and is well-known in lesbian circles, having plenty of self-confidence and sexual experience. Piki and the narrator become a couple and share a sense that anything is possible for them, despite their financial difficulties. Even within this phase of passion and happiness, the narrator plants some clues to the continuation: for example, Piki does not like to go to cafés or grocery shopping. In fact, she seldom leaves her home. In the beginning of the novel, the narrator states that, when they met, both had been diagnosed with severe depression. The narrator catalogues symptoms and medications, albeit in a normalized way. Among their friends, it was not uncommon to have a psychiatric condition, the narrator explains; 'almost everybody's mornings started with a number of pills' (Oksanen 2005, p. 28). Just as homosexuality is narrated as a norm in the world of Piki and the narrator, mental illness does not bear the stigma of disability, even if - as in Piki's case-it is impairing in reality.

The novel starts with a quote from the lyrics of Madonna's album 'True blue', thus immediately indicating to the reader that this is a love story. The novel's five parts all have a song lyric as a motto. These mottos change character as the plot moves on to a definite crisis: from Madonna's carefree love song, to 'The Ballad of Lucy Jordan', famously performed by Marianne Faithfull, which describes the mental breakdown and attempted suicide of a housewife (Dederer 2006). Just like the title references the 1962 film What Ever Happened to Baby Jane?, starring Bette Davis and Joan Crawford, the mottos function as interpretive clues for the reader. I will return to the film as an intertext later.

Quayson mainly reserves the category 'disability as normality' for autobiographies and biographies, but also includes texts where 'disability is used as a pointed critique of social hypocrisy' (2007, p. 52). This is, indeed, the case in Baby Jane. The retrospective composition of the story 
allows for a juxtaposition of the world where women can love women; where you can be poor and depressed without people judging; with a middle-class, heterosexual world in which the narrator ends up after the relationship with Piki has ended. The contrast between these two worlds shows the difference between a world where you do not have to pass as normate-whether with regard to sexuality or ability - and a world 'enforcing normalcy', as Lennard J. Davis has expressed it (1995). Bérubé writes that Quayson's category 'disability as normality' corresponds to Garland-Thomson's 'realistic' mode of visual representation, in which 'disability is simply itself, and not (in Garland-Thomsons typology wondrous, sentimental, or exotic' (Bérubé 2016, p. 54).

However, the novel presents different ways of regarding deviations from the normate. In the middle-class, heterosexual world the narrator tries to move on to, homosexuality and depression must be hidden; however, this world provides the narrator with financial safety and a refuge from the parts of Helsinki where everything reminds her of Piki. The changed economic conditions in the heterosexual relationship with Joonatan cause the narrator to reflect on vulnerability in relation to the uneven distribution of resources: 'With resources like this, Piki could have lived a comfortable life, been cared for by proper doctors and taken a taxi to the beach every night, if she wanted to' (Oksanen 2005, p. 62). Piki's life is fraught with precarity - that is, the normative constructions of the society she lives in place her in a position where employment and income are unreachable privileges. There is a price to the breaking of normative conceptions about sexuality and ability in the world of Piki and the narrator. Challenging the normate means placing oneself in a vulnerable position.

As a counter-example, there is Joonatan, the man the narrator moves in with after the end of her relationship with Piki. Adopting his way of life means moving from a position of precarity and vulnerability to a position of relative safety and compliance with norms. In effect, the novel is harsh in its critique of the oppression of the normate, by connecting health, resources and social agency with heterosexual normalcy, while illness, disability and poverty affect the homosexual community, which lives in what almost seems like a separate Helsinki that is removed from the privileges of the normate. In this novel, disability - in this case, psychiatric disability - can be read as part of a critique against the normate. In light of the theories about disability and vulnerability that have been previously presented, it is clear that disability is not used as a narrative prosthesis by 
Oksanen. There is no stabilization of normality, and no recovery from or overcoming of disability-neither for Piki, who decides to end her life, nor for the narrator, who is deeply depressed in her relationship with Joonatan, and who eventually ends up in prison. It is a narrative of disintegration, rather than of recovery.

Even though disability is not stigmatized in the world of Piki, the novel seems to link psychiatric conditions to a patriarchal and heterosexual oppression paired with economic precarity, especially since Piki and the narrator begin to sell used underwear to heterosexual men in order to be able to support themselves. The world of Piki and the narrator cannot, then, just be understood as a free place where disability is normality (in Quayson's sense). It is clear that there is also an individual level. Piki has been ill for a long time, and is hiding the severity of her anxiety. Thus, 'disability as normality' is only true from the perspective of the narrator, and cannot be sustained when Piki's health deteriorates. Piki, herself, is ashamed of her condition. She hides it and will not admit that she depends on her ex-girlfriend, Bossa, to carry out her everyday chores.

It is within this relationship that the reference to the 1962 film What Ever Happened to Baby Jane? makes sense. In the film, a paraplegic exmovie star (Blanche, played by Joan Crawford) is held captive by her sister (Jane, played by Bette Davis), who was a famous vaudeville star as a child. Blanche's disability makes her completely dependent on her mentally unstable sister, who mistreats her and starves her. In Oksanen's text, Piki is indeed captive, like Blanche, in her own home, and it is the gradual revelation of this to the narrator that drives a wedge into their relationship. Both Bossa and Jane act as prison guards, and both use the strategy of limiting food to control and torment Piki and Blanche, respectively. Moreover, both put dead birds in the food in order to provoke a reaction of horror (Oksanen 2005, p. 209). In a dialogue, Piki also states that What Ever Happened to Baby Jane? is Bossa's favourite movie (Oksanen 2005, p. 170).

The narrator recognizes that Piki's loss of autonomy is not due to a disabling illness, but to Bossa's manipulation of her. Here, the novel follows the plot of the movie. Blanche's disability makes her vulnerable to the oppression of her sister, but she is not oppressed because she is disabled. Just as Jane oppresses Blanche out of envy of her career, Bossa oppresses Piki out of jealousy of her new girlfriends. However, while it is suggested that Blanche dies from starvation at the end of the film, Piki's 
death is more violent. After the narrator stabs Piki in a bout of desperation, the relationship between the narrator and Piki is broken off for some time. When Piki makes contact again, she is in bad shape. Bossa has Piki's card and keys, and only brings Piki food occasionally. Piki demands that the narrator help her commit suicide, which she plans to do by taking medicine, putting a plastic bag over her head and taping it around her throat. The role of the narrator is to see to it that the suicide works, and then to deliver a letter to Bossa in order for the body to be found.

The fact that it transpires that it after all was Bossa who killed Piki reinforces the parallelism between Bossa and Jane. The intermedial relation between the film and the novel is on a separate level to the intermedial relations between the novel and the references to music previously mentioned. The latter can be seen as articulating feelings that are not explicitly formulated by the novel, while the film provides elements of the plot and points to the main theme of the novel: dependency and control. The reference to What Ever Happened to Baby Jane? as a psychological horror film also reinforces what could be called the 'horror' of vulnerability: the insight that the social and physical vulnerability that is unavoidable for all humans is a fearsome state that may expose us to physical and psychological suffering and exploitation.

Scully's critical assessment of 'the assumption that disabled people have special vulnerabilities' that set them apart from non-disabled people (2013, p. 205) may help us to understand disability and vulnerability in Baby Jane. In line with Scully, I argue that, in this novel, disability is not to be seen as an 'autonomy deficit' (Scully 2013, p. 212) represented by Piki's dependence on Bossa. I propose that the novel does not link disability to a special vulnerability. Rather, Piki is made especially vulnerable by the societal and psychological conditions: her already mentioned precarity, and her disabling at the hands of Bossa-that is, the constant affirmation of her inability to go outside or to manage everyday chores. Scully underlines the importance of examining exactly why people with disabilities are typically regarded as more vulnerable than non-disabled people. Impairments may cause vulnerabilities, but how this vulnerability is experienced is highly dependent on how society responds to it (2013, p. 217).

I argue that the novel Baby Jane questions the way of thinking about disability as a lack of autonomy. Piki's two most important relationships, the one with Bossa and the other with the narrator, present two different kinds of dependency: Piki's and the narrator's dependencies are mutual, 
which is evident in the narrator's flashbacks during her relationship with Joonatan. With Piki, she wasn't a 'visitor in a relationship' and her 'hands felt at home' (Oksanen 2005, p. 59). Bossa, on the other hand, is not driven by love but, rather, by jealousy and a wish to control Piki. Here, dependency is, in fact, not directly produced by disability. Instead, it is the asymmetric relationship with Bossa that exposes Piki to threats to her physical health and reduces her autonomy, and (in the eyes of the narrator) worsens her psychiatric condition.

The narrator reflects on the severity of Piki's state, and concludes that it is the absence of proper treatment, such as therapy, and Bossa's interference that has worsened her condition (Oksanen 2005, p. 196). This conclusion is in line with Scully's statement that 'a high proportion of the vulnerabilities commonly associated with disability are therefore contingent rather than inherent, because they are secondary to a particular social response to impairment' (Scully 2013, p. 209). From a relational perspective, such as Scully argues for, social relations entail dependency, but also make autonomy possible. The narrator longs for a relationship with Piki in which they can be mutually dependent on one another. But, due to Bossa's continual confirmation of Piki's dependence, and to the many years of maltreatment (for example, through excessive prescription of medications), Piki and the narrator never succeed in realizing this autonomy through dependence.

\section{Grace: Vulnerability, Illness and Control}

Like Oksanen, Norwegian Linn Ullmann is an acclaimed Nordic writer whose works have been translated into several languages. Her most recent novel, Unquiet (2019/2015) was nominated to the Nordic Council's Literature Prize. Grace was published in Norway in 2002 and received the literary award The Reader's Prize in Norway.

Grace is a short novel that describes the cancerous disease and subsequent death of Johan Sletten (simply referred to as 'Sletten' by the narrator), who is a former journalist in his late sixties. Various episodes of Sletten's life are narrated, such as his two marriages and his relationship with his son, who no longer wants to be in contact with him. Although the narrator lets us follow Sletten's thoughts and perceptions very closely, a distance is marked from time to time. One such occasion is on the very first page, when the narrator appears in the text by referring to Johan as 'my friend Johan Sletten' (Ullmann 2005, p. 3). However, from what the 
narrator gives the reader to understand about Sletten, he hardly seems to have any friends.

The novel begins when a doctor informs Sletten that his condition is 'alarming' (Ullmann 2005 , p. 3). Sletten's vulnerability is immediately set in focus: he feels offended that the doctor addresses him by his first name, since he likes to maintain a certain distance with others and shuns intimacy between strangers. This insistence on dignity, propriety and autonomy is, as it turns out, connected to his desire to have control and not be vulnerable. In other words, his ideal is the neoliberal fantasy of an autonomous subject, free from vulnerability and dependence. He is in pursuit of invulnerability, one might say (Gilson 2014, pp. 75-76). When it is clear that the cancer has spread and cannot be cured, Sletten asks his wife, a doctor, to end his life in order to spare him the humiliation and shame of being a burden, a 'vegetable' (Ullmann 2005, p. 111). He wants to remain in control and not lose his autonomy. She initially recoils, even though she is pro-euthanasia in theory; eventually, however, she agrees.

There is a background to Sletten's wish to control his death, which is presented in retrospect. Sletten's father became ill and died when Sletten was a child. The night before his death, he was found 'crawling naked on all fours through their neighbor's garden, leaving a trail of shit behind him' (Ullmann 2005 , p. 24). When the father understands what has happened, he cries with shame and begs his wife not to leave him alone in his misery. She, however, closes the door and leaves; while Sletten's father wails in his room, his mother and big sister cover Sletten's ears with their hands until it stops (Ullmann 2005, p. 25) —that is, until his father dies. This event in Sletten's childhood is presented by the narrator at the beginning of the novel. The question asked in this episode is: How vulnerable and disabled can a person become without losing their humanity in their own eyes and in the eyes of their fellow humans? Sletten's answer to this question is that there is a possibility that the loss of certain bodily and cognitive abilities will rob you of your humanity and put an unreasonable burden on those close to you. This is the fate he wants to avoid, and the reason he asks his wife to end his life.

Although the idea of assisted suicide is at the core of the novel, it circles around situations in which people become vulnerable in different ways. After a 20-year-long unhappy marriage, Sletten loses his first wife, Alice, in a car crash. Sletten had wished for her to die, and had once pushed her from a jetty into the water although she couldn't swim. The situation on the jetty involved an element of trust: you trust your family members 
not to take advantage of your vulnerability. However, in this case, Sletten does just that-he takes advantage of his wife's vulnerability, not intentionally to kill her, but to experience a sense of control in a relationship in which he feels dominated. By transgressing trust in this way, he exposes his wife to her vulnerability and dependence on him, the kind of 'permitted dependency' in families that, according to Scully (2013, p. 217), is naturalized and viewed as unproblematic. In this episode, however, it is exposed and to some extent de-naturalized.

Sletten saves his wife from drowning, and they recover from this episode in their lives; but then, the narrator states abruptly, 'as luck would have it, she was run over' (Ullman 2005, p. 11), making the frailty of human life the centre of attention again. Sletten's son by his first wife is described as 'transparent and brittle' (Ullman 2005, p. 12). His second child with Mai, his second wife, is aborted because the foetus is injured. Sletten thinks of the baby as a child-his child — while his wife calls it 'defective' and 'deformed' (Ullmann 2005, pp. 38-39). Her rationale is that she cannot bear to give birth to it, and that Sletten had not even been able to take care of a healthy child, and could not be expected to manage a disabled one. But Sletten thinks of the baby's little heart, pumping twenty-eight litres of blood every night and day. Mai, being a physician by profession, represents a medical and rational perspective instead.

In all these retrospectives, which are brought about by Sletten's disease, human vulnerability is the common denominator. Although disability is not foregrounded in this narrative, vulnerability is, in different ways: in addition to vulnerability as illness, in the case of Sletten's father and Sletten himself, the narrative puts forward an ontological vulnerability that is shared by all humans, as well as the ethical challenges to life constituted by euthanasia and abortion.

As Sletten's condition worsens, his body starts to change. He has a disfiguring boil on his face 'transforming him, even in his own eyes, into a monster with two heads, one big and one little, that scared other people away' (Ullmann 2005 , p. 44). This description can be read as an allusion to Pascal Pinon, who was both a historical person and the two-headed circus 'monster' in Per Olof Enquist's well-known novel Downfall. A Love Story (1985). As in Enquist's novel, the second head has a life of its own in Grace:

Sometimes it was huge, pulsating and purple as an eggplant; sometimes it was pallid and lackluster. Like a newborn infant, it had to be tended and 
soothed. It was drained of fluid, smeared with salves, and occasionally even swathed with bandages.

He once claimed to have been woken by the sound of the boil crying. (Ullmann 2005, pp. 44-45)

When Sletten looks at himself in the mirror, he imagines that the boil grins at him (Ullmann 2005, p. 62). His body is not his own, and is revolting against what he perceives as himself-largely, a disembodied self. It is also clear from the episode with the mirror that Sletten has incorporated a particular way of looking at deformity as monstrosity, which could be distinguished as 'exotic' from Garland-Thomson's (2002) four types of visual rhetoric (i.e. the wondrous, the sentimental, the exotic and the realistic). The exotic 'presents disabled figures as alien, distant', and is characterized by 'curiosity or uninvolved objectification' (GarlandThomson 2002, p. 65). On the one hand, Sletten separates himself from his - in his own eyes - deformed body, thus objectifying it. On the other hand, the body refuses to be objectified, and demands care and attention. His body looks back at him. This signifies a transformation of Sletten's understanding of himself. His dream of being autonomous and able to exercise control over his body can no longer be upheld.

Sletten's gradually progressing illness also brings him in contact with the vulnerability of others. He thinks about his father, the unborn child and situations in which his son, Andreas, needed help, but in which Sletten couldn't face Andreas's vulnerability. This confrontation with vulnerability - his own and that of others-transforms Sletten. Even though, at the beginning of his illness, Sletten was convinced that he wanted his wife to end his life, by the end, his desire is not so clear. When Mai says that it is time, Sletten wants to protest but cannot make her hear him. Although the novel by no means explicitly takes sides in the question of assisted suicide, it is possible to read his wife's commitment to her promise as being as rational and medical as her decision to end her pregnancy. Even though Sletten sees himself as a monster in one stage of his illness, by the end, his disabled and vulnerable condition does not prevent him from trying to defend his life and experiencing its value.

In Vulnerable Subjects, Couser (2004) discusses what he names 'euthanography'; that is, 'narratives in which euthanasia (in any form) is considered, but not necessarily enacted' (p. 124). He uses this concept in the context of life writing-more precisely, in narratives by suicide assistants, whose stories are 'determined by their complicity in the death 
they narrate' (Couser, p. 125). Grace, however, is not primarily narrated from the point of view of Sletten's wife, although the narrator informs the reader about the aftermath. Mai calls up the doctor in charge of Sletten and admits to the assisted suicide, while being prepared to be handed over to the police. However, both agree to keep it a secret instead. Then Mai sits by Sletten's bed for a while, but feels that there is no point. 'What was it that she wanted? To hear him say that it was good finally to rest?' (Ullmann 2005, p. 130).

Couser (2004) argues that, in order to be 'rhetorically compelling and ethically satisfying, euthanography must present the suicide as rational, autonomous, and uncoerced' (p. 125). Representations in a novel are not subject to the same rhetorical constraints. In Grace, despite the previous discussions between Sletten and his wife-which may be taken as proof of a rational, un-coerced and autonomous decision-this is not quite how it plays out. Sletten experiences his perception changing, and floats in and out of consciousness. When Mai speaks to him, he understands that she cannot hear his answer. When Mai asks him 'It is time...isn't it?' (Ullmann 2005 , p. 127), referring to the promise that she has made to him, Sletten has lost the ability to communicate. He cannot say the words to Mai that are nevertheless communicated to the reader: 'Don't, Mai! Not yet! Please! Wait till it grows light' (Ullmann 2005, p. 128).

The narration of Sletten's last moments at the hospital seems to confirm that he has moved beyond the ideas of autonomy, control and dignity. His vulnerability did not make him less human, but made him value life more. The illness brings disabilities that Sletten resents, but ultimately opens up a new ability as well: for the first time, Sletten is able to experience and acknowledge his own and others' vulnerability without resentment. This ability was not accessible to him when he was an able-bodied man, governed by his pride and principles. In this text, vulnerability and disability thus have a transformative power. Sletten finally develops a new sense of self-worth that does not depend on dignity, decency and control, but on a sense that he values his life, despite how circumscribed it has become.

\section{CONCLUSION}

I have taken as my starting point an ontological understanding of vulnerability and an understanding of disabled people not as a separate group with separate needs, but as people who are more likely to be disabled by 
societal norms due to their impairments. As is shown by the reading of Baby Jane and Grace-two novels that do not explicitly represent disability as a theme- $a$ focus on vulnerability helps to disrupt the idea of 'the disabled' as a separate group and as a specific theme in literature. Both novels engage in the experience of vulnerability and of becoming disabled in the eyes of oneself and others. Both also bring to the fore questions of dependency and autonomy - that is, relational aspects of vulnerability and disability.

In the case of Baby Jane, the title can be taken as a paratextual indication that the narrative somehow concerns disability; it guides the reader to understand imprisonment and dependence as main themes that are common to the film and the novel. Although the precarity caused by different transgressions of normalcy, such as homosexuality, seems partly to explain the psychiatric disorders experienced not only by Piki, but also by the narrator and many of their friends, this is not the whole explanation. The interpretation of the narrator is that Piki's dependency on Bossa, whose controlling 'help' is disabling Piki, is another important factor in the deterioration of her condition. In Grace, Sletten has to rid himself of the illusion that he can be autonomous and in control, and gradually come to terms with his, and others', vulnerability. As his illness progresses, Sletten passes through a stage in which he objectifies his own body. $\mathrm{He}$ sees his body as a monster, which can be described as the able-bodied fear of the disabled body. In the end, though, he still values his life, despite his suffering and loss of control and dignity.

Both stories end in death. In the case of Piki, she plans her death as a suicide assisted by the narrator, but it ends in murder. When it comes to Sletten, the planned voluntary euthanasia becomes involuntary instead, when Sletten can no longer communicate. In Grace, this act is initially presented as a wish to escape humiliation and dependency on Sletten's part, while his wife is motivated by rational arguments to relieve suffering. In Baby Jane, the planned assisted suicide can be seen as manipulated by Bossa, who leaves Piki with no other option. In both cases, death as a subjective decision by Piki and Sletten is contradicted by how their lives are actually ended: by the violent intervention of others.

Both stories engage in a critique against what Garland-Thomson calls 'the normate'. Sletten initially equates his value as a human being with the fulfilling of certain norms of autonomy and dignity. His illness means a transgression of these norms, exposing him to his own and to others' vulnerability. In Baby Jane, the normate is critically examined through the 
juxtaposition of middle-class heteronormativity with the economic and social precarity in Piki's social circle.

Disability as a narrative prosthesis is very common in fiction-for example, I would argue, in the portrayal of the autism-spectrum detective Saga Norén in Bron/Broen. She is used as a 'crutch upon which literary narratives lean for their representational power, disruptive potentiality, and analytical insight' (Mitchell and Snyder 2000, p. 49), thus shedding light on the good and bad sides of postmodern normalcy. Disability in the two texts discussed here is, instead, a consequence of normalcy. Therefore, disability can be read as a critical position that reveals the vulnerability of subjects in general, not only of those who are explicitly narrated as disabled.

\section{Note}

1. Since Baby Jane has not been translated into English, the translations of quotations in this chapter are mine. There is no translation to English of Stalin's Cows, either. I have used the same translation of the title as is used on Oksanen's webpage, http://www.sofioksanen.com/books/stalinin-leh mat/. Accessed 9 June 2019.

\section{REFERENCES}

Bérubé, M. (2016). The Secret Life of Stories from Don Quixote to Harry Potter. How Understanding Intellectual Disability Transforms the Way We Read. New York and London: New York University Press.

Butler, J. (2009). Frames of War: When Is Life Grievable? London: Verso.

Butler, J. (2015). Notes Toward a Performative Theory of Assembly. Cambridge, MA: Harvard University Press.

Couser, G. T. (2004). Vulnerable Subjects: Ethics and Life Writing. Ithaca and London: Cornell University Press.

Couser, G. T. (2009). Signifying Bodies: Disability in Contemporary Life Writing. Ann Arbor: University of Michigan Press.

Davis, L. J. (1995). Enforcing Normalcy: Disability, Deafness, and the Body. New York: Verso.

Dederer, C. (2006, 20 March). Bad poem, great song. How singer Marianne Faithful rescued a story about a lost housewife from its creator, Shel Silverstein. Poetry Foundation. https://www.poetryfoundation.org/articles/ 68509/bad-poem-great-song. Accessed 9 June 2019. 
Enquist, P. O. (1986/1985). Downfall: A Love Story (A. Paterson, Trans.). London: Quartet Books.

Fahlgren, S. (2013). Lisbeth Salander-feministiskt svar eller provokativ fråga? In S. Fahlgren, A. Johansson, \& E. Söderberg (Eds.), Åtta genusvetenskapliga läsningar av den svenska välfärdsstaten genom Stieg Larssons Millenium-trilogi (pp. 85-94). Sundsvall: Genusstudier vid Mittuniversitetet.

Freeman Loftis, S. (2015). Imagining Autism: Fiction and Stereotypes on the Spectrum. Bloomington and Indianapolis: Indiana University Press.

Garland-Thomson, R. (2002). The politics of staring: Visual rhetorics of disability in popular photography. In S. L. Snyder, B. J. Brueggemann, \& R. GarlandThomson (Eds.), Disability Studies: Enabling the Humanities (pp. 56-75). New York: MLA.

Garland-Thomson, R. (2017/1997). Extraordinary Bodies: Figuring Physical Disability in American Culture and Literature (Twentieth Anniversary Edition). New York: Columbia University Press.

Gilson, E. C. (2014). The Ethics of Vulnerability: A Feminist Analysis of Social Life and Practice. New York and London: Routledge.

Hirsch, M. (2016). Vulnerable times. In J. Butler, Z. Gambetti, \& L. Sabsay (Eds.), Vulnerability in Resistance (pp. 76-96). Durham and London: Duke University Press.

Knight, A. (2014). Disability as vulnerability: Redistributing precariousness in democratic ways. The Journal of Politics, 76(1), 15-26.

Kulick, D., \& Rydström, J. (2015). Loneliness and Its Opposite: Sex, Disability, and the Ethics of Engagement. Durham and London: Duke University Press.

Ma, S. (2014). My Aspergirl: Stieg Larsson's Millenium Trilogy and Visualisations. The Journal of American Culture, 37(1), 52-63.

Mitchell, D. T., \& Snyder, S. L. (2000). Narrative Prosthesis: Disability and the Dependencies of Discourse. Ann Arbor: University of Michigan Press.

Oksanen, S. (2003). Stalinin lehmät. Helsinki: WSOY.

Oksanen, S. (2008/2005). Baby Jane (J. Orlov, Trans.). Stockholm: Bazar.

Oksanen, S. (2010/2008). Purge (L. Rogers, Trans.). London: Atlantic.

Oksanen, S. (2017/2015). Norma (O. Witesman, Trans.). London: Atlantic.

Puar, J. K. (2017). The Right to Maim: Debility, Capacity, Disability. Durham and London: Duke University Press.

Quayson, A. (2007). Aesthetic Nervousness: Disability and the Crisis of Representation. New York: Columbia University Press.

Scully, J. L. (2013). Disability and vulnerability: On bodies, dependence, and power. In C. Mackenzie, W. Rogers, \& S. Dodds (Eds.), Vulnerability: New Essays in Ethics and Feminist Philosophy (pp. 205-221). Oxford: Oxford University Press.

Shakespeare, T. (2013). Disability Rights and Wrongs Revisited. Hoboken: Taylor \& Francis. 
Shildrick, M. (2002). Embodying the Monster: Encounters with the Vulnerable Self. London and Thousand Oaks, CA: Sage.

Ullmann, L. (2005/2002). Grace (B. Haveland, Trans.). London: Picador.

Ullmann, L. (2019/2015). Unquiet (T. Reinhard, Trans.). New York: W. W. Norton \& Company.

Open Access This chapter is licensed under the terms of the Creative Commons Attribution 4.0 International License (http://creativecommons.org/licenses/by $/ 4.0 /$ ), which permits use, sharing, adaptation, distribution and reproduction in any medium or format, as long as you give appropriate credit to the original author(s) and the source, provide a link to the Creative Commons license and indicate if changes were made.

The images or other third party material in this chapter are included in the chapter's Creative Commons license, unless indicated otherwise in a credit line to the material. If material is not included in the chapter's Creative Commons license and your intended use is not permitted by statutory regulation or exceeds the permitted use, you will need to obtain permission directly from the copyright holder.

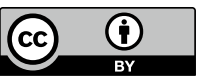




\title{
Life of a Fatso: Young, Fat and Vulnerable in a Scandinavian Society of Perfection
}

\author{
Elise Seip Tønnessen
}

The Scandinavian welfare system is based on ideas of equal access to education and employment. Taking part in society and contributing one's share is seen as a right as well as a duty. Indeed, success in education is connected to high employment later in life, which is a prerequisite for the survival and success of the welfare state. With an educational system that offers the right to 13 years of schooling, it is a paradox that three out of ten pupils in Norway do not finish upper secondary school (normally three years) within a time frame of five years (Sommer 2016). The situation is parallel in the other Nordic countries (Markussen 2010). ${ }^{1}$ This has led to a growing concern for this group of young people, since their failing education is seen to connect to mental health problems and future unemployment (Anvik and Waldahl 2017). In a qualitative study taking the perspective of young people who are not in education, employment or training, Anvik and Waldahl $(2017$, p. 19) raise the question 'whether

\footnotetext{
E. S. Tønnessen $(\varangle)$

University of Agder, Kristiansand, Norway

e-mail: elise.s.tonnessen@uia.no
}

(C) The Author(s) 2020

A. M. Dancus et al. (eds.),

Vulnerability in Scandinavian Art and Culture, https://doi.org/10.1007/978-3-030-37382-5_9 
the welfare state's partitioned help services are able to deal with the complexity of the challenges that the young people face'.

While statistics tell us about increased risks of marginalization depending on social status, disabilities and migration (Markussen 2010), the voices of the young people involved talk of shame and guilt, and that the feeling of failure is reinforced by the awareness of all the welfare state has done for them. They have a desire to be seen as whole people, not merely as users or patients (Anvik and Waldahl 2017). It is this complexity that I aim to shed light on in my analysis of Synne Sun Løes' young adult novel Miss (2017), featuring a young woman who is, indeed, a dropout, but also a resource. Fiction may offer a different kind of access to the full picture than surveys and statistics.

The title Miss carries a double reference-on the one hand, to Ea's feeling of being a mis(s)fit; on the other hand, to her critical stance to her best friend turning into a 'Little Miss Perfect'. Dropping out of school, over-eating and skipping her exercise are some of the means Ea uses to place herself as an outsider and, hence, in opposition to perfectionism. She insists on describing herself as a fatso ('tjukkis') and regards herself as a social loser. Hence, her most vulnerable features are central in her resistance to living up to expectations for young females in contemporary Scandinavian society. As Ea struggles with her increasingly fat body, she can also be seen as a symptom of an affluent society where the young no longer see any sense in reaching for a future. In all, these voices convey a social criticism that I will try to catch in my final discussion.

Two themes are recurrent in Ea's position as an outsider: her decision to drop out of school, and her over-eating. These are the two reasons Ea gives for why she has been going regularly to therapy since she was 13 (Løes 2017 , p. 20). Together, they represent both social and bodily protest, making her strong as she exposes her vulnerability.

\section{Young AND Vulnerable}

In a certain sense, one can claim that being young in itself means being vulnerable. Young people are in a phase of transition from child to adult, from being taken care of to taking responsibility for their own life. According to Erik Erikson's stages of psychosocial development, the period from puberty to young adult is characterized by the specific challenges of finding an identity, followed by a stage where the challenge is to 
develop intimate relationships and friendships. Failing to meet the challenge of identity may lead to problems with role confusion later in life, while the lack of intimate relationships may lead to isolation (Erikson and Erikson 1998). Specific to Erikson's theory is his emphasis on sociocultural and biological forces in a person's development. Unlike other theories of development from child to adult, he also recognizes that development carries on throughout a lifetime, and that previous crises may be solved later in life. The existential question of the teens is: Who am I and what can I be in terms of occupation, gender roles, politics, and beliefs?

The Danish scholar Ayoe Quist Henkel points to this feeling of vulnerability as a basic characteristic of young adult fiction:

Basically, youth literature conveys a range of emotions that are particularly prominent in the period between being child and adult: often in a form representing and reflecting on the feeling of being in an existential vacuum characterized by vulnerability and uncertainty bordering to desperation. (Henkel 2011, p. 24, my translation) $)^{2}$

This has been reflected in Norwegian contemporary young adult fiction, as emphasized by the recent juries of The Ministry of Culture's prizes for children's and young adult literature, highlighting central themes such as identity and the uncertainty of youth. Eeg, leading the jury for publications from 2017, specifically mentions Miss, by Synne Sun Løes, as an example of an outsider who rebels against parents, the establishment and the social norms connected to body, appearance and schooling (Eeg 2018).

Synne Sun Løes' novel may be seen as part of a Scandinavian trend in some ways. But the novel also stands out from typical stories about young teens struggling to fit into new social arenas, in its thematic complexity as well as in the form of narration. The main character, Ea, is 16 years old, and on the point of dropping out from her first year in upper-secondary school. She defines herself as a misfit, apparently with no interest in adapting to social expectations. Rather, her life can be understood as a protest against her well-adjusted parents' expectations. Her mother is a doctor, a general practitioner; her father is an accountant: they both expect Ea to make the best of her abilities, live a healthy life and prepare for a successful future. In contrast, Ea has dropped out of school and spends her days knitting small garments for pets (dogs and cats), reading, going to her therapist - and eating. 
The narrative is strongly focused on Ea's body and personal life, relating mainly to family and therapists. Apart from Fanny, who has been Ea's best friend since their mothers met in the maternity ward, there is hardly any mention of classmates or social life at school. During the book, Ea develops a relationship to her neighbour Viggo, a rich heir who is even more of a dropout than herself, mostly taking drugs and watching television series. In addition to the close-up on Ea's personal life, the novel gradually reveals a social context that includes political and ideological issues, as well as the history of Ea's extended family.

Much attention is given to Ea's close relationship to her Aunt Edith, and the importance of this relationship becomes apparent when the reader learns that Edith committed suicide and Ea was the one who found her drowned in the bath exactly one year before the present story begins. Edith was Ea's mother's twin sister and appears to have been a complete contrast: while the mother is skinny, Edith was fat; while the mother is ambitious, hardworking and stressed, Edith was an artist leading a free, but poor life. As the story unfolds, we learn how these contrasts have dominated the mother's life and led to her complete break from her own parents. Both sets of grandparents are surprisingly distant, busy with their own affluent lives and travels.

The novel is structured in two main parts, and covers the period from September, when Ea turns 16, until July the following year. The first part runs through the autumn until New Year's Eve and describes Ea's downward development spiral from the moment she decides to drop out of school. The second part runs from January until July, displaying a gradual change of perspective from introspective disgust to an outward interest in other people's lives wherein Ea takes on more responsibility. Within each section, the story is told through a varied set of perspectives, which are visually marked by different font styles. All the perspectives relate to Ea and her first-person narrator, but the distinction between them opens up the opportunity to see the ambivalences and tensions in her situation.

\section{Vulnerability and Resistance}

In answer to what vulnerability is, Mackenzie et al. (2014) propose three different sources of vulnerability. First, they claim that vulnerability is inherent to being human, since we exist in bodies that may be hurt, and we are dependent on others who may not always fill our needs. This source of vulnerability is closely connected to understanding the human 
condition as based in the corporeal and the social. My claim, that being young is a state of vulnerability, can be understood along these lines. Second, Mackenzie et al. point to specific situations as a source of vulnerability. This view ties vulnerability to context in time and space. In Miss, the fact that Ea finds her Aunt Edith drowned in the bath after committing suicide makes Ea specifically vulnerable. The third source of vulnerability is characterized as pathogenic, and is closely connected to questions of power and dependency. Mackenzie et al. (2014, p. 9) point to how institutional structures, as well as interpersonal relationships, may become sources of power that can be misused, thus failing to meet the very needs they were designed to address. Dependency may occur in professional relations, such as between therapist and patient. In family relations, the child's dependency on adult care is typically changing through adolescence and this, in itself, may cause imbalance and displacements in dependency and vulnerability in times of transition. In Ea's case, it is particularly interesting to discuss whether her outsider behaviour is a healthy or harmful reaction to what she experiences in relation to parents and therapists.

According to Judith Butler, vulnerability can manifest on individual and collective levels, and it can take bodily or linguistic forms. Linguistic vulnerability is expressed by name-calling and discursive categories. Discourses produce ideals and norms that act on us, and shape the ways we act and understand ourselves. Butler's main example is about how gender is performed and assigned through language. In my analysis of Miss, it may be interesting to look at how Ea negotiates discourses of her as being fat, client, daughter, school dropout and so on.

Judith Butler presents a discussion on how vulnerability relates to resistance, where she points out how vulnerability must be understood within social and material relations:

What I am suggesting is that it is not just that this or that body is bound up in a network of relations, but that the body, despite its clear boundaries, or perhaps precisely by virtue of those very boundaries, is defined by the relations that make its own life and action possible. As I will hope to show, we cannot understand bodily vulnerability outside this conception of social and material relations. (Butler 2016, p. 16)

Butler points to how humans are formed by social norms 'that precede us', and comments on her understanding of performativity as dual rather 
than opposites, comprising 'both the processes of being acted on and the conditions and possibilities for acting' (Butler 2016, p. 18). Butler's discussion is set within a social and political context, where she claims that vulnerability and resistance condition each other: "vulnerability, understood as a deliberate exposure to power, is part of the very meaning of political resistance as an embodied enactment' (Butler 2016, p. 22). Moving her ideas into literary analysis of fiction, I find the relational and performative aspects of vulnerability interesting, as well as the social context in which these relations, actions and discourses are set.

Returning to the dilemmas of the Scandinavian welfare states concerning dropouts from school, I find the novel Miss by Synne Sun Løes (2017) an interesting case for discussing questions of vulnerability and resistance. How is the dropout positioned in relations to family, friends, institutions of support and society as a whole? How may her vulnerability be understood, and how can resistance change her position?

Miss was selected by the International Youth Library as one out of six Norwegian titles for The White Ravens international catalogue 2017, where it was labelled with the key words 'Overweight; Outsider; Norm; Differentness' (White Ravens 2017). In some ways, it represents a tendency in Norwegian young adult fiction of increased interest in the vulnerability of young girls in contemporary society. In other ways, it transcends this trend. The first part of the analysis will be thematic and discuss two main questions: What has made this teenager from a well-off family so vulnerable? And what forms of resistance do we see? In addition, my analysis will point to formal features, such as how the resistance is voiced and in what kind of discourse it is expressed. Finally, I will discuss what this novel may reveal about contemporary Scandinavian society, and how it offers perspectives on the social norms and discourses that 'precede us and that form the constraining context for whatever forms of agency we ourselves take on in time', to put it in Judith Butler's words (2016, p. 18).

\section{Miss-A Network of Relations}

The relational nature of being situated in the world is integrated in the very structure of the novel. The story is told as a collage of voices through which we follow Ea through her dialogues with key relationships in her life: her successful parents; her late aunt, with whom she identifies; her friends; her therapists and, not least, her own body. 
As already mentioned, one person of particular significance for Ea is her Aunt Edith, her mother's twin sister. At the point when Ea writes her story, a year has passed since Edith committed suicide by drowning herself in the bath. This incident is never explicitly mentioned within the family-it is taboo. But the experience remains there, immediately beneath the surface, which can be seen in the reactions of Ea's mother when she finds the book The Sacred Art of Dying under Ea's bed. This experience may represent a double trauma in Ea's life: not only has she lost her beloved aunt in the worst way possible, this trauma is also haunting her relationship to her mother, who is terrified that Ea may turn out the same way.

The story about the twin sisters Edith and Birgitte (Ea's mother) unfolds gradually. Ea retells what she has heard from Aunt Edith about a constant conflict between Edith and her mother (Ea's grandmother), who considered her daughter mentally disturbed and tried to slim her down by force as early as at the age of 10. Ea's mother seems to have been squeezed between sister and mother and, ultimately, she had chosen to give her loyalty to her sister. However, she never talks about it after the death of her sister. Her stance is not revealed until Ea's grandmother contacts her, suggesting that the little family could join the grandparents in their new vineyard in Italy for a summer vacation. The two have not spoken for nine years, so this conversation is very disturbing to Ea's mother. She drops her guard and Ea sees her mother soften and weaken, and become a person who needs her help. In this situation, Ea's mother finally speaks to Ea about the wrongs done to her sister-a situation that mirrors what she sees happening to Ea.

Ea's core family is vulnerable because of its isolation from extended relations. Mother, father and child are at each other's mercy when there are no other close relations to support them in times of difficulty. Ea has no siblings, no cousins, and the only close relative outside the core family seems to have been Aunt Edith. All four grandparents are alive and well, but they seem too busy living their own individual lives to be close to their grandchild during her difficult times. Admittedly, her paternal grandparents are mentioned as a possible solution to her quitting school. But the fact that they are called by their forenames, Else and Tor, and not referred to as Grandmother and Grandfather, indicates that family commitment is not their first priority. They live in Houston, Texas, in a big house with its own gym and swimming pool. Even more distant are 
her maternal grandparents, who turn out to be part of the problem when they try to enter the scene after nine years of withdrawal due to conflict.

While Ea's relation to Aunt Edith reveals a similarity that appears to be a scary reminder of Edith's destiny, her relation to Viggo next door has the opposite effect. With Viggo, Ea finds herself saying the same kind of things that her parents say to her: 'Even if you don't need to work for a living, it is not a bad idea to have a job [...] for your own mental health' (Løes 2017, p. 200). ${ }^{3}$ She tells her therapist that she is worried about Viggo, because he has no ambitions for his life, and he will not go out for a walk, and just sits indoors and watches television series (Løes 2017, p. 146). Meeting Viggo and his family triggers Ea's soundest instincts. She refuses to smoke marijuana with him, and when Viggo's skinny mother suggests that she may just throw up all the food she eats, $\mathrm{Ea}$ is appalled. It appears that meeting someone she sees as more vulnerable than herself demonstrates to Ea the nature of her limits.

Summing up this part of the thematic analysis, we may see Ea's vulnerability as both inherent and situational. She is in an age of transition, and she is at her most vulnerable at the point when she is supposed to enter upper-secondary school. This is not uncommon among teenagers in Scandinavian countries, as witnessed by dropout statistics. At this point in a teenager's life, societal expectations increase, in parallel with the end of compulsory schooling. A more specific reason for her vulnerability is situational, connected to her identification with her Aunt Edith and her fate. In Ea's case, it is hard to judge whether her specific situational vulnerability triggered her inherent vulnerability at the point in her life where dropping out could carry serious consequences. The fact that she has been receiving therapy since the age of 13 , two years before she was faced with her aunt's suicide, points to a more longstanding vulnerability. But it may also point to the expectations and solutions of a certain class.

\section{A Vulnerable Body}

Miss has been read as a book about eating disorders by some of the reviewers. 'Intelligent on eating disorders' is the title of Anne Cathrine Straume's review (2017, my translation). However, Straume connects the weight problem to Ea's position in society: 'Eating disorder is not a choice one makes, rather it is a consequence of an inner or outer pressure where power over the body may appear as the only way to cope' (Straume 2017). 
Ea is not just chubby, she is fat. Looking into the mirror, she sees $104 \mathrm{~kg}$ of body mass distributed on her $166 \mathrm{~cm}$ height. She weighs twice as much as her skinny, ambitious mother. Her mother has made some rules in exchange for accepting that Ea chooses not to go to school: she is supposed to go for a walk or do some exercise every day, besides doing independent studies. Hence, the vulnerability of being fat is mainly expressed through the mother's concern. In her worries, Ea's mother is not just mirroring the politically correct understanding of individual responsibility for maintaining a healthy body. Her worries are also the result of experiencing the decay of her own sister, a fear that is only mentioned in affect. This means there are collective as well as individual norms and ideas that precede Ea's situation and act on her, and Ea's resistance is best understood as a reaction to this situation. She has, however, reached the age - and the size-that prevents her parents from controlling her. So, staying inactive and over-eating is a very clear sign of resistance. Nevertheless, Ea understands the dangers of over-eating and, to herself, she sometimes admits that she is afraid of getting too fat to move around, and of ending up like her Aunt Edith, who was so fat in the end that she could barely move.

Throughout the book, we find repeated chapters with the heading 'Life of a fatso' ('Livet til en tjukkis'). These are set in bold; ironically, the word for bold typeset in Norwegian translates to 'fat'. By labelling herself a fatso, Ea manages to counteract her own discursive vulnerability. At one point, her friend Fanny asks why she uses the form 'tjukkis' for 'fatso', not the more common 'tjukkas'. ${ }^{4}$ Ea's answer shows a clear strategy of discursive power in insisting on her own form of the word. She claims that a woman cannot be 'tjukkas'. 'Tjukkas smells of hairy truck driver with sweaty buttocks. If you are a woman, you are Tjukkis', Ea claims, adding that the female version smells sweet and synthetic (Løes 2017, p. 296). In Ea's middle-class context, her body is not being talked about in such a blunt way. In fact, Ea says that her therapist Elliot never mentions her body and seems to avoid seeing it. This opens a void that Ea fills with resistant discourse.

In the first fatso chapter, Ea defends fatsos in society, claiming that they deserve more respect for the hard work it takes to eat a great deal of unhealthy food (Løes 2017, p. 43). She claims that fat people contribute to economy, since they consume a lot of food, and require a great deal of textiles to cover their fat bodies. They also contribute with entertainment, as being a perfect cast member for a reality show. She also compares fatsos 
to old people, sketching a life situation of reduced activity. One sign of change in Ea's life is when she starts searching for fat role models. She reflects on why so many people seem to hate Lena Dunham in the television show Girls and concludes that the reason is that she muddles up their prejudices: a fat person should be shy, shameful and a failure, but Lena Dunham is fat (or, at least, not skinny), smart, rich and leads a successful life (Løes 2017, p. 139). These observations point to a developing consciousness about the possibility of resistance.

\section{Social Vulnerability}

Dropping out of upper-secondary school at an age between 16 and 19the age when one becomes an independent subject and should be able to make major decisions about one's own life-is the most common outsider position for youth in the Nordic welfare states. Expecting the entire population to finish 13 years of schooling is a rather new phenomenon that seems to expect the entire population to abide by middle-class values of education. It is well-known from welfare research that there is a statistical connection between education, employment and health (Anvik and Waldahl 2017).

Ea's mother knows all about this from her experiences as a general practitioner. Hence, her worries must be seen as very realistic, and her coping strategy is mainly discursive. She refuses to put the label 'school dropout' on her daughter and prefers to say she is taking a break. In an affluent family, there are ways to disguise the problem-in this family, the story is that Ea will spend the spring term with her paternal grandparents who currently live in the USA. The mother also knows all about how to handle the formalities around her daughter staying away from school. Even so, she seems terrified of failing as a parent and makes Ea promise not to let her mother's friends become aware of what is happening. When Ea's therapist tries to challenge Ea to tell him what she is afraid of, Ea answers that 'it is mom who is scared, not me. I am not the type' (Løes 2017 , p. 159). What her mother seems to be scared of is the long-term consequences of not finishing an education in today's society, where there are few job opportunities for unskilled workers. Central, here, is the social stigma for Ea, and indirectly for her mother, who sees Ea's situation as a sign of inadequate parenting.

The novel offers no explanation why Ea does not want to go to school. There are no indications that she cannot cope with the school subjects; 
she is fond of reading, and seems to collect ideas and thoughts from quite sophisticated philosophers. Her cultural references represent an interesting mix of popular and classical culture, from books 'for dummies' to The Sacred Art of Dying. ${ }^{5}$ This is a mix typical of a world with digital access to endless cultural materials. Her problem seems not to be that she cannot follow the schooling but, rather, that she does not see the point of it. She does not want to abide by social rules and norms. Another form of resistance is that she does not participate in social media. When everybody forgets about her birthday in the opening of the book, the explanation that Ea and Fanny come up with is that it is because she is not on 'Snap, Insta or Facebook', so no one was reminded about her birthday. Not being on social media is equivalent to not existing in the social world, Ea reflects (Løes 2017, p. 15).

This resistance to doing what everyone else takes for granted bears witness to Ea as an independent person. This is confirmed by Fanny when she and Ea are back together. She says: 'You have always had such incredible self-confidence. Just naturally inside you, while I...I am dependent on having everyone noticing how clever I am, to be able to feel like a real human.' Her conclusion is that Ea is a good friend to be with: 'I can be myself because you are yourself' (Løes 2017, p. 242).

Socially, Ea's problem seems to be that she is not adjusting to society's expectations of a young, well-off and intelligent girl from one of the best parts of the city. This gives rise to an abundance of ironic comments on contemporary society. According to herself, Ea is actually quite successful in business life. She has set up an Internet shop where she sells small garments for pets that she makes herself: she is crocheting bikinis for dogs, and knitting swim suits for cats. The irony of using one's independence for something totally meaningless in the grand scheme of what the world needs reflects back on a society where values are only counted in money. Bikinis for tiny creatures also reveals an obvious contrast to her own fat body, demonstrating vulnerability through resistance.

Throughout the book, we also find chapters where Ea makes 'career plans'-altogether, 19 plans distributed across five chapters (Løes 2017, pp. 81, 152, 228, 267, 316). Each plan is discussed with its pros and cons. Her first plan is to become a new, modern Buddha. The pros are that it only requires her to 'think, meditate, breathe, live and suffer' (Løes 2017 , p. 81 ), but the con is that she cannot allow herself to be really angry. So she discards that idea. In the same way, she goes through all the other ideas-becoming a dog walker, a philosopher, chocolate taster, 
housewife, librarian, living from disability benefits, to mention but a few, until she finally settles for being herself (Løes 2017, p. 316). The pro is that she does not have to waste her life trying to be like everyone else. The con is that she cannot escape herself, no matter how dull or tragicomic her life will be. This insight is what leads up to the ending of the book, where Ea embraces all good things in her life.

\section{A YeAR OF CHANGE}

The novel is structured in two parts with a turning point that links them. The book starts with a chapter where Ea lists all the things that she hates, starting with emotions and her body. It ends in a symmetrical way, with Ea's list of all the things she loves, ending in an abundance of emotions: 'emotions in all sorts of flavors, colors and shapes...Quivering, tingling, prickly, tickling, itchy, crawling...sweet, salt, bitter, angry, happy, longing...scared...(Just love it.)' (Løes 2017, p. 321). Throughout the autumn, from Ea's forgotten birthday until New Year's Eve, life seems to grow darker and more hopeless every day. Ea is trapped in her position as outsider, she falls out with her best friend, therapy seems to have become a habit that does not lead anywhere, and the notion of just having a break seems less and less credible. So, what is it that makes Ea's life take a turn for the better?

A series of events seem to point in the same direction. The first thing that happens in part II is that Ea is told that her psychiatrist has died. This is an ironic follow-up to their last meeting, where Elliot tries to explain to Ea that he cannot go on treating her for much longer. Ea's reaction is totally directed towards herself, she does not see his situation. The last thing she says is, 'You can sleep. But don't die. If you die, I will hate you for the rest of your life. I will sue you!' (Løes 2017, p. 160). In this new situation, Ea agrees to try going to a youth coach her mother has found, Marielle. Initially, Ea is deeply sceptical of anyone named Marielle and, indeed, their first meeting is far from a success. Marielle's approach is quite the opposite of Elliot's. She characterizes him as the protective type, using the metaphor 'bubble wrap', while Marielle is more provocative, like 'itching powder' (Løes 2017, p. 256). It is Marielle who surprises Ea by asking her if she wants to become a feminist. And she raises the question as to where the problem lies: in the fat body, or in society. She recommends that Ea reads a book entitled Fat Is a Feminist Issue by the British psychotherapist and activist Susie Orbach (Løes 2017, p. 218). 
Marielle talks about unhealthy ideals and fat being one of the biggest taboos in contemporary society.

The first sign that something is changing in Ea is her anger. She is angry with life, with her parents and Fanny, with all the anorectics of the world. And she is angry with herself and her own body (Løes 2017, pp. 189-190). The next emotion that appears is compassion. This is due to a change in her relations, first, with her mother, who suddenly needs support and comfort, then with Fanny, who turns out not being so perfect after all. And, finally, her father is involved in a bicycle accident and needs her help. She even feels compassion with Marielle, when she gets chicken pox, but still sticks to their appointment. The change in Ea seems to be in her ability and willingness to see other people's perspectives. In the first part of the book, she is constantly protecting herself by shutting out other people's perspectives. Whenever her mother tries to convince her what is good for her, she answers with irony or exaggeration. Since she is an intelligent dropout, she masters the discourse that could have impressed her opponents, but she uses it for her own purposes. An example can be found in an early clash with her mother, who expresses her concern about Ea not going to school:

Idleness as such is not the root of any evil, on the contrary it is a truly divine life, as long as you are not bored...Søren Kierkegaard.

'Do you want to be completely idiot in your head? Is that what you are trying to do?' mom wheezed.

'Søren was no idiot', was my dry answer. 'Besides, school functions as a prison or a mental hospital, it is only concerned with defining, classifying, controlling and directing people...Foucault said something like that. And he was not an idiot either.' (Løes 2017, p. 33)

This example demonstrates how Ea's resistance is not only bodily, in that she is over-eating and denies leaving the house; it is also discursive (Butler 2016), and shows how Ea, as a result of her social status in a welleducated family, holds the resources for resistance by being able to pick apart her mother's arguments. A teenager who talks about Kierkegaard, Foucault and Buber (Løes 2017, p. 35) may seem a bit too much, if that was what she did all the time. But, typical of a teenager, Ea shifts quickly and unpredictably from the super-intellectual to the childish. Right after 
her Foucauldian critique of power in the school system, she tells her mother that no one can become a normal person when her name consists of only two vowels; an inadequate name inevitably leads to an inadequate person, she claims (Løes 2017, p. 34) This discursive resistance may protect her from her mother's demands and her therapist's challenges but, at the same time, it increases her vulnerability by driving her into total isolation.

The only person that Ea does not feel the need to meet with this protective shield is her Aunt Edith. The chapters about her relationship with Aunt Edith are formulated as letters, each one of them starting with 'Dear Aunt Edith'. These chapters seem to be Ea's sanctuary in the first part of the book. The language Ea uses to express her feelings to Aunt Edith is personal, close and honest. She protects herself against emotions in all other contexts, and refuses to answer Elliot when he finally asks her what she is afraid of. At their last session, she exclaims: 'What is the use of emotions, anyway?' (Løes 2017, p. 160). But in her letters to aunt Edith, she is direct and clear: 'I miss you' (Løes 2017, p. 25), 'What shall I do, Aunt Edith? With myself and my life?' 'I trust you' (Løes 2017, p. 26).

The collage of texts is characterized by different styles, adjusted to the relationship in focus in each chapter. What the chapters have in common is that they all seem to be genres of personal expressions. In a digital world, these are found as new genres of self-writing practices in blogs and online diaries (Lüders et al. 2010, p. 955). In spite of the fact that Ea is not participating in social media, she is well acquainted with the Internet, and its discursive practices of self-presentation seem to afford discursive resources that Ea applies in her reflections on her life and relations. Her repeated titles, such as 'Life of a fatso', 'Elliot' or 'Little Miss Perfect', resemble blog posts in terms of labelling, as well as personal linguistic form. Her self-presentations include listing who she is, what she hates and loves, and what kind of career she may choose. Jill Walker Rettberg (2014) explores how self-representations develop in digital media. She draws connections from pre-digital writing practices such 'diaries, memoirs, commonplace books and autobiographies', to blogs and written status updates (Rettberg 2014 , p. 1). What is different in the digital age is that what used to be private is made public, multiplying the relations these self-presentations enter into, and adding a social pressure to perform a reflective identity. 


\section{Whose Problem Is It Anyway?}

Sending Ea to therapy to remedy her position as an outsider is a typical individualistic way of dealing with the problem. This solution is questioned when Ea's therapy sessions come to an abrupt end. After Marielle has been away on holiday for three weeks, she says to Ea: 'You are as you are, and that is fine [...] Hence, you don't need to come here anymore. You are a smart young lady' (Løes 2017, p. 285). She adds that she is very impressed with the Internet shop Ea has set up, and that she is not worried about her future at all. She even issues a diploma saying that Ea is 'Fit as a fiddle!' (Løes 2017, p. 318). This raises the question of whether Ea has been 'normal' and healthy all the time. Has therapy only led to perpetuating her in a role as sick and vulnerable? The dependency Ea displays in her relation with her first therapist, Elliot, may point in that direction. Ea often reflects on how Elliot seems sleepy and bored. Her remarks often reveal that the most important thing she has learnt through therapy is being a patient. She plays the role close to perfection, which also means that she knows exactly what to say to please her therapist, or to veer off on a tangent from one of the rare challenges he puts to her when asking what she is afraid of. This strategy does not work with Marielle. With her unorthodox methods of provocation, Marielle is able to take Ea by surprise and shake her out of her habitual rut. However, the contrast between the traditional therapist and the modern coach is not as straight forward as it may seem. Even if the course of events proves Marielle right, Elliot is portrayed with sympathy, whereas the description of Marielle is more ironic. Who knows what three years of talking to Elliot has meant to Ea, perhaps they prepared her for Marielle's provocations? In the fictional context, one of Marielle's important contributions is to provide feminist awareness and to introduce the possibility of resisting all the expectations of family and society.

The novel does not answer questions regarding how Ea ended up as a fatso and a dropout in the first place. Many factors in her life point to a resourceful and well-protected person. Her parents are well-educated and show a keen interest in her life. The family is well-off and live in one of the best parts of the city. At one point, her mother accuses Ea of suffering from 'West side sickness' ('vestkantsyken'; Løes 2017, p. 136). This concept points to the irony of youth in the best parts of town-which is the west side, in the case of Oslo-who struggle just as much as the children of single mothers and the unemployed (Løes 2017, p. 137). Youth 
from the west side of the city are just as depressed, use drugs and struggle with the pressure to perform, Ea's mother has learned on a seminar in community medicine. Indirectly, she seems to ask if Ea's problem is just being spoilt and not being willing to put any effort into her life. On a more global scale, this question could be posed concerning how youth in Scandinavian countries take the welfare system for granted, and what consequences that carries for their understanding of how they are positioned in the world.

In the first part of the book, Ea is quite clear that she does not want to be 'normal', to adjust to the middle-/upper-class respectability that is expected from her. She avoids emotions of any kind, protecting herself behind ironic comments and exaggeration. She states explicitly that she wants to remain in control, which seems to be the explanation for why she hates it when Fanny pops in on unannounced visits. All these reactions increase the distance between Ea and other people and contribute to her position as an outsider. Even though her mother's worries are hidden behind the thick layers of irony that Ea's voice adds, the reader realizes that there is some truth to the problems her mother foresees. The fate of her Aunt Edith is but one example of where marginalization could lead.

Through Ea's voice, we see glimpses of a society that expects everyone to follow the same route to perfection. She seems to be displaced in her criticism of contemporary society: 'I say that I long for another time. A time without mobile phones and social media. Likes and Selfies' (Løes 2017 , p. 46). Towards the end of the novel, Ea reflects on 'The life of Miss Misfit' and why she does not fit in, concluding that 'EVERYTHING is too tight' (Løes 2017 , p. 312). She asserts that 'There is too little stretch in the society-skinny-skinny-jeans' (Løes 2017, p. 312). Hence, the problem is not Miss Misfit, but a society that does not provide enough flexibility and space for her expansion, either bodily or mentally.

In her criticism of society, Ea's comments may be strong and to the point. Yet, these comments are set in a context where Ea is obviously a part of the same society that she is criticizing. She is critical of modern media but earns her money from selling pet garments on the Internet, a production of goods that can only be valued in a society where communication has become a commodity. And she finds her wisdom not only from traditional philosophers, but also from modern life coaches and commercial self-help literature, as can be seen when she mentions Tony Robbins as 'the man in my life' (Løes 2017, p. 290). She asserts that 'Tony R. can be trusted, he is always available, non-stop-night-and-day, never sleeps. 
Every time I need some popular-psychological Pepper to pep me up, I just search his name, and there he pops up. Tony R. Full of energy and golden peppercorns' (Løes 2017, p. 290).

To what extent is Ea's situation typical of being young in contemporary Scandinavia? She belongs to what has been termed the 'Skam generation', referencing the popular television series Skam [Shame] (Andem 2015-2017) that peaked at the time when Miss was published. The Norwegian Broadcasting Corporation (NRK) did extensive research into their target group of girls aged 16 before they launched this story about a group of young people at an upper-secondary school in Oslo in September 2015 (Lindtner and Skarstein 2018, pp. 14-15). Shame may seem to be a more relevant characterization of Ea's emotional state than of the social group of characters in Skam. Nevertheless, the experience of being self-conscious to a degree that may lead to feelings of worthlessness-and, hence, social withdrawal-seems to be typical of Ea's generation. The series was character-driven, focusing on one character each of the four seasons, hence foregrounding emotions, values and relations between the individual and the group. The technique of transmedia storytelling, distributing events between online video clips and postings in social media created what the Danish film scholar Anne Jerslev (2016) termed 'emotional virtual reality'. The focus on individual identity work resonates with trends in young adult fiction, where identity, missing relations and outsider positions were recurrent themes throughout the same period, according to the juries awarding the yearly book prizes for literature for children and the young. ${ }^{6}$ As contemporary narratives, these stories reflect the challenges young people go through in terms of being made responsible for creating their individual selves in a culture of high achievement and ubiquitous social control. At the same time, these stories enter into the discourses and social norms that form the conditions and opportunities to perform our lives, according to Butler (2016).

The culture of mediated self-presentations discussed in this chapter (Rettberg 2014) sets some typical frameworks for young lives across the modern western world where online life is not constrained by geographical borders. When Ea finally settles for 'being myself' as career goal, this may not be as straightforward as it sounds in a society where selfpresentations are filtered to fit into social media. It is Ea's experience that she does not exist (socially) unless she is present on social media. Finding out who you are, as the central challenge of development in Ea's age 
group, used to be a question of defining the 'I' in relations to other people in face-to-face encounters with relatives, peers, teachers and so on. In Ea's isolation, she meets very few people face-to-face. For a period of time, she talks only to her mother and father, and to the therapists who are paid to talk to her. This points out how much the individual is left to herself in the social class to which Ea belongs.

In the novel, the trend for individualism is underlined by the way the story is structured, voicing the important relations in Ea's life individually. Each short chapter focuses on one relation, Ea and her mother, Ea and her father, Ea and Aunt Edith, Ea's relation to her two friends Fanny and Viggo, and her relation to therapist Elliot and coach Marielle. There is no sense of extended family or community in terms of class, school or other kinds of fellowship. This situation may be typical of the class to which Ea belongs, adhering to values of strong, self-sufficient individuals. Early in the book, Ea declares to her mother that 'love means more than money' (Løes 2017, p. 106), but she has to admit that her mother has a point when she answers that it is easy for Ea to say, as long as she does not have to make money, but merely spend it. Ea then reflects on what her life would be like if her parents were working-class.

The class perspective is mostly touched on indirectly in the novel. In discourses of social democratic welfare states, class tends to be overrun by ideals of equality. Welfare institutions are established to provide equal access to education and health care. In return, citizens are expected to make the best of the opportunities offered. This may be one of the trends that lead to a society of perfection, since there is no excuse for not coping with the expectations of greater society. The kind of pressure that makes Ea feel that everything is too tight (Løes 2017, p. 312) may come not only from her class background but, paradoxically, from the expectations inherent in a modern welfare system.

\section{CONCLUSion}

I started out my analysis asking what has made Ea so vulnerable. What makes this question interesting is that, on the surface, she is wellprotected and on the fortunate side of society. However, she is subject to the inherent vulnerability of being young and in a phase of transition. She is also subject to the situational vulnerability of experiencing her aunt's suicide and, ultimately, the pattern of conflicts in her mother's family. In reaction to this situation, her resistance is expressed in the form of 
over-eating and dropping out of school-which are powerful forms of resistance in the class and society to which she belongs. This raises more general questions about the pressure to perform and invent a self in modern society, and about how we handle situations where young people do not quite fit the required standards.

The novel Miss portrays vulnerability in a young person's life through a series of different text forms, providing a puzzle for the reader to complete by combining all the relations and perspectives presented. Ea's vulnerability is inherent; hence, it can shed light on the drama of being young and struggling to find out who you are, and why and how you are placed in this world in a more general sense. But it is also situational, bearing witness to how every individual is at the mercy of the relations around her, and how individual choices may carry consequences in wider circles.

Ea's resistance is both bodily and discursive, and her creative use of metaphoric language opens up alternative views on her situation and experiences, causing the reader to laugh and cry simultaneously. Indirectly, her very personal accounts of her life and position pose serious questions to contemporary society. The welfare state grew out of an ideal of a community of solidarity where everyone should perform according to their ability and receive support according to their needs. In a modern society, where new media and discourses challenge the performing of self, this novel shows a shift of focus from community to individual, from contributing to the collective 'we' to creating an 'I'. This self-conscious individual may seem strong in her strategies of resistance, as Ea does by turning her back on social expectations. However, as Ea's turning point comes from realizing the vulnerability of others, her story also carries a critique of this individualism.

\section{Notes}

1. With a possible exception for Finland. However, the statistics are based on different ways of delimiting the group of school dropouts and, consequently, cannot be compared directly (Markussen 2010, pp. 14, 73).

2. The quote in original: 'Helt grundlæggende formidler ungdomslitteraturen et udvalg af de emotioner, der er særligt tilstedeværende i perioden mellom barn og voksen: ofte i form av gengivelse af og refleksioner over at befinde sig i et eksistentielt vakuum preget av sårbarhed og usikkerhed grænsende til desperation.' 
3. All translations of quotes from the book from Norwegian to English are mine.

4. According to the dictionary Bokmålsordboka, 'tjukkas' means a fat boy or man. There is no equivalent form of the word for a fat woman; the female form "tjukkis" has been created by the author.

5. Presumably referring to the book by Kenneth Kramer: The Sacred Art of Dying: How the World Religions Understand Death, first published in 1988.

6. Schäffer (2015) talks about identity and adaptation as important themes, along with the uncertainty of youth; Lande (2016) points out a specific focus on introvert voices in the books from 2015, and mentions identity as a recurrent theme in children's literature published in 2016, posing the question 'Who am I? Where do I belong?' (Lande 2017); whereas Eeg (2018) highlights the outsiders searching for identity as particularly interesting in the books published in 2017.

\section{REFERENCES}

Andem, J. (2015-2017). Skam. NRK.

Anvik, C. H., \& Waldahl, R. H. (2017). Excluded youth in Iceland, the Faroe Islands and Norway. Nordic Welfare Research, 2(1), 17-29.

Butler, J. (2016). Rethinking vulnerability and resistance. In J. Butler, Z. Gambetti, \& L. Sabsay (Eds.), Vulnerability in Resistance (pp. 12-27). Durham and London: Duke University Press.

Eeg, M. (2018). Speech by the jury leader at the award ceremony, 8 March 2018. Norwegian Ministry of Culture's annual prizes for literature for children and the young. Retrieved from https://barnebokinstituttet.no/aktuelt/flukt-folel ser-og-humor-her-er-vinnerne/.

Erikson, E. H., \& Erikson, J. M. (1998). The Life Cycle Completed: Extended Version. New York: W. W. Norton.

Henkel, A. Q. (2011). Billeder af ungdomsliv-temaer og tendenser i den nye ungdomslitteratur. In A. Q. Henkel (ed.), Stjernebilleder. Ungdomslitteraturindforing og lesninger bind III (pp. 14-37). København: Dansklærerforeningens forlag.

Jerslev, A. (2016, November 3). Skam III, en verden af følelser. Kommunikationsforum. Retrieved from https://www.kommunikationsforum.dk/artikler/ Anmeldelse-af-SKAM-III. Accessed 24 April 2019.

Lande, A. K. (2016). Speech by the jury leader at the award ceremony, 4 March 2016. Norwegian Ministry of Culture's annual prizes for literature for children and the young. Retrieved from https://barnebokinstituttet.no/wp-content/ uploads /2016/03/Juryleders-tale-ved-prisutdelingen-4.-mars-2016.pdf.

Lande, A. K. (2017). Speech by the jury leader at the award ceremony, 7 March 2017. Norwegian Ministry of Culture's annual prizes for literature for children 
and the young. Retrieved from https://barnebokinstituttet.no/wp-content/ uploads/2017/03/Talen-juryleder-KUD-prisene-2017.pdf.

Lindtner, S. S., \& Skarstein, D. (Eds.). (2018). Dramaserien Skam: Analytiske perspektiver og didaktiske muligheter. Bergen: LNU/Fagbokforlaget.

Lüders, M., Prøitz, L., \& Rasmussen, T. (2010). Emerging personal media genres. New Media \& Society, 12(6), 947-963.

Mackenzie, C., Rogers, W., \& Dodds, S. (2014). Introduction: What is vulnerability, and why does it matter for moral theory? In C. Mackenzie, W. Rogers, \& S. Dodds (Eds.), Vulnerability: New Essays in Ethics and Feminist Philosophy (pp. 1-29). New York: Oxford University Press.

Markussen, E. (2010). Frafall $i$ utdanning for 16 til 20-airinger $i$ Norden (TemaNord, 2010:517). Copenhagen: Nordisk Council.

Rettberg, J. W. (2014). Seeing Ourselves Through Technology: How We Use Selfies, Blogs and Wearable Devices to See and Shape Ourselves. New York: Palgrave Macmillan.

Schäffer, A. (2015). Speech by the jury leader at the award ceremony, 9 March 2015. Norwegian Ministry of Culture's annual prizes for literature for children and the young. Retrieved from https://barnebokinstituttet.no/kult urdepartementets-priser/kulturdepartementets-priser-for-barne-og-ungdomsli tteratur-2014/juryens-begrunnelser-for-bokaret-2014/.

Sommer, M. (2016). Jeg er meg—et menneske på vei-ikke et problem som skal fikses. Tanker om hva unge tenker om psykiske helseproblemer og deltakelse i skole og arbeid. Tidsskrift for psykisk helsearbeid, 13(12). https://www.idunn.no/tph/2016/01-02/jeg_er_meg_et_menneske_paa _vei_ikke_et_problem_som_skal_. Accessed 2 October 2018.

Straume, A. C. (2017, May 2). Intelligent om spiseforstyrrelser. NRK. https:// www.nrk.no/kultur/bok/bokanmeldelse-av-_miss_-1.13497876. Accessed 8 January 2019.

White Ravens. (2017). Miss. In The White Ravens: A Selection of International Children's and Youth Literature. Munich: International Youth Library. http://whiteravens.ijb.de/book/635. Accessed 8 January 2019. 
Open Access This chapter is licensed under the terms of the Creative Commons Attribution 4.0 International License (http://creativecommons.org/licenses/by $/ 4.0 /$ ), which permits use, sharing, adaptation, distribution and reproduction in any medium or format, as long as you give appropriate credit to the original author(s) and the source, provide a link to the Creative Commons license and indicate if changes were made.

The images or other third party material in this chapter are included in the chapter's Creative Commons license, unless indicated otherwise in a credit line to the material. If material is not included in the chapter's Creative Commons license and your intended use is not permitted by statutory regulation or exceeds the permitted use, you will need to obtain permission directly from the copyright holder.

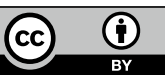




\section{Vulnerable Viewer Positions: Queer Feminist Activists Watching Paradise Hotel}

Fanny Ambjörnsson and Ingeborg Svensson

Uncertainty strikes on the way up the stairwell. There are evidently two possible doors to choose from, both decorated with home-made door signs full of names. A scruffy head of hair peeks out from one of the doors. She nods cheerfully and points up: 'You're here to watch Paradise, right? It's one floor up.'

The collective, beyond the half-open door, smells like a collective usually does - a pleasant combination of boiled chickpeas, old incense and

Parts of this chapter were published earlier in Swedish (Bohlin and Gemzöe 2016).

F. Ambjörnsson ( $₫)$

Department of Ethnology, History of Religions and Gender Studies, Stockholm University, Stockholm, Sweden

e-mail: fanny.ambjornsson@gender.su.se

I. Svensson

Uppsala University, Uppsala, Sweden

e-mail: ingeborg.svensson@etnologi.uu.se

(C) The Author(s) 2020

A. M. Dancus et al. (eds.),

Vulnerability in Scandinavian Art and Culture, https://doi.org/10.1007/978-3-030-37382-5_10 
compost. It is soon to be joined by the smell of freshly popped popcorn, for it is Wednesday, the day devoted to joint viewing of Paradise Hotel.

In queer feminist activist circles, in Sweden and in other countries, there exists the phenomenon of gathering in groups to follow reality shows on TV. The purpose of this chapter is to investigate how this phenomenon can be understood. What emotions are involved and what meaning does it hold for the viewers? More generally, we are interested in how different forms of vulnerability are handled, mobilized and negotiated through the queer feminist viewers' meeting with the reality TV format Paradise Hotel.

The chapter starts out by contextualizing the study, describing the empirical data as well as the TV show to which the data relates, and at the same time positioning the lesbian, gay, bisexual, and transgender (LGBT) community in Sweden as a vulnerable and politically visible group. The subsequent section discusses theories of the reality genre, highlighting the relationship between the media and the audience, as well as discussing feminist re-readings of viewing positions as potentially transforming and empowering, rather than merely repressing. Tapping into theories of vulnerability-where the vulnerable is conceptualized as a relation and resource, rather than a subject position or victimhood-we use the activists' different affective investments in the programme to single out a queer feminist viewer position. Finally, the group watching of Paradise Hotel is analysed as a deeply vulnerable practice, where the queer feminist activists simultaneously negotiate marginalization, subordination and a longing for inclusion in mainstream society, as well as a potential middle-class advantage.

\section{The Viewers ANd Their Context}

The study is based on data consisting of interviews with a total of 11 people, as well as two participant observations during the actual viewing of the show. ${ }^{1}$ The interviewees live in a medium-sized city in southern Sweden and identify as lesbians/dykes or transgender. They are between 19 and 29 years old, and are all involved in the city's queer feminist activist circles. The group is differentiated by class but ethnically relatively homogenous (all of them grew up in Sweden). They were chosen because, as they have done for an extended period of time, they gather regularly to watch various reality programmes: this season the programme is Paradise Hotel. 
Group viewing of so-called reality programmes is not an unusual practice (Edin 2005). Surveys show that the viewership (in Sweden and in other countries) mainly consists of adolescents, young adults and women (Edin 2005; Hill 2005). The people we have interviewed are therefore not unusual. However, as political activists with particular involvement in queer feminist issues, we found it intriguing to investigate how they reason about watching programmes that are usually described as both heterosexist and commercial (Edwards 2004; Brown 2005; Skeggs and Wood 2012).

The group that we interviewed thus identifies as 'queer feminist activists', a term that has gained traction in a Swedish context ever since queer theory's establishment in Sweden in the 1990s (Ambjörnsson 2016). Don Kulick (2005) describes how the queer lines of reasoning in Sweden have mainly been combined with and filtered through a feminist analysis, something he believes has contributed to its strong position in a country with an influential women's movement (cf. Dahl 2011). In recent years, increased interplay between feminist, queer and anti-racist activism has taken place, resulting in presumably progressive public policies of gender, sexual equality and cultural diversity nationwide.

Although statistics show that LGBT people, women and ethnic minorities are marginalized and vulnerable in different ways, feminist, queer and 'diversity' perspectives have found their way into Swedish institutions (Koivunen et al. 2018). With this background in mind, it seems even more so interesting to investigate how different forms of vulnerability are handled and mobilized through the queer feminist TV viewers' encounters with the reality TV format of Paradise Hotel.

\section{Paradise Hotel and the Reality Genre}

Reality TV can be defined as a genre that claims to portray reality (Ganetz 2008). The programmes have 'ordinary' people in the main roles instead of actors, and they lack a script. Unlike the documentary, participants are put into reality programmes in staged situations. Reality TV also often contains elements of interaction with the audience-the viewers can participate in and influence who wins or loses. Anja Hirdman (2008) concludes that reality TV does not describe the relationship between an external reality and the representation of it, as is the case in the traditional documentary. Rather, the format is about the relationship between the medium and the audience. Yet another way to characterize the genre 
is that, rather than claiming to represent the truth, it is mainly about creating proximity and capturing the present. In line with this reasoning, Beverley Skeggs and Helen Wood (2012) claim that the communicative relationships that develop in the reality genre break down the division between the audience and programme participants, and thereby offer an extended social area where the critical distance between text and subject is reduced or-in some cases-is non-existent. Our article will mainly deal with the relationship between the medium and the audience, between the queer feminist viewers and the programme Paradise Hotel. But we also want to investigate how viewing the programme can be related to the informants' reality. It is in this meeting between fiction and reality that various forms of vulnerability are mobilized, managed and contested.

The programme we are dealing with in this chapter is Paradise Hotel which, at the time of the interviews, was broadcast on the Swedish commercial TV channel TV3. Paradise Hotel was conceived by an English production company and, since 2003 , has been produced in different versions in several countries worldwide. In Sweden, the number of viewers has consistently stayed at approximately 300,000 people, with a web audience as of the latest season (2019) amounting approximately to an additional 250,000 viewers. According to the statistics, two-thirds of these were women and the largest viewership group was between 15 and 24 years of age. ${ }^{2}$

The programme is about a group of young men and women who reside in a luxury hotel in paradisiacal climate. The camera's foci are scantily clad, muscly, silicone-boosted bodies: alcohol abounds and every night is a party. The participants' goal is to stay as long as possible at the hotel. This is done by pairing up with a person of the opposite sex. Anyone who ends up without a partner must check out of the hotel. The last couple left at the hotel wins 500,000 Swedish kronor, which they must decide whether to share with their partner... or not. In this way, until the very end, one runs the risk of being betrayed.

Paradise Hotel can be said to be part of the sub-genre of game shows. It is a game, although it contains no clearly defined elements of competition. Instead, the programme is centred around coalitions and rivalryto choose, to be chosen, or to be rejected. The viewer is mainly entertained by spats, sex, drunkenness, gossip and strong emotions. The rules of the game are constantly in flux and, in addition, the couples who manage to create a stable alliance are counteracted by novel contrivances by the producers. Uncertainty and unpredictability can be described as the 
core of the programme format (Madsen and Brinkman 2012). At the same time, the seriality is central-every new season is based on similar characters staying in the same environment, for several weeks in a row (Jerslev 2004). One can even go so far as to claim that the participants appear in accordance with a kind of soap opera repertoire, where similar lines, behaviours and characters return from season to season (Edin 2005, p. 26).

\section{Reality Shows, Agency and Vulnerability-A Theoretical Approach}

The reality genre has been criticized for intermediating neoliberal values, where surveillance and self-development are key ingredients in the construction of a self-controlling citizenship (Ouellette and Hay 2008). Furthermore, researchers have argued that the genre communicates and maintains limiting norms regarding whiteness, class, gender and sexuality (Ganetz 2008; Skeggs and Wood 2012). At the same time, since the 1980s, feminist research has discussed how women's consumption of romantic, mass-produced so-called 'junk culture' (wherein the reality genre can be said to be included) must also be understood as identity work and meaning making (Radway 1984; Ang 1985). Inspired by the feminist research tradition's interest in consumers, recent research has focused on the emotional response involved in the reception (Kavka 2008; Gorton 2009; Abrahamsson 2018). For example, Beverley Skeggs and Helen Wood (2012, p. 113) describe reality TV as a genre that is more about intervention than representation: 'a mode of television in which viewers' own lives are dramatically at stake in the mediation of everyday interpersonal drama'. The focus is therefore on the genre's characteristic immediacy and visually evident emotionality, which in itself is intended to enable openings beyond existing power dynamics.

This, of course, does not mean that power relations and potential vulnerabilities are rendered uninteresting. Rather, this 'turn' to embodiment and affect within feminist cultural studies has increased the interest in ways of understanding vulnerability as complex interrelations connected to power (Ahmed and Stacey 2001; Ahmed 2004; Koivunen 2010). Instead of understanding vulnerability as equivalent to passivity and victimhood, this strand of theorizing highlights both its connections to regulation and subjugation, and its power to bring together and mobilize political agency—what Koivunen et al. (2018) calls the 'double edge of 
vulnerability'. Especially within queer thinking, scholars have called for the need to reclaim and redefine vulnerability as a resource, as well as a common human condition (Shildrick 2002; Butler 2004). For instance, in her exploration of the role of trauma in lesbian public cultures, Ann Cvetkovich (2003) argues for the healing power of vulnerability in working through sexual stigma. Understanding sexuality and sex as areas that, by necessity, make the body vulnerable, Cvetkovich emphasizes how this vulnerability may, at the same time, offer a transformative space for political and personal agency—a reparative strategy (cf. Sedgwick 2003).

Drawing on this theorizing, regarding vulnerability less as a subject position but, rather, as a 'relation to a field of objects, forces, and passions that impinge on us or affect us in some way' (Butler 2016, p. 25), we want to investigate the relationship between the feminist queer activists and the reality format Paradise Hotel. How do the viewers react to participants who fight, humiliate, joke, threaten and perform gross actsmostly within the framework of what can be described as sexism, class contempt and homophobia? Inspired by Sara Ahmed's $(2004$, p. 8$)$ theorizing on relationality as different forms of emotional orientation, we are specifically interested in reactions of 'towardness' or 'awayness', through affective movements. We also relate these different affective investments to theoretical conversations on camp as a specifically queer way of handling vulnerability, both within the queer community (here: the queer feminist viewers) and in relation to the object of desire (here: the reality TV format Paradise Hotel).

Thus, by focusing on the workings of the medium in terms of affectwhich, in turn, compels the viewers to approach or distance themselves, to connect or to retreat-we want to discuss how different forms of vulnerability are mobilized, negotiated and managed through a queer feminist viewer position.

\section{Watching as Political World Making}

The people we interviewed have many friends who jointly watch reality TV shows one or several times a week. However, it was not at all a given that we would end up settling on Paradise Hotel specifically, for the group that we interviewed. Rather, the series is considered one of the more extreme in the reality genre. One of the viewers describes how they coincidentally ended up in front of the show and were repulsed. 
Maja: Like, I don't want to watch it on my own. I never thought I'd start watching this.

Eli: No, me neither!

Maja: And then I did it once and I just felt incredibly sick!

Fanny: What made you feel sick then?

Maja: Everything, I was about to say. How they behave, how they look. How they talk to each other and about each other and about everything. The hetero stress. Ugh. Yeah, and that the whole programme idea is so idiotic, that there's no logic to it, no point.

Livia: Yeah, those who get kicked out are allowed in again. I still don't get it.

Maja: It's just a big pile of fucking dog shit.

Why it is Paradise Hotel they all gather to watch, three days a week for almost three months, is something they themselves mull over. Much of it is about the community, of watching it together. During the interview, they all sit, concentrating intensely, on a large sofa in front of an old CRT TV. One of them has their feet in someone's lap, another fiddles with someone else's hair, and all the while a brownish-yellow cat prowls around their legs. When the programme introduction starts, they laugh aloud and sing along. Then total silence is demanded. The communication between the series' participants often consists of unclear lines, scarcely comprehensible without the utmost concentration. Emotional opinions are therefore delayed until advertising breaks, when viewers laugh hysterically, scream loudly, jump up and down on the sofa, applaud or gripe over participants' actions. As an outsider, one finds oneself quite lost-this is obviously a routine with which they are all well-acquainted, a common ritual. Several of them also describe how watching the show permits a routine in everyday life, even outside of watching time. They have created a common Facebook group around Paradise Hotel, they organize a wager on who will be the winner, and they have, as we will return to later, even tried to approach the programme participants in real life (IRL) on a night out.

As we can see, it is far from a passive, routine type of viewership they engage with. In their in-depth engagement with Paradise Hotel, our subjects could rather be described as fans (Duffett 2013). Unlike the classic definition of fandom, where worship and the cultural production that arises around this worship is centred on a specific object or person, these viewers focus on the community, rather than the object (Fiske 1992). 
None of them report wanting to watch Paradise Hotel on their own. They consume it is as a group, with a sense of community.

One explanation they give for why they watch reality shows together is that the programmes, and the interaction around them, becomes a sort of cohesive glue-something, along José Munoz' (1999) line of thinking, one could call 'world making' (cf. Ahmed 2006). Another reason is that watching, as they describe it, is perceived as a 'relaxation for the brain'. This is something reception studies of so-called junk culture have shown in various contexts (Skeggs and Wood 2012; Liliequist 2000). Evelina explains, giggling, that while others may go to the spa, she and her friends watch Paradise. 'Maybe it's a universal need to recharge to be able to face "hard reality".'

However, in order for the programmes to be perceived as relaxing, a different common denominator is required; namely, the political identification as queer feminist. As mentioned earlier, the viewers are all active in different queer feminist contexts. They choose to live in alternative types of relationships, live in a collective and in opposition to the gender binary norms, and they regard their political convictions as a central part of everyday life. This common outlook on the world becomes, so to speak, the prerequisite for being able to relax and create community around watching Paradise Hotel.

Rachel: I think you have to make yourself clear first. That's what I feel. But when I know I'm with someone I know shares my views, we have the whole analysis of how awful it is, then it would be unnecessary to make a statement about it. Then you just want to enjoy it-the sexism! (laughter) 'You have to indulge and enjoy it to its fullest!'

But it is not only a common political agenda; it is also about a common attitude to the political agenda. That is how Rachel describes what happened when she attempted to watch Paradise Hotel with her partner Jona.

Rachel: We watched an episode of Paradise Hotel together, but she couldn't stand it. And then we were going to watch another episode, and it was like she needed to comment on it all the time. And then said I: 'Enough, you can stop watching it and I'll watch on my own in peace!' (She laughs.) 
In a safe context where the political analysis and attitude to the programme is shared, the viewers can thus allow themselves, as Rachel jokingly puts it, to 'indulge and enjoy it to its fullest'. One simply does not have to be on guard when everyone already knows beforehand that the programme is politically reprehensible. In her analysis of debates about trigger warnings in feminist online forums, Katariina Kyrölä (2018) suggests the term 'vulnerable world making' (paraphrasing José Munoz' concept) to describe the enterprise of creating safer spaces for those living with trauma or societal stigma. Through trigger warnings (i.e. warnings about content that may be upsetting or offensive, or that could trigger post-traumatic stress), the activists try to avoid exposure to potentially injuring messages, thus performing a gesture of care for oneself and related others. The queer feminist viewers of Paradise Hotel also engage in a vulnerable world making, but instead of avoiding the possible triggers, they expose themselves to the worst kind of heterosexist 'junk'. Their potential vulnerability is thus managed, not by avoidance but by exposure-in a safe, queer feminist room.

\section{A Distant Reality}

A prerequisite for feeling safe when watching the programme is, thus, the shared attitude towards the programme. But the comfortable viewing is also about the fact that the programme's representation of reality feels distant. The forms of expression of gender and sexuality that the participants portray are admittedly both familiar and common in countless pieces of media. At the same time, they are perceived as so far removed that they do not intersect with the experiences of our interviewees' everyday lives. Instead, the programmes serve as an opportunity for our subjects to steal a glimpse of this 'hetero spectacle', to take part in something with which they are not quite familiar. Bella explains that it feels comforting to watch such crap TV and be able to conclude that she is 'so fucking far from all that'.

Bella: It's reality TV, but it's also a bit of fantasy. It feels a bit like that, because they are there in such strange conditions. The only thing they get is, like, alcohol. They have nothing else to do. It is a pretend world that's just completely absurd.

Eli: Also, about the fantasy world, like, the kind of people that participate are people I rarely meet.

Bella: Never! (States with emphasis.) 
Eli: And to look into it, into their thoughts and how they tick. Yeah, it really is quite crazy sometimes.

Bella: I really think that's the main purpose. That's what defines relaxing television for me. Like I can't watch anything that's too close to home, because it hurts all the way into my heart. But I can watch whatever sexist shit if it's a costume drama for example. If it's set in aristocratic countries in the 18th century... Then I'm like: 'go for it!' And the same with this. It's so fucking distant, so there's no way you could be provoked; on the contrary, you can just indulge in it and think to yourself: 'Who the hell would want to be heterosexual!?'

One aspect of the viewership that is perceived as pleasurable and safe is that the exhibited heterosexuality is perceived as distant and removed. In comparison to the shagging, fighting, partying and scantily clad participants in Paradise Hotel, the viewers feel somewhat more normal themselves. The feeling of normality, however, is based on the fact that Paradise Hotel cannot be correctly classified as exhibiting normative heterosexuality. Rather, it must be regarded as hyperbolic in the sense of the obscene, exaggerated and shameless (Madsen and Brinkman 2012). The participants' bodies are fit, covered with tattoos and piercings, clearly gone through plastic surgery and they exhibit a studied scantiness of clothing. They undress, bathe naked, make out, shag and sit on the toilet while unashamedly talking about how horny they are-all on camera. It is the illusion of a youthful, lustful and shameless heterosexuality that is put on display. Nevertheless, it is highlighted time and time again that the obscene, dissolute and non-respectable is also class coded-the participants do not embody a bourgeois intellectual ideal with control and moderation as main markers (cf. Skeggs 1997). Several of them talk of Paradise Hotel as their opportunity to 'become something'-at the same time as producers repeatedly edit sequences that show their lack of general education. The viewers' sense of normality is thus based on a feeling of distance, not only to the exhibited heterosexuality, but also to the subordination of a class position. At the same time, the distancing includes a fascination for precisely that which is perceived as unbridled and tasteless. The characters in the programme play the role of living out the life that, for different reasons, one has never gained access to, not been able to live, or opted to not choose. 


\section{Approaching 'The Ordinary'}

If one of the conditions for being able to watch the programme is its perceived distance from everyday life, there is, in the same movement, a desire for intimacy with other viewers. By watching a reality TV series for young people, they also have something in common with all other young viewers between 15 and 30 years. Several of them describe this as a longing to share common cultural expressions with others, more 'ordinary people'. Rachel describes how an important aspect of their viewing of reality TV is precisely the 'mainstream feeling'; keeping up with the discussions at work and recognizing the names that appear on the evening paper posters. Maja also describes how watching it makes her feel closer to 'the mainstream'. When she worked with young people a few years ago, she started reading blogs written by participants in Paradise Hotel, to keep up with the collective conversation. She points out that watching Paradise Hotel gives insights into other worlds and, at the same time, opportunities to learn new things.

Maja: So, I'm aware of the concept of girls making out with each other to make the guys horny, but there's been a lot of guys making out with other guys. And then I've been a little like: 'what now?' 'No, am I a little ...?' Like being completely behind with the thing that apparently you're not supposed to have unerect nipples, I got to learn...

Livia: What?

Bella: 'Sauna tits', like Aina said!

Maja: You can't have sauna tits! And then I was like: 'What, isn't it a bit shameful to have stiff nipples?' And they were like: 'No, that was so ten years ago...'

(Everyone laughs.)

Maja: You're supposed have stiff nipples and guys make out with guys at parties. New stuff!

Approaching 'the alien' thus includes a multitude of aspects - they learn new things, become more 'mainstream competent' and feel involved in a larger community. Here, also, we are dealing with an ongoing construction of normality. By consuming the same TV programmes as their workmates, learning the names of the participants and revelling in soap opera gossip, they feel more involved in a community from which they otherwise partly distance themselves, in which they partly do not always feel included. 
The willingness to approach can thus be regarded as a processing of their sexual exclusion. At the same time, and in the same movement, the distance to the mainstream and 'the popular' is emphasized. Beverley Skeggs and Helen Wood (2012) claim that, for the middle class, a distinctive motivation to consume mass culture is self-development; one learns something about an imagined other world, a learning that in the future can constitute a cultural capital. Through this line of reasoning, we can conclude that the viewers' approachment and learning constitute a managing of a vulnerable sexuality as well as a creation of middle classthat their attempts at feeling normal are based on a subordination of an assumed vulnerable class position.

\section{When Reality TV Becomes Reality-From Lesbian Heaven to Paradise Hotel}

So far, we have described how the interviewees relate to the series as remote and thereby partly manageable. By alienating it, they can also approach it in different ways: revel in it, enjoy it, learn from it and fetishize it. The movement is thus an approach that is made possible by alienation. However, there are sequences in the conversation when their own and the series' realities meet-and the boundaries partly collapse.

Eli: We had found out that Samir, a fun guy, I think, and Jeppe, the abso-

lute worst, would be coming to a club exactly fifty meters away from here.

Livia: Where we also usually go to another club called Lesbian Heaven.

(They laugh.) If I hadn't been there, at Lesbian Heaven, I don't know if I'd thought it was as fun.

Maja: Like, the same place, yeah.

Eli: It was free and we thought: 'Why not? Let's go there!'

Livia: So we went there, half past eleven, like after bedtime.

(The others giggle.)

Eli: And had dressed up in shirts... Lesbian shirts...

Fanny: Ahh, you had dressed up as lesbians?

(Everyone laughs.)

Eli: And so we go past the guards, who gave us a strange look. Or maybe they didn't.

Livia: Yeah, it's just so crazy that we went there! And then we came into this completely empty room with three girls sitting and drinking drinks 
and an empty dance floor. And so we sat down there, very uncomfortably in a small sofa group.

Eli: I was so ashamed! I just felt, 'No, no, no, no, no, no!' I felt that my wall was being razed or my distance to them.

Livia: But they weren't there, they were going to be coming...

Eli: It was cancelled, apparently. So we sat there waiting...

Fanny: In your lumberjack shirts?

(Laughs.)

Eli: For twenty minutes. Then I went out and asked the bartender: 'Where is Samir and Jeppe?' (One of them erupts in bubbling laughter.)

Eli: 'Where are they?' (In a demanding tone.)

Eli: And then she said, 'No, I'm terribly sorry, but they've cancelled.' (In a soft/feminine service voice.)

(The others giggle.)

Eli: It was also during Pride Week (Pride was the theme of one week's episode of the programme, author's comment) and one of the participants had come out as bisexual and then Samir had said: 'Really fucking brave of you to have done that on TV. You are my role model.' So we had kind of said we were gonna come out of the closet for him so that we would become his role models.

(Everyone giggles.)

Eli: Force our way through the crowd and say, 'We're coming out!'

Eli: And get his attention somehow! But then they didn't show up...

(One of them sighs a big sigh, contemplating the memory.)

Fanny: If there had been more than three other people there, would you then have thought that you stood out from the others?

Livia: We had done that, because we were sitting there in our corner and looking completely out of place.

Eli: I think we already thought we stood out. I think I had a picture in my head of the people that would come there and that they were like those three girls in short dresses sitting there. So I already felt pretty fucking stupid.

Livia: Yes, but that's what was so strange. 'Cause it was like then when we were sitting there... We went there and then it felt like I was being quite ironic and kind of like: 'Ohhh, I'll put on my lumberjack sweater!' And when you come in there I'm gonna greet Samir in a different way than these other fans who are more mainstream. But then, when we sat there, it was like I realized I was no different. Or, like, we're just as ridiculous as them.

Maja: To sit there at the pub and suddenly find it a bit embarrassing, it's also because the distance creates some kind of feeling that we're a little 
bit better than them. A little better than the fans who went there unironically, who haven't dressed up or have made it a thing of going there.

In this sequence reality makes an intrusion-or is it perhaps rather that they, inspired by watching Paradise Hotel, allow the different realities to meet. Suddenly they are forced to relate not only to a media text, in a safe social environment and with the TV screen as a filter, but also to the actual people in the TV series (who admittedly did not show up). In the same way, the other viewers become a reality to which to relate. Who are they really in relation to other viewers and fans? And what would they be in relation to the real Jeppe and Samir?

By letting go of the boundaries between fiction and their own reality, they jeopardize the distance on which we have hitherto concluded their viewership to be based. The visit to the pub is thus a precarious endeavour. How is it that they dare to leave their safe space at all?

First, we can note that the specific place plays a central role. The intended meeting takes place at a location near their home, a place they have previously visited and that is partly subculturally coded, in that it previously housed the ambulatory lesbian nightclub Lesbian Heaven.

The time of the visit is also vitally important. Paradise Hotel has just had what is called Pride Week, when the participants are encouraged to play with gender transgressions and homosexual urges. This week, two new participants have joined the programme, a bisexual girl and a transvestite. When Samir explicitly expresses his admiration for the bisexual Linnea's courage to come out on TV, it is seen by the informants as if they, too, were addressed. As they somewhat jokingly express, they, too, want to come out in front of Samir. They want to show who they are, get Samir's recognition and perhaps even become his role models. Based on these premises, they get the idea of joining the game. They dress in identical lesbian coded lumberjack shirts-and act hyperbolically, similar to way the participants in Paradise Hotel do (given the already determined soap opera repertoire).

However, this closing of distance also makes them vulnerable. As Lotten Gustafsson (2002) notes, the vulnerability in the act of playing is linked to the fact that the participant is required to perceive and interpret the meta-communication of play signals accurately. In this case, it is unclear whether they are even recognizable as participants in the game. And Samir never shows up. Instead, they sit uncomfortably waiting, 'long 
after bedtime', feeling increasingly out of place, together with three other girls, who are probably also there to 'play'.

In their engagement with Paradise Hotel, they have obviously imagined themselves as different than other viewers. This hierarchy becomes clear when they suddenly sit side by side in the same room, waiting for Jeppe and Samir. In this act of closing the distance, they no longer perceive themselves as superiors. Neither are they equals. Rather, it is they themselves who, in their own eyes, appear to be incomprehensible, strange and wrong. Moreover, the former feeling of superiority is also felt as neither politically nor ethically desirable-in the actual situation. The distancing, as we have previously discussed in terms of approachment and superordination, is simply not as possible when reality encroaches. They cannot enjoy this form of mass culture in a comfortable way outside of their safe space. They see their elitism, do not stand for it, feel their vulnerability and go home with an unfulfilled goal.

\section{Too Much of A Good Thing}

When the fantasy world suddenly comes to resemble reality, the viewers are put in more or less ethical dilemmas. Another such ethical dilemma seems to arise when the content of the programme is about their own identifications, when the fiction is simply no longer perceived as distant, but as approaching their own reality.

Fanny: So Pride Week, didn't it feel quite comfortable in the end?

Evelina: No, there was so much transphobia that it was hard to watch. Like it was meant to make you laugh. It just felt like: 'Ugh!!' (In a tired, distancing tone.) It went something like this: a guy came who was in drag, a drag queen, and then all the guys went on a date with him. And all guys were like: 'Ew, a dude in girl clothes!' But in the end, they still thought it was fun. And then he had a competition where those guys were supposed to get into full drag. And it was just like everyone laughed at looking funny in their dresses.

Bella: Mmm... The idea was that they were supposed to let go, be generous and open and give people a laugh.

Evelina: Then that makes me think that what was difficult about it was that maybe it came a step closer, so to say...

In the conversation above, we see how the viewers find it harder to digest the representation of a reality they themselves are familiar with. 
At the same time as Pride Week, which makes some of them feel emboldened enough to join the game and seek out the programme participants IRL, they feel that non-heterosexuality is misrepresented. They apparently become stricter-and feel more uncomfortable-when Paradise Hotel delves in LGBT matters and Pride; that is, their own reality.

Another form of distancing arises when the content of the programme involves a distant hyperbolic fiction that they can revel in and be horrified by-when they are reminded that violent expressions and oppressive rhetoric also exists outside the programmes.

Fanny: You say it's comfortable because it's so far away and a little uncomfortable when it comes too close?

Evelina: Yes, last week was so hard!

Eli: Exactly, it was unpleasant. You're just like: 'People like that walk around on the streets! Ew! Those are evil people!'

(The others agree.)

Maja: They sang like some kind of rape song. And this thing about begging for sex.

Malle: And Jeppe, or somebody, had jerked off to a picture of Emily. And Jeppe has so much fucking power and is a real pig and everyone does what he says. It's uncomfortable.

Maja: Yeah, he sits there and says in the interview that he's gonna piss on everyone...

Livia: Yeah, but he did say sometime, like, that he's not there to be liked by the girls. No, he wants to walk down Götgatan receiving high fives from guys who respected him for shagging lots of chicks and being boss.

When the programmes become difficult to regard simply as fiction, when the boundary between realities break down and reality becomes too intrusive, it obviously becomes harder to swallow. Above all, this applies when the homophobic and sexist elements become too obvious, when the guys behave like pigs towards the girls, or when the participants act homophobic and transphobic. Then the viewers throw their support behind the vulnerable-in solidarity with girls, gay men and transgender people, they jump up and down on the sofa in anger over the boys' mean actions and rude sex jokes. They pep talk the female participants to stand up for themselves when they occasionally try to exact revenge, and laugh with schadenfreude when one of them manages to manipulate a guy to get sent home. When the producers let the girls have a whole day for themselves alone at the hotel-and they gigglingly teach each other how to shove 
a ball up their vaginas and then trick one of the guys to put it in his mouth-it is talked of as one of the best episodes in the series. When one of the girls, in front of the camera, describes the 'girls' day' as the nicest and best of the entire stay, everyone applauds.

In many ways, these emotional responses to the programmes are similar to a heterosexual sex war, where there is always the risk that the 'wrong' side wins. This is also what happens when Jeppe, a person they all strongly dislike and who they perceive as a heterosexist male chauvinist, suddenly comes back into the programme with great odds of winning. Earlier in the series he had been voted out - they had all cheered and felt happy all week. Now he has returned for no obvious reason. They describe themselves as very bummed out. If Jeppe wins, that means that he will walk out - out into real life-with half a million kronor in prize money. And suddenly the fiction is no longer a distant fantasy, but takes place in their own environment, on both Götgatan and in their own neighbourhood. A person that previously actively participated in the communal viewing left when they found it 'too disgusting'. And at the prospect of the last few episodes, several of the participants feel uncomfortable.

Eli: It's like everyone agrees with what he says. That he's constantly saying that he's so strong and everyone believes him.

Bella: Yeah, but that's because people are afraid of him. Because he threatens to beat them up.

Livia: Yeah, well in that case it's pretty fucking bad.

Bella: That's why it's so disgusting that he's got a role like that, that you can feel is also real in some way.

Eli: When he came back it was like it wasn't just us who were shaking with fear. It was all of them.

Livia: But, like, if he wins, I don't think I'm gonna want to watch this anymore.

$E l i$ : Yeah, it's over then (some teasing laughter.)

Livia: Come on, I mean next season.

\section{Managing Vulnerabilities-A Queer Feminist Viewer Position}

The reality genre's game shows do not make for high culture capital. Neither is one assumed to learn anything, as is the case in a large share of the reality programmes: how to raise children, lose weight, fixing one's finances and so on. Instead, Paradise Hotel is a long-lasting, rather anarchic booze party with half-naked bodies, a great deal of alcohol and plenty 
of talk about sex. Neither does following Paradise Hotel generate any activist or feminist brownie points.

So, how then can one make sense of the feminist queer activists' consumption of Paradise Hotel? With a focus on affect-the emotional response and direction the programmes generate-as a starting point, we have suggested a number of answers to that question. By gathering together, several nights a week, around the TV, they create a common safe space in which they can relax, enjoy themselves and let go. By estranging themselves from the programme, they establish themselves as more normal. At the same time, the viewing habit also includes an approachment - to popular culture and the 'mainstream world' outside their own activist bubble. A possible answer to what the viewers do with the programme is that they negotiate and experiment with different forms of vulnerability: they handle their own sexual exclusion, make themselves more normal and, in the same breath, distance themselves from a class coded sexuality. Another answer is that, by watching Paradise Hotel, they make themselves queer feminists. In this final discussion, we would like to spend some time on how this queer feminist viewer position could be described.

Paradise Hotel can be considered a text that viewers approach in a specific way. It is, as we have shown earlier, not only the political agenda that must be shared for the viewing to feel safe and entertaining; it also requires a special attitude to the programme-what we choose to call a 'queer gaze'. Studies on the consumption of so-called junk culture often emphasize how contemporary consumers take on, what one usually calls, an ironic viewing position (Jameson 1984; Liliequist 2000). By placing the product inside quotation marks and approaching its message from an ironic viewing stance, it is possible for viewers, not least those from the middle class, to consume cultural expressions that are otherwise usually described as class marked 'junk'. The queer gaze is reminiscent of an ironic viewing stance-but only partially. In the following section, we would therefore like to examine possible differences when using the concept of camp.

Camp can be characterized as a style, an aesthetic, or a way of thinking that takes hold of hyperbole and artificiality and celebrates the unnatural, failed and fallen (see, for example, Sontag 1966; Dollimore 1991; Cleto 1999). In addition, camp also requires seriousness. Rather than an ironic, detached gaze, the attitude is based on emotional proximity that can aptly be described as a self-parodying dedication. 
Camp often stands in relation to mass-produced and commercial pop culture. The person that 'camps', however, is outside the majority culture, historically in a predominantly male homosexual culture (Cleto 1999). In an article about schlager music, emotions and Swedish homosexual culture, Tiina Rosenberg (2005) describes schlager music consumption among gays as camp, and mainly a male, homosexual resistance strategy. 'Camp', writes Rosenberg $(2005$, p. 354), 'is a way of relating to the world that has been particularly important for homosexuals as a refuge from heteronormativity.' In this sense, it can be understood as, in Eve Kosofsky Sedgwicks (2003, pp. 123ff.) words, a reparative strategy-a specifically queer way of handling vulnerability.

So, what does camp have to do with Paradise Hotel? It is to be regarded as a form of excess and exaggeration of a tabooed and culturally shunned part of reality, something often cherished among camp practitioners (Sontag 1966). This is also how one of the viewers describes the programme in our conversation, as 'big pile of fucking dog shit'. Seen from this point of view, Paradise Hotel makes for a relaxing time on the sofa, where the queer feminist viewers, along with other like-minded people, in a contradictory and fascinated fashion, can engage with heterosexual stereotypes and revel in exaggerated ideals. The point here is that they are remarkably un-ironic; the viewing can more aptly be characterized by intimacy, empathy and great emotional engagement. Thus, in safe spaces, we see how they let go, engage and, in a way, solidarize with the rejected 'junk'.

Paradise Hotel, however, is not to be considered as any popular cultural product. Through its aesthetics and programme concept, it is criticized for being extra 'trashy' (cf. Hagström 2014; af Kleen 2014; Gustavsson 2014; Arif 2015). As viewers, we are invited to watch shamelessly and be entertained by the participants' unabashed behaviour-they get drunk, argue, cry and have sex unashamedly, with open curtains. In this sense, the programme can be said to be an exercise in shamelessness (Madsen and Brinkman 2012). And within here lies a deeper explanation of the programme's attractiveness to the queer feminist viewers. In their identification with queer, in its broad sense of that which is excluded, there exists, so to speak, queer brownie points to be collected. Queer is a movement in the direction of the despicable, rejected and, above all, shameless-not aiming at a rectification and recognition but, rather, to embrace the fallen as well as the 'failure' (Halberstam 2011). In this way, the informants' involvement can be expected to give rise to a deeper identification 
with and care for the vulnerable and despised. On some level, the programme participants' constant fear of being socially and sexually excluded from the programme, handled through shameless and sexually provocative behaviour, is culturally and emotionally recognizable by the queer feminist viewers. Paradise Hotel is thus possible to like-not despite, but because of its terrible shamelessness. In addition, we see how the viewers, through their consumption, overcome themselves-in the sense that not everything has to be completely 'correct' all the time. In their view of themselves as norm-critical feminists and anti-capitalists, they are simply not straight-rather, they are shameless and queer. Through a camp approach to the programme, they collect queer points, so to speak, and reinforce their view of themselves as queer feminists, embracing the vulnerable.

The camp attitude could thus distinguish a generally ironic late modern viewing stance from the queer feminist viewers' attitude more reminiscent of the gay men's camp viewing of schlager music (cf. Rosenberg 2005). However, in a similar fashion to gay men's consumption of schlager music, the approach to Paradise Hotel also contains an element of subordination. In the moment that I make something camp (that is, make it lovable garbage'), I have also made myself superior. Through its celebration of a stereotyped femininity, gay culture's camping of femininity has often been criticized for reproducing the binary gender system and, thus, female subordination (Robertson 1996, pp. 3f.). In a similar fashion, we see how the queer feminists' delight in the class coded hetero spectacle enhances a class division. The camp attitude thus tends to participate in structures that perpetuate existing hierarchies.

In this way, the queer feminist camp viewing of Paradise Hotel resembles gay men's consumption of schlager music. At the same time, it is a much more complicated enterprise. For, in the camp consumption of Paradise Hotel, it is not just a case of the subordinate and vulnerable predominantly woman and gay man, exaggerated and exposed, but also the superordinate oppressive man. And here, we see how viewers end up in a dilemma. They solidarize with and idealize participating women, gays and transgender people, but devote the greatest energy to hating the chauvinistic heterosexual men. When the person they all perceive as the worst offender ends up winning the whole thing, they lose the drive that previously compelled them to watch. At this point, it is no longer possible for them to celebrate and be dedicated to the shameless and fallen; rather, it seems reasonable to stop watching and begin to question the whole 
enterprise. At this point, it seems, both their will and ability to camp the programme ceases.

The camping thus appears to be a more vulnerable project for the queer feminist activists, precisely because of their identification and/or solidarity with the female position. Camp also becomes more difficult to carry out when they leave their safe space and enter the real world; when they, so to speak, camp themselves by exaggerating and giving into the lesbian stereotype. The endeavour of staging themselves as stereotypical lesbians, in lumberjack shirts-to offer themselves up as participants in a joint game-fails, not only because the programme participants do not show up, but mainly because the lesbian stereotype is not sufficiently culturally recognizable. Unlike the gay man that 'sissies around' or 'transes about' (like the transgender person in the programme), the lesbian position is simply not equally viable. It is not, at this time in history, as culturally recognized and has no specific role to play. Thus, camp, from this perspective, comes to be regarded as a more difficult undertaking for a person holding a female identification/position.

\section{CONCLUSION}

To sum up, we can conclude that the queer feminist viewer position that we have investigated is centred on the intricate ways of handling and experimenting with different forms of vulnerability-their own, and that of the programme participants and the other viewers.

Through emotional reactions of 'towardness' and 'awayness', the queer feminist viewers handle their sexual exclusion, make themselves more normal at the same time as they distance themselves from a class coded sexuality. However, the viewing differs from an ironic viewing stance by not being ironically detached. Rather, it builds on the simultaneous approaching and distancing of the vulnerable and fallen, mirrored by the programme participants' ongoing struggles to handle social and sexual exclusion through strategies of shamelessness. Watching Paradise Hotel thereby becomes a possible way of overcoming and managing sexual exclusion. Thus, unlike the closed feminist forums trying to avoid possible triggers and potential vulnerability through trigger warnings, the viewers deliberately expose themselves to sexist, homophobic 'trash' by using a camp attitude. However, as a reparative strategy, it is a deeply vulnerable enterprise. When the abuse becomes too obvious and the men in the programme behave too reprehensibly, it is no longer possible to camp. 
Neither does camp work when they put their own identities at stake and perceive themselves as unrecognizable. There is nothing left to do other than to turn off the TV—at least, as Livia notes, until the next season.

\section{Notes}

1. The material, which was collected in 2015 , consists of two group interviews, one with three interviewees and one with seven, lasting about three hours each. An additional one-hour interview was conducted with one interviewee. Two participant observations were performed during the actual interviews. All material has been transcribed verbatim.

2. The information is derived from MMS (Mediemätningar i Skandinavien), www.hottoptv.mms.se. Accessed 6 June 2019.

\section{REFERENCES}

Abrahamsson, E. (2018). Enahanda läsning: En queerteoretisk tolkning av romancegenren. Stockholm: Makadam.

af Kleen, B. (2014, September 19). Paradise Hotel är motsatsen till frigörelse. Dagens Nyheter.

Ahmed, S. (2004). The Cultural Politics of Emotion. Edinburgh: Edinburgh University Press.

Ahmed, S. (2006). Queer Phenomenology: Orientations, Objects, Others. Durham: Duke University Press.

Ahmed, S., \& Stacey, J. (2001). Introduction: Dermographies. In S. Ahmed \& J. Stacey (Eds.), Thinking Through the Skin. London: Routledge.

Ambjörnsson, F. (2016). Vad är queer? Stockholm: Natur \& Kultur.

Ang, I. (1985). Watching Dallas: Soap Opera and the Melodramatic Imagination. London: Methuen.

Arif, A. (2015, January 16). Könsroller in absurdum. Feministiskt perspektiv.

Bohlin, A., \& Gemzöe, L. (Eds.). (2016). Fiktion och verklighet: Mångvetenskapliga möten. Stockholm: Makadam.

Brown, L. S. (2005). Outwit, outcast, out-flirt? The women of reality TV. In E. Cole \& J. H. Daniel (Eds.), Featuring Females. Feminist Analyses of Media. Washington, DC: American Psychological Association.

Butler, J. (2004). Precarious Life: The Powers of Mourning and Violence. London: Verso.

Butler, J. (2016). Rethinking vulnerability and resistance. In J. Butler, Z. Gambetti, \& L. Subsay (Eds.), Vulnerability in Resistance. Durham: Duke University Press. 
Cleto, F. (Ed.). (1999). Camp: Queer Aesthetics and the Performing Subject-A Reader. Ann Arbor: University of Michigan Press.

Cvetkovich, A. (2003). An Archive of Feelings: Trauma, Sexuality, and Lesbian Public Cultures. Durham: Duke University Press.

Dahl, U. (2011). Queer in the Nordic region: Telling queer (feminist) stories. In L. Downing \& R. Gillett (Eds.), Queer in Europe: Contemporary Case Studies. Farnham: Ashgate.

Dollimore, J. (1991). Sexual Dissidence: Augustine to Wilde, Freud to Foucault. Oxford: Clarendon Press.

Duffett, M. (2013). Understanding Fandom: An Introduction to the Study of Media Fan Culture. London: Bloomsbury.

Edin, A. (2005). Verklig underhållning: Dokusåpor, publik, kritik. Stockholm: Institutet för mediestudier.

Fiske, J. (1992). The cultural production of fandom. In L. A. Lewis (Ed.), The Adoring Audience: Fan Culture and Popular Media. London: Psychology Press.

Ganetz, H. (2008). Talangfabriken: Iscensättningar av genus och sexualitet $i$ svensk talang-reality. Centrum för genusvetenskap: Uppsala Universitet.

Gorton, K. (2009). Media Audiences: Television, Meaning and Emotion. Edinburgh: Edinburgh University Press.

Gustafsson, L. (2002). Den förtrollade zonen: Lekar med tid, rum och identitet under Medeltidsveckan på Gotland (Doctoral dissertation). Stockholm: Nya Doxa.

Gustavsson, M. (2014, September 9). De har inga mobiler att försvara sig med i Paradise Hotel. Dagens Nybeter.

Hagström, J. (2014, August 23). Rent människoförakt i Paradise Hotel. Göteborgs-Posten.

Halberstam, J. (2011). The Queer Art of Failure. Duke: Duke University Press.

Hill, A. (2005). Reality TV: Audiences and Popular Factual Television. London: Routledge.

Hirdman, A. (2008). Televiserad verklighet och emotionernas betydelse. In A. Edin \& P. Vesterlund (Eds.), Svensk television: En mediehistoria. Stockholm: Statens ljud-och bildarkiv.

Jameson, F. (1984). Postmodernism, or, the cultural logic of late capitalism. New Left Review, 146, 53-92.

Jerslev, A. (2004). Vi ses på TV: Medier og intimitet. Köbenhavn: Gyllendal.

Kavka, M. (2008). Reality Television, Affect and Intimacy: Reality Matters. Hampshire: Palgrave Macmillan.

Koivunen, A. (2010). An affective turn? Reimagining the subject of feminist theory. In A. Koivunen \& S. Paasonen (Eds.), Disturbing Differences: Working with Affect in Feminist Readings. London: Routledge. 
Koivunen, A., Kyrölä, K., \& Ryberg, I. (2018). Vulnerability as a political language. In A. Koivunen, K. Kyrölä, \& I. Ryberg (Eds.), The Power of Vulnerability: Mobilising Affect in Feminist, Queer and Anti-racist Media Cultures. Manchester: Manchester University Press.

Kulick, D. (2005). Inledning. In D. Kulick (Ed.), Queersverige. Stockholm: Natur \& Kultur.

Kyrölä, K. (2018). Negotiating vulnerability in the trigger warning debates. In A. Koivunen, K. Kyrölä, \& I. Ryberg (Eds.), The Power of Vulnerability: Mobilising Affect in Feminist, Queer and Anti-racist Media Cultures. Manchester: Manchester University Press.

Liliequist, M. (2000). Våp, bitchor och moderliga män: Kvinnligt och manligt $i$ såpoperans värld. Umeå: Boréa.

Madsen, O. J., \& Brinkman, S. (2012). Lost in paradise: Paradise Hotel and the showcase of shamelessness. Cultural Studies-Critical Methodologies, 12(5), 459-467.

Munoz, J. (1999). Disidentifications: Queers of Color and the Performance of Politics. Minneapolis: University of Minnesota Press.

Ouellette, L., \& Hay, J. (2008). Better Living Through Reality TV. Oxford: Blackwell.

Radway, J. A. (1984). Reading the Romance: Women, Patriarchy, and Popular Literature. Chapel Hill: University of North Carolina.

Robertson, P. (1996). Guilty Pleasures: Feminist Camp from Mae West to Madonna. Durham: Duke University Press.

Rosenberg, T. (2005). Schlager, känslor och svensk homokultur. In D. Kulick (Ed.), Queersverige. Stockholm: Natur \& Kultur.

Sedgwick, E. K. (2003). Paranoid reading and reparative reading, or, you're so paranoid, you probably think this essay is about you. In E. K. Sedwick (Ed.), Touching Feeling: Affect, Pedagogy, Performativity. Durham: Duke University Press.

Shildrick, M. (2002). Embodying the Monster: Encounters with the Vulnerable Self. London: Sage.

Skeggs, B. (1997). Formations of Class and Gender: Becoming Respectable. London: Sage.

Skeggs, B., \& Wood, H. (2012). Reacting to Reality Television: Performance, Audience and Value. London: Routledge.

Sontag, S. (1966). Against Interpretation, and Other Essays. New York: Dell. 
Open Access This chapter is licensed under the terms of the Creative Commons Attribution 4.0 International License (http://creativecommons.org/licenses/ by $/ 4.0 /$ ), which permits use, sharing, adaptation, distribution and reproduction in any medium or format, as long as you give appropriate credit to the original author(s) and the source, provide a link to the Creative Commons license and indicate if changes were made.

The images or other third party material in this chapter are included in the chapter's Creative Commons license, unless indicated otherwise in a credit line to the material. If material is not included in the chapter's Creative Commons license and your intended use is not permitted by statutory regulation or exceeds the permitted use, you will need to obtain permission directly from the copyright holder.

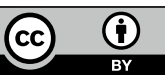


Mobilising the Pain of Others 


\title{
The Art of Begging
}

\author{
Adriana Margareta Dancus
}

Begging migrants from Romania have been a familiar sight in major European cities ever since Romania joined the European Union (EU) in 2007. Following the economic crisis in the EU, these migrants have become increasingly visible in Norway and Sweden as well, where affluence, combined with a legal acceptance of begging, has made both countries attractive destinations for this group of people (Djuve et al. 2015; Olsson 2015). As the numbers of begging migrants continue to rise, the public and policy debates about begging in Scandinavia become more heated and polarized. Right-wing political parties in both Norway and Sweden have lobbied for a national ban on begging, while non-profit organizations such as Kirkens Bymisjon (The Church City Mission), which perform outreach work on the streets of Norwegian towns and cities, have repeatedly called for acceptance and care for this group of migrants. The bone of contention in public and policy debates in Scandinavia has been whether or not ringleaders and traffickers control the begging migrants (Djuve et al. 2015; NRK 2017).

\footnotetext{
A. M. Dancus $(\bowtie)$

Department of Languages and Literature Studies, University of South-Eastern Norway, Bakkenteigen/Borre, Norway

e-mail: Adriana.M.Dancus@usn.no
}

(C) The Author(s) 2020

A. M. Dancus et al. (eds.),

Vulnerability in Scandinavian Art and Culture, https://doi.org/10.1007/978-3-030-37382-5_11 
Such debates demonstrate that the figure of the begging migrant is a highly affective trope, mobilizing an entire spectrum of emotional responses from empathy and a willingness to help, to consternation and fear. But what happens when contemporary Scandinavian artists involve begging migrants from Romania in their art? How do Scandinavian artists initiate collaborations with real begging migrants in the 2010s? In this chapter, I discuss these questions by looking more closely at two projects: Toleranshuvan Reloaded. "A pair of rubber gloves called tolerance" (2015, from now on referred to as Toleranshuvan Reloaded) and the multiplatform project Det kunde varit jag (It Could Have Been Me) (2012-2015). The first is a performance at the Malmö Fine Arts Museum for which the Swedish theatre group Institutet paid two begging migrants from Romania to pose as beggars ${ }^{1}$ in one of the museum's white rooms. The performance was part of a larger exhibition at the Malmö Fine Arts Museum entitled The Alien Within-A Living Laboratory of Western Society, which brought together a think tank around the political work of German theatre director, filmmaker and visual artist Christoph Schlingensief (Malmö Konsthall 2015). It Could Have Been Me is a project led by the Swedish cartoonist Sara Olausson in collaboration with Felicia Iosif, a woman from Romania begging in a Stockholm suburb. It combines graphic short stories drawn by Olausson with various forms of community action, including fundraising on social media. There are other collaborations between Scandinavian artists and begging migrants from Romania that could have been included in this chapter, such as Presserom (2014) by the Norwegian artist Morten Traavik and How Do You Become a Successful Beggar in Sweden? (2015) by the Swedish artist Cecilia Parsberg. Given the scope of this chapter, I have chosen to limit my discussion to Toleranshuvan Reloaded and It Could Have Been Me because both projects have generated significant public debates and left affective traces that I could track through a review of the media and a book issued in connection with It Could Have Been Me. ${ }^{2}$ I frame my approach to these two projects through the notion of vulnerability as tactical.

In the introduction to the book Vulnerability in Resistance, the editors point out how 'the concept of vulnerability always operates in a tactical field': groups in positions of power commonly deny and disavow their own vulnerability and, instead, project it onto those whom they seek to contain or exclude; on other occasions, the very same groups may deploy the language of vulnerability about themselves as a way to protect their own privilege (Butler et al. 2016, pp. 4-5). In a separate chapter 
in Vulnerability in Resistance, American philosopher and gender scholar Judith Butler (2016) comes back to the notion of vulnerability as tactical, and distinguishes between forms of corporeal and linguistic vulnerability. Her theoretical observations are grounded in non-violent street protests in which protesters deliberately expose their vulnerable bodies to power (police, security, military) in a call for justice and equality. Further, Butler couples this form of corporeal vulnerability to a linguistic vulnerability, in so far 'who we are, even our ability to survive depends on the language that sustains us' $(2016$, p. 16). She then explains that vulnerability is a 'way of being exposed and agentic at the same time' (2016, p. 24), 'neither fully passive, nor fully active, but operating in a middle region' (2016, p. 25), and concludes that vulnerability can be 'marshaled and mobilized for the purposes of resistance' (2016, p. 26). In other words, vulnerability, as Butler defines it, plays an important role in resistance and should not be understood in opposition to it.

How can Toleranshuvan Reloaded and It Could Have Been Me be understood through the lens of vulnerability as tactical, and how does this theoretical approach lend itself to a critical reading of the use of real people in art? I will begin this chapter with a discussion of begging and vulnerability.

\section{Begging AND VULNERABILITY}

On 16 May 2014, Sweden's Radio Channel 1 invited Sara Olausson, the artist behind the multiplatform project It Could Have Been Me, to debate in a morning news programme against Björn Söder, a profiled name in the far-Right, nationalist party Sweden Democrats (Pl-morgon 2014). The topic of discussion was an anti-begging poster campaign launched by the Sweden Democrats in metro stations around Stockholm, a campaign many travellers regarded as 'racist and deceiving propaganda' (Asplund 2014). Söder was given the opportunity to speak first. He began by claiming that criminal networks controlled the migrants who begged in Sweden. He then argued for a ban on begging as the only effective measure to address the problem:

The most important thing is to look at those who are exploited. Should we allow that they continue to be exploited? And second, should we take care of all the citizens in Europe? All the countries that are part of the EU have 
pledged to take care of their citizens. Romania is responsible. (Pl-morgon 2014 , my translation)

Although Söder does not use the word 'vulnerability', he implies that begging presupposes vulnerability in at least two senses: the vulnerability of the begging migrants, who are exploited by criminal networks; and the vulnerability of the Swedes, who have no responsibility to take care of foreign citizens from other EU countries.

In contrast to Söder, who uses various reports and statements to back up his party's anti-begging campaign, Olausson underlines her own experiences of making the acquaintance of begging migrants on the streets of Stockholm and that witness a very different picture: 'They are very poor and vulnerable people, who have come here to survive, and I have not come across organized begging. None of us who work closely with these people have' (my translation and emphasis). Olausson sees the begging migrants' vulnerability as a result of the poverty and the discrimination these people face in Romania, where they are unable to find jobs. She also underlines that Swedes should help people in need, irrespective of their national affiliation: 'I also want to stop begging. As I said, it does not do anyone any good. But we must have an alternative, otherwise these people are left to die' (Pl-morgon 2014, my translation).

The debate between Söder and Olausson is illustrative of how both those in favour and those against a ban on begging use vulnerability as an important argument in public debates in Scandinavia. ${ }^{3}$ In an attempt to bring clarity to such debates, a team of researchers from the Norwegian research foundation Fafo conducted fieldwork and interviewed several hundreds of Norwegian outreach workers and homeless Romanian citizens (both ethnically Roma and non-Roma) who begged, collected plastic bottles and sold small items on the streets of Oslo, Stockholm and Copenhagen (Djuve et al. 2015). The Fafo-researchers addressed the question of vulnerability as a separate point in their investigation. They concluded that the homeless street workers from Romania were, indeed, vulnerable, but not to trafficking, as claimed by many politicians in Norway and Sweden (Djuve et al. 2015, p. 80). Instead, vulnerability in this group took many other forms: the vulnerability to being exploited for casual work, and unrealistic expectations regarding the rewards from begging; the vulnerability to falling prey to petty crime and abuse in an attempt to survive on the streets of Scandinavian capitals; the vulnerability to alcohol and drug abuse, and to the risk of being entangled in the local 
drug scenes; and the vulnerability to the risk of not being able to earn enough through begging and pay back their debts to the minibus drivers that facilitated their travel to Scandinavia (Djuve et al. 2015, pp. 84-85).

The Fafo-report analysed vulnerability exclusively as a condition inscribed in the bodies of the begging migrants. In Norway, in the late spring of 2017, vulnerability was, however, attributed to the inhabitants of Oslo, whose recreational areas and kindergarten yards the begging migrants from Eastern Europe transformed into what was referred to as 'Roma camps' filled with garbage and human excrement (Kirkerud and Baraldsnes 2017). The municipal authorities in Oslo were summoned to find effective solutions to prevent the spreading of disease among the inhabitants of Oslo. Kindergarten children living in the exposed areas were of particular concern, as kindergarten personnel found several of them playing in areas where excrement had been passed outdoors by the migrants (Kirkerud and Baraldsnes 2017). If Söder was concerned with the economic toll put on Sweden by foreign citizens, in 2017 in Norway, it was the public health argument that made the headlines, this time advanced on behalf of kindergarten children whose vulnerability was exacerbated by begging migrants who took over their playgrounds. In this way, the migrants' vulnerability was framed in competition with that of Norwegian children.

These examples taken from Sweden and Norway show how vulnerability is used in a tactical field when begging migrants become the subject of debate. Vulnerability is an argument embraced both by those who are against and those who are for a ban on begging. Vulnerability is not merely a condition of the begging migrants, but also a description Norwegians and Swedes use about themselves in their interactions with the begging migrants. Additionally, vulnerability is a contested phenomenon that some voices tie, first and foremost, to organized crime and trafficking. Others see vulnerability primarily as a question of poverty, discrimination and unrealistic expectations. Scandinavian artists such Olausson and the theatre group Institutet participate in this tactical field when they choose to involve real begging migrants in their projects. The fact that Toleranshuvan Reloaded and It Could Have Been Me are simultaneously social interventions and artistic gestures dependent on the participation of real people makes it quite challenging to discuss these projects. The British art historian and critic Claire Bishop has been at the forefront of theoretical debates about the use of real people in art. I therefore wish to make a 
brief theoretical detour to Bishop, before turning to a discussion of the two Swedish projects.

\section{The Use of Real People in Art}

Bishop (2006) shows that, since the 1960s, many artists have used real people in their art, particularly with the advent of what has been described as the 'socially engaged', 'participatory', or 'relational' art of the 1990s. By 'real people', Bishop means 'participants from outside an artistic context who are chosen by the artist to represent a particular socio-economic demographic, ethnicity or gender' $(2006$, p. 62). Rather than using their own bodies to stage a performance for the public, high-profiled artists such as the Spanish artist Santiago Sierra delegate their performance to real people with a socioeconomic, racial and ethnical background that is quite different from that of the audience. Elsewhere, Bishop (2004) calls artistic gestures such as Sierra's 'antagonistic relational art'; that is, art that disrupts and provokes discomfort and frustration, rather than cultivates a convivial, positive relationship between the artist and the audience.

Shannon Jackson (2011), American rhetoric and theatre scholar, discusses how Bishop's penchant for antagonism in art instituted a problematic distinction between those artists who underlined the importance of community and conviviality, and those who cultivated tension and discomfort. Whereas Bishop (2006) criticized the first group for neutralizing the viewer's capacity to think critically and for trading off aesthetical for ethical concerns, she praised the latter for providing edgy art material with an aesthetic impact that shook the viewer into critical reflection. Jackson (2011), instead, argues that '[R]adically antagonistic art does not need to exist either in an extra-aesthetic space of community action or in an aesthetically protected space of ambiguous discomfort' (p. 60, emphasis in original).

The two Swedish projects to which I now wish to turn attention demonstrate how Bishop's critical intervention on behalf of antagonistic art is particularly deceiving when we shift our focus away from antagonism and towards vulnerability as tactical. The theatre group Institutet delegates their performances to begging migrants from Romania against remuneration when casting real migrants as beggars inside an art gallery. Olausson, on the other hand, is an activist artist who decides to put herself on display together with Felicia Iosif. She sits down next to Iosif while the latter is begging. She also shares her own vulnerabilities as a mother, 
wife and artist in her graphic art and through her public participation in rallies and on social media. As we will see, this shared performance turns out to be quite costly for Olausson, provoking angry responses from some members of the audience. Neither Toleranshuvan Reloaded nor It Could Have Been Me can be easily placed on the antagonistic-convivial dyad instituted by Bishop, especially not when vulnerability becomes the centre of the investigation. Let us look more closely at each of the projects through the lens of vulnerability as tactical.

\section{Delegating Performance In Toleranshuvan ReLOADED}

Toleranshuvan Reloaded was artistically led by Anders Carlsson from the theatre group Institutet and builds on an earlier performance by the same group from 2010, entitled Toleranshuvan ('The Tolerance Hood'). For Toleranshuvan, the artists designed a collection of Ku Klux Klan inspired hoods to express tolerant values. Sent to party leaders and used at various public events, these tolerance hoods were meant to illustrate how tolerance could become a mechanism to avoid contact with the other, a way for the tolerant to hide behind their tolerant values. In 2015, Institutet returned to the ideas developed in Toleranshuvan but, instead of using hoods, they used the white art space as a place to question the Swedish public's tolerance with regard to begging migrants on the streets of Malmö. In an email to the author, Carlsson describes Toleranshuvan Reloaded as a multifaceted project with 'many behind-the-scenes stories that are highly relevant for a deeper understanding' of it (Carlsson 2017a). ${ }^{4}$ These stories make evident how both artists and begging migrants involved in Toleranshuvan Reloaded use vulnerability in a tactical field and, therefore, why this project is not simply antagonistic art as defined by Bishop. In what follows, I wish to reconstruct these stories and then flesh out the vulnerabilities at stake.

Carlsson and his team created what the Swedish press occasionally called a 'social installation', which the artists themselves described as 'an exhibition focusing [on] what happens inside of us, when-in an artspace-we meet the ones we are used to meet (but not really meet) in the street' (Institutet 2015). To be precise, two begging migrants from Romania, a couple, Marcela Chereși and Ioan Luca Lăcătuș, were paid to sit in begging postures in one of the smaller exhibit rooms at the Malmö's Fine Arts Museum for two hours, four days a week, for two weeks. 'We 
wanted to create a laboratory situation in which one can explore one's own image as a donor', says Carlsson in an interview (Stenbäck 2015). ${ }^{5}$

With the help of the Romanian activist and DJ Cătălin-Mihai Marghit, who was also paid by the project, Institutet recruited Chereși and Lăcătuş on the streets of Malmö, where they were begging, and invited them to act as beggars inside the Malmö Fine Arts Museum. Marghit also functioned as interpreter but, as Carlsson (2017b) explains, Institutet also used sign language to communicate with the two as well as some Italian words. Chereși and Lăcătuș received remuneration for their participation in the project, which they then taxed in Sweden: 140 Swedish kronor per hour, an honorarium recommended by the Swedish Union for Performing Arts and Film for people with an expert competence (Carlsson 2017b).

The two were chosen because they had a retable story to tell as well as 'an attitude and a look suitable for a sympathetic identification in the media' (Carlsson 2017b). The story told by Chereși and Lăcătuș was that their house burned to the ground on New Year's Eve in 2012, which then led to Lăcătuş losing custody of his two children from a previous relationship. The couple, now expecting their first child together, left Romania to beg in Western Europe in the hope of gathering enough money to rebuild their house and reunite their family.

As to their look and appearance, they were both in their late twenties, with white complexions, dark hair and brown eyes. Lăcătuș had an oval face framed by a beard, with slightly elongated eyes and a long, aquiline nose, while Chereși had a round face with full lips, thinly plucked eyebrows and long hair tied in a ponytail or covered with a Palestinian headscarf, also tied behind. For the performance, they wore warm, casual clothes, such as jumpers, pants and winter boots, and used props such as stools, a crutch and a homemade cardboard sign reading in capital letters in Swedish: 'I have two children and they have no house to live in. I need your help. Thank you' (my translation).

To enter the room, the visitors walked through a dark corridor adorned with five dark screens displaying the following text in Swedish: 'Today you do not have to give.' In the art room, Chereși and Lăcătuş sat in silence across from each other, at times on their stools, at other times directly on the wooden floor (see Fig. 11.1)

In the middle of the room, there was a bench on which visitors could rest. A large image of Institutet's logo was displayed on one of the walls; on another, collages and diagrams by the artist Linnea Carlsson outlining 


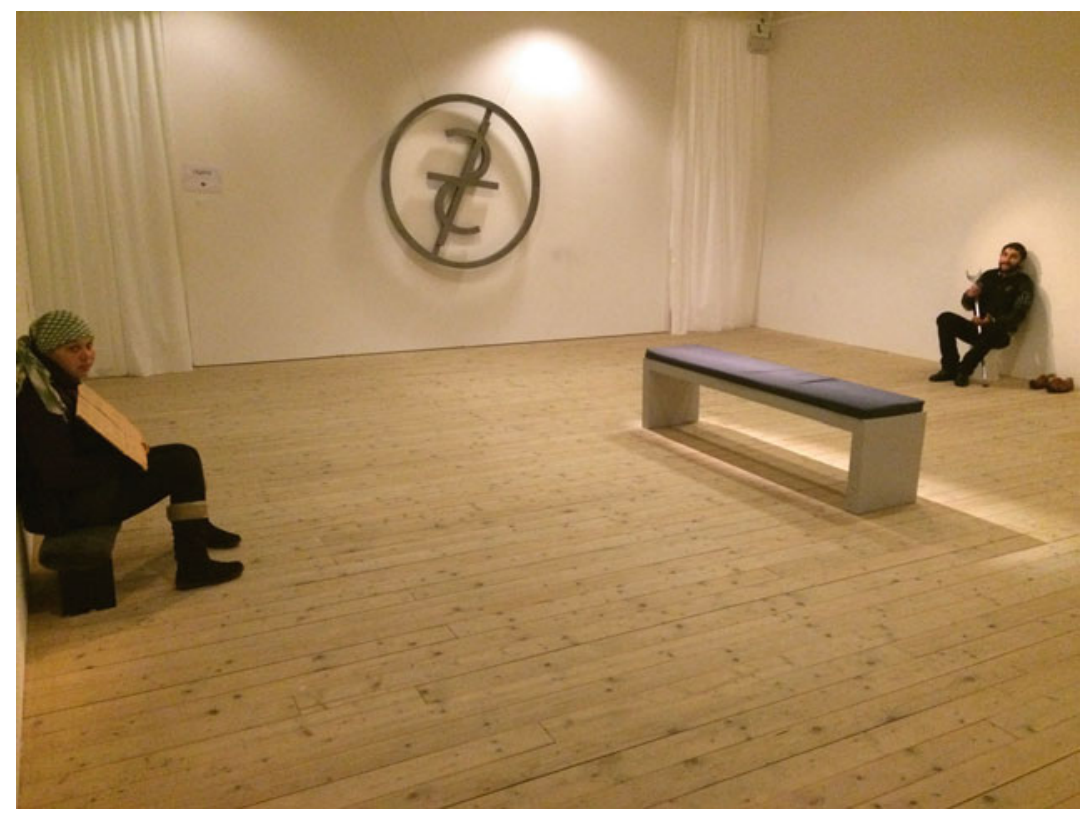

Fig. 11.1 Marcela Chereși and Ioan Luca Lăcătuş on display as beggars inside Malmö’s Fine Arts Museum (ㄷ Anders Carlsson at Institutet)

possible ways to protect the rights of the poor, such as the use of satire and social media, revolt and even guerilla warfare (Millroth 2015). As the artistic leader of Toleranshuvan Reloaded explains, one of the ideas sketched in the collages was the organization of a camp in which the poor would receive military training to attack those institutions that allowed the proliferation of injustice in our Western societies (Carlsson 2017b).

The visitors were not allowed to give money to the beggars. Neither were the beggars able to enter into a dialogue with the visitors, as no translator was present in the room. The dialogue was reduced to eye contact and small facial gestures. In the Swedish press, the visitors speak of meeting the two beggars with silence, humility, confusion, discomfort, a feeling of disempowerment and embarrassment. One woman chose to sit down next to Lăcătus,, rather than looking down on him; other visitors fled the embarrassment of the situation turning their gaze on Linnea Carlsson's collages (Stenbäck 2015). The scenarios of action outlined in 
the sketches were, however, not reassuring. Indeed, the thought of the poor organizing themselves in an army capable of performing acts of terror must have been unnerving, particularly when two potential 'soldiers' in that army sat at the visitors' feet and watched their movements in the exhibit room.

Eating their lunch in the museum's popular restaurant Smak, other museum guests explained why they chose not to see the performance: 'It is a pity that people are forced to beg and that artists then exploit their situation, I am not interested in that', one woman declared to the Swedish press (Ankersen 2015, my translation). Chereși and Lăcătuș were, on one occasion, asked to explain how it was for them to be displayed as beggars in an art gallery. 'People feel sorrier for us here than on the street', says Cheressi, while her boyfriend adds, 'It feels easier, it is warmer in here and there is a different atmosphere than out there' (Stenbäck 2015).

While some welcomed Institutet's willingness to test the visitor's tolerance by displaying begging migrants from Romania as beggars (Millroth 2015; Jönsson 2015), others deplored the project's insistence on focusing on the white and privileged Swedish public (Ekman 2015; Israelson 2015; Rooth 2015). Aaron Israelsson (2015), who at the time of the performance worked as editor-in-chief of the Swedish street magazine Faktum, called for art that brought to the fore the suffering of the poor, while journalist, writer and activist Kajsa Ekis Ekman (2015) suggested that Institutet put managers and directors on display, instead of beggars. The Swedish art historian, critic and author Thomas Millroth was, in principle, positively inclined to the idea of Toleranshuvan Reloaded because the performance blocked compassion and denied the visitor a better self-image. Yet, Millroth had an objection: 'Why should they [Chereși and Lăcătuş] be restricted to the art room of Institutet, why aren't they allowed to beg openly in Restaurang Smak or in the ongoing exhibition in the great hall?' (Millroth 2015, my translation).

Several representatives of the Roma communities in Sweden and Europe reacted negatively to the way in which Institutet showcased Chereși and Lăcătuș as Roma. Soraya Post, Swedish politician and member of the European Parliament, called the performance a 'freak show' in which the poor Roma were reduced to silent objects for the visitors to contemplate (Berglund 2015). Five days after the exhibit closed, Georghe Răducanu from the European Roma and Travellers Forum in Strasbourg sent an official letter of complaint to the director of Malmö's Fine Arts Museum. In the letter, Răducanu (2015) deplored the ways in which 
Toleranshuvan Reloaded reinforced stereotypes and prejudices about the Roma communities by casting Lăcătuş and Chereși in the predictable role of beggars. According to him, this artistic gesture impinged on the dignity of the Roma communities. He ended his letter with the following encouragement:

You would do so much more for tolerance by showcasing sides of Roma communities unknown to the general public, instead of capitalizing on a particularly difficult situation in which many members of the Roma communities find themselves. (Răducanu 2015)

In the aftermath of the performance, Institutet launched a fundraising campaign to gather 100,000 kronor for Lăcătuş and Chereși; however, the campaign was brought to a halt shortly after, before the two had received any money. Institutet had reasons to believe that Lăcătuş and Chereși lied about their story and provided other misleading information (Carlsson 2017b). After a Swedish citizen contacted Institutet with allegations of serious fraud against Lăcătuş and Chereși, Carlsson and his team decided to stop the fundraising and denied any form of contact with either of them, including contact on social media. In an email correspondence with the author, Carlsson adds:

To me, the story [that of Lăcătuş and Chereși] is unprecedented and deceiving. It amuses me that we, the artists, together with the press, were fooled in the end. I do not put any moral blame on them [Lăcătuş and Chereși] for having taken advantage of the situation and lied about their background. They told and showed what could give them an income. I think it is quite understandable. But it was very bad what they did to that man, which is why I do not have any form of contact with them. (Carlsson 2017b)

When reconstructing the various phases of Toleranshuvan Reloaded (preproduction, exhibition, reception, follow-up), it becomes clear that the Malmö exhibit draws on and sustains various forms of vulnerability that begging migrants, artists and the audiences share in unexpected ways. In the exhibit room, Lăcătuş and Chereși deliberately expose their bodies, yet they are not really able to speak out as Butler's street protesters do. The lack of common language skills and the absence of an interpreter makes it very difficult for visitors and beggars to interact with each other. Coupled with the fact that the visitors are not allowed to give money, this 
linguistic vulnerability, which visitors and beggars share, enhances the visibility of the beggars' corporeal vulnerability. In the white art space, visitors 'feel sorrier' for the two beggars, although the infrastructure provided by the Museum bears no comparison to what the begging migrants face on the open streets of Malmö in winter.

If some members of the Roma communities regarded Toleranshuvan Reloaded as a deplorable artistic gesture that reduced the two migrants to passive objects, the way the fundraising campaign ended suggests that Lăcătus and Chereși were neither fully passive, nor completely exposed, but, rather, partly active and even creative. According to Carlsson, the two marshalled and mobilized vulnerability in the media and in the art space in order to maximize their income. It is unclear to what extent the allegations of fraud brought against Lăcătuş and Chereși were well-founded. This chapter is not interested in settling that argument. On the other hand, it is worthy of note how Carlsson invokes the trope of fraud in order to explain the artistic gesture behind Toleranshuvan Reloaded. Historically speaking, fraud and imposture have been important arguments in anti-begging legislation and proposals, as can be seen in several American cities from the late 1800s to the 1970s, while 'fake beggars' who trick others into giving are recurrent figures in Hollywood silent films (Schweik 2009, pp. 108-137). In the 2010s in Sweden, it is clear that fraud continues to remain a powerful trope in the language of begging also in a project meant to confront Swedes with their intolerance towards begging migrants. Although Institutet paid Lăcătuş and Chereși to pose as beggars, Carlsson still felt 'fooled' in the end, although he did not put any moral blame on the two migrants. This suggests that Lăcătuș and Chereși were not mere passive objects displayed in a 'freak show', but 'crafty takers' 6 who took advantage of the situation as best as they could. In the second Swedish project I now wish to discuss, being exposed and agentic at the same time is also at play, although the nature of the collaboration between the artist and the begging migrant is quite different from what we see in Toleranshuvan Reloaded.

\section{Sharing Performance in It Could Have Been Me}

During the period 2012-2015, the Swedish cartoonist Sara Olausson developed a multiplatform project in close collaboration with Felicia Iosif, a woman from Romania begging in the suburbs of Stockholm where Olausson lived. The catalyst of the project was the friendship between 
Olausson and Iosif, and which Olausson decided to share publicly in an attempt to help her Romanian friend and fight prejudices against begging migrants. The project involved multiple platforms and formats that cut across aesthetic and extra-aesthetic spaces: graphic short stories; photographs; interviews with the press; a radio documentary; a Facebook page to raise funds to help Iosif and her husband build a house in Romania; street protests in support of begging migrants; a political debate on radio between Olausson and the party secretary of the Sweden Democrats, Björn Söder; and even a TEDx talk Olausson gave in Gothenburg in December 2015.

In 2015, the book Det kunde varit jag (It Could Have Been Me) came out, crediting both Olausson and Iosif as co-authors. In addition to Olausson's cartoons and own reflections, the book contains screen shots from Google Translate and Facebook, excerpts from Facebook posts, photographs, a drawing made by Iosif's daughter, several conversations between Olausson and Iosif interpreted by Arina Stoenescu, two short interviews with other Swedes that have been involved in helping begging migrants from Romania (Anna Silver and Aaron Israelson), the text of Emil Jensen's song 'Tror du det?' ('Do You Think?'), and a brief factsheet about the Romanian Roma written by Arina Stoenescu. The book not only documents Olausson's project but, at the same time, affords her the opportunity for critical reflection on it, which is why I will use it as an interface to the forms of vulnerability at play in this project. This means that the focus of my analysis is not on the transmedial character of Olausson's project, a topic that certainly deserves critical attention, but one that lies outside the scope of this particular chapter. Instead, I use the book as a starting point from which to access vulnerability in three different respects: (i) a friendship between two women, (ii) that developed under the supervision of the media, (iii) in a Scandinavian political climate that became increasingly hostile to begging migrants from Eastern Europe.

In two separate graphic short stories, we learn the story of Sara (Olausson, born 1972) and Felicia (Iosif, born 1984), whose destinies met when Sara's five-year-old son grabbed Felicia's begging cup from where she sat on the pavement. Both stories are drawn by Olausson, first published by Pioneer Press and later reprinted in the book It Could Have Been Me. Olausson's drawing style is naïve, simple and subjective, with Olausson using a variety of lines and patterns to underline the emotional content of the situations depicted in the panels. In the reprinted edition of Felicia, black is offset with white, two shades of grey and two shades of purple 
(a darker and a lighter variant). In the reprinted edition of Sara in the same book, the colour pallet consists of two shades of red (a bright and a pale version), white, black and the same shades of grey from Felicia. The choice of colours, purple and red, respectively, underlines the feminine dimension of both graphic short stories. They are portraits of two women who step up in the public eye to tell the story of their friendship and how they were brought together.

Felicia introduces Iosif and how she ended up begging on the streets of Stockholm. It is co-authored by Olausson and Iosif, and is told in first person. Olausson lends her pen to tell Felicia's story, but it is Iosif who functions as the narrator. It is her voice that we hear. In the book It Could Have Been Me, Olausson explains how she and Iosif communicated through a 'language soup' mixing Romanian, Swedish, English and other invented words and sounds (Olausson and Iosif 2015, p. 41). This communication process was initially facilitated by Google translate, a rudimentary translation service that helped the women connect, yet it also led to misunderstandings. Eventually, Romanian-Swedish graphic designer Arina Stoenescu, whom Olausson already knew, became involved as an interpreter (Olausson and Iosif 2015, p. 43).

A pivotal moment in Felicia's graphic short story is her father's deadly chainsaw injury. This tragic event is presented as the beginning of the demise of Felicia's family. 'Mother was 33 years old, with six children and a million tears, poverty's jaws closed around us', explains the narrator in voice-over against many streams of purple teardrops shedding from two stylized eyes sketched as a bundle of lines (Olausson and Iosif 2014, p. 14). The visual motif of the drop ties Felicia's difficult situation in Sweden as a homeless migrant to the sorrow and pain left after her father's death: cold raindrops in Sweden that prevent her laundry from ever drying, raindrops and 'a million' teardrops on the day Felicia's father died, teardrops falling from Felicia's eyes when she shamefully confesses that her family in Romania thinks she has a job in Sweden: 'Mother does not know I am sitting here. Nor do my siblings' (Olausson and Iosif 2014, p. 14) (see Fig. 11.2).

Felicia's friendship with Sara is presented as the result of divine intervention: 'I prayed to God for a friend. Maybe he heard me' (Olausson and Iosif 2014, p. 15). Sara's friendly gesture to sit down beside Felicia provides a much needed emotional buffer in a cold and wet country indifferent — and, at times, directly hostile — to begging migrants. 'Today, she sat down beside me. Her name is Sora. In my language, Sora means 


\section{MOTHER DOES NOT KNOW I AM SIIIING HERE. NOR DO MY SIBLINGS.}

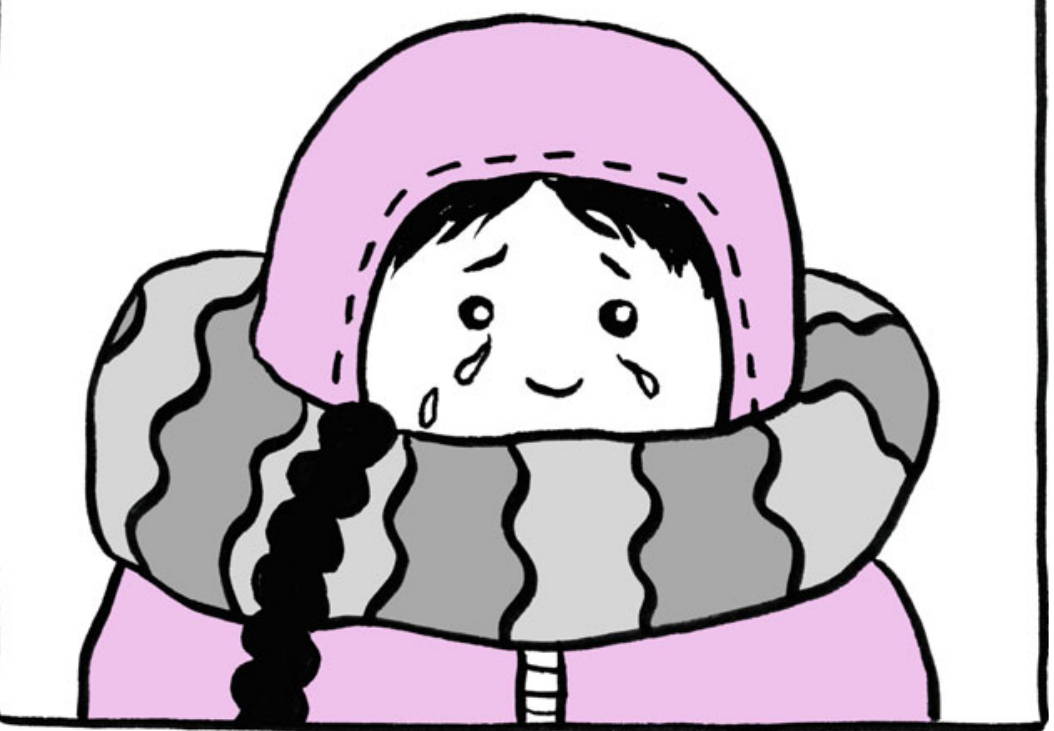

Fig. 11.2 Tears falling down Felicia's face. Panel from the graphic short story Felicia (2015) (@ Sara Olausson)

sister!', says Felicia in voice-over in the last panel showing a long shot of the two women sitting next to each other covered in a black-and-white striped blanket (ibid.).

In the graphic short story Sara, the reader gets to hear Olausson's version of how she met and befriended Felicia. Like Felicia, Sara is also told in first person narrative, this time from Sara's perspective. Sara introduces herself as a mother of three who struggles: 'But life is not easy. There is something in me that is broken' (Olausson and Iosif 2015, p. 23). ${ }^{7}$ She confesses having suffered from postpartum depression and continues to draw her professional anxieties, existential dilemmas and hectic daily routines. The first meeting with Felicia is presented as a turning point in Sara's life. In the last panel of the story, we see Sara and Felicia sitting next to one another in a frontal long shot, holding arms, both looking 
down at a little bird in the right corner of the panel. Sara confesses in voice-over: 'She (Felicia) opened my eyes and the door to something I could not imagine' (Olausson and Iosif 2015, p. 38).

Unlike Felicia, which makes extensive use of voice-over, Sara is less text based and more dialogic. Many panels have no text whatsoever and several panels use only speech bubbles to capture Sara's inner thoughts and her brief interactions with others. The visual motif of the drop encountered in Felicia is also used in Sara, both the raindrops and the teardrops. In fact, Olausson starts her story with a frontal medium closeup of herself dressed in a black coat with a black-and-white striped scarf wrapped around her neck against a grey sky covered in white raindrops: 'My name is Sara. I walk around here every day as if I were in an aquarium' (Olausson and Iosif 2015, p. 22) (see Fig. 11.3). The cold and wet

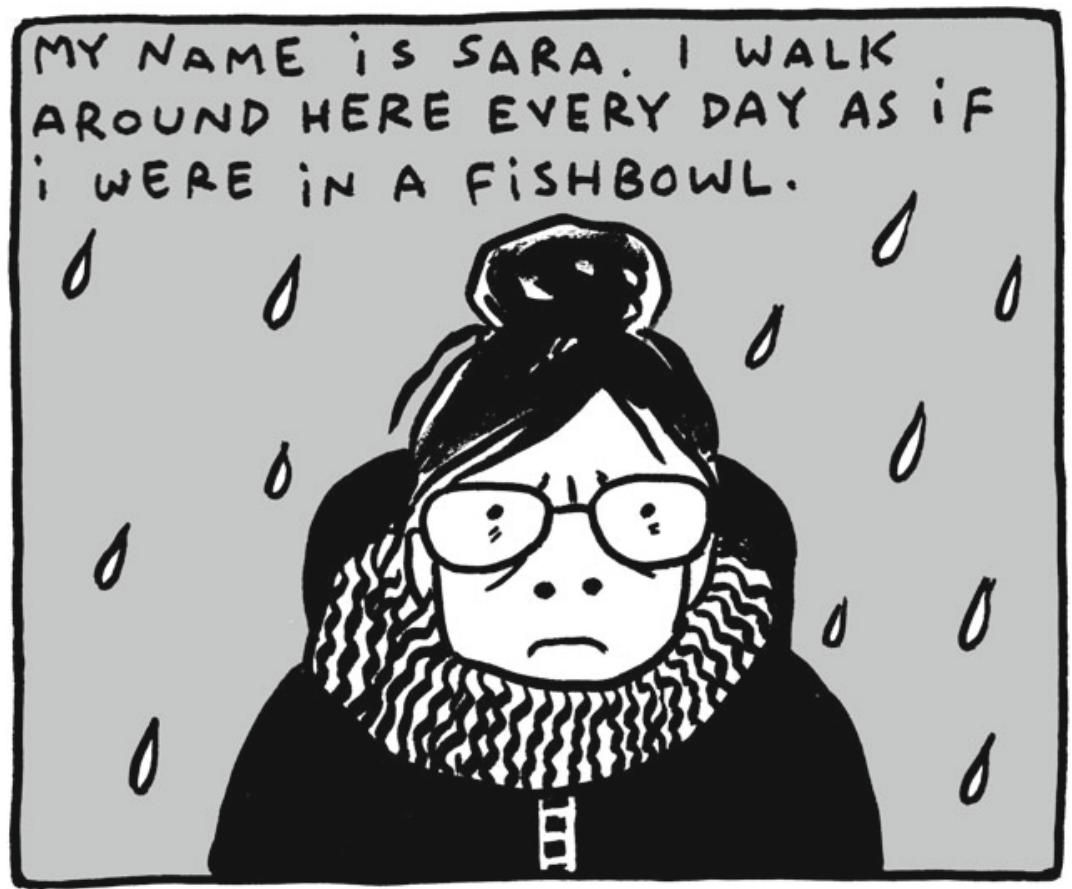

Fig. 11.3 Raindrops falling down on Sara. Panel from the graphic short story Sara (2015) (@ Sara Olausson) 
Swedish climate, in which Felicia's laundry and tears never dry, is heavy also for Sara, who feels 'angry', 'obnoxious', 'infinitely tired', and 'broken' (Olausson and Iosif 2015, pp. 22-23). The night after the interaction between Sid and Felicia, Sara is lying in bed shedding many tears (Olausson and Iosif 2015, p. 37). It is as if Felicia's unexpected gesture to give Sid a coin from her begging cup unleashes the rain Sara has accumulated inside herself. Two women, one from Romania and the other from Sweden, are about to become friends against all odds, because of all the tears.

In the book It Could Have Been Me, Olausson reflects on the challenges of developing this friendship in the spotlight of the camera. Olausson's avid engagement to help Iosif and other begging migrants from Eastern Europe attracts the attention of the media. On her first trip to Romania to visit Iosif in her home, a film team follows the two women closely. In addition, Olausson takes audio recordings of the conversations between her and Iosif. In a series of 13 panels in black and white, which are published in the book It Could Have Been $M e$, we see Olausson holding a recorder in front of Iosif. Both she and Iosif are in tears, while the back of Arina Stoenescu's head pops into the foreground of the panel: 'It is like participating in a docusoap. It is difficult, but it has to be like this now. This is important. Everyone must listen' (Olausson and Iosif 2015 , p. 62). The recordings from Romania are later to be included in a 29-minute radio documentary entitled Sara och Felicia-vem hjälper vem? [Sara and Felicia: Who Helps Who?]. Made by Maria Ridderstedt for the radio show Tendens on Sveriges Radio, the radio documentary aired on 13 October 2014. In addition to Olausson's recordings from Romania, Ridderstedt included excerpts of interviews with Olausson in which the artist talks openly about her family's frail economy.

In the book It Could Have Been Me, Olausson clarifies why she chose to talk about economic strains in a radio documentary about begging:

I choose to expose my own difficult situation so that people get it that I do not have some magical powers or economic resources. My economy is at the moment hard pressed as I live in a small three-room apartment of 57 square meters together with my husband and our three children. (Olausson and Iosif 2015, p. 105)

In the same book, Olausson also discusses how her decision to expose herself derailed the entire focus away from begging, and towards her own 
parenting and giving skills. One listener was so provoked by Olausson's confessions on the radio that she sent her a personal message on the Facebook page It Could Have Been Me in which she accused her of serious child neglect. In the book, Olausson quotes the entire Facebook message, but without revealing the name of the sender, together with her reply, in which she reassured all the 'haters in the inbox' that she was a good caretaker and warned them that she would post their 'hateful' messages publicly if they did not stop (Olausson and Iosif 2015, p. 105). And if the 'haters' demonized Olausson as an irresponsible mother, others glorified her generosity (Olausson and Iosif 2015, p. 65). In the media stir, Iosif and other begging migrants are pushed into the background, while details about Olausson's personal life and her dedication to help begging migrants are foregrounded. This comes at a price for Olausson. In a Facebook post from January 2015, Olausson writes: 'Tired. Resigned. There is not much happening on this page right now... But hang on, I will come back./Sara' (Olausson and Iosif 2015, p. 105).

The friendship between Olausson and Iosif received a great deal of public attention not only because of its unique character, but also because of the political stir created by the far-Right nationalist party Sweden Democrats in connection with their anti-begging poster campaign referred to earlier in the chapter. As already mentioned, Sveriges Radio invited Olausson to debate against Björn Söder from the Sweden Democrats in a morning news programme on their main channel Pl (Pl-morgon 2014). In the book It Could Have Been Me, Olausson includes some reflections on her encounter with Söder. She confesses the debate with the politician from the Sweden Democrats was one of the most challenging things she did in connection with the project, a political confrontation that required mental preparation. She envisioned Söder as a vulnerable infant and initiated small talk with him before the debate. During the debate, she looked him in the eye and met his arguments with mindfulness (Olausson and Iosif 2015, p. 131).

If Björn Söder represents a party with which Olausson completely disagrees, at another point in the book the artist identifies herself with a Sweden Democrat when doubt sneaks in and she starts questioning her endeavour. On her fourth visit to Romania, Olausson has to 'fight against her inner Sweden Democrat' when she realizes that the needs of the poor are too big for her to appease and she feels that she is being taken advantage of: 
Exhaustion turns into anger. I should not follow the anger. I think the same thoughts; I feel the same feelings like a Sweden Democrat. Send them home so that I can walk around and shop in peace! Leave me alone at the metro station and stop playing the accordion when I want to have it quiet and read a book! (Olausson and Iosif 2015, p. 107)

A dedicated helper, Olausson too is vulnerable to a political discourse that projects vulnerability onto the begging migrants in order to exclude them from Sweden at the same time as it deploys the language of vulnerability to protect Swedish privilege. This speaks of how the multiplatform project It Could Have Been Me exposes not only Iosif's vulnerability as a poor migrant begging on the streets of Stockholm, where she endures cold, indifference, blatant racism and eviction, to name a few. It also flags out Olausson's own vulnerability: an economically pressed mother of three children, whose husband decides to move out and ask for divorce (Olausson and Iosif 2015, p. 137); a cartoonist who earns less in comparison to other artists working in other kinds of media (Olausson and Iosif 2015, p. 137); a well-meaning Swede who, at times, feels the demands of the poor become unreasonable (Olausson and Iosif 2015, p. 107); a storyteller dependent on rudimentary communication tools such as Google translate and whose story about Felicia changes from the graphic short story Felicia to the book It Could Have Been Me once Arina Stoenescu steps in and helps to interpret, clarifying that Felicia and her family knew very well she would come to Sweden to beg (Olausson and Iosif 2015, pp. 80-83).

\section{Begging Migrants in Art AND THE TACTICS OF VULNERABILITY}

Toleranshuvan Reloaded and It Could Have Been Me are examples of how contemporary Scandinavian artists initiate collaborations with begging migrants from Romania in an effort to engage with sociopolitical challenges facing Scandinavian societies today. Theorizing how artists employ participants from outside an artistic context in their work, Claire Bishop (2006) institutes a distinction between antagonistic and convivial art, whereby the first underlines discomfort and frustration in the protected space of the museum, while the latter cultivates conviviality in the extra-aesthetic space of community action. Through a reconstruction of the various phases of the two Swedish projects, and with a focus on 
vulnerability, I have shown how neither Toleranshuvan Reloaded nor It Could Have Been Me easily fit Bishop's critical distinction. Toleranshuvan Reloaded starts off as a performance in the museum's white room and ends in aborted fundraising. It Could Have Been Me unfolds on different platforms that cut across aesthetic and extra-aesthetic spaces, including graphic short stories, political debates on radio and fundraising through social media. In both projects, the begging migrants from Romania lend their bodies and stories to Scandinavian artists in the hope of making enough money to build a house for their families in Romania. If Carlsson and his team concluded that Lăcătuș and Chereși took advantage of the collaboration with Institutet to maximize their income, Olausson presents Iosif throughout the project as a friend in need, despite misunderstandings and moments of doubt and frustration.

Vulnerability as a condition commonly projected onto the begging migrants is deployed in a tactical field, with unpredictable changes and results. In both projects, the Scandinavian artists and audiences share linguistic vulnerability with the begging migrants from Romania. Carlsson and Olausson speak of how communication was truncated by the lack of a common language, while the visitors of Toleranshuvan Reloaded reported discomfort and frustration in the absence of an interpreter in the museum's white room. Moreover, Olausson shares vulnerability with Felicia Iosif when she decides to expose herself not only by sitting on the pavement next to her friend, but also when she talks publicly about her frail economy, mental struggles and family conflicts. Olausson's engagement comes at a great price: her parenting skills are questioned; she goes through a break-up as the project comes to an end and is disarmed when faced with the increasingly hostile political climate to begging migrants in Scandinavia. Unlike her colleagues at Institutet, who only reference this political climate to create discomfort in the art room, Olausson uses her project as a platform to take an active role in the political debate, such as when she meets Björn Söder from the Sweden Democrats in a radio debate. This makes Toleranshuvan Reloaded a safer project for the artists themselves, although Lăcătus, and Chereși seem to have highjacked the artistic gesture when they allegedly lied about their background. 


\section{Notes}

1. The terms used to describe citizens of Romania who beg on the streets of Scandinavian cities vary greatly across and within the Scandinavian countries, including denominations that underline administrative categories ('EU-migrants'), ethnic categories ('Roma', 'Gypsy'), national categories ('Romanians') and socioeconomic categories ('street workers') (Djuve et al. 2015, pp. 10-11). All these denominations are politically charged, as is the term 'beggar' itself. Given the focus of the chapter on the practice and language of begging, I have chosen the phrase 'begging migrants from Romania' to refer to those Romanian nationals who end up begging abroad. I use the term 'beggar' to describe strictly the performances commissioned by Scandinavian artists such as those at Institutet and in which real people are asked to play beggars for an audience.

2. In her book The Cultural Politics of Emotions, Sara Ahmed (2004) argues that emotions work similarly to money: the more they circulate, the more effective they become. Ahmed shifts the attention away from what emotions are towards what emotions do, and to the effects emotions generate through circulation. I am influenced by Sara Ahmed in the way I understand emotions and how I track them down in the media debates and the PR material released in connection to the two artistic projects I analyse in this chapter.

3. In January 2015, the Conservative and Progress parties in Norway issued an official proposal to ban begging nationwide. In this official document, begging migrants from Eastern Europe were described as vulnerable to human trafficking, while the criminalization of begging was seen as the only effective measure by which to address the vulnerability of this group of people (The Department of Justice 2015). Similar arguments became central in the debates sparked by the TV documentary Lykkelandet ('The Happy Country', NRK 2017), which is Norway's most viewed TV documentary to date, leading to unprecedented public engagement (Fordal 2017).

4. This and all the following translations from Carlsson are mine.

5. This and all the following translations from Stenbäck are mine.

6. Discussing Norwegian missionary work in Cameroon, the Norwegian anthropologist Marianne Gullestad coins the term 'crafty takers' to capture how Cameroonians in key positions have, over the years, developed new, creative forms of dishonesty to embellish developmental aid funds (Gullestad 2007, p. 277).

7. This and the following English translations from the Swedish book It Could Have Been $\mathrm{Me}$ are mine. 


\section{REFERENCES}

Ahmed, S. (2004). The Cultural Politics of Emotion. New York: Routledge.

Ankersen, D. (2015, January 28). Här ställs tiggare ut som konst. Dagens ETC, p. 10.

Asplund, M. (2014, May 13). Folk rasande på SD-kampanj mot tiggeri. Aftonbladet. https://www.aftonbladet.se/nyheter/article18867655.ab. Accessed 10 January 2019.

Berglund, S. (2015, January 29). Soraya Post om de utställda tiggarna: 'Låter äckligt'. ETC. https://www.etc.se/inrikes/soraya-post-om-de-utstalldatiggarna-later-ackligt. Accessed 10 January 2019.

Bishop, C. (2004). Antagonism and relational aesthetics. October, 110, 51-79.

Bishop, C. (2006, February). The social turn: Collaboration and its discontents. Artforum, 44(6), 179-185.

Butler, J. (2016). Rethinking vulnerability and resistance. In J. Butler, et al. (Eds.), Vulnerability in Resistance (pp. 12-27). Durham and London: Duke University Press.

Butler, J., Gambetti, Z., \& Sabsay, L. (2016). Introduction. In J. Butler, et al. (Eds.), Vulnerability in Resistance (pp. 1-11). Durham and London: Duke University Press.

Carlsson, A. (2017a, August 15). E-mail to author.

Carlsson, A. (2017b, October 11). E-mail to author.

Djuve, A. B., Friberg, J. H., Tyldum, G., \& Zhang, H. (2015). When Poverty Meets Affluence: Migrants from Romania on the Streets of the Scandinavian Capitals. Oslo: Fafo and Rockwool Foundation. http://www.fafo.no/ images/pub/2015/954-innmat-trykk.pdf. Accessed 10 January 2019.

Ekman, K. E. (2015, January 30). Ställ ut de rika på museum-inte de fattiga. ETC. https://www.etc.se/ledare/stall-ut-de-rika-pa-museum-inte-de-fattiga. Accessed 10 January 2019.

Fordal, J. A. (2017, June 12). Bred støtte til 'Lykkelandet'-dokumentar. NRK. https://www.nrk.no/informasjon/bred-stotte-til-_lykkelandet_-dokumentar1.13542626. Accessed 10 January 2019.

Gullestad, M. (2007). Picturing Pity: Pitfalls and Pleasures in Cross-Cultural Communication-Image and Word in a North Cameroon Mission. New York: Berghahn Books.

Institutet. (2015). Toleranshuvan Reloaded. "A pair of rubber gloves called tolerance”. http://institutet.eu/2015/01/institutet-pa-konsthallen-malmo7-toleranshuvan-reloaded-a-pair-of-rubber-gloves-called-tolerance/. Accessed 10 May 2019.

Israelson, A. (2015, January 29). Utställningen handlar inte om tiggarnas utsatthet. SVT. https://www.svt.se/opinion/article2636160.svt. Accessed 10 January 2019. 
Jackson, S. (2011). Social Works: Performing Art, Supporting Publics. New York: Routledge.

Jönsson, D. (2015, February 3). Förvirrande stark 'tiggarperformance'. Dagens Nyheter. https://www.dn.se/kultur-noje/konst-form/forvirrande-starktiggarperformance/. Accessed 10 January 2019.

Kirkerud, K., \& Baraldsnes, R. (2017, April 20). Slår full alarm om romleire: Barnehagebarn tilgrises av avføring. TV 2. http://www.tv2.no/a/9073210/. Accessed 10 January 2019.

Malmö Konsthall. (2015). The Alien Within-A Living Laboratory of Western Society. Information sheet. https://www.konsthall.malmo.se/utstallning/thealien-within-a-living-laboratory-of-western-society/. Accessed 11 May 2019.

Millroth, T. (2015, January 29). En skriande kontrast. Det är din självbild, inte tiggarnas, som prövas. Sydsvenskan, p. 5.

Norsk kringskasting (NRK). (2017). Lykkelandet ('The Happy Country').

The Department of Justice, Norway. (2015, January 22). Horing-forslag til endring $i$ straffeloven 1902 og 2005 (ny $\$ 350$ a og ny $\$$ 181a om forbud mot organisert tigging). https://www.regjeringen.no/no/dokumenter/hoeringforbud-mot-organisert-tigging/id2362547/. Accessed 10 January 2019.

Olausson, S., \& Iosif, F. (2014). Felicia. Stockholm: Pionier Press.

Olausson, S., \& Iosif, F. (2015). Det kunde varit jag. Stockholm: Kartago Förlag.

Olsson, J. (2015, April 29). Dubbelt så många tiggande EU-migranter senaste året. SVT Nyheter. https://www.svt.se/nyheter/inrikes/dubbelt-sa-mangatiggande-eu-migranter-senaste-aret. Accessed 10 January 2019.

Parsberg, C. (2015). How Do You Become a Successful Beggar in Sweden? https://ceciliaparsberg.se/how-do-you-become-a-successful-beggar-insweden/. Accessed 10 May 2019.

Pl-morgon. (2014, May 16). Debatt om SD-kampanj mot tiggeri. Sveriges Radio. http://sverigesradio.se $/$ sida/artikel.aspx?programid $=1650 \&$ artikel= 5863965. Accessed 10 January 2019.

Răducanu, G. (2015, February 10). Letter sent to Diana Baldon, Director, Malmö's Fine Arts Museum. European Roma and Travellers Forum, Strasbourg.

Rooth, P. (2015, January 28). Konstprojekt kritiseras för att objektifiera migranter. Skaines Fria. http://www.skanesfria.se/artikel/116570. Accessed 10 January 2019.

Schweik, S. (2009). The Ugly Laws: Disability in Public. New York: New York University Press.

Stenbäck, C. (2015, January 25). Fattigdom väcker tankar på Konsthallen. Skainska Dagbladet. http://www.skd.se/2015/01/25/fattigdom-vackertankar-pa-konsthallen-2/. Accessed 10 January 2019.

Traavik, M. (2014). Presserom. http://traavik.info/works/ukunst-. Accessed 10 May 2019. 
Open Access This chapter is licensed under the terms of the Creative Commons Attribution 4.0 International License (http://creativecommons.org/licenses/ by/4.0/), which permits use, sharing, adaptation, distribution and reproduction in any medium or format, as long as you give appropriate credit to the original author(s) and the source, provide a link to the Creative Commons license and indicate if changes were made.

The images or other third party material in this chapter are included in the chapter's Creative Commons license, unless indicated otherwise in a credit line to the material. If material is not included in the chapter's Creative Commons license and your intended use is not permitted by statutory regulation or exceeds the permitted use, you will need to obtain permission directly from the copyright holder.

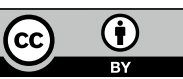




\title{
Partitioning Vulnerabilities: On the Paradoxes of Participatory Design in the City of Malmö
}

\author{
Erling Björgvinsson and Mahmoud Keshavarz
}

While we are told that the democracies and social fabrics of different societies and communities have become weakened due to the aggression of global capitalism, there is an increasing demand for participation among different actors who share different views but, nonetheless, have a stake in a particular issue. As such, 'participation' has become the buzzword in modern democracies, where equality only seems to be granted through initiating, managing and running different and multiple participatory projects in which it is assumed that underrepresented groups and individuals will be granted a voice.

Among the various participatory and collaborative methodologies and approaches in arts, media and design, the Scandinavian approach to participatory design has become established in academic, non-governmental

E. Björgvinsson

University of Gothenburg, Gothenburg, Sweden

e-mail: erling.bjorgvinsson@gu.se

M. Keshavarz $(\bowtie)$

Uppsala University, Uppsala, Sweden

e-mail: mahmoud.keshavarz@antro.uu.se

(C) The Author(s) 2020

A. M. Dancus et al. (eds.),

Vulnerability in Scandinavian Art and Culture, https://doi.org/10.1007/978-3-030-37382-5_12 
and even governmental sectors in Nordic countries. It is viewed as an approach and method to remedy the assumed lack of participation. This chapter discusses Scandinavian participatory design, its initial aspirations in the 1970s and its paradoxes in the present (2020) when working with local communities in poor European neighbourhoods. The chapter also questions the assumptions held about who is rendered vulnerable and under what conditions; who has fewer resources and is in need of participation and empowerment. We argue that, while the idea of participation is often taken for granted and is equated with democracy, the concept and practice of participation has at no time been neutral. Participation has its own histories, logics and politics, and produces different relations and politics in different contexts, with different actors and different needs. Both the call and the process of participation always takes place in an already partitioned world. As such, participation does not necessarily give equal voices to participants, as is frequently assumed. Rather, it produces new categories of participant, ignores certain other categories and lifts up particular types of participant depending on the power relations involved. ${ }^{1}$

This chapter traces one such instance, when a group of participatory design researchers collaborated with a group of marginalized young music artists from the Swedish suburb of Rosengard. Rosengard, the population of which mainly comprises first- and second-generation migrants, is located in Malmö, the third biggest city in Sweden. Malmö has a population of $340,000,30 \%$ of whom were born outside of Sweden. Erling Björgvinsson was one of the main design researchers behind the project; therefore, this chapter aims to reflect and problematize the project retrospectively. In this chapter, the authors, reflect on how the assumption about the vulnerabilities of a certain group made the call to participation an imperative from the design researchers' perspective. Furthermore, they explain how that assumption continued throughout the process, despite the fact that the group assumed to be vulnerable was actively pushing back against that assumption. This, however, was ignored, as the image of who is vulnerable and in need of empowerment was so strong that it formed the basis of the participatory design project from its very inception. We conclude that participatory methods do not necessarily overcome or resist vulnerabilities that arise due to unequal development but, rather, generate other forms of vulnerabilities that cannot be recognized by employing the same framework used to locate the vulnerability to be overcome with participation. To counter this paradox, we propose part-taking as a working concept that is mindful of the active processes of taking, giving, sharing or 
separating parts - in other words, processes of partitioning vulnerabilities, unfolding through different power relations involved in any participatory setting.

\section{Scandinavian Participatory Design: Aspirations to Side with the VulNerable}

The current dominant participatory design approach within academic design environments has its origins in what is known as Scandinavian Participatory Design. This approach to participatory design has its roots in 'post-war political movements striving for industrial democracy including forms of co-determination by unions and "shopfloor" workers in decision making and efforts to improve the quality of working life, in the broad context of democratization of society' (Gregory 2003, p. 64). As such, Scandinavian participatory design was clearly a political positioning that emphasized siding with vulnerable individuals and groups who should have a say in the process and outcome of the designs that affect them. This position became quite strong in relation to the commercial and industrial designs of the time, which assumed the designer as the expert and sole knower of 'good design'. Since its beginnings in the late 1970s, when it was focused on design for workplaces in relation to their transformation given the advent of computer technology, Scandinavian participatory design (Bjerknes et al. 1987; Bødker 1996) has been guided by two sets of values. These two sets of values have subsequently become its leitmotifs. The first value leitmotif was that those affected by a design should shape the outcome of it; the second was that the role of participatory designer was to side with those who were termed 'resource-weak participants'. This was clearly seen as democratizing design and innovation (Ehn and Kyng 1987) by means of decentring the role of designers-unlike the situation with regard to commercial design processes. This was reflected in the acknowledgement of designing as a collaborative endeavour that emphasized attending to the needs and interests of the underrepresented groups and individuals, who should be part of the process of designing. This aimed not only to address the needs and interests of users, but also to inform and challenge the structures and systems shaping workplaces.

To pay attention to the importance of involving all relevant participants in the process of designing also meant acknowledging the importance of tacit knowledge. This was addressed particularly in the case of design for workplaces by developing ways of designing where the tacit aspects 
of workers' knowledge connected to specific work tasks could be envisioned, articulated and tried out. This was realized by the designers and the participants tried out future work practices with the aid of various prototypes constructed out of paper and cardboard (Ehn and Kyng 1991). The underpinning critique posed by participatory design was focused on a rational view of work where work and competence could be formally and explicitly planned and described. This was a prevalent perspective in the late 1970s and early 1980s with regard to computer science, interaction design and organizational studies (Suchman 1987). The acknowledgement of tacit knowledge thus understood the work as a socially organized and situated activity and, in doing so, emphasized the politics of representation as material transformation.

The underlying convictions in participatory design were that embodied and tacit 'language' of workers was not 'heard', and that they could not speak for themselves on how their work practice could be transformed. For these reasons, the importance of taking the part of the socalled 'resource-weak' participants was emphasized, which in most cases was realized through the involvement of local trade union representatives. As well as enacting specific future work tasks, participatory design also engaged in setting up debates on broader organizational workplace issues. This was undertaken by putting conflictual perspectives on the table through design games that resembled strategy board games. Such joint decision making processes focused on more traditional representational politics.

Although early participatory design stressed the importance of the mutual learning of designers and participants, and siding with the resource-weak participants, in practice, the forms of participationincluding the materials provided, and the settings and the representation-tended to be framed by the designers. For instance, what forms of learning and by who they were envisioned and enacted, can be a subject for debate. One can question whether the designers' learning included what Spivak (1993) calls 'learning to learn how to listen'. The discrepancy in learning between those who initiate participation (designers) and those called into participation (workers and their representatives) was acknowledged to some degree, which led to incorporating ethnography and ethnomethodological studies into participatory design processes. However, this still meant that resource-weak participants, although perhaps not voiceless subaltern subjects, were seen to be in need of being 
amplified and empowered through the abilities of designers and ethnographers. What also was taken for granted was the positions of different participating subjects as fixed within the existing institutional structures. As such, the main focus was on the material transformation of work, rather than the redistribution of power between workers, designers and employers. What drove participatory designing forward was the acknowledgement that everyone participates from their position as recognized by the need to participate: the worker expresses their need as a worker; the designer shares their skills as a designer; the employer participates as an employer. The essentialization of roles and identities framed by the participatory intervention generated unified subjects and homogenous groups, and thus ignored the differences, internal conflicts and power relations within each group of participants.

While participatory design has changed since the late 1970s, nonetheless some of its foundational assumptions and paradoxes have remained. Assumptions such as that workers could not speak for themselves and needed help to articulate a language, achieved through design, for the communication of their needs and desires; or that being a worker was an essentialized condition that made one vulnerable in relation to the transformation of the workplace, thus producing a homogenous group called 'workers'. However, some of these assumptions will be challenged in this chapter as we follow the trajectory of participatory design, from its engagement with the trade union representatives of the 1970s to dealing with civic organizations and self-organized communities in the poor neighbourhoods of European cities inhabited by the working-class migrant population.

As participatory design expanded, so did its deployment in other contexts than Nordic workplace democracy supported by trade unions. Subsequently, participatory design-also known as 'co-design' and, more recently, 'social innovation'-became entangled with 'design thinking' and 'design management' in commercial and entrepreneurial sectors tackling social, environmental and economic issues. Participatory design gradually became a method, rather than a process, in any context and form of designing used merely to extract the 'user' needs required to deliver and sell the best fitted 'solution' to a concrete problem (see Sanders and Stappers 2008).

Since the early 2000s, participatory design researchers have explored how they can engage in reforming issues in various public spheres by linking public, private and civic actors. Given the diversity of perspectives, 
concerns and interests in any public sphere, such an approach investigates the creation of common spaces, using terms such as 'socio-material assemblies', 'Things' and 'infrastructuring', where differences and conflicts may be negotiated through long-term engagement and multiple productions, rather than one single product (Björgvinsson et al. 2010, 2012a, b). Critical to the commercial transformation of participatory design to extract 'user' needs, participatory design researchers have argued, in line with early participatory design leitmotifs, for democratic bottom-up change processes where particular attention should be given to the resource-weak individuals and communities who are excluded from the existing infrastructure of life and work, and who are deemed more vulnerable. It is in this context that participatory design in public spheres has become progressively more popular in governmental institutional agendas, because 'existing structures and policies have found it impossible to crack some of the most pressing issues of our times' (Murray et al. 2010). However, the ambitious claims made by the call for participation in this new context, in practice, may produce a type of facilitation and engagement that has an ambiguous relationship with new and dispersed forms of governance in neoliberal times. Although against extracting 'user' needs, participatory design researchers and the less vulnerable participants, such as public institutions and entrepreneurs, have not been able to acknowledge fully how they shape the terms of participation (Keshavarz and Mazé 2013) and what they gain from the collaboration since they see their roles as mere facilitators-contributors who apparently do not shape the content and direction of participation. In the next section, we will show why this assumption is wrong and how-in taking a facilitating role in linking public, private and civil actors-participatory design researchers, while initiating participation with the aim of empowerment and overcoming the vulnerabilities of resource-weak individuals and communities do, indeed, generate other forms of vulnerability. This becomes possible only through negating how the assumed vulnerable condition is already an active and generative position.

\section{Parting Participants by Participation}

We will now turn to a case where participatory design was deployed to connect a music organization from Rosengård in Malmö to a media company and national actors such as the Swedish public service radio Sveriges Radio and the TV station Sveriges Television. The project was carried 
through Malmö Living Labs for co-production, social innovation and new media, based at Malmö University, which was a research environment that engaged in creating common spaces where private, public and civic actors, amongst other could collaborate together in relation to cultural production. Erling Björgvinsson was part of this Lab, which ran between 2007 and 2012, and was funded, first, by Vinnova (a Swedish government agency that administers state funding for research and development) and, later, by the EU structural fund. ${ }^{2}$

The case study focuses on how the strong participants—such as the researchers and the media company-despite framing the participatory engagement as a bottom-up participation of a democratic nature, owned the process, the terms of participation, the framing of the issue, and the way knowledge was acquired, materially transformed and represented. The needs for the more vulnerable participants were, thus, defined and determined by what the project owners perceived they could offer; the part they could give to the resource-weak participants. Furthermore, the case study focuses on how participation has increasingly become more obsessed with participatory models and methods-in particular, those that generate connections and links between what are seen as diverging social spheres, rather than outcomes. Finally, the case study will show how this leads to partitioning the various vulnerabilities involved.

The collaboration was based on working with a music grassroots organization that, in its own words, worked for multi-ethnic encounters and societal inclusion through cultural activities-partly to counter negative images of migrants as projected by mass media. The members of the music organization were youth music artists, dancers and journalists who were the children or grandchildren of migrants who mainly lived in Rosengard. More powerful actors collaborating directly with the music organization were a medium-sized media company, Malmö Living Labs researchers and, indirectly, Sveriges Television and Sveriges Radio. The collaboration, one of many the researchers conducted with the music grassroots organization, focused on exploring grassroots mobile media broadcast production in connection with Musikhjälpen in 2008; this is a live music show that appeals for money each year to support a specific humanitarian cause. It is set up in a public square and takes place in a different city each year. Three radio or television personalities are locked inside a glass house installed in a public square for six days, and they broadcast live on Sveriges Radio and Sveriges Television. Viewers and listeners send 
text messages requesting a particular song, each request costing a certain amount of money and thereby raising funds.

The medium-sized company was appointed to run the event. They won the bid as Sveriges Radio and Sveriges Television considered they had the best proposals for drawing people to the location of the event, as well as how to make the grassroot initiatives in Malmö visible through the mobile media production facilities that the music grassroots organization had available.

The Lab and its researchers departed from the idea that new media activities cut across private, public and civic spheres in relation to law, policy making and funding that shape who can engage in cultural productions and determine their form and content. Journalism, film, literature and music each comprise numerous complex public spheres that cut across public and private spheres due to how they are regulated and funded (Foucault 1973, 1977; Barry 2001). The Lab work was based on an aesthetic-political perspective that favoured ways of working where 'marginalized' cultural producers, such as young music artists, were brought into partnerships with established strong public and private actors, such as national TV and radio, by means of participatory methods.

One of the issues, prior to the launch of event, related to what each partner received from the collaboration. The media company and one of the researchers in the Lab had the double agenda of promoting both the music organization and its leader because, alongside this collaboration, they were working on selling a television production idea that would be led by the leader of the grassroots music organization. After much debate and disagreement amongst the researchers-which importantly, and paradoxically, did not involve the young members of the music organizationthe Lab and the media company decided to frame the music organization main broadcast webpage as the leader's broadcast channel, with the leader's of the organization's name appearing in the logo, rather than the organization's channel. The grassroots music organization's broadcast thus, primarily, became a vehicle to promote and increase the chance of convincing Sveriges Television to fund the media company and the music organization leader's idea for a programme. This was, in practice, marketdriven lobbyism, rather democratic decision making or an experiment, as claimed by the researchers or imagined by the promises of participatory design.

During the six days of Musikhjälpen, a longstanding conflict in Rosengarrd peaked. The background was that a private owner, Contentus, 
which rented out its premises to numerous non-governmental organizations, and a mosque decided not to prolong the contract and, instead, planned to rent out the premises to Rosengard's district administration and a rental housing company, MKB. This led to the occupation of the premises and ensuing conflicts between the occupants and the police and fire brigade, which was covered extensively in national and international media.

The conflict directly affected the street-journalism collaboration. Due to the mass media coverage of the conflict, suddenly the municipality, which provided the music organization simple premises, felt that music organization had too few activities going on in Rosengård. This was untrue. In fact, the organization engaged many more youngsters in their different activities than the youth activities run by the district administration. Beside this, the district administration had actively worked on recruiting some of the music organization 'leaders'. This consequently created conflict within the organization that, in turn, generated factions among its members. Nevertheless, the district administration pressured the music organization, as they wanted to be able to provide evidence that they had actively engaged in constructive activities in Rosengård from a municipal perspective.

The decisions made by the media company and the researchers in promoting only certain parts of the organization-in particular, its leaderand, in turn, the district administration's pressure on the music organization, exacerbated by mass media, merged into each other to the extent that the organization was torn asunder. What had started out as a democratic engagement had, in practice and undemocratically, favoured certain interests and elements of the participation and oppressed others. While the marginalization of the organization in relation to the public sphere mediated by the big actors was the realization on which the participatory project had embarked, in practice the participation and the process of linking different actors generated new vulnerabilities among the most marginal individuals in the organization. This, however, did not stop those who were badly affected from actively pushing back. A faction of the organization rightly demanded that the specially designed broadcast webpage channel for the event-designed for and based on the identity of one of the leaders-be shut down. The branding, the naming of the Internet domain name, the logo and the structuring of the website had come about through the exclusion of the youngsters from participating in the design and development process. 
The case, although framed as 'giving voice' and empowering the 'marginal' participants through connecting them to normative and powerful actors, was violent and unjust in its realpolitik. It assumed that the organization consisted of unified subjects and homogeneous members, and that one leader could represent the whole organization. Through this assumption, the participation set by design researchers, in truth, tore the music organization apart. The vulnerabilities imagined by participatory design researchers were addressed through a certain type of participation that, eventually, empowered the researchers, the media company and one individual within the organization. This, however, caused a rupture in the social fabric of the organization. While the aspiration to connect all the actors came from the marginalization of young music artists, the participants that benefited nevertheless ignored the vulnerable condition of the young music artists as a productive mode from which they wanted to partake in a different manner.

\section{Disconnecting by Connecting}

While highly situated, the case discussed is not exceptional. This needs to be read in the context of the city of Malmö and its transformation since the turn of the millennium. During the first two decades of the twentieth century in Sweden, the private, public and civic spheres entwined in a distinct way that was highly different from that of the 1970s, when participatory design was taking its initial shape in Nordic countries. The welfare state and workers unions had become significantly weakened, and work precarity and competition increased. Cultural production had now been transformed into creative industries, which emphasized entrepreneurship, innovation and profitability that favoured small-sized new media companies, while it also made cultural work for most more precarious in the form of freelancing. The term 'creative industries' was a product of the Blair government and its establishment of a Creative Industries Task Force in 1997 (Flew 2002, 2011), which influenced Sweden as well. It was a task force aimed at capturing and promoting the enterprise dynamics of cultural producers in the new economy (Cunningham 2002). Closely linked to Blair's venture into creative industries was Charles Leadbeater, who advised the British government on the relationship between the knowledge-driven economy and networked media. While promoting social entrepreneurship, he juxtaposed old and allegedly defunct organizational models found in big companies and universities with the more 
agile, inventive and passionate self-organized professional amateur producers (Leadbeater 1997, 1999; Leadbeater and Miller 2004). He argued that, in order to foster innovative and globally competitive creative practices, what needed to be acknowledged and supported was the value of knowledge capital and social capital; this, in turn, demanded organizational reorientation in the form of creative communities that were based on networks and distributed ownership. McRobbie (2003) critically argued that such idealization of the creative entrepreneur happened at a time when societal structures that supported new creatives were considerably diminished, which lead to increased competition, instability and mobility amongst cultural producers. This is closer to the reality on the ground than that put forth by policy makers and innovation evangelists.

Social and cultural entrepreneurship played a significant role in the 'reinvention' of Malmö, for its transformation from a slumbering harbour city after a period of post-industrial decline. The transformation was heavily influenced by Richard Florida's idea of the importance of the creative class in making cities vital (2002). Dalia Mukhtar-Landgren (2006) points out how the transformation of Malmö-which was centred on supporting knowledge-based entrepreneurial work, building attractive harbour houses, offering vital multicultural city life and cheap services-was heavily policy-driven. Furthermore, she discusses how the policies and political statements related to the transformation in Malmö tend to paint a binary opposition between the green entrepreneurial Western Harbourwhich came to stand for the bright future, and the so-called 'migrant' and 'working-class' districts such as Rosengård, which were described as problematic due to high unemployment and criminality, thereby hampering the city's economic growth. Rather than being discussed as effects of specific and active political and economic processes that transformed and directed Malmö towards segregation, these binaries became taken for granted as truth. On the basis of the 'truth', new social and cultural development and research projects, and efforts to innovate using participatory and collaborative methods were launched to 'activate' and 'empower' those who were left behind in the process of transformation.

Although some of the researchers active in Malmö Living Labs were critical of not only the idea of cultural industries, but also the social and economic redemptive value of the creative class and their entrepreneurship, nonetheless they initially believed in the value of networking across public, private and civic sectors. In particular, they thought it was important to support marginalized civic actors and small cultural producers, 
many of them from Rosengård, in gaining access to larger arenas and powerful partners that were dominating the current public spheres.

In hindsight, Björgvinsson and those working in the Lab were immersed in the ideals that Boltanski and Chiapello (2005) have critiqued as the 'projective city'. A projective city, as a dominant idea governing cities in the 1990s, is a future- and project-oriented city where economic profit and social justice are brought into accord. More precisely, projective has the double meaning of 'project-oriented' and 'projection', as in future-oriented, given that the value of a project is foremost valued in relation to the extent to which it can create new networks, rather than what it achieves in the form of concrete outcomes. In the projective city, the highly valued and employable persons are those who run a multiplicity of transient projects concurrently, and who can link different spheres, given their belief in a distributed creativity and innovation. A particular value is ascribed to those that can multiply connections and proliferate links-not least, the links and connections between unexpected and socially diverging social spheres. Those being linked, however, if they are unable to provide connections, are seen as having little value. The overriding importance ascribed to generating new projects and connections, preferably between diverging social spheres, means that any form of activity can be termed a project. In the projectification of the social life of vulnerable groups, participatory design researchers and stronger cultural workers surmount and blend voluntary work, unpaid and paid work, and stable and unstable ways of making a living, with the hope that this may lead to a new project, another project, yet another projectification. Participatory design researchers as connectionists thus become indifferent to the difference between opposed intentions and values - such as pure commercial, profit-driven endeavours - and civic and social engagement, and what connecting them implies politically, socially and economically. Given that the civic organizations such as the grassroots music organization were unlikely to provide connections and links to what were deemed valuable partners in the eyes of the bigger actors, while the researchers and other strong actors could do so, meant that as the less vulnerable actors increased their value and status the more vulnerable actors did not. What was thus framed as democratic participation and inclusion was fundamentally proliferating exclusion, marginalization and, furthermore, dependency on the middle-class cultural workers and researchers who provide new connections and projects. This uneven relationship in what parts are taken and by whom they are given is clearly revealed when one locates 
it in the context of the proliferation of collaborative and participatory projects in Rosengard in Malmö, where these projects use terms such as 'innovation', 'democracy' and 'inclusion' in their funding applications.

Malmö is, indeed, an exemplary projective city that engages in projects with socially divergent spheres. As the Sydsvenskan article 'Mycket babbel-lite verkstad' (Mikkelsen 2012) describes, between 2000 and 2011 a total of 345 research and development projects were started in Rosengård alone-none of which brought about improved school results and employment rates. This led Nabila Abdul Fattah (2014) to write an article in ETC on 16 December in which she said: 'Stop making us into laboratory rats. I am tired of experimentally engaged people who exploit the system for their own profit, who can tick off that they have done an asphalt safari and done "good".'

Once specific sites and spaces are rendered as places in need of participation, then design practices, such as participatory design, embark on such narratives and turn these places into something else. They compose material, technological, cultural and social practices into compositions of meanings that can be consumed, exchanged and mediated in favour of specific ideologies and interests. However, as discussed, the participation enacted through such approaches in practice often presents a kind of facilitation, linking and engagement with an ambiguous relationship to new and dispersed forms of governance and entrepreneurship in neoliberal times. That is to say, such projects often produce an economic rationale that keeps them separate from the politics involved in the very same situation, as politics may be understood as an exclusive matter of the state (Kiem 2011). Participation is advocated in so far as it diversifies the types of stakeholder, but does not unsettle the forms of hegemonic orders that sustain the economic interests of the state, markets, entrepreneurs and certain classes. People participate to express their shifting interests and values, and to practice their rights in the social sphere (in the best case), while remaining recognizable by the very attributed vulnerabilities that facilitate the status quo-vulnerabilities that make designers turn their attention to those bodies in the first place, as potential collaborators or participants in a design project. Participation, then, becomes a means of affirming the vulnerabilities that could be used to sustain certain practices of power within the current neoliberal rationale. By producing multiple choices, but only within a given framework, participation adjusts and adapts to power structures for the sake of facilitating participatory potentials, by giving a sense of collaboration without taking into account 
the politics of different and contradictory positions, hierarchies, conflicts, dissents and norms that actually constitute politics.

Conflict and dissensus are, in fact, inherent in the political nature of any participation. Participation is not about reaching all-inclusive agreement in order to move on. Neither is it about composing different elements and bringing different actors together to envision possible futures, choices and alternatives within a given framework and setting. Instead, the example discussed shows that participation is about how taking a part, sharing a part, or acting a part in an already partitioned dynamic environment can point to various unrecognized or less-recognized power relations and vulnerabilities involved in any partitioned space produced by any form of participation. As any such call for participation should always be thought of in relation to how such a call partitions the already existing vulnerabilities into a set of social and economic relations and connections that unequally mobilize certain actors while immobilizing others.

\section{Refusal of the Vulnerable Parts}

There has been much academic publishing around participatory design and social innovation, especially in historically strong welfare states such as those of the Nordic countries and the UK. Much of this scholarship, while it may point to different difficulties and issues at hand, nonetheless affirms the necessity and the positive impact of participatory approaches to different social, economic and environmental issues. However, their impact is not evaluated according to a politics of justice and equality demanded and practised by those individuals deemed vulnerable in the first place. The success of these projects lies in the ability of researchers and designers to generate an academic or commercial narrative of the helplessness and vulnerability of the abstract figure of the migrant, worker, elderly and youth, and thus receive acclaim for providing assistance, facilitation and empowering strategies to the vulnerable. ${ }^{3}$ Consequently, this produces specific human beings that are merely understood to exist in order to be helped and protected. On the other hand, these design interventions help the design community to imagine-as well as to satisfy - themselves in relation to the relevancy of their work for our current urgent conditions of growing inequality and precarity.

What happens in participatory design interventions is that vulnerability becomes an ontological condition of those who are deemed to be in need of support and participation. In such interventions academics, municipal 
actors and cultural workers make the assumption that, without the more powerful actors, the marginals cannot change or affect their conditions on their own. Rather than supporting the autonomy of the marginalized, the participation turns the condition into a binary, making one group a homogenous body in need of support and connection, and the other as those with the resources to connect. In such a process, participatory design researchers disavow their own vulnerability, interest and desires, and project them onto one group as comprising its essential condition. As argued by other scholars, vulnerability 'emerges as part of social relation' (Butler et al. 2016) and, as such, through encounters made possible by initiatives of participation. If vulnerability is to be understood as 'politically produced, unequally distributed through and by a differential operation of power' (Butler et al. 2016), the case of participatory design shows that the attempt to resist or overcome the imagined vulnerability is always already about the strategic re-distribution and partitioning of the different vulnerabilities involved. This strategic redistribution, however, runs the risk of aligning with powerful actors because of economic dependency, the value of connections and networking, neoliberal channelling and breaking of the existing autonomous communities and solidarity networks through picking and harvesting active individuals and boosting their careers.

One should remember that to ask for participation is always a call to ask for certain types of participation. It is a demand to follow duties that have not been followed. Take, for instance, the figuration of nation, often represented and imagined as a sacred whole, a transcendental entity or, in secular terms, a body. In order to feel that one is a member of a body, parliament or gathering, one must remember that one is a part of a body as well. Sara Ahmed (2012), in her discussion on wilfulness, states that wilfulness refers to the part that, through its willing against the will of the whole, has forgotten that it is just a part and nothing more.

In order for parts to become parts, they need to acquire a duty. This duty can be thought of as a life duty, which is to say, it must be willing to preserve the life and happiness of the whole body. This means that parts should be sympathetic to each other in order to remain a part or member. This, in turn, demands a form of obedience. Therefore, if a part is not willing to be only a part, a part that follows its duty as a part, then it threatens to break the whole apart. Ahmed makes this clear when she says: '[a] rebellion is a rebellion of a part'. 
The rebellion or the break in the whole-in the body that calls for certain types of participation-is therefore not to be dismissed as a mere conflict of interest. Rather, it is a wilful rebellion of a part as it performs its opposition to its duties, roles, vulnerabilities and attributions, which would perhaps be perceived as a threat to other parts and the will of the whole, a threat to the smoothness and fluidity of participation. To tell the stories of this momentary rebellion, as in the case of a small group of young music artists, is also to disrupt the fluidity and smoothness of participation presented by its advocates, academics and governmental actors alike.

To recognize the differentiated vulnerabilities and the process of its partitioning, we propose the term 'part-taking' (Keshavarz 2016). Parttaking is not flat. It reminds us that a part is, and can be, by its condition, separable from the action that makes it identical to part-taking as whole. As with the story of the grassroots music organization and its younger members, part-taking reminds us that there are other forms, such as partsharing and part-acting, that are simultaneously involved in shared situations.

Thinking about taking a part, refusing a part, sharing a part, acting on a part and risking a part is not a matter of reflection on participation but, rather, it is the very essence of participation itself, understood through the concept of part-taking. Part-taking not only makes us aware of the different values, norms, positions, uneven and unequal benefits within any assembly and gathering, any encounters of multiple actors; part-taking can also challenge assumptions on whose vulnerability is the driver and mobilizer of the call to participation. Part-taking can further expose and make accountable those who the vulnerability of others guides them to initiate participatory projects. More importantly, it can develop sensitivities to recognize the resistance and the struggles of those taken to be the most vulnerable beyond the attributed vulnerability, rendering them passive.

\section{Notes}

1. Scholars in different fields have already challenged the concept of participation. See Bishop (2012), for a critique of participatory, community and relational art emerging since the 1990s; see Miessen (2010), for a critical survey of the term used in architectural and urban design projects. Most importantly, Bill Cooke and Uma Kothari (2001) have challenged the 
seductive claims of participation within the context of participatory development projects, and ask participatory practitioners and theorists to reassess their own role in promoting a set of practices that are, at best, naive about questions of power and, at worst, serve systematically to reinforce, rather than overthrow, existing inequalities.

2. What actors and groups can acquire governmental funding is of particular relevance because research funding is one of many infrastructural devices for the distribution of resources and power. EU structural funds were created to level out differences between regions. It is an example of multilevel organizing of democracy where public and private actors collaborate horizontally across local, regional, national and European levels to promote their interests. This is an organizational form that is not particularly transparent, open, or public, and that is heavily driven by lobbyism. It is an organizational form that, according to some, is a new form of democratic decision making, while others argue that semi-transparent lobbyism is antidemocratic (Erlingsson 1999). The Malmö Living Labs is an example of the later. The larger project, which was headed by Moving Media Southern Sweden, received 25 million kroner, whereof 10 million kroner went to Malmö University and the rest to Malmö Incubator and Moving Media City.

3. Like many other participatory design projects, the narrative published around the case, discussed by the researchers and media company involved, was also that of success. Erling Björgvinsson, however, has critically reflected on the project in another context (see Björgvinsson 2014).

\section{REFERENCES}

Abdul Fattah, N. (2014, December 16). Sluta göra oss i förorten till labbråttor. ETC. http://www.etc.se/ledare/sluta-gora-oss-i-fororten-tilllabbrattor. Accessed 23 February 2017.

Ahmed, S. (2012). A willfulness archive. Theory \& Event, 15(3). https://muse. jhu.edu/. Accessed 19 September 2012.

Barry, A. (2001). Political Machines: Governing a Technological Society. London: Athlone.

Bishop, C. (2012). Artificial Hells: Participatory Art and the Politics of Spectatorship. London: Verso.

Bjerknes, G., Ehn, P., \& Kyng, M. (1987). Computers and Democracy: A Scandinavian Challenge. Aldershot: Gower Publishing.

Björgvinsson, E. (2014). Collaborative design and grassroots journalism: Public controversies and controversial publics. In P. Ehn, E. M. Nilsson, \& R. Topgaard (Eds.), Making Futures: Marginal Notes on Innovation, Design, and Democracy (pp. 227-255). Cambridge, MA: MIT Press. 
Björgvinsson, E., Ehn, P., \& Hillgren, P.-A. (2010). Participatory design and democratizing innovation. In Proceedings of the 11th Biennial Participatory Design Conference (29 November-3 December). Sydney, Australia.

Björgvinsson, E., Ehn, P., \& Hillgren, P.-A. (2012a). Design things and design thinking: Contemporary participatory design challenges. Design Issues, 28(3), 101-116.

Björgvinsson, E., Ehn, P., \& Hillgren, P.-A. (2012b). Agonistic participatory design working with marginalized social movements. CoDesign: International Journal of CoCreation in Design and the Arts, 8(2-3), 127-144.

Bødker, S. (1996). Creating conditions for participation: Conflicts and resources in systems development. Human-Computer Interaction, 11(3), 215-236.

Boltanski, L., \& Chiapello, E. (2005). The Spirit of New Capitalism. London: Verso.

Butler, J., Gambetti, Z., \& Sabsay, L. (Eds.). (2016). Vulnerability in Resistance. Durham: Duke University Press.

Cooke, B., \& Kothari, U. (Eds.). (2001). Participation: The New Tyranny? London: Zed Books.

Cunningham, S. (2002). From cultural to creative industries: Theory, industry and policy implications. Media International Australia Incorporating Culture and Policy, 102(1), 54-65.

Ehn, P., \& Kyng, M. (1987). The collective resource approach to systems design. In P. Ehn \& M. Kyng (Eds.), Computers and Democracy-A Scandinavian Challenge (pp. 17-58). Aldershot, UK: Avebury.

Ehn, P., \& Kyng, M. (1991). Cardboard computers: Mocking-It-Up or hands-on the future. In J. Greenbaum \& M. Kyng (Eds.), Design at Work: Cooperative Design of Computer Systems. Hillsdale, NJ: Lawrence Erlbaum Associates.

Erlingsson, G. Ó. (1999). Ekonomi, demokrati och identitet $i$ ett Europa under omvandling. En analys av ett forskningsomraide. Lund: Department of Political Science, Lunds Universitet.

Flew, T. (2002). Beyond ad hocery: Defining creative industries. Paper presented at Second International Conference on Cultural Policy Research, Wellington, New Zealand.

Flew, T. (2011). Origins of creative industries policy. In T. Flew (Ed.), The Creative Industries: Culture and Policy. London: Sage.

Florida, R. (2002). The Rise of the Creative Class. New York: Basic Books.

Foucault, M. (1973). The Birth of the Clinic. London: Tavistock.

Foucault, M. (1977). Discipline and Punish: The Birth of the Prison. London: Penguin.

Gregory, J. (2003). Scandinavian approaches to participatory design. International Journal of Engineering Education, 19(1), 62-74.

Keshavarz, M. (2016). Design-Politics: An Inquiry to Passports, Camps, and Borders (PhD dissertation). Malmö: Malmö University. 
Keshavarz, M., \& Mazé, R. (2013). Design and dissensus: Framing and staging participation in design research. Design Philosophy Papers, 11(1), 7-29.

Kiem, M. (2011). Designing the social, and the politics of social innovation. Design Philosophy Papers, 9(3), 207-216.

Leadbeater, C. (1997). The Rise of the Social Entrepreneur. London: Demos.

Leadbeater, C. (1999). Living on Thin Air: The New Economy. London: Penguin.

Leadbeater, C., \& Miller, P. (2004). The Pro-Am Revolution: How Enthusiasts Are Changing Our Economy and Society. London: Demos.

McRobbie, A. (2003). 'Everyone is creative': Artists as pioneers of the new economy? Zürich: Museum für Gestaltung. http://www.k3000.ch/becreative/ texts/text_5.html. Accessed 2 July 2019.

Miessen, M. (2010). The Nightmare of Participation. Berlin: Sternberg Press.

Mikkelsen, J. (2012, April 5). Mycket babbel-lite verkstad. Sydsvenskan. http:// www.sydsvenskan.se/. Accessed 23 February 2017.

Mukhtar-Landgren, D. (2006). Den delade staden-Välfärd för alla i kunskapsstaden Malmö. Fronesis, 18, 120-132.

Murray, R., Caulier-Grice, J., \& Mulgan, G. (2010). The Open Book of Social Innovation. London: The Young Foundation.

Sanders, E. B.-N., \& Stappers, P. J. (2008). Co-creation and the new landscapes of design. CoDesign, 4(1), 5-18.

Spivak, G. C. (1993). Can the subaltern speak? In L. Chrisman \& P. Williams (Eds.), Colonial Discourse and Post-Colonial Theory: A Reader. New York: Harvester Wheatsheaf.

Suchman, L. (1987). Plans and Situated Actions: The Problem of Human Machine Communication. Cambridge, UK, and New York: Cambridge University Press. 
Open Access This chapter is licensed under the terms of the Creative Commons Attribution 4.0 International License (http://creativecommons.org/licenses/ by $/ 4.0 /$ ), which permits use, sharing, adaptation, distribution and reproduction in any medium or format, as long as you give appropriate credit to the original author(s) and the source, provide a link to the Creative Commons license and indicate if changes were made.

The images or other third party material in this chapter are included in the chapter's Creative Commons license, unless indicated otherwise in a credit line to the material. If material is not included in the chapter's Creative Commons license and your intended use is not permitted by statutory regulation or exceeds the permitted use, you will need to obtain permission directly from the copyright holder.

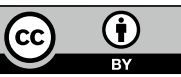




\title{
Facing War: On Veterans, Wounds, and Vulnerability in Danish Public Discourse and Contemporary Art
}

\author{
Ann-Katrine Schmidt Nielsen
}

\section{INTRODUCTION}

In the controversial portrait series RAMT. 15 danske politikere [HIT. 15 Danish politicians; my translation] (2011), artist, activist and pilot Simone Aaberg Kærn transposes typical facial war wounds onto the portraits of 15 Danish politicians. The depictions all imitate traditional portraits, they are drawn in neutral colours-and they are all extremely gory: jaws are blown off, blood flows and the former Prime Minister is missing an eye. Kærn has previously employed the portrait to investigate the violence of war. In the series with the resounding title RAMT. Sarrede danske soldater $i$ Helmand [HIT. Wounded Danish soldiers in Helmand; my translation] (2010), wounded soldiers are portrayed in a manner similar to the politicians. Although the title of this series indicates that the depicted soldiers are Danish, the caption reveals that the faces are, in fact, those of wounded

\section{A.-K. S. Nielsen $(\bowtie)$}

Aarhus University, Aarhus, Denmark

e-mail: norasn@cc.au.dk

(C) The Author(s) 2020

A. M. Dancus et al. (eds.),

Vulnerability in Scandinavian Art and Culture, https://doi.org/10.1007/978-3-030-37382-5_13 
Afghans that have undergone a conspicuous 'Nordification'. Read together, these two series present us with multiple, layered faces and 'travelling' war wounds that inevitably conjure up the disturbing questions: Where do these wounds originate? Whose faces have seen such violence?

Kxrn is a much-debated Danish artist. Most of her work revolves around contemporary Danish warfare, and she has visited remote war zones on several occasions. In the 'aero-feminist' film project Smiling in a War Zone (2006), Kærn goes on a solo flight from Denmark to Kabul and, in 2011, she stayed in Libya during the revolt and incipient civil war. Nationally, she is best-known for her controversial, official portrait of resigned Prime Minister Anders Fogh Rasmussen and the large-scale triptych Batalje [Skirmish] (2016), which depicts the war in Libya. The Museum of National History and the Danish Defence commissioned this piece as an official battle painting, but rejected it before its actual realization. In the words of Major General Per Ludvigsen, the preliminary sketch did not convey 'the actually quite happy story' (Sangild 2016, my translation) of the Libyan war. Hence, Kxrn's oeuvre is large, interesting and controversial. However, this chapter focuses on the two entangled RAMT series, since they tangibly bring to the fore the wounding and vulnerability of bodies in Danish warfare. This issue has proved central in Denmark's transformation from a small, pacifist state to a warring coalition partner in the post-Cold War era (Sørensen 2015).

This chapter addresses Judith Butler's adaptation of the Levinasian face of the Other and Jacques Derrida's hauntology, and argues that the depictions of the wounded faces of Danish politicians and soldiers may, paradoxically, convey a haunting encounter with the suffering, wounded Other, the non-Western victim, of Danish warfare. This is of crucial pertinence in the Danish media and political contexts, which are dominated by the hypervisibility of the wounded veteran. The intense focus on the wounded Danish body, the chapter argues, serves as a means of promoting a narrative of unidirectional violence and erasing the vulnerable, wounded Other from public view-an act of erasure that Kærn's layered faces and travelling war wounds complicates. The chapter outlines the public discourse on the wounded veteran through the Prime Ministers' speeches on 5 September, the National Flag-flying Day for Deployed Personnel, and the central series of articles Hjem fra krigen [Home from the War; my translation], published by the national Danish newspaper Jyllands-Posten. ${ }^{1}$ Representing national media and domestic 
politics, these are privileged sites in the public production of the discourse on the wounded veteran. The chapter proceeds to analyse Kærn's portrait series through a palimpsestic mode of reading uncovering traces, engaging absent-presences of hauntings and interpreting the 'complex layering of diverse texts' (McLoughlin 2018, p. 174). ${ }^{2}$

\section{SPEAKING OF WAR-SEPTEMBER 5TH}

On a bright, sunny afternoon in the early autumn of 2018, thenDanish Prime Minister Lars Løkke Rasmussen gave the annual speech at the national event honouring and commemorating all Danish personnel deployed since 1948. Danish flags waved from the top of the parliament building against a clear blue sky, long rows of uniformed soldiers were ranked in front of the Prime Minister, and the Danish Crown Princess resided as a royal representative in the midst of it all.

Since 2009, 5 September has been a national flag-flying day, when Denmark pays its respects to all those who have been deployed in areas of conflict. ${ }^{3}$ The flag-flying day is part of an extensive, ongoing national effort to assume a new role as a warring nation, and to negotiate the concomitant political and sociocultural remilitarization (Christensen 2015; see also Sørensen and Pedersen 2012, on homecoming parades). Since the end of the 1980s, Danish foreign policies have been increasingly (re)militarized. During the 1990s and 2000s, Danish troops were deployed in military missions involving actual combat situations for the first time in over a century (Wivel 2013; Sørensen 2017; Lidegaard 2018). However, the human, societal and cultural consequences of this thorough remilitarization did not attract significant national attention until around 2008 (Pedersen 2017) and, in 2010-almost a decade into Denmark's participation in the Afghanistan war-the liberal-conservative government presented the first Danish veteran policy.

In 2010, the media directed immense attention on the veterans. The central series of articles, Hjem fra krigen, which later won the prestigious Cavling Prize award, ran throughout the year in the national newspaper Jyllands-Posten, investigating the difficult lives of physically and psychologically wounded veterans in Denmark. This is a two-part series: one devoted to the physical wounds, and the other to the psychological wounds of Danish warfare. In the article that introduces the second part of the series, the problem is presented in this way: 'They went away to 
help others. Today they are the ones who need help and society's knowledge about veterans' welfare is limited' (Pedersen and Westh 2010, my translation). The veterans' problems and a criticism of the failing welfare state were immediately picked up by other media. Headlines such as 'The mental minefield' (Jyllands-Posten, 2010, 20 June), 'Helpless war veterans in the woods' (Ekstra Bladet 2010, 21 June), and 'Soldiers wait in line to get help' (Jyllands-Posten 2010, 20 December) abounded in national newspapers. ${ }^{4}$ As such, the veteran as somebody either physically or psychologically wounded by war gained extensive national visibility in 2010 .

Since 2010, a great deal of the ignorance cited as the motive behind the article series Hjem fra krigen has been eliminated. National surveys and research have shown that no more than $30 \%$ of a veteran population deployed in the period 1992-2009 report that they have been either repatriated, wounded or self-evaluate as injured (physically or psychologically) due to deployment (SFI 2012). Other research results 'normalize' veteran suicide rates (Veterancentret 2016). This attests to the fact that the larger part of Danish veterans return home without permanent wounds and scars. However, to this day, the notion of the veteran as marked and vulnerable prevails in contemporary media discourses (e.g. Pedersen 2017).

Lars Løkke Rasmussen's address to the veterans on 5 September 2018 was consistent with the intense focus on the wounds of war in contemporary Denmark:

Dear soldiers and dear veterans. Denmark owes you many thanks. [...] To return home is not always easy. Nobody, who has been deployed, returns home unaffected. Many return stronger. But some return with serious scars on both body and mind. I was reminded of this this morning when I cycled from Høvelte to Copenhagen together with veterans who are physically and psychologically wounded. It was the last stage of the Ride 4 Rehab race. ${ }^{5}$ Incredibly strong people. Who fight for a decent life. But who have been severely marked by their contribution to Denmark. (Rasmussen 2018, my translation)

While the Prime Minister does outline two alternatives-the war may either strengthen or scar the soldier-the greater part of the address focuses on the difficulty of homecomings, and is concluded by the introduction of a new bill granting economic compensation to veterans wounded before August 1996. Hence, notions of violence and trauma, 
struggle and wounds, resonate in the Prime Minister's speech, and stick to the veteran body (Ahmed 2014). His use of the phrase, 'scars on body and mind' is instructive and generic - the phrase occurs in five of the eight 5 September speeches. As such, the hypervisibility of the Danish body wounded by war may lead us to infer that the figure of the wounded veteran plays a central role in the process of negotiating the meanings of Danish (re)militarization.

\section{Framing Wounds}

In her thorough discussion of the flag-flying day, The Figure of the Soldier: Discourses of Indisputability and Heroism in a New Danish Commemorative Practice, historian Tea Dahl Christensen (2015) also notes the tendency to present veterans as a strong, 'yet also a distinct and vulnerable group with special needs to which society is obliged to attend' (p. 358). Her focus is the discursive construction of the soldier figure in the official speeches on 5 September 2013. However, she also touches on the veteran figure, as the hypervisibility of the vulnerable veteran challenges the discursive construction of 'the soldier as a peace-loving figure waging ethical warfare' (Christensen 2015, p. 360). She concludes that, by being a wounded and vulnerable body, the veteran brings violence back into discourses on contemporary warfare and soldiering-a violence that the official representatives of the Danish state have tried to erase and mute through a humanitarian discourse of contemporary warfare as nonviolent and just: 'the wounded veterans distort this image by also being wounded, vulnerable subjects in a mission that admittedly is a violent war' (Christensen 2015, p. 360).

Christensen is right when she contends that the wounded body of the veteran brings violence back into discursive view. However, something does not quite add up. If the wounded veteran reveals 'cracks in the image of the soldier as strong and as a non-combatant' (Christensen 2015 , p. 359), as proposed by the official speakers on the flag-flying day, then why do these very same speakers repeatedly return to this warwounded body? Why is the mention of 'scars on body and mind' by now a generic element of the Prime Minister's 5 September speech? Why has the wounded veteran body-an indexical trace of war's violence-become a fixture in Danish media and political discourse on contemporary wars? I suggest that, rather than merely distorting ideas of non-violent warfare, the hypervisibility of the wounded veteran body has become a means of 
framing violence in ways that promote a narrative of unidirectional violence, and bestow visibility on some victims of war, while erasing others from view in the eyes of the Danish public.

In Precarious Life (2004) and Frames of War (2009), Judith Butler engages with the framing of vulnerability and violence. 'Framing' refers to the workings of normative schemes in the production of some lives-and not others-as valuable, vulnerable human subjects (Butler 2009, pp. 2$5)$. She asks, for example, '[h] ow do our cultural frames for thinking the human set limits on the kind of losses we can avow as loss?' (Butler 2006, p. 32), and investigates vulnerability as both a shared human bodily condition and a differentially distributed feature marking some lives as less alive, less 'grievable', and more disposable than others. While 'the fundamental sociality of embodied life' (Butler 2006, p. 28) means that the sustenance of our lives is always dependent on and in the hands of others (Butler 2009, p. 14), cultural, discursive and visual frames limit our apprehension of this shared vulnerability. Thus, some lives are excluded, muted, or not even perceptible as living in the first place:

These norms work to give face and to efface. [...] There are ways of framing that will bring the human into view in its frailty and precariousness, that will allow us to stand for the value and dignity of human life, to react with outrage when lives are degraded or eviscerated without regard for their value as lives. And then there are frames that foreclose responsiveness, where this activity of foreclosure is effectively and repeatedly performed by the frame itself-its own negative action, as it were, toward what will not be explicitly represented. (Butler 2009, p. 77)

The cited preoccupation with the face-of giving face and effacingstems from Butler's adaptation of the Levinasian notion of 'the face of the Other'. According to Levinas, the face of the Other confronts me with an absolute otherness that I can never fully know, fix into identity, or collapse into sameness (Levinas 1996, pp. 190-192; Butler 2006, pp. 145-146). Encountering this Other face to face as a vulnerable, suffering, defenceless human being makes a fundamental ethical claim on me to apprehend the common human vulnerability, and to respond to it with non-violence (Levinas 1996, p. 195). For Levinas, the true ethical encounter with the vulnerable Other must be a face-to-face encounter, as all attempts at representation are forms of capture or fixation that fail the unrepresentability and the radical otherness of the Other (Levinas 1996, pp. 194-196; 
Butler 2006, p. 145). However, as Butler's cultural analysis is concerned with how the suffering of the distant Other in contemporary conflict and warfare may come into public view, she suggests that representation may, indeed, paradoxically, give face to the Other, convey the vulnerability and humanity of the distant Other, if it admits to its fundamental failure:

For representation to convey the human, then, representation must not only fail, but it must show its failure. There is something unrepresentable that we nevertheless seek to represent, and that paradox must be retained in the representation we give. (Butler 2006, p. 144)

Hence, for representation to convey a sense of the vulnerability and humanity of the Other, it must openly and knowingly admit to the incompleteness and failure of such representation and, thus, point beyond itself (Butler 2006, p. 150). We can never grasp and represent the Other as a human being in its absolute otherness-representation always captures and tames, excludes and frames. However, at the same time, Butler contends, we must never cease trying to represent in a way that is more sensitive to the cries and the face of the suffering Other: "We would have to interrogate the emergence and vanishing of the human at the limits of what we can know, what we can hear, what we can see, what we can sense' (Butler 2006, p. 151).

Returning to the wounded veteran in Danish media and political discourse, it becomes clear how the wounded veteran is the emblem of war's violent reality, whereas the faces and agonies of other bodies, the nonWestern victims of warfare, are effaced altogether. Anthropologist Birgitte Refslund Sørensen comments along the lines of Butler's thinking on the hypervisibility of the violated veteran in contemporary Denmark:

In Denmark, portraits of all dead and most severely injured soldiers have been published in newspapers, books, and online [...] In contrast, dead enemies and civilian casualties are not even mentioned by numbers, officially due to practical obstacles or strategic considerations but nevertheless suggesting that these are lives of lesser worth. (Sørensen 2015, p. 233)

As such, the differential distribution of visibility, wounds and vulnerability creates a narrative not of non-violence, but of unidirectional violence: as the faces and cries of wounded, vulnerable, dying Others are erased and excluded from public view, the veteran becomes visible as 
the sole victim of war's violent reality. Hence, the violence of war is admitted visibility in the Danish public-however, only when this violence is directed at the soldier's body. This insistence on the vulnerability of Danish bodies is paradoxical and in contrast to, for example, American attempts to keep (coffins of) deceased soldiers from public view (e.g. Butler 2006; Mortensen 2008). However, crucially, it works to erase the violence perpetrated by the veteran soldier directed at a vulnerable Other. The wounded, victimized veteran does not also occupy the discursive position of the violent perpetrator. Hence, the hypervisible war wounds of veterans in the Danish public works to exclude from discursive view the agonies of the wounded, vulnerable, non-Western Other of contemporary warfare, and establish a narrative of unidirectional violence directed at passive, victimized, self-sacrificing soldiers' bodies.

This discursive employment of the wounded veteran ultimately sustains the Danish war effort in two interlinked ways: (i) by framing violence as unidirectional, the war effort seems acceptable-perhaps even 'humanitarian'- to a Danish population until recently considering itself by and large pacifist (Sørensen 2015); (ii) by focusing on the wounded Danish body, the enemy Other is positioned as the sole aggressor and evildoer of war; he is the active agent of violent acts that wound Danish soldiers. Paradoxically, for this violence to end, the aggressive, violent enemy has to be extinguished. Thus, the figure of the wounded veteran reinforces the righteousness of warfare. ${ }^{6}$ As such, the opposition between wounded veteran and enemy aggressor also taps into and re-enhances the dichotomous moral structure of contemporary coalitional warfare promoted by, for example, George Bush and former Danish Prime Minister Anders Fogh Rasmussen: 'Either you're with us, or you're with the terrorists' (Butler 2006, p. 2).

Hence, Kærn's portrait series interfere in a media and political context characterized by an overwhelming focus on the agonies and cries of the national war victim, the Danish veteran, and the complete invisibility, the effective effacement of the Other, the Afghan, Iraqi, Libyan and other victim of war. In the following sections, I will trace the multiple layers of Kærn's portraits in order to analyse how this interference plays with the in/visibilities of vulnerable bodies, and may lead us to encounter the face of the Other, as well as to reflect on the framing of wounded faces. 


\section{Wounding Politicians-RAMT II}

You are looking at a neatly drawn portrait, coloured pencil on brown cartridge paper (Rosenvinge and Villemoes 2013). The colours are neutral, subdued and a little washed out: shades of brown, grey, white, beigeyrose. The medium close-up framing portrays the upper torso and the face against a neutral background. The depicted Prime Minister wears a suit and a tie. This is a standard portrait of a politician, a white Western man in power.

However, the Prime Minister's left eye is missing. A bloody crater and some sort of indefinable white matter (goo? bone? brain?) has replaced it. Crimson streams of blood run down his cheek and spill onto the white shirt and the bluish tie. The jacket, with the yellow ribbon on the lapel indicating his support of deployed soldiers, is neither torn nor tainted. The Prime Minister stares off into the distance with a dreamy but determined look on his face, seemingly unaffected by the streaming blood, the gore, and the gaping facial wound.

Fifteen similar portraits comprise the RAMT. 15 danske politikere series, in which Kxrn depicts the entire range of changing Danish Prime Ministers, Foreign Ministers and Defence Ministers from the mid-1990s and throughout the 2000s. Hence, these are the men and women involved in the political decisions leading to Danish participation in remote, coalitional warfare. The depictions all imitate the form of traditionally drawn portraits, the colours are the same neutral tones, and they are framed in similar ways - and they are all gory. Former Foreign Minister Mogens Lykketoft's jaw is gone, bits of his tongue are visible in the open bleeding mouth, and pieces of flesh hang from his cheeks; former Prime Minister Helle Thorning-Schmidt bleeds from the nose and the eyes, her mascara is smudged and blood streams from two deep (lethal?) holes in her forehead; former Defence Minister Søren Gade's cheek has been blown off, his left eye is bruised and swollen, and the cheekbone is laid bare. Yet, they do not seem to suffer any excruciating pain; they all keep up appearances.

The portrait series was part of the 2013 group exhibition Krig, kunst og Danmark [War, Art and Denmark; my translation] at Holstebro Museum. At the time, Kærn was already a controversial artist, as she had painted the abovementioned official portrait of resigned Prime Minister Anders Fogh Rasmussen in 2010. However, RAMT tapped into 
and resonated with contemporary discussions about freedom of expression and visual arts ignited in 2005 by the so-called 'Muhammed drawings', and increasing public anxieties about impending terrorist attacks against Danish democracy. In democratic societies, violence-even if symbolic-against elected politicians is the ultimate transgressive act. This had already been shown to be the case in Denmark 10 years earlier, when two left-wing activists threw red paint at then-Prime Minister Anders Fogh Rasmussen and Foreign Minister Per Stig Møller while screaming 'You have blood on your hands'. This protest against the Iraq war put the activists in jail for three and four months each, and was widely condemned (Politiken 2015, January 6). As such, Kærn's series-which applies the same logic of transgression, albeit in a different medium and genre, and for different ends-also provoked media debate when it appeared. According to Kærn, the portraits were meant to cause a stir that would lead the Danish public to discuss and reflect on the reality and routinization of Danish warfare (Information 2013, March 20). However, contrary to intentions, the actual debate seemed to reignite arguments from the Muhammed crisis regarding (artistic) freedom of expression, (selfcensorship, media, power and the depiction of faces, and was dominated by a rather paradoxical indignation at the unsolicited 'portrayal' of the Danish politicians. Former Foreign Minister Per Stig Møller, for example, stated that the artist was free to depict his face in any manner, thus subscribing to an unnegotiable notion of absolute freedom of expressionhowever, significantly, he added that the portraits were 'almost' a defence of terrorists, and 'an attack on us [politicians], who tried to stop terrorism' (Per Stig Møller in Berlingske, 12 March 2013, my translation).

Indeed, at first glance, the transgressive gesture stands out and makes the aesthetic logic of the portraits seem rather straightforward: Danish politicians in charge of the military missions abroad are aggressively attacked and positioned at the other, receiving end of violence. Hence, the portraits apply a technique of wounding in order to visualize moral responsibility, and to make present the absent and often invisible effects of remote warfare. Art historian Jacob Wamberg has called the series an 'act of symbolic terrorism' (Information, 20 March 2013; see also Juergensmeyer 2003). By making the politicians the target of war's violent reality, they are in a very concrete and tangible way faced with, and held responsible for, the decisions they made while in office. A logic of reciprocity seems to be the concept of the wounding; the command 'do unto others as you would have them do unto you' in the most literal 
sense. However, the portraits are more than mere finger-pointing and blaming of the politicians. They have a greater potential, and cause a more profound disturbance than, for example, the paint-throwing incident. This has to do with the distribution of power and responsibility in each case. Whereas the paint-throwing established a clear-cut difference between the leftist activists and the liberal-conservative government, pacifists and warmongers, innocent and despicable, good and bad, and placed sole responsibility in the 'bloodied' hands of the Foreign Minister and the Prime Minister, Kærn's portraits are murkier, and question such clear-cut templates of responsibility through notions of democracy, complicity and political representation.

Kxrn's portrait series hold no single person accountable: the politicians depicted are many, and each has been part of democratically elected governments. Thus, the act of wounding and assigning responsibility is directed not only at them, but also at the entirety of Danish society, and voters as such (Rosenvinge and Villemoes 2013). By way of juxtaposition, the portrait series attest to an insistence on the collective political responsibility underlying contemporary Danish warfare: while seven of the portraits depict ministers from the liberal-conservative governments of the 2000s, the other eight portraits depict the Social Democrats, Social-Liberals and Socialists, who were in power throughout most of the 1990s and from 2011-2015. Hence, the 15 politicians represent a broad range of the political spectrum. Kxrn thereby points to the fact that Danish warfare has been an established political practice for more than two decades, conducted by several different democratically elected governments. None of the then-major political parties may be absolved of responsibility and, as Kærn strikingly states, at some point in time every Danish citizen has probably voted for, or sympathized with, one of the 'wounded', responsible politicians and/or parties (Rosenvinge and Villemoes 2013). ${ }^{7}$ Hence, the sheer number of politicians depicted underscores not only the duration of Danish involvement in contemporary warfare, but also the democratic backdrop to this practice. Through a technique of 'wounding', Kxrn gestures at the democratic complicity and political preconditions of contemporary Danish warfare.

The intended message of the portrait series seems readily legible: we all have a share in the violence and wounds of contemporary warfare, and must reflect on this. The series speaks to us of the complicity of political representation, the potentially violent consequences of democratic decisions, and the collective responsibilities of voters and politicians alike, 
through the wounded faces of Danish ministers. However, there is something more at stake, something that draws our eyes back to the portraits again and again, something that haunts us: it is the fascination of the gore, the ambiguity of disgust, and the transgressive aesthetics of the gaping wound and missing jaw in Mogens Lykketoft's face; it is the enigma of Søren Gade's incipient smile, of Lars Løkke Rasmussen's dreamy but determined stare, and of their seeming unaffectedness by the streaming blood; and it is the zombielike gaze of Helle Thorning-Schmidt, the uncertainty of whether she is dead or alive, and the unsettling questions: From where exactly are these wounds transposed? Where do they originate? Whose faces have seen such violence?

\section{Transposing Wounds-RAMT II}

The technique of transposition is remarkably explicit in Kærn's portrait series. Some of the politicians look dreamy and content, others tired and concerned, but none of the faces display the utter horror, pain and distortion that the facial wounding dictate. There is a disconnection between the corporal marks of extreme violence and the faces: the indexicality of the wound is revoked. ${ }^{8}$ Thus, although we may feel outrage and indignation at the transgressive symbolic gesture, we do not really feel sorry for the unaffected politicians, since the strategy of 'fictionalized' wounding is easily decoded. There is no pretence of a direct corpo-reality, and no sympathy or compassion is invoked on behalf of the politicians. The faces maintain a purely political-symbolic function, and do not convey the portrayed Other as a vulnerable, suffering human being.

However, it seems insufficient to conclude that the portraits pertain simply to the workings of representational democracy, and that no sense of human suffering is conveyed by the series. This is attributable to the fact that, while the wounding is fictionalized, the wounds themselves retain a recalcitrant sense of displaced indexicality and corporeality. Hence, the bleeding, open wounds relentlessly raise the nagging question of transference and point beyond (Butler 2006) the portrayed faces to conjure up the bloody realities of the distant wars Denmark is waging. Returning to Butler's point about representational 'failure' as the premise of conveying the vulnerability of the Other, we may consider the portraits as openly and knowingly failing. The portrayed faces do not and cannot capture and represent a distant suffering Other. However, the transposed wounds perpetually attest to this failure, and thus convey a 
sense of human suffering. Hence, the explicitly 'failed' wounding of the politicians paradoxically evokes the very real effects of the political decisions allowing such wounding in other settings, and of other faces. Thus, we are left with the question of who is actually 'given a face' in these portraits, when the faces depicted do not convey a direct encounter with a suffering, vulnerable Other, but the facial wounds nevertheless point beyond the represented faces as a residue of human suffering and vulnerability.

\section{FACING VETERANS OF WAR-RAMT II}

In light of the contemporary Danish focus on the wounded veteran, and Kxrn's own statement that she drew the portraits at the behest of a Danish veteran and artist with PTSD in order to draw more attention to wounded soldiers (Rosenvinge and Villemoes 2013), the answer seems obvious: the wounds of war conjure the wounded faces of the nation's veterans. And, indeed, the absent presences of soldiers haunt the portrait series in a number of ways.

Turning to the margins of the portrait series, a rather banal observation may suggest this: each portrait is named after the minister depicted. Although this is standard in the portrait genre, it is worth noting that Kærn has chosen to deploy first names only in most titles, so that the portraits of the three former Prime Ministers are called Anders, Helle and Lars. $^{9}$ This may be read as a continuation of the dismantling of the gap between politicians and private citizens, and the redistribution of a sense of responsibility in civil society. However, to a Danish art audience, these first name titles also bring to mind the 'war paintings' by Danish artist John Kørner. For his War Problems series (2008-2009), Kørner produced more than 20 large-scale paintings that depict various scenes from the war-stricken Afghan landscape. Kørner was one of the first artists to examine contemporary Danish warfare from an aesthetic standpoint, and, to the Danish public, his enormous, brightly-coloured and airy depictions of war are probably still some of the best-known examples of war art. In 2008-2010, the paintings received extensive publicity: it was announced that Kørner created one painting for each soldier killed in Afghanistan (however, he never did; roughly half the paintings have been made so far), and the Crown Prince and Princess commissioned him to create a special edition mural of such a war painting in their private residence. However, the names included in the series' titles drew 
particular attention: each painting has a title such as, Mark, Jacob under the horse, and Thomas. These are the names of Danish soldiers killed while deployed in Afghanistan. The very real use of the deceased soldiers' names clashed with the paintings' almost abstract style, and the fact that Kørner had never been to Afghanistan himself and consciously avoided extensive research into the war. Hence, the scenes depicted are not artistic reproductions of the fatal situations leading to the soldiers' deaths, but the artist's aesthetic vision of Afghan landscapes and Danish warfare. However, his use of actual soldiers' names creates a haunting reality effect, and conjures up the very real, fatal consequences of remote warfare in the midst of the abstract, beautiful scenes. Hence, Kxrn taps into this unsettling use of the first name in contemporary Danish visual art: the first names in the titles of the politicians' portraits continue to conjure up the names of the fatally wounded soldiers that haunt War Problems. Anders, Helle and Lars call for the absent presences of Mark, Thomas and Jacob under the horse, the deceased soldiers. However, at the same time Kærn also displaces and renegotiates Kørner's use of the referentiality of the name: in her portraits, what haunts us is not the reality effect of the names as such, the identities of the very real politicians, but the fictionalized transposition of the presumably equally real, gaping facial wounds, which call the wounded soldiers to mind.

Kærn's deliberate use of materials, form and genre enhance this haunting presence of wounded soldiers in the politicians' portraits. As mentioned, each portrait has been drawn with coloured pencil on brownish cartridge paper (Rosenvinge and Villemoes 2013). The colours are subdued and washed out, leaving the wounded faces almost translucent at some points, allowing the brown cartridge paper to show through. As cartridge paper has historically been used in ammunition as paper cartridges for firearms, a long history of violence and war is invoked solely by the materiality of the portraits.

When combined with the portrait genre, the brownish colour of the paper also recalls the sepia hue of old photographs: portraits of uniformed, long-dead young men on bureaus in family homes. Owing to the politicians' facial disfigurement, one particular medico-photographic genre comes to mind: the photographic documentation of the gueules cassées [broken faces] of World War I. The term 'gueules cassées' was coined in 1921 by a French veteran to designate those soldiers who, like himself, survived violence to the head, and had to live with serious facial disfigurements (Pichel 2017). The 'broken' faces of these veterans were 
subject to prolonged documentation and photographing in hospital settings, to improve and disseminate medical knowledge. The photographs were "completely focused on the face of the patient, who was sitting in an unrecognizable space still wearing the military uniform or, sometimes, the ward clothes. This kind of portrait [...] aimed to focus the viewer's attention on the facial damage' (Pichel 2017, pp. 88-89). The formal similarity to the politicians portrayed 'uniformed' in dark suits against a neutral background is striking. However, importantly, Kærn's portraits are still bleeding. There is no attempt to stitch together and heal the wounds, reconstruct the face and close the door on the past. Instead, 'the past lives in the very wounds that remain open in the present' (Ahmed 2014, p. 33, my italics). Hence, Kærn's portraits are in conversation with a visual genre invented and conditioned by modern warfare and medical research. The wounded politicians are drawn against a material backdrop of cartridges, facial disfigurement, the pursuit of medical progress, and violence. However, instead of sealing and healing this history of violence, Kærn leaves the wounds open and the blood streaming. This may be read as a way of avoiding the fetishization of the veterans' wounds (Ahmed 2014), observable in public discourse, but when we conclude this chapter, we will return to the hauntological potential of the streaming blood.

The portrait series works by imposing a visually evident vulnerability on the politicians' bodies, in order implicitly to evoke-through a number of more or less explicit traces-the vulnerability of the bodies they are responsible for deploying to war zones: Danish soldiers. However, in the following section, we will examine how the portraits not only convey an encounter with this veteran Other, but also with the distant suffering Other of contemporary, remote warfare.

\section{FACING THE OTHER-RAMT I}

RAMT is a title Kærn has used before. In 2010, she produced a portrait series named RAMT. Sarrede danske soldater $i$ Helmand, which was a part of the 2012 exhibition Krig i kunsten [War in the arts, my translation] at The Museum of National History. In all formal aspects, these portraits resemble the later series that bears the same title: they are characterized by subdued, neutral colours; they are made with coloured pencil on brownish paper; and they depict seriously wounded faces in a medium close-up framing. The weaving together of titles, style and format calls on us to read the two series together. They are embroidered into and 
haunt each other. However, in the 'original' series, all those portrayed are purportedly unknown Danish soldiers, not prominent politicians. Moreover, we do not question the indexicality of the wounds in these faces: the exhausted gaze, the raised eyebrows, the chapped lips and the bloodied bandage all confirm the pain and suffering of the soldiers depicted. Hence, the portraits of this earlier series of wounded soldiers persist as a scar, a watermark, a haunting presence beneath the portraits of the politicians. Thus, our reading seems confirmed. The gaping wounds in the faces of the politicians point beyond, to these bleeding portraits, to the faces of wounded Danish soldiers. What is haunting and unsettling in the latter series is the wounding and death of the soldiers represented in the original portrait series. Thus, it may be said that Kærn's two portrait series ultimately sustain the focus and investment in the wounded veteran body as identified in media and political discourse. Even if the portraits complicate political representation and responsibility, and reject the fetishization of the war wound, they nevertheless pertain to domestic victims of war. Hence, the wounded, suffering, non-Western Other seemingly disappears from view once again. However, one may wonder, why do all the soldiers depicted have piercing blue eyes?

When examining the portraits of the wounded soldiers, their azure blue eyes and almost orange hair and beards strike you as odd. You may want to explain it away as a trait of nationality and 'Nordic-ness': these young Danish men simply have a typical Nordic appearance. This, however, seems unsatisfactory: in the midst of the neutral, sepia-like hue of the portraits, these two colours - orange and blue - stand out in an almost shrilling way. Why these insistent blue eyes, why this unnatural yelloworange hair, why this overdoing of Nordic traits? The answer, once again, is given in the margins, in the captions that often accompany the reproductions of the drawings: the wounded soldiers are, in fact, not Danes, but local, wounded Afghans 'made Danish' by changing their hair and eye colour (Figs. 13.1 and 13.2). ${ }^{10}$

One article explains this 'Nordification' as being due to the artist's lack of access to pictures of wounded Danish soldiers, leaving her with no other models than wounded Afghans (Rosenvinge and Villemoes 2013). This seems implausible, because, as Brigitte Refslund Sørensen suggests, wounded Danish soldiers have been rather visible in Danish media, and pictures of Danish and/or other Western soldiers may be accessed online; for example, in helmet camera footage on YouTube. However, we could accept this explanation, until we catch another glimpse of the odd orange 


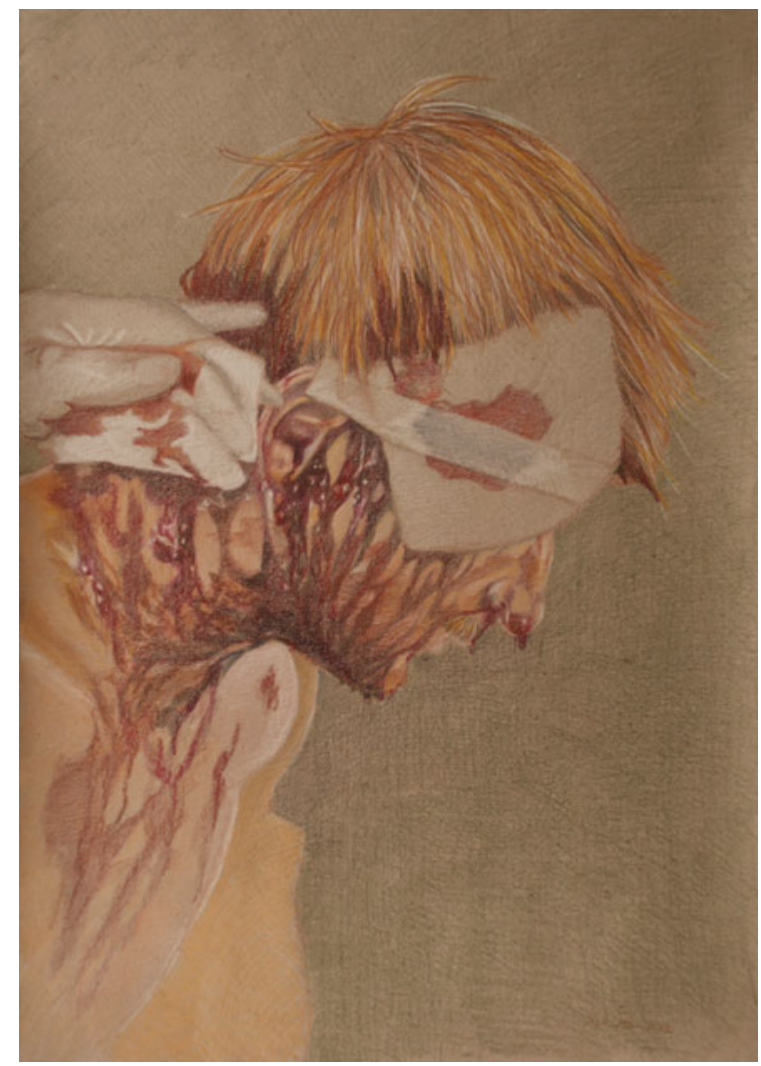

Fig. 13.1 By (C) Simone Aaberg Kærn, 2010, coloured pencil on rough paper. The 'soldiers' are wounded Afghans who have been made 'Danish' by changing their eye and hair colour

beards. Surely, an accomplished artist such as Kærn-educated at Goldsmiths and The Royal Academy of Fine Arts in Copenhagen-could have implemented 'Nordicness' in a less shrill, off-putting manner?

Thus, we have to take Kærn's overdoing at face value, and ask why the portraits insist on the shrill orange hair and the chilling blue eyes in the hybridized Afghan-Danish faces. I suggest that the blatancy of the transformation of the faces is-like the transposed wounds in the politicians' faces - a means of failing at, of undermining, openly and knowingly, the 


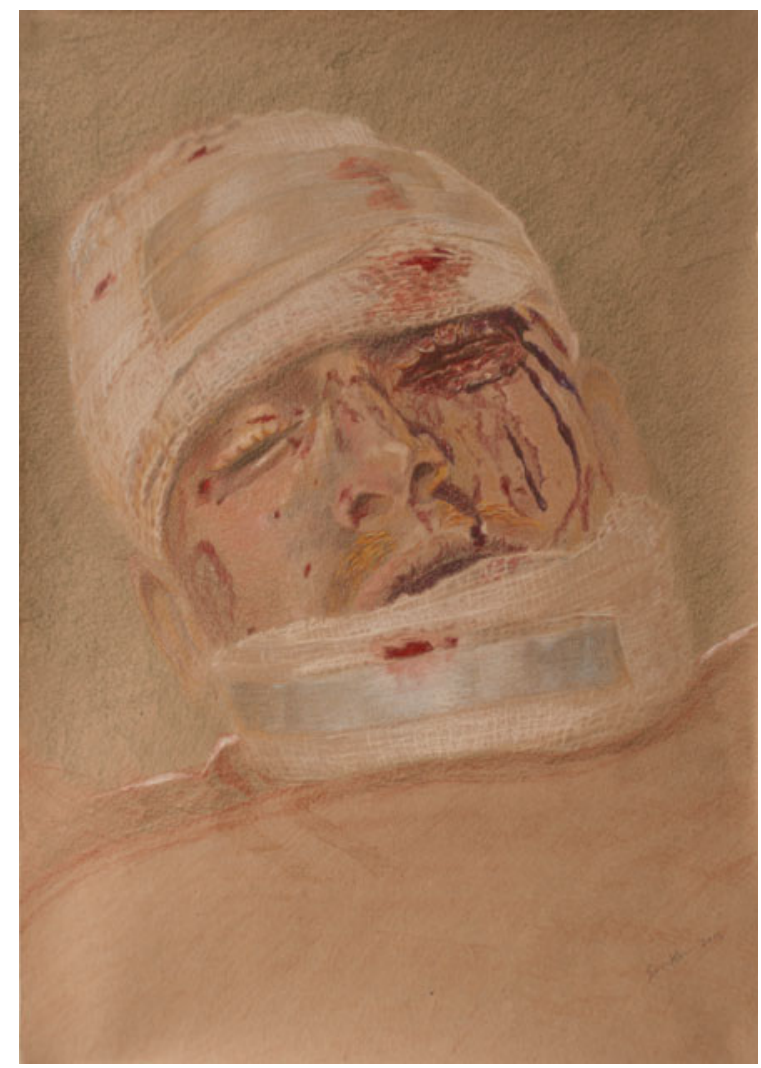

Fig. 13.2 By (C) Simone Aaberg Kærn, 2010, coloured pencil on rough paper. The 'soldiers' are wounded Afghans who have been made 'Danish' by changing their eye and hair colour

act of representation, and, thus, of pointing beyond (Butler 2006) to all that is not captured in the portraits. Hence, although these faces, in contrast to those of the politicians, do indeed explicitly express suffering and convey vulnerability, it is a displaced or distributed suffering and vulnerability that stems not only from the 'portrayed' wounded 'Danish soldiers', but also from the absent-present bodies of Afghans, the civilian, allied and enemy victims of Danish warfare. Thus, through its striking hybridization of faces and the explicit 'failure' of representation, the RAMT series 
actually conveys an encounter with the suffering Other of contemporary, remote warfare. Retract the orange beard, the uniform, and the blue tint of the eyes, and we uncover and encounter the suffering face of a distant, unknown Other, wounded by war.

When bringing Butler's thinking to bear on Kærn's works, we can see how the portrait series' layering of faces and representational 'glitches' is a way of renegotiating the distribution of the in/visibilities of different victims of war in Danish public discourse. As Kærn employs the hypervisibility of Danish wounded veterans, she also undermines and renegotiates the national framing of lives, and suffering of war, through a technique of folding, layering and haunting. In a haunting encounter with the absentpresent Other of distant warfare, we are faced with the vulnerability of Danish and Afghan, combatant and non-combatant, Western and nonWestern bodies alike. Ultimately, the shared human vulnerability evoked by the portraits works as a call for non-violence when facing these distant, suffering human beings.

\section{Being Haunted-the Political Potential of Streaming Blood}

There is one final trace of blood streaming down the layered faces that we need to address. To grasp this last bloody complication, I wish to weave a hauntological thread into the Butlerian analysis. ${ }^{11}$ In Spectres de Marx (1993), Derrida, who, like Butler, works with a Levinasian ethics of encounter, suggests that we will have to learn to live with ghosts. Not in order to rid ourselves of them through an act of exorcism, but to cultivate a position of radical openness and responsibility. 'No justice [...] seems possible or thinkable without the principle of some responsibility, beyond all living present, within that which disjoins the living present, before the ghosts of those who are not yet born or who are already dead' (Derrida 2006, p. xviii). Derrida's notion of haunting is not solely a matter of violent pasts living on, but also of possible unknown futures to come (back). By way of 'an affirmative thinking of the messianic and emancipatory promise as promise' (Derrida 2006, p. 94), Derrida couples the ghost with the event of the 'future-to-come': democracy and justice (always, perpetually) to come. Thus, Derrida's hauntology spectralizes and radicalizes the relation to the Other of Levinas and Butler. ${ }^{12}$ The haunting encounter becomes more than a way of perceiving a shared human vulnerability - it is a means of interrogating the way to live 'more justly' 
(Derrida 2006, p. xviii), of assuming ethical and political responsibility for the ghosts of past lives lived, and the lives to come, the spectres to which we are ethically bound.

Returning to the portraits, I contend that the perpetually bleeding wounds of war comprise such a haunting. Looking at the streaks of blood streaming down cheeks and foreheads, you may feel an immediate urge to wash the faces and bandage the wounds, to clean and to heal. However, Kærn's insistence on the open wound hinders us from stitching together, looking forward, and moving on: these bleeding wounds haunt us with unsettling questions about the logics of violence, and the past, present, and future production of war-wounded bodies. Certainly, the portraits' gore is also simply a way of catching and holding the eye. However, Kxrn probably could have attained the same reaction by portraying faces severely scarred by war. The temporality of such depictions, however, would be radically changed: the scar pertains to the past, whereas the perpetually bleeding wound is of the past, the present now, and the future moments of encounter. As such, the streaming blood is not only an indexical trace of violence overcome, but also of the perpetual wounding and bleeding of bodies in present and future wars. It inscribes an immediacy or ongoing-ness that the scar does not. Hence, the portrait series do not convey only a layered ethical encounter with the suffering human Other of distant wars, they also conjure up the violent injustices of contemporary Western warfare, and question the ongoing real-time infliction of such war wounds. The streaming blood haunts us as a remainder of violence-past, but also raises political questions of the future-to-come. The open wounds forge a political potential in the portrait series, and impel us to stop the wounding of bodies, to engage in other forms of global relations, and to cultivate other ways of living together.

\section{Notes}

1. According to the Prime Minister's Office's archive of speeches, the Prime Minister has given an annual speech at the national flag-flying day event in Copenhagen since 2009-except in 2014 and 2016, when other governmental representatives gave the speech. This means that the liberal Prime Minister Lars Løkke Rasmussen (in office from 2009-2011 and from 2015 to 2019) has given the speech six times, and Social Democrat Helle Thorning-Schmidt (2011-2015) has given it twice. These eight speeches given on 5 September by Prime Ministers Lars Løkke Rasmussen 
and Helle Thorning-Schmidt form the basis of this analysis. In line with the increasing national focus on veterans, since 2010 it has been customary for the Prime Minister to address the veterans and/or veterans' concerns in the speech.

2. Technically, the term 'palimpsest' is used to designate a manuscript where an original text has been partly erased and overwritten by another text, so that two or more texts occupy the same page. However, the term has been adopted to indicate a theoretical prism for investigating relationality, layering, spectrality, and reworking, for example, by Andreas Huyssen in Urban Pasts (2003), and by Gerard Genette in his seminal work on interor trans-textuality, Palimpsestes (1997). A palimpsestic mode of reading registers temporal complexities, hauntings and traces of histories, and proceeds by uncovering layers of presence in a given work. In this chapter, 'text' is understood as any cultural signifying practice or artefact.

3. On a national flag-flying day, state authorities have to display the Danish flag to mark the day as a day 'of particular national importance' (Christensen 2015, p. 352).

4. I have translated all newspaper headlines.

5. 'Ride 4 Rehab' is a national bicycle race for wounded veterans.

6. Also see Rasmussen (2011), on how, paradoxically, the death of Danish soldiers in Afghanistan did not initiate a public debate on the strategies and goals of the war, but came to be seen as a confirmation of the moral righteousness of the mission (Rasmussen 2011, pp. 98-102).

7. From a contemporary point of view, it is striking that no members of the influential right-wing Danish People's Party have been portrayed and 'wounded'. However, this attests to the party's preference for an oppositional role and avoidance of ministerial power, rather than to a political bias in the artwork.

8. In this way, the portraits differ from the portrait series Det virtuelle teskehold (2009) ['The virtual gang of goons', my translation] by Danish painter Benny Vigan Madsen. In creating her portrait series, Kærn has been accused of imitating, and even plagiarizing, Madsen's series of five paintings depicting Danish politicians posing as boxers with bruised faces and clenched fists. These accusations only added to the intensity of the media debate on Kxrn's drawings, and even led Madsen to produce two additional paintings for his series, depicting himself and Kxrn as bruised boxers. However, in contrast to Madsen's efforts at realism and accuracy, Kxrn makes the act of transposing explicit, as she insists on the overt clash of war wounds and unaffected Danish politicians. From the beginning, the portraits were conditioned by this clash: Kærn reportedly started by painting an accurate portrait of each politician, and then subsequently added the war wounds (Rosenvinge and Villemoes 2013). 
9. However, the portrait of former Defence Minister Søren Gade is titled 'Gade', and thus employs his last name.

10. It has not been possible to track down the exhibition catalogue, or the original captions used for the 2012 exhibition. Thus, it is impossible to say whether this key information was accessible to the audience at the exhibition. However, on her website Kærn (2018) displays these portraits, along with the following caption: 'by Simone Aaberg Kærn 2010, coloured pencil on coarse paper. "The soldier" is a wounded Afghan, who has been “made Danish” by changing his eye and hair colour' (my translation).

11. In her later works, Butler touches on haunting a few times, as a prism for the spectral existence of the excluded, muted lives lived 'outside' of cultural, visual and discursive 'frames' (Butler 2009, 2006). As such, the Butlerian notion of haunting also pertains to the framing of lives as un/grievable and in/visible. However, as I see it, she tames the ghost, as it is continually traced back to safe ontological ground in the human Other. In this notion of haunting, there is a certainty that the deconstructive hauntology radically undoes.

12. Importantly, Derrida introduces a 'visor effect', so that the ghost may always see you, but you may never see the ghost. Thus, the face of the Levinasian encounter is hidden, and the otherness of the Other is radicalized (Derrida 2006; Rösing 2009).

\section{ReferenCes}

Ahmed, S. (2014). The Cultural Politics of Emotion (2nd ed.). Edinburgh: Edinburgh University Press.

Butler, J. (2006). Precarious Life: The Powers of Mourning and Violence. New York: Verso.

Butler, J. (2009). Frames of War: When Is Life Grievable?. New York: Verso.

Christensen, T. D. (2015). The figure of the soldier: Discourses of indisputability and heroism in a new Danish commemorative practice. Journal of War \& Culture Studies, 8(4), 347-363.

Derrida, J. (2006). Spectres of Marx. New York: Routledge.

Elmelund, R. (2013, March 20). En symbolsk terroraktion. Information.

Genette, G. (1997). Palimpsests: Literature in the Second Degree. Lincoln: University of Nebraska Press.

Huyssen, A. (2003). Present Pasts: Urban Palimpsests and the Politics of Memory. Stanford: Stanford University Press.

Juergensmeyer, M. (2003). Terror in the Mind of God: The Global Rise of Religious Violence. Berkeley: University of California Press.

Kærn, S. A. (2018). Ramt-Soldater, Afghanistan. http://krigogkunst.dk/ ramt-soldater-afghanistan/ Accessed November 26, 2018. 
Lévinas, E. (1996). Totalitet og Uendelighed: Et essay om exterioriteten. Copenhagen: Hans Reitzels Forlag.

Lidegaard, B. (2018). Danmark $i$ krig. Aarhus: Aarhus Universitetsforlag.

Lyngberg, C. (2015, January 6) Overblik: De mest opsigtsvækkende politisk motiverede overfald. Politiken.

McLoughlin, K. (2018). Veteran Poetics: British Literature in the Age of Mass Warfare, 1790-2015. Cambridge: Cambridge University Press.

Mortensen, M. (2008). Den digitale slagmark: Danske soldaters krigsvideoer fra Afghanistan. Kosmorama, 241, 25-35.

Pedersen, L. N., \& Westh, A. (2010, June 20). Det mentale minefelt. Jyllands-Posten.

Pedersen, T. R. (2017). Soldierly Becomings: A Grunt Ethnography of Denmark's New 'Warrior Generation' (Doctoral dissertation). Department of Anthropology, Faculty of Social Sciences, University of Copenhagen, Copenhagen.

Pichel, B. (2017). Les Gueles Cassées: photography and the making of disfigurement. Journal of War \& Culture Studies, 10(1), 82-99.

Rahbek, B., \& Rix, L. (2013, March 20). I krig og kunst gælder alle kneb. Berlingske.

Rasmussen, L. L. (2018). Statsminister Lars Løkkes tale ved Flagdagen for udsendte soldater den 5 September 2018. http://www.stm.dk/_p_14724.html Accessed October 4, 2018.

Rasmussen, M. V. (2011). Den gode krig. København: Gyldendal.

Rosenvinge, L., \& Villemoes, S. (2013, April 29). Din minister bløder. Atlas.

Rösing, L. M. (2009). Den sene Derrida, eller: Er Claus Beck-Nielsen et spøgelse? Passage, 61, 75-89.

Sangild, T. (2016). Hvordan maler man den danske krigsindsats? Zetland. https://www.zetland.dk/historie/s8dQBmNm-ae2KvJdE-7fa28 Accessed November 29, 2018.

SFI. (2012). Soldater efter udsendelse: En spørgeskemaundersøgelse. København: SFI, Det National Forskningscenter for Velfærd.

Sørensen, B. R. (2015). Veterans' homecomings: Secrecy and postdeployment social becoming. Current Anthropology, 56(12), 231-240.

Sørensen, B. R. (2017). Public commemorations of Danish soldiers: Monuments, memorials, and tombstones. Critical Military Studies, 3(1), 27-49.

Sørensen, B. R., \& Pedersen, T. (2012). Hjemkomstparader for Danske Soldater. Slagmark, 63, 31-46.

Veterancenteret. (2016). Selvmord blandt veteraner: 1992-2014. Ringsted: Veterancenteret.

Wivel, A. (2013). Danmarks militære aktivisme. In K. S. Kristensen (Ed.), Danmark $i$ krig: Demokrati, politik og strategi $i$ den militere aktivisme (pp. 27-52). København: Jurist-og Økonomiforbundets Forlag. 
Open Access This chapter is licensed under the terms of the Creative Commons Attribution 4.0 International License (http://creativecommons.org/licenses/ by $/ 4.0 /$ ), which permits use, sharing, adaptation, distribution and reproduction in any medium or format, as long as you give appropriate credit to the original author(s) and the source, provide a link to the Creative Commons license and indicate if changes were made.

The images or other third party material in this chapter are included in the chapter's Creative Commons license, unless indicated otherwise in a credit line to the material. If material is not included in the chapter's Creative Commons license and your intended use is not permitted by statutory regulation or exceeds the permitted use, you will need to obtain permission directly from the copyright holder.

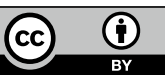




\title{
The Politics of True Crime: Vulnerability and Documentaries on Murder in Swedish Public Service Radio's P3 Documentary
}

\author{
Mats Hyö̈nen, Maria Karlsson and Madeleine Eriksson
}

This chapter investigates vulnerability in relation to P3 Documentary, a podcast format that has been aired by Sveriges Radio, Sweden's public service radio, since 2005 . It is the most popular radio programme in Sweden with 600,000 listeners weekly (Kantar Sifo 2019) and, bearing in mind that the country's whole population is only 10 million people, it is an influential authority.

A majority of the P3 documentaries recount themes related to vulnerability in various ways. However, the most common topic is crime,

M. Hyvönen $(\bowtie) \cdot$ M. Karlsson

Uppsala University, Uppsala, Sweden

e-mail: mats.hyvonen@antro.uu.se

M. Karlsson

e-mail: maria.karlsson@littvet.uu.se

M. Eriksson

Stockholm University, Stockholm, Sweden

e-mail: madeleine.eriksson@sofi.su.se

(C) The Author(s) 2020

291

A. M. Dancus et al. (eds.),

Vulnerability in Scandinavian Art and Culture,

https://doi.org/10.1007/978-3-030-37382-5_14 
staged in more than half of the programmes. The most frequent crime is murder. A selection of 19 documentaries on murder will be studied in this chapter, using a mixed-method approach with both quantitative and qualitative means. By analysing the choice of murder cases and how the documentaries are voiced and structured, the chapter will investigate how the emotional vulnerability of the listener is addressed. Emotions bring us together and tear us apart, Sara Ahmed writes, pointing towards the cultural and political work they perform (2004). Inspired by Ahmed, the overarching question in the chapter is how that work is carried out in the 19 programmes.

The concept of vulnerability will be described and the programmes will then be placed within the field of the study of crime and radio documentaries. Special attention is paid to how the narration relates to the aims of Swedish public service radio. This is followed by a quantitative analysis of the form and content of the programmes, which was undertaken by charting the length and ordering of voice sequences: the narrator, interviews, clips from other media, and of other kinds of voices and sounds. Finally, the question of the emotional invocations by way of form, voice sequences and content will be addressed. Three aspects will be analysed in this section: the representation of controversial cases, the use of fear and horror, and the function of experts.

\section{VUlnerability AND EMOTION}

There can be no doubt that media and vulnerability form a liaison in which different wounds - be they societal, individual, or environmentalare not only frequently acknowledged ethically, but are also exploited. This is certainly true of the crime documentary, a very successful genre in terms of the number of programmes available across both 'old' media, for example, TV, radio and cinema, and 'new', such as streaming services and podcasts. With its rewriting of the boundaries between the private and the public, and its focus on emotion and suspense (Horeck 2014), the modern crime documentary is a format that, to a considerable degree, both recognizes and feeds on different kinds of individual and societal vulnerabilities.

The $P 3$ documentaries on murder thematize the vulnerabilities of the victims, perpetrators, authorities and the justice system, and fulfil the media's mission to recognize vulnerability - the very condition required for bodies to be grievable at all (Butler 2004). This chapter, however, 
does not so much deal with recognition as with how the murders are represented, and what emotional work the programmes perform (Ahmed 2004).

It is important to keep in mind that the documentaries represent cases of subjects who are already injured addressing a listener that is injurable (Cole 2016). Although the documentaries thus re-present injuries, this chapter is primarily concerned with the ontological condition of the injurable listener ${ }^{1}$ as vulnerable. This approach corresponds with Sara Ahmed's understanding of vulnerability which she, in a discussion on fear of crime, defines as the subject's 'openness', its 'bodily relation to the world', that involves a sense of danger 'anticipated as a future pain or injury' (2004, p. 69).

To Ahmed, it is important that emotional attachments are understood as cultural practices, not psychological states that move from within and outwards to others $(2004$, p. 4$)$. Thus, the representation of murder cases invokes and assembles emotions in the listener, felt as fear, love, grief, anger, compassion and so on. It is crucial to understand that feelings and affects are already in the world when the subject arrives, and that they circulate in very particular ways (Ahmed 2004, p. 98). Emotions are, in other words, already attached to different things or objects when the subject is exposed to them, and the documentary listener is vulnerable to emotions linked to, for instance, victims, perpetrators, friends and family.

In addition, emotions are constantly moving about in culture, they 'move, stick and slide' as Ahmed puts it-but they also move the subject (2004, p. 14). The cultural and political work of emotions is that they push some subjects away while pulling others together (Ahmed 2004, p. 2). For instance, while some people are bound together by love's work of aligning, others are excluded by the same work-they can be feared and/or hated. This is a main mechanism in many attitudes, for instance, racism (Ahmed 2004, p. 52). How this emotional work of moving the listeners is performed by the documentaries will be exemplified in this chapter.

First, though: what are the specifics of the radio documentary, the crime documentary, and P3 Documentary? 


\section{Radio Documentary ANd Crime Documentary}

At the heart of documentary practice lies questions of truth and reliability. Documentary makers claim to show and speak the truth, and their audiences expect to receive 'truthful representations of facts and trustworthy arguments' (Werner 2016, p. 1048). However, the claim to truth finds different expressions in different kinds of documentary and in different kinds of media, and key in much research on the documentary is how the relationship between reality and representation is to be understood.

In a documentary, the representation of reality is neither completely false nor objectively true (Bruzzi 2006). Rather, truth is the result of a negotiation between the documentary and its subject. Thus, the relationship between reality and representation can be seen as a productive, dialectical one (Bruzzi 2006, p. 6). In this negotiation, the narrator is a constituent part, no matter what opinion one has on the claim of truth (Bruzzi 2006, p. 72). This is not least true for the film documentary, to which researchers of radio often turn (cf. Crook 1999; Hedemann 2006; Björkman 2009; Lindgren 2011; Åberg 2012; McHugh 2012, 2014).

Nichols $(1991,2001)$ has discussed the narrator's significance to different modes of documentary filmmaking. In its most traditional form, 'the expository mode', the voice is authoritative. The narrator, referred to as 'the voice of God'-a position of power-leads the viewer through the images, and the voice-over explains their meaning and puts them in context. In more recent forms, however, such as 'the observational', the voice is absent. Here, pure observation through sound and image derives its authority from the supposedly objective mimesis. Again, Nichols (1991, 2001) refers to an omnipotent address, and a powerful logos oriented argumentation.

Bruzzi argues that the narrator's voice is stereotypically discredited by Nichols, since it is based on a belief that objectivity is, in fact, achievable. She asks what would happen if the voice was not seen as an instance of omniscience or objectivity but, rather, as one of an inquiring helplessness? ' $[\mathrm{E}] \mathrm{ven}$ when it is most conventionally used $[\ldots]$, the limitations of the voice-over do not preclude the possibility of an alternative interpretation being left open and accessible to the audience', Bruzzi explains (2006, p. 72). It is therefore reductive to not distinguish between different uses of the voice within the single documentary (Bruzzi 2006, p. 58). The style of narration may resemble that of the 'voice of God'-for example, 
by being factual-but does not necessarily have the pretentions of being authoritative and all-knowing.

All documentaries, however, make claims to truth and thus speak with authority. The question is how this is performed. Since the radio documentary on crime is the object here-what is the role of the narrator and other voices in this format? According to Werner (2016, p. 1050), the expository mode dominates the field of criminal law, and therefore 'most documentaries $[\ldots]$ have a rather moralizing and educational tone-they come with a message'. Since the verbal message is central, and is important for the way in which, for example, victims are portrayed, the argumentative set-up of expository documentaries runs the risk of reducing the complexities of individuals and their lives to mere illustrations of the central message (Werner 2016, p. 1051). This is the case of so-called 'True Crime', a term used to include 'any true accounts or case studies of real crime and its aftermath' that often refers to documentaries 'using an investigative mode either to "solve" or to recall the details of notorious murders or other atrocities' (Biressi 2004, p. 402). True crime roots back to pamphlets by British authors between 1550 and 1700 reporting on capital crimes (MacMillan 2016) and, later, to Truman Capote's and Norman Mailer's influential True Crime paragons. It has become a hugely popular topic. What counts as True Crime has changed over the years, though. Today, they are exaggerated in style and strive to impact real cases (Bruzzi 2016, p. 267). The ambition to have influence on legal cases leaves little room for doubt, and fits well into the kind of authority that the expository mode evokes. In these thesis-driven documentaries, the voice-over must be certain-it is a vital part of the convention.

But what about crime documentaries within a public service context where claims of being impartial and truthful are essential? And when there are no images-how are objectivity, authority and power represented? While, in film, it is possible to talk about the course of events and simultaneously show related visual material, radio is limited to forefront one element at a time, accompanied only by sounds. How then, if at all, is the balance between impartiality, truthful authority and intriguing storytelling achieved in relation to the vulnerable listener? 


\section{$P_{3}$ DOCUMENTARY}

Documentaries are thriving on TV and streaming services such as Netflix and $H B O$. A hunger for reality has made its presence felt since the early 1990s, and there seems to be a never-ending demand for authentic stories. Theories put forth to explain this success include the rise of reality TV and the renegotiation of boundaries between the private and the public in the age of social media (Massumi 2002; Skeggs \& Wood 2012; Horeck 2014). The ongoing 'documentary boom' (Austin 2007) is partly also explained by the new marketing opportunities and distribution forms opened up by digitization.

One prominent example of this is the podcast, its advantages over traditional radio being that, for example, you can listen when and where you want to a wide range of niche programmes. Podcasts of various kinds are rapidly growing in popularity. In Sweden, between 2015-2018, the share of people over the age of 12 who listen to podcasts at least once a month increased from 18 to $30 \%$. About $70 \%$ of Swedes in the age group between 16 and 35 years listen monthly, and more than $35 \%$ of them tune in on a weekly basis. It is now more common for people aged between 16 and 25 years to listen to podcasts than to FM radio (Davidsson \& Melin Mandre 2018). In 2018, 12 Swedish podcasts attracted a weekly audience of over 100,000 people. The biggest by far was P3 Documentary, which is one of Sveriges Radio's most successful programmes ever with its 600,000 listeners.

Most of the episodes are downloaded via iTunes, which indicates a primarily young audience (Sveriges Radio 2016). Sveriges Radio describes the programme as a 'gateway to [Sveriges Radio's] wide range of documentaries' on all its channels (Sveriges Radio 2016, p. 79). ${ }^{2}$ Furthermore, P3 Documentary serves as a part of Sveriges Radio's self-legitimation as a public service institution because it successfully combines popularity with serious content. Sveriges Radio's channel P3 targets a younger audience. Music and entertainment are major elements, but it also aims to involve the listeners in current social issues. In this context, P3 Documentary is important, since it is 'a perfect example of how complicated [...] events and developments are explained, deepened, and packaged in such a way that it becomes attractive to a broad audience' (Sveriges Radio 2017, p. 18). 'The purpose of the documentaries', according to Sveriges Radio itself, 'is to portray important events in modern Swedish history in order to better understand the present times' (Sveriges Radio 2015, p. 52). 
P3 Documentary is a good example of the abundant documentaries on crime, which are gaining in cultural prominence and resonance (Bruzzi 2016). Even though P3 Documentary is not entirely committed to crime, a dominant portion of its programmes deal with it: of the 260 programmes published as podcasts from the start in 2005 until 2017, 137 $(53 \%)$ are on crime. Murder occurs in 43 programmes, which makes it the dominant theme among crime documentaries.

The $P 3$ crime documentaries on murder share traits with film and TV documentaries, but they also differ. While the former evoke doubt by presenting previously unknown facts, and challenge verdicts, the justice system and the actions of authorities, P3's aim seems to be to remain neutral on issues that have been widely debated. This does not mean that they refrain entirely from remediating critique of, for instance, authorities' actions; and they navigate through the cases by choosing certain angles and facts that give an indication of the programme-makers position. None of the programmes can be said to advocate an explicit, strong opinion, though. First and foremost, they retell the events of spectacular murders. In fact, the only 'news' presented is initial interviews with family members and friends.

All 19 documentaries in this study deal with well-known cases, and many of them have had a political, social and legal impact on Swedish society. Examples of this are the murder of Swedish foreign minister Anna Lindh in 2003, the honour killing of Fadime Sahindal in 2002, the murder of a 10-year old girl, Engla, by a stranger, and Therese Johansson Rojo, murdered by a boy from her school. All these cases received extensive attention in the national media (in three cases, the funerals were broadcast on national TV) and they can, in terms of public indignation, be described as national traumas subject to collective mourning.

The ambition of the documentaries is to retell, and in part to re-enact, these widely known cases. With very few exceptions, the programmes stick to the same formula: to tell the stories mainly chronologically, based primarily on information from the police investigations. The programmes in themselves are not explicitly controversial, but some of the cases chosen are, and one question is how this is dealt with, considering the public service aim of impartiality. In this, not only is the role of the narrator crucial, but also the degree to which attempts are made to move the audience, to create suspense and to sensationalize the circumstances.

To discuss the function of different kinds of voices and, not least, the ways in which they potentially move the listener, an analysis of individual 
clips was conducted to map the order of events guided by the different voices, and to measure their length compared to the run-time of the programme. ${ }^{3}$ The dominant voice turned out to be that of the narrator $(27.8 \%$ of the average programme run-time). How then, should the typical narrator of the 19 programmes be described?

The narrator's position is, to begin with, seemingly objective, linking together content and guiding the listener through the case material in a basically chronological pattern. Any criticism is conveyed implicitly through other voices, such as experts with whom interviews are conducted, usually without the questions being included. Through the voices, but also, of course, by the ordering of and choice of content, it is possible sometimes to discern standpoints. Straightforward critique is only expressed when the programmes deal with media ethics. This neutral stance may reflect Sveriges Radio's ambition to be correct, independent and impartial (Sveriges Radio 2014).

But are the P3 documentaries on murder 'impartial' and, therefore, 'neutral'? The following section addresses this question by analysing two documentaries where the murders have been committed by immigrants at a time when migration is Sweden's most controversial issue. It suggests that, in highly charged cases, the effort of maintaining a neutral stance does not achieve the intended impartiality due to the format's dedication to suspense and sensationalism. Both cases are retellings of so-called 'honour killings', committed at the beginning of the millennium. The first programme, in 2005, is juxtaposed with one from 2016, by which time the P3 Documentary format has become more streamlined. What emotional work is done when a highly charged murder case is retold in a format aimed at being attractive to more than half a million young listeners?

\section{$P_{3}$ Documentary and the Controversial Case}

'The Murder of Fadime Sahindal' is from 2005 and is the first programme aired in P3 Documentary. It deals with a case that can be described as a brusque wake-up call for the Swedish public regarding honour killings. Fadime Sahindal was active for young immigrant women's rights, and had influential friends in politics. She had a Swedish boyfriend who was not accepted by her family and had to go into hiding. In 2002, she was murdered by her father outside her sister's apartment. The case created intense and long-lasting discussions. Fadime was collectively mourned in 
Sweden; the public funeral was broadcast on TV and attended by both politicians and members of the royal family.

The documentary not only tells the story of the murder, but also clearly aims to inform the public on a crime about which Swedish society had little knowledge. The case is calmly and cautiously retold from a wide perspective (the narrator's voice takes up only $19 \%$ of the runtime, and 10 different people's voices are heard). The contextualization accounts for the pressure put on Fadime's family from relatives in Sweden and elsewhere. Fadime's political work and private struggles, memories of her, and the way she is mourned are also recognized. Care is given to the manner in which the programme ends: church bells from the funeral open the programme as well as close it, and those who attended the funeral acknowledge the grief of the relatives that were present.

Since the presence of the narrator's voice is relatively limited, the mode of this documentary can, in Nichol's (1991) terms, be characterized as observational rather than expository. However, the attention to context and the calm and cautious tempo does not imply authority and omniscience. If anything, the narrator is inquiring (Bruzzi)—which is unusual in crime documentaries, where the 'voice of God' dominates (Werner 2016 , p. 1050). The focus on complexity, recognition and closure, rather than on the promotion of suspense and sensation, leaves a range of possible positions open to the listener-one being the ability to understand the tragedy from the point of view of the Sahindal family. The documentary does not stir up hate and fear but, rather, sadness and compassion, pointing in several directions. It fits within the $P 3$ aim to be impartial, correct and independent.

'The Honour Killing of Abbas Rezai'-aired more than 10 years after the Fadime Sahindal documentary, and a decade after he was murderedis different. This may be due to the fact that, by this time, the documentary format of $P 3$ had found its form. It is more spectacular, plot oriented, driven by suspense and focused on sensation. Many passages are preceded by music or other sounds. Any opportunity to withhold information is taken. The narrator appears to be all-knowing, takes up more $(38 \%)$ of the run-time ${ }^{4}$ and drives the chain of events forward chronologically, rarely pausing to broaden the context. In other words, the melodramatic aesthetics of 2016 create an air of crime fiction.

In addition, there has also been a change in Sweden's political landscape. In 2016, immigration is debated on a daily basis in media and 
society. In 2005 , the nationalist movement was certainly growing in Sweden, but the biggest party-the Sweden Democrats: hostile to immigration, with its roots in a neo-Nazi party-was still not in parliament. From 2014 onwards, though, the Sweden Democrats have occupied about 15\% of parliamentary seats, and the party is an influential, increasingly normalized actor in Swedish politics. The Sweden Democrats is primarily addressing the fear of immigration (research has partly related that fear to the country's rapidly growing economic gaps; see, for example, Therborn 2018). Sweden counted its highest number of migrants ever in 2015163,000 (Migrationsinfo.se 2019) —and its capacity to deal with them, as well as the terms for asylum, has been and still is the topic of intense discussion. In other words, P3 could take for granted that a documentary on the honour killing of Abbas Rezai would become a part of these discussions.

Nineteen-year-old Abbas came alone to Sweden from Afghanistan a year before he met and fell in love with Mariam, a young Afghani woman. According to comments made by a friend in the documentary, Mariam was controlled by her brother, had to wear a veil and was not allowed to meet male friends or to use the Internet unsupervised. According to the programme, she was supposed to marry a cousin approved by her high-status family. Abbas' family was of low rank, and he could not be considered acceptable. Mariam ran away to Abbas. Eventually, she called her mother though, who claimed that the family had changed its mind and persuaded the couple to come to visit them. So, Mariam and Abbas headed to Högsby to celebrate their engagement: but, the listener is warned, Mariam's family had other plans. Mariam was drugged so as to make her sleep, and Abbas was killed. No details are withheld. Information on the horrific torture of Abbas is repeated several times, as well as have been sign-posted at the beginning of the programme. Recordings from the trials repeat the information again. An investigator states that this is the worst case of which he has ever heard, and this is also repeated. The conclusion of the affair-where the brother, who took the blame, and Mariam finally bear witness against their parents-is a climax that has been enigmatically hinted at earlier. In the closing section, there are a few contextualizations from Högsby. One is a speculation on the case's effects on a local election, where the Sweden Democrats party's share of the votes rose. It is supported by an interview with a Sweden Democrats politician. Another is the information that Högsby stopped all immigration-with the support of the migration authority-because of 
the murder. At the very end of the programme, the head of immigration coordination in Högsby expresses her relief that the building where the 'shameful' murder took place has been torn down.

What does this documentary $d o$ in terms of emotion? It is evident that the programme's proximity to the intense debate on migration in Sweden-where fear of violence and immigrants is a major theme-evokes emotion.

The documentary, then, is clearly structured around an opposition of good and evil. It is invested in securing the 'Swedishness' of Mariam and Abbas, who are positioned as typical teenagers set in the Swedish culture: school, the library, playing soccer; and friends are interviewed. Mariam's family though, which is claimed to see itself as high-status Afghani-as 'descendants of Mohammed'-is not described by anyone, and we are not given any information about their daily life. What the listeners find out about the parents, besides the horrific nature of their behaviour, is that they made their daughter wear a veil, kept her under strict surveillance, and aimed to marry off her to a cousin in exchange for money. In a short, re-mediated interview, the parents blame Abbas for the events. An interpreter assists at the interview, indicating that the parents do not speak Swedish. ${ }^{5}$ Thus, through a process of 'othering' (Ahmed 2004, p. 16), Mariam's parents are positioned as the un-Swedish others who are unintelligible and dreadful.

In addition to the tension between good and evil, another melodramatic trait is used in the documentary - the overdetermination of detail: Mariam's veil. It is mentioned a number of times in the programme. First, in the beginning, when the listener learns that Mariam had to wear a veil. Then on the run, in Abbas' home, where she does not wear it. Back with the parents, she wears it again, but at the trial, when she bears witness against her parents, the veil is off ('Without veil, with two bodyguards'). The veil is a good example of what Ahmed calls a 'sticky' object (2004, p. 11). A sticky object, or a sticky word, is, according to her, imbued with affect. It invokes emotions that circulate in culture and between bodies, and pulls people together into communities or nations (Ahmed 2004, p. 89). The repeated reference to the veil in the programme therefore moves the listener. It is used as a sign glued to the hateful other culture to which the parents belong. The unveiling, then, proves to the listener that Mariam does not belong to the other, that she is not part of their hate that threats Swedish values, the national subjects, and, ultimately, the nation as a whole. 
The 'emotional reading of others as hateful' ties the white nation and its imagined subjects together, Ahmed writes (2004, p. 43). The repetition of the details of the detestable torture of Abbas that are heard and repeated in the programme may invoke such readings. Following Ahmed's thought on the emotional mechanisms of racism, this is due to a fantasy where the hateful threatens the ordinary-it is in a crisis-and the ordinary person becomes the real victim of the hate. 'The ordinary becomes that which already was under threat by the imagined others' (Ahmed 2004 , p. 43). The injured-Abbas-becomes the normative subject, and the hateful-the parents - turn into the hated others. This hate is, says Ahmed, spread out in different directions across figures that threaten different kinds of losses; for example, lost jobs, lost land, lost non-violated and pure bodies. The metonymic slide does the work of making crime synonymous with migration, and what makes the migrants resemble each other is their 'unlikeness' from 'us' (Ahmed 2004, p. 43).

This unlikeness is expressed in the interviews with Högsby representatives. The speculations on how the Sweden Democrats votes rose after the murder, and the municipality putting a stop to immigration because of it-sanctioned by the migration authority-point to the metonymy being at play, as does the closure the programme offers. The last words go to the former head of local migration coordination, who comments on the torn down apartment house where the murder took place. It was a symbol of the shameful, she says, and therefore she is happy that the house no longer exists.

Although the narrator's voice takes up $38 \%$ of the programme, it never takes the time to explain or nuance the chronologically presented events. There is no attempt to educate the listener, either on legal matters or on the decade-long ongoing discussion of honour killings in Sweden. The documentary sticks to a dramatized formula where distance, a critical journalistic stance and contextualization are absent. In fact, the reference to melodrama in the analysis above is important. Once a theatrical form, the genre's mix of strong sentiments, the spectacular, iteration and moral polarization was a way to appeal to large audiences. By means of, say, the silent film and melodramatic traits in fiction, its aesthetics was inherited by block buster Hollywood movies (Brooks 1995). Melodramatic elements are key in crime fiction and have been associated with reality TV (Skeggs $\&$ Wood 2012). In the controversial cases of P3 Documentary, the use of melodramatic traits complicates the public service aim of impartiality. It moves the listener and it does political work. 
The above analysis implicates that the choice of murder cases, in relation to how they are moulded by the format, is important to how the listener is moved. So, how does P3 Documentary select its murders?

\section{Women and Children, Fear and Horror. $P_{3}$ Documentary's Selection of Murders}

According to Arthur (2005), there is a greater need in society for an emotional connection with real-life stories in the context of post $9 / 11$ terrorism, but this trend was already visible in the rise of the reality TV that predated it. Bruzzi shares this observation when describing the film documentary as often 'emotion-driven, sensual, and [...] primal in its appeal' (2006, p. 248), in opposition to Nichols' view of the (film) documentary as intellectual, cerebral, and sober (Nichols 1991, 2001). Thus, the P3 documentaries on murder correspond to the trend in the present documentary boom when it comes to the emotional, even though they do not explicitly 'whip up social outrage by campaigning against wrongful convictions' or expose 'gross injustices' (Horeck 2014, p. 152).

As the P3 Documentary format becomes more established, the programmes are increasingly focused on emotions that attach to ideological and political tendencies in society. The selection of murder cases certainly bears witness to this trend. It is not motivated in relation to a more general idea anywhere, more than the aim to 'portray important events in modern Swedish history in order to better understand the present'. In the documentaries on murder, these 'important events' do not align with actual crime statistics. This is probably due to two factors. First, the programme-makers need cases regarding which there is a great deal of archive material. Second, they focus on the most spectacular cases.

According to the Swedish National Council for Crime Prevention, murder victims are often young men from socially vulnerable areas (BRA 2014). Of the 113 people killed as a result of lethal violence in 2017, only 27 (24\%) were women (BRA 2018). Typically, when women are the victims of murder, the perpetrator is their male partner and the crime is committed at home. In addition, lethal violence against children is extremely rare-about four to five cases are reported every year. Yet, of the 19 episodes of P3 Documentary that deal with murder, 14 are about cases in which women or children were the victims ( 9 women and 4 children). Furthermore, in 7 of these cases ( 3 children and 4 women) -9 , if 
one counts the cases where the victims were men-the perpetrator was unknown to the victims.

Many of the selected murder cases are reminiscent of horror movies and take place in nightmarish circumstances. A majority of the programmes describe how the victims were subjected to torture, sexual assault, and/or unprovoked assaults by strangers. Often, the perpetrators are people with whom the victims have an intimate relationship: parents or loved ones. The injuries on the bodies of the victims, and, not least, the places in which they were encountered, invoke horror film clichés: they are found deep in the woods, submerged in water, hidden under rocks and, in two cases, the perpetrators had tried to set fire to the bodies to destroy evidence. The listeners are taken along on reconstructions where the perpetrators point out the scene of the murder and describe in detail what happened. With the exception of four documentaries (in which the killings were related to gang violence, football hooliganism, drug dealing, and the antagonism between skinheads and immigrant youth) all the programmes draw on a horror film lexicon (Biressi 2004) with perpetrators who are unknown and, often, mentally ill, or, which is equally frightening, parents who murder their children or partners who kill their loved ones.

Fear is obviously crucial to the programmes. Considering that more than half of the victims are female, and that the documentaries have farreaching claims to the truth, they retell the narrative of women being particularly vulnerable, especially outside their homes. However, women's fear is, as Sara Ahmed has argued, not an effect of their 'inevitable vulnerability'; rather, it is a 'response to a threat of violence' (Ahmed 2004, p. 69). According to her, stories of women's vulnerability circulate as authorized narratives of what should be considered as dangerous and the places of which to be afraid. The $P 3$ documentaries on murder contribute to these narratives. Although it is a widely known fact that most murders of women $(80 \%)$ in Sweden are committed by their partners, and almost exclusively at home (Forselius \& Granath 2017), the documentaries persuasively suggest that women should be on their guard when moving outside alone. The safe place for women is at home, thus moving unaccompanied in public becomes illegitimate, inappropriate and irresponsible. The many narratives of danger and safety in the documentaries suggest a restriction of women's access to public space (Stanko 1990). The 'mobility of some bodies involves [...] the restriction of the mobility of others', and 'what is fearsome as well as who should be afraid is bound up 
with a politics of mobility' (Ahmed 2004, p. 70). So when, for instance, at the end of 'The Murder of Elin Krantz' (2017) —another highly controversial case, where a migrant raped and killed a young Swedish woman in a suburb, at night-her friend says that she will never go on public transport at night again, it is a lesson on mobility.

The cases chosen by P3 Documentary and the staging of the events are thus not culturally and politically innocent. Additionally, the threat conjured up in the programmes is not only mainly directed at teenage girls and adult women, but also at female children. Two of the documentaries describe cases in which 10-year-old girls were kidnapped, raped and murdered when they were outside playing; one programme deals with the murder of a four-year-old girl playing outside her preschool. In all these cases, the perpetrator was unknown to either the children or their families.

\section{FAMILY, MURder, INTIMACY}

The most emotionally charged voices in the documentaries belong to the families and to the friends of the victims. This group represents the people actually injured, and they amount to more than one-fifth $(22 \%)$ of the total run-time of the 19 documentaries. A few examples show the often very intimate level of the representation of these voices. Actors read text messages, full of love and hate, sent between two 15-year-old perpetrators who, in a love triangle, conspired and murdered their classmate ('The Murder of Therese Johansson Rojo'). There are interviews with mothers, such as Engla Höglund's ('The Murder of Engla Höglund'), or siblings who's voices break - the sister of Elin Krantz, for instance.

To involve close ones is crucial to the documentaries on murder. The interviews with family members are not only presented as new information in the promotion texts, they are P3's main contribution, since the rest of the case already has been reported by different kinds of media and, in some cases, even retold in books and TV documentaries.

People that were close to the victim are also used as a reminder that anyone of us could have been the victim-our children, siblings, partners, friends. Where did the victims grow up, what did they like to do, who were they, ${ }^{6}$ were they happy? This information is presented through interviews with friends and/or family usually at the beginning of the programmes. The listener knows that this loss could have been my loss. This 
identification produces a 'likeness' between the listener, the family members and the victims. Thus, it aligns the listeners with the victim. Simultaneously, it pushes them away from the perpetrator, since what aligns with some others, aligns against different others (Butler 1997; Ahmed 2004, p. 52).

The aligning of the listener with others can be framed within what Berlant (2008) has termed 'the intimate public', which she defines as a 'porous affective scene of identification among strangers that promise a certain experience of belonging, and provides a complex of consolation, confirmation, discipline and discussion about how to live'. The experiences of belonging are created 'in proximity to the technologies that make "it" a site of affective investment and emotional identification' ( $p$. viii). A part of that site of intimacy is the device that brings the message across. Grusin (2010) has noted that the Abu Ghraib photos did something beyond present their horrific content. People recognized the use of media, the photos were 'not fundamentally different as media practices than what we do with our digital cameras [...] when we capture scenes of a wedding or a birthday'. This made the experience a 'bodily feeling both of the affectivity of these digital images and of the affinity between our own practice of distributing affect across and through other media' (Grusin 2010, p. 89).

Drawing on Grusin's example, Horeck (2014) has discussed intimacy in the light of the use of common media practices - in her case, home videos-in crime film documentary. One can argue that a similar bodily identification with media practices exists in, for instance, the context of reality TV, which often takes place in a home and usually is watched in a home (Skeggs \& Wood 2012). But, in the crime documentary podcast, or in the Abu Ghraib case, the device itself 'draws attention to the potential proximity of such documentary images to crime and death' (Horeck 2014 , p. 160), and, of course, corresponds with the audience's own ways of distributing photos and different kinds of affect via their technical devices.

Listening to the documentaries on murder via podcast is, in other words, a specific digital experience similar to that addressed by Grusin and Horeck. Pictures and videos cannot be shown, but the majority of the P3 documentaries contain reports on the mobile phone usage of victims, perpetrators and witnesses. Text messages are read out aloud, referred to as evidence, or included to set the case in a sentimental context of love, family and friends. While the audience is listening to the podcast on 
their phones-on the move, perhaps simultaneously answering a text message - the bodily practice of using them is recognized in the programme, and is connected to a context of murder. As Grusin (2010) points out, the feeling of proximity is bodily both through the content of the messages and the way the listeners themselves use their phones.

When it comes to sites of intimacy, it is also worth highlighting the temporal clash between the private and the public. A text message sent before a crime - or even during a crime - can be retrieved and then broadcast publicly. This marks out a new relational area between the public and the private that Massumi calls the 'quasi-public' sphere (2002). It is a site where the media user is aware that others are present, even though the communication is directed at family, colleagues or friends. The increased representation of media practices in art and other media creates affinity, but also attaches to a sense of paranoia: 'What if my messages one day become public?'

Another function of the affinity created between the listeners through interviews with families is that reaffirming family is, and always has been, a part of the conservative strain of mediatized crime. Narratives of crime 'appear to reinforce conventional ideals about love, family and society', since it frames the victim within them, and triggers and strengthens the cliché (Jermyn 2007). This has been the case throughout the history of melodrama, where crime and the justice system have played a significant role. Crime was connected to the unsubtle hammering in of bourgeois family values through a matrix of oppositions, guided by good or evil. The villains were always a threat to the family, especially innocent women and children (Brooks 1995). The P3 podcast documentaries on murder make visible how persuasive these values still are and, not least, the ontological vulnerability of the listeners in relation to them.

\section{The Function of Experts}

Another instance that can have a political impact on the format and the listener is the expert. Different kinds of experts appear in the programmes: representatives of the justice system (prosecutors, lawyers and the police), other experts (criminologists, medical expertise, journalists), and employees of societal institutions (social services, politicians, health care workers, schools). They make up about $27 \%$ of the average programme's run-time (the retellings from the police investigations and verdicts by the narrator have not been included). These official voices are, in relation to the truth, 
a significant part of what makes a documentary into a documentary, and not fiction.

According to Werner (2016, p. 1043), documentaries have become 'important tools for education and the spread of imageries of [...] criminal justice'. The $P 3$ documentaries on murder do spread such 'imageries', but they do not educate-in fact, they rarely use the experts to explain the law at all. Judges or criminal law researchers are not used to explain the differences between, for example, different kinds of intent, or how murder is distinguished from manslaughter, and so on. Lawyers and prosecutors are also rarely addressed as professionals. In the documentary on Fadime Sahindal, for example, the lawyer is mostly addressed as a friend. Instead, the focus is on criminology_profiles of serial killers and crime statistics - psychology, or the dealing with criminals and victims within social services.

Since we are dealing with the staged, dramatized reconstructionextracts of events re-presented and neatly tied together for the sake of suspense-of already highly mediated murder cases, many of the sources of facts are already charged with different emotions in relation to the audience. For instance, most of the professionals interviewed have previously appeared in different kinds of media-not least other documentaries.

In addition, facts are often delivered by celebrities. It may be a star lawyer-Peter Althin or Leif Silbersky, or a renowned professor of psychiatry, such as Sten Levander. Or, as in 4 of the 19 programmes, the retired professor of criminology and crime fiction writer Leif G. W. Persson. For years, he has been an expert in popular crime TV shows and a celebrity continuously cropping up in the media. Thus, his function in P3 Documentary is not only to educate the listener in matters of criminology - an air of suspense attaches to him, of cases that have been hard to solve - and of crime noir.

Persson is part of the Nordic crime fiction success. Like many others, he is influenced by the Swedish author alias Sjöwall/Wahlöö (Per Sjöwall and Maj Wahlöö) who, in the 1960s, renewed the genre (Wendelius 1999; Berglund 2017). Their novels focus on worn-out policemen, carrying out their life-consuming work in a decaying welfare state. This twist of the genre became the Nordic noir, nowadays endlessly televized and filmed (Berglund 2017).

The public is familiar with crime fiction conventions, and the use of them is routine in the crime documentary (Arthur 2005, p. 20; Horeck 
2014 , p. 152). The interrelatedness of crime fiction and the documentaries on murder is obvious, not least in the promotional texts. As in the marketing of crime fiction, certain information is withheld, and the condensed themes are often presented as though the programme is a thriller or a horror story. P3 Documentary 'tells a story about a culture of silence, jealousy, revenge, murder and drugs' ('Our Restaurant and Bar'); or 'tells the story about when the unimaginable happens four days before high-school graduation day: On murder, love, and obsession in a teenage world' ('The Murder of Therese Johansson Rojo'); or 'tells the story about unparalleled violence, assault, and torture' ('The Case of Bobby').

The Swedish welfare state-once meant to overcome vulnerability by means of social engineering - is today moving closer to what literary critics in the 1960s saw as a Sjöwall/Wahlöö dystopia (Wendelius 1999). Recent decades have seen cuts in social insurance systems, and there is an increase in the number of poor sick people, poor retired people, poor immigrants and poor children. Economic gaps expand faster in Sweden than in the rest of Europe (Therborn 2018). The critique of institutions not doing what they are supposed to-be it the police, social services, health care, immigration, schools-pours out of the documentaries on murder read as a whole, and does so mainly through interviews with officials from different institutions and authorities. It addresses an awareness of vulnerability-not only to the potential exposure of crime-of large groups, a sense of insecurity, where the welfare state is no longer to be trusted. In this context, one of the manifold appeals of the P3 documentaries could be the built-in Nordic noir dystopia-which many fear is now being realized. The spectacular murder finally solved then becomes reassuring proof of the continued existence of the welfare state.

\section{CONCLUSION}

With their large audiences, one can assume that crime documentaries play an important part in the representation of crime and the justice system, and that they contribute to conceptions that influence public discourse. As Jamie Bennett (2017) puts it, 'Within the criminal justice system', documentaries are important 'not only because of the public fascination with crime and punishment, but also because the everyday workings of the criminal justice system often remain outside of the direct experience or sight of most people'. Even though it is difficult to measure the impact 
in a reliable way, it is safe to say that crime documentaries raise 'significant issues about the representation of the law in the digital era, perceptions of justice, narrative and evidence, the increased "jurification" of audiences and the instability of truth' (Bruzzi 2016, p. 280). However, from the perspective of the implied listener and vulnerability, there is more than the audience being educated about crime and the legal system at work.

P3 Documentary's programmes about murder cases arguably contribute to the circulation, invoking and assembling of emotions in and between listeners in particular ways. They perform both cultural and political work by pushing some of their listeners - vulnerable to emotions linked to victims, perpetrators and family-away from each other while pulling others together (Ahmed 2004, p. 2).

The format of the murder documentaries in P3 Documentary share traits with melodrama and therefore, in controversial cases, moves the listener in certain political directions. The example of honour killings, and the difference between the early (2005) and recent (2016) programmes on the subject, show that while the former was more thoroughly contextualized, the latter was focused on the heightening of emotion and suspense, the juxataposition of good and evil through the repetition of sticky words, the details of horrific violence, and a metonymic sliding and moving about of hate. Due to this, listeners were drawn together in defence of the national subject and, ultimately, the nation as a whole. In addition, P3 Documentary on murder distributes a politics of mobility aimed at women and children by drawing on horror conventions. These aspects are all amplified by the intimacy created by the interviews with the victims' family and friends. They align the listeners through the love of likeness, as well as by the impact of the use of technical devices in the programmes that corresponds to the listeners' own use of it.

Finally, even though one could link the use of experts to the intent to represent reality and truth, to a high degree such experts are used to create suspense, as well as to point to vulnerabilities in the welfare society. The analysis shows that the focus on the listeners' emotional vulnerability through the suspense-driven format complicates P3 Documentary's aim to be impartial. 


\section{Notes}

1. By 'listener' we do not, of course, refer to the empirical listener, but to an 'implied listener' (derived from Iser's [1978] concept of the 'implied reader'), and its responsiveness to the aesthetic traits of the programme.

2. All translations of Swedish texts concerning P3 Documentary (i.e. titles and descriptions from Swedish Radio) are ours.

3 . The running time for each category of voices and their share of the total running time of the 19 documentaries is distributed as follows: Interviewees take up $49.9 \%$. Within this category, family, relatives and acquaintances dominate with $19.5 \%$ of the running time, followed by police and prosecutors (13.8\%) and journalists (3.5\%). External recordings and other sounds make up $15.6 \%$ and $6.8 \%$, respectively, of the total running time.

4. Not only did the number of documentaries on murder increase in the period 2016-2017, so did the average time occupied by the narrator. Between 2005-2015, 11 documentaries on murder were broadcast, with the narrator occupying, on average, $25 \%$ of the running time. In 2016 and 2017, no less than eight P3 documentaries dealt with murder cases and the narrator's share of the running time increased to an average of $32 \%$.

5. All Swedish parties underline the importance of learning Swedish. Some want to make it into a condition for citizenship.

6. Of the 19 documentaries, 12 include the name of the victim in the title. Nine of these documentaries deal with cases where the victims were women.

\section{REFERENCES}

Åberg, C. (2012). Radioanalys: Att undersöka radions lyssnare och program. Lund: Studentlitteratur.

Ahmed, S. (2004). The Cultural Politics of Emotion. Edinburgh: Edinburgh University Press.

Arthur, P. (2005). Extreme makeover: The changing face of documentary. Cineaste, 30(3), 18-23.

Austin, T. (2007). Continuity and Change: The Documentary 'Boom'. Manchester: Manchester University Press.

Bennett, J. (2017). Documentaries about crime and criminal justice. In H. N. Pontell (Ed.), Oxford Research Encyclopedia on Criminology and Criminal Justice. Oxford: Oxford University Press.

Berglund, K. (2017). Död och dagishämtningar: En kvantitativ analys av det tidiga 2000-talets svenska kriminallitteratur (Doctoral dissertation). Uppsala Universitet, Uppsala.

Berlant, L. (2008). The Female Complaint: The Unfinished Business of Sentimentality in American Culture. Durham: Duke University Press. 
Biressi, A. (2004). Inside/out: Private trauma and public knowledge in true crime documentary. Screen, 45(4), 401-412.

Björkman, S. (2009). En lyssnares röst. Stockholm: Carlsson Bokförlag.

BRÅ (The Swedish National Council for Crime Prevention). (2014). Lethal Violence in Sweden 1990-2014: A Description of Trends with a Specific Focus on Firearm Violence. Stockholm: Brottsförebyggande rådet.

BRÅ (The Swedish National Council for Crime Prevention). (2018). Konstaterade fall av dödligt våld: En granskning av anmält dödligt våld 2017. Stockholm: Brottsförebyggande rådet.

Brooks, P. (1995[1976]). The Melodramatic Imagination: Balzac, Henry James, and the Mode of Excess. New Haven: Yale University Press.

Bruzzi, S. (2006). New Documentary. London: Routledge.

Bruzzi, S. (2016). Making a genre: The case of the contemporary true crime documentary. Law and Humanities, 10(2), 249-280.

Butler, J. (1997). The Psychic Life of Power: Theories in Subjection. Stanford: Stanford University Press.

Butler, J. (2004). Precarious Lives: The Powers of Mourning and Violence. New York: Verso.

Cole, A. (2016). All of us are vulnerable, but some are more vulnerable than others: The political ambiguity of vulnerability studies, an ambivalent critique. Critical Horizons, 17(2), 260-277.

Crook, T. (1999). Radio Drama: Theory and Practice. London: Routledge.

Davidsson, P., \& Melin Mandre, Å. (2018). Svenskarna och internet 2018. Stockholm: Internetstiftelsen i Sverige.

Forselius, N., \& Granath, S. (2017). Dödligt våld. In L. Wallin (Ed.), Brottsutvecklingen i Sverige fram till àr 2015. Stockholm: Brottsförebyggande rådet, BRÅ.

Grusin, R. A. (2010). Premediation: Affect and Mediality After 9/11. Basingstoke: Palgrave Macmillan.

Hedemann, B. (2006). Hør og Se. Kristiansand: IJ-forlaget.

Horeck, T. (2014). 'A film that will rock you to your core': Emotion and affect in Dear Zachary and the real crime documentary. Crime Media Culture, 10(2), 151-167.

Jermyn, D. (2007). Crime Watching: Investigating Real Crime TV. London: I. B. Tauris.

Kantar Sifo. (2019). Poddtoppen 2018:2. https://www.kantarsifo.se/nyheter-ochpress/poddtoppen-20182. Accessed January 25, 2019.

Lindgren, M. (2011). Journalism as Research: Developing Radio Documentary Theory from Practice. Perth: Murdoch University.

MacMillan, K. (2016). True crime reporting in early modern England. In H. N. Pontell (Ed.), Oxford Research Encyclopedia on Criminology and Criminal Justice. Oxford: Oxford University Press. 
Massumi, B. (2002). Parables for the Virtual. Durham: Duke University Press.

McHugh, S. A. (2012). Oral history and the radio documentary/feature: Introducing the 'COHRD' form. The Radio Journal: International Studies in Broadcast \& Audio Media, 10(1), 35-51.

McHugh, S. A. (2014). RadioDoc review: Developing critical theory of the radio documentary and feature form. Australian Journalism Review, 36(2), 23-35.

Migrationsinfo.se. (2019, June 18). Den tillfälliga lagen. https://www. migrationsinfo.se/flyktingar/den-tillfalliga-lagen/. Accessed June 3, 2019.

Nichols, B. (1991). Representing Reality: Issues and Concepts in Documentary. Bloomington, IN: Indiana University Press.

Nichols, B. (2001). Introduction to Documentary. Bloomington, IN: Indiana University Press.

Radio, Sveriges. (2014). Public Service-Handbok. Stockholm: Sveriges Radio.

Radio, Sveriges. (2015). Public Service-Redovisning 2014. Stockholm: Sveriges Radio.

Radio, Sveriges. (2016). Public Service-Redovisning. Stockholm: Sveriges Radio.

Radio, Sveriges. (2017). Public Service-Redovisning 2016. Stockholm: Sveriges Radio.

Radio, Sveriges. (2018). Public Service-Redovisning 2017. Stockholm: Sveriges Radio.

Skeggs, B., \& Wood, H. (2012). Reacting to Reality Television: Performance, Audience and Value. London and New York: Routledge.

Stanko, E. (1990). Everyday Violence: How Women and Men Experience Sexual and Physical Danger. London: Pandora.

Therborn, G. (2018). Kapitalet, överbeten och alla vi andra: Klassambället $i$ Sverige - det raidande och det kommande. Lund: Arkiv.

Wendelius, L. (1999). Rationalitet och kaos: Nedslag $i$ svensk kriminalfiktion efter 1965. Hedemora: Gidlund.

Werner, W. G. (2016). Justice on screen-A study of four documentary films on the International Criminal Court. Leiden Journal of International Law, 29(4), 1043-1060. 
Open Access This chapter is licensed under the terms of the Creative Commons Attribution 4.0 International License (http://creativecommons.org/licenses/ by $/ 4.0 /$ ), which permits use, sharing, adaptation, distribution and reproduction in any medium or format, as long as you give appropriate credit to the original author(s) and the source, provide a link to the Creative Commons license and indicate if changes were made.

The images or other third party material in this chapter are included in the chapter's Creative Commons license, unless indicated otherwise in a credit line to the material. If material is not included in the chapter's Creative Commons license and your intended use is not permitted by statutory regulation or exceeds the permitted use, you will need to obtain permission directly from the copyright holder.

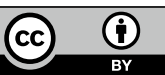




\section{INDEX}

A

Abdul Fattah, Nabila, 259

able-bodiedness, 2, 151, 154

Adrian, Stine Willum, 112, 113, 118 aesthetics, 8, 20-22, 24, 25, 29, 57, $127,128,133-135,155,158$, $212,213,228,235,242,276$, 278-280, 299, 302, 311 affect, 9, 46, 57, 58, 60-63, 65-67, $73,84,133,153,160,199,200$, $212,243,249,261,301,306$ and fear, 181, 224, 293 and shame, 36, 58, 70, 71

affect theory, 7, 71, 72

Afghanistan, 20, 36, 38, 49, 83, 120, 269, 279, 280, 287, 300

Ahlin, Margita, 140

Ahmed, Sara, 7, 12, 34, 40, 199, 200, 202, 243, 261, 271, 281, 292, 293, 301, 302, 304-306, 310

Ajkic, Leo, 8, 34, 35, 40-48, 51 Ali, Goli Mohammed, 36

Ali, Hassan, 36

Ali, Husein, 36
Althin, Peter, 308

Anderson, Joel, 86, 88, 89

Angerstein, John Julius, 26

Anker, Helle, 106, 113, 114, 120

Anker, Morten, 106, 120

Ankersen, Dag, 232

Antonioni, Michelangelo, 24, 25

Anvik, Cecilie Høj, 173, 174, 182

Arendt, Hannah, 82, 91

Arthur, Paul, 303, 308

Asplund, Mathias, 225

asylum seekers, 34-38, 48, 82

Austin, Thomas, 296

B

Babels hus [House of Babel] (TV series), 137, 141, 142

Baby Jane (Novel), 11, 154, 158, $159,162,168,169$

'The Ballad of Lucy Jordan', 159

Batalje, 268

begging, 2, 4, 12, 223-230, 232-236, 239-243

Bennett, Jamie, 309

(C) The Editor(s) (if applicable) and The Author(s) 2020

A. M. Dancus et al. (eds.),

Vulnerability in Scandinavian Art and Culture, https://doi.org/10.1007/978-3-030-37382-5 
Bergen, 41, 45

Bergman, Ingmar, 24, 25, 127, 132

Berlant, Laurent, 306

Berndt \& Anita (TV film), 128, 129, 136, 140, 144

Bérubé, Michael, 152, 153, 156, 160 bioethics, 69

Biressi, Anita, 295, 304

Bishop, Claire, 227-229, 241, 262

Björk, Anna, 104

Blindheim, Anne Marte, 48

Bødker, Cecilie, 68

Bodnia, Kim, 104

body, 9, 24, 34, 35, 38-41, 45, 47, $50,56-63,65,68,70-73,76$, $90,95,115-117,123,135$, $137,153,157,162,165,166$, $168,174-176,178,180,181$, $183-185,200,261,262,268$, $270,271,274,282$

Boltanski, Luc, 258

border, 3, 6, 33, 41, 104, 108, 109, 113,189

Bosnia/Bosnian, 8, 34, 41-43, 47, 50,51

Bourriaud, Nicolas, 20, 25, 28

Boussnina, Sarah-Sofie, 104

Bratt, Bengt, 128, 129, 138

Bron/Broen [The Bridge] (TV series), $103,127,152,169$

Bro, Nicolas, 104

Brown, Wendy, 29

Bruzzi, Stella, 294, 295, 297, 299, 303,310

Buber, Martin, 185

Bush, George, 274

Butler, Judith, 2, 3, 5, 9, 10, 19, $21,33-35,38,39,48,49,88$, $152,157,177,178,185,189$, 200, 224, 225, 233, 261, 268, 272-274, 278, 284, 285, 288, 292, 306
C

Caché, 20, 27

camp, 213

Carlsson, Anders, 229-231, 233

Carlsson, Linnea, 230, 231

Cathy Come Home (TV play), 134

Caulier-Grice, Julie, 252

Chiapello, Eve, 258

Chow, Pei-Sze, 108, 109

Christensen, Tea Dahl, 58, 269, 27l, 287

Christiansen, Lene Bull, 43, 44

Chun, Wendy Hui Kyong, 76

Cleland, John, 64

Cohen, Jem, 26, 30, 110, 122, 123

comics, 139

community, 10, 12, 87, 108, 110, 139, 141, 160, 188, 190, 191, 196, 200-202, 205, 224, 228, 232-234, 241, 247, 248, 251, 252, 257, 260-262, 301

compassion, 4, 37, 40, 47, 87, 185, $232,278,293,299$

consent, 4, 9, 55, 56, 60, 62, 63, 65, $67,68,72,75,156$

copyright, 55, 56, 62, 63, 66, 67, 72

Couser, G. Thomas, 156, 166, 167

Crawford, Joan, 159, 161

creative class, 257

crime, $1,5,7,13,38,55,57$, $66,103,109,120,121,127$, $129-131,133,137,140,142$, $143,226,227,291-293,295$, 297, 299, 302, 303, 306-310

Cvetkovich, Ann, 200

D

Davis, Bette, 159, 161

Davis, Lennard J., 153, 160

De andre [Nowhere Home] (Film), 8, $34-36,38,40,41,48,49$ 
De dagar som blommorna blommar [The Days the Flowers Bloom] (TV series), 141

Deleuze, Gilles, 57, 61, 66, 73, 74

Demetriou, Demetrakis Z., 41, 50

Denmark

artificial reproductive technology, 6, 111

freedom of speech, $6,56,63,64$, 72,73

gender equality, 7

warfare, 268, 269, 273

dependence, 157, 162-165, 168

Derrida, Jacques, 268, 285, 286, 288

design, 2, 4, 6, 12, 64, 127, 247-252, 254-256, 258-263

Det kunde varit jag [It Could Have

Been Me] (Art project), 224, 235

disability, 11, 29, 86, 151-163, 165, 167-169, 174, 184

Dixon, Rosalinda, 96

documentary

crime, 292, 306, 308

film, 2, 8, 9, 34, 35, 50, 294, 303, 306

pod radio, 13

Dodds, Susan, 21

Dokument inifrån [Inside Documents]

(TV series), 130

Downfall. A Love Story (Novel), 165

Dunham, Lena, 182

Dyfverman, Henrik, 133

E

Eeg, Mari, 175, 192

Ekelöf, Gunnar, 132

Ekman, Kajsa Ekis, 232

embodied dignity, 94, 97

emotion, $13,44,45,50,84,94,116$, $118,175,184-186,188,189$, 198, 213, 243, 292, 293, 301, $303,308,310$ empathy, 22, 25, 44, 87, 95, 213, 224

empowerment, 248, 252

En midsommarnattsdröm [A Midsummer Night's Dream] (TV series), 127, 138

Enquist, Per Olov, 165

Erikson, Erik H., 174, 175

ethics, 5, 8, 20, 21, 28, 29, 42, 69, $93,94,156,157,285,298$

ethnicity, 2, 25, 58, 228

Eva \& Bengt (TV film), 140

F

face, $74,116,117,165,166,174$, 202, 226, 230, 234, 267, 268, 272-276, 278-288

Fahlgren, Siv, 154

Faithfull, Marianne, 159

family, 4, 11, 13, 23, 24, 27, $37,39,43-46,60,83,104$, $106-108,111,114,115,119$, $121,138-141,156,157,164$, $176-180,182,185,187,190$, 230, 236, 239, 241, 242, 280, 293, 297-301, 305-307, 310, 311

Fanny Hill (Novel), 64

Faqiri, Khalid, 36

Fat Is a Feminist Issue (Book), 184 fatso, 174, 181, 187

Faustman, Erik 'Hampe', 132

feminism, 8, 21, 64, 69

feminist cultural studies, 199

Fenton, Rachel Anne, 106-108, 111 , $112,118,121$

fiction, $3,5,11,23,26,58,109$, $120,121,127-130,132,133$, 135-137, 139, 140, 142, 143, $152-154,156,174,175,178$, $189,198,208-211,299,302$, 308, 309 
Fineman, Martha A., 2, 5, 9, 21, 25, $82,85-87,106,107,111,112$, 121,122

Finland, 75, 122, 133, 191

Florida, Richard, 257

Flukt [Escape] (TV series), 8, 34, 41, $44,48,50$

Fogh Rasmussen, Anders, 268, 274-276

Forbrydelsen [The Killing] (TV series), 127

Foster, Hal, 20

Foucault, Michel, 69, 185, 254

freedom of speech, $6,8,9,55,56$, $62,63,65,68,69,71,72$

Frello, Birgitta, 43, 44

Friedan, Betty, 141

Friedland, Sarah, 76

Frisch, Hartvig, 64

Friställd [Laid Off] (TV series), 128, $138,139,144$

G

Gade, Søren, 275, 278, 288

Gallefoss, Lars Petter, 34

Gardell, Jonas, 141

Garland-Thomson, Rosemarie, $154-156,158,160,166,168$

Gelsted, Otto, 64

gender, 2, 8, 22, 25, 34, 35, 41, 46, $47,68,73,92,107,122,153$, $175,177,197,199,202,203$, $208,214,225,228$ equality, 7,8

Genette, Gerard, 287

Gilson, Erinn C., 2, 21, 25, 29, 42, $47,69,70,87,164$

Girls (TV series), 182

global, 2, 4, 6, 34, 35, 48, 49, 64, $65,67-69,74,90,92,93,108$, $111,143,152,188,247,286$

Gnanalingam, Brannavan, 24
Gonzales-Torres, Felix, 29

Grandi, Nicolás, 29

Grear, Anna, 2, 25

Gregory, Judith, 249

grief, 37, 38, 87, 293, 299

Grusin, Richard A., 306, 307

Gullestad, Marianne, 35, 243

Gustafsson, Lotten, 208

Gyllene år [Golden Years] (TV series), 128

$\mathrm{H}$

Hamberger, Lars, 110

Haneke, Michael, 20, 22, 24, 25, 27 , 29

hauntology, 268, 285, 288

Helin, Sofia, 104, 128

Hem till byn [Home to the Village]

(TV series), 128

Henkel, Ayoe Quist, 175

Henningsen, Poul, 64

Hill, Annette, 128, 197

Hirdman, Anja, 197

Hirsch, Marianne, 151, 152

Hjelm, Keve, 138

Hoffman, Dustin, 23

Holst, Åsa, 106, 115

Holst, Freddie, 104, 106, 115, 118, 120

Holst, Jan Fredrik, 106

Holten, Emma, 56, 68, 75

Honneth, Axel, 84, 86-89, 94

honour killing, 297, 298, 300, 302, 310

Horeck, Tanya, 292, 296, 303, 306, 308

horror, 13, 161, 278, 292, 309

film, 25, 162, 304 
I

Indoktrineringen i Sverige [Indoctrination in Sweden] (Book), 138, 139,141

infertility, 10, 104-109, 111, 114, $115,117,119,121-123$

Inghe, Gunnar, 131, 133

Inghe, Maj-Britt, 131, 133

Inland Empire (Film), 57, 66

Institutet, 12, 224, 227-230, 232-234, 242, 243

integration, 6,58

interfaces, 9, 56-60, 62, 65, 69-71, 235

Internet, 6, 9, 55-57, 63, 65, 67-69, 73-76, 183, 186-188, 255, 300

Iosif, Felicia, 12, 224, 228, 234-236, 239-242

Israelson, Aaron, 232, 235

\section{$\mathrm{J}$}

Jackson, Shannon, 228

Jacobs, Jason, 135, 137

Jarman, Derek, 29

Jerslev, Anne, 58, 60, 189, 199

Johansson, Lennart F., 138

Johansson Rojo, Therese, 297

Johansson, Rune, 136

Jourbavande [On Duty] (TV series), 136,137

\section{K}

Kærn, Simone Aaberg, 6, 12, 267-269, 274-283, 285-288

Kierkegaard, Søren, 185

Knapp, Mikaela, 141

Koch, Lene, 105, 111, 112, 114, 115, 122,123

Koivunen, Anu, 2, 3, 7, 133, 197, 199

Kørner, John, 279, 280
Krig, kunst og Danmark [War, Art and Denmark] (exhibition), 275

Krogh Nissen, Asbjørn, 114

Kroløkke, Charlotte, 112, 113, 118

Kulick, Don, 3, 152, 158, 197

Kurdistan, 36, 49

Kyrölä, Katariina, 203

L

Lande, Anne Kristin, 192

Larsson, Anna-Maria, 106, 113, 114

Larsson, Emil, 104, 106, 120

Larsson, Stieg, 127, 153

Leadbeater, Charles, 256, 257

lesbian, gay, bisexual, and transgender (LGBT), 2, 10, 196, 197, 210

Levander, Sten, 308

Lévinas, Emmanuel, 272, 285

Lindh, Anna, 297

Lindhardt, Thure, 104

Lindstedt, Carl Gustav, 137

Loach, Ken, 133, 134

Løes, Synne Sun, 11, 174, 175, 178, $180-190$

loss, $21,49,83,84,87,122,154$, $161,164,168,302,305$

Ludvigsen, Per, 268

Lykketoft, Mogens, 275, 278

Lynch, David, 57, 66

M

Mackenzie, Catriona, 2, 21, 23, $85-87,89,176,177$

Madonna, 159

Malmö, 103, 104, 143, 233, 234, $248,252,254,256,257,259$

Malmö Fine Arts Museum, 12, 224, $229,230,232$

Mani, Lata, 29

Mankell, Henning, 143

Marghit, Cătălin-Mihai, 230 
Mårlind, Måns, 103

masculinity, 8, 20, 22-24, 27-29, 41

hybrid, 8, 41, 44

M.A.S.H. (TV series), 135

Massumi, Brian, 57, 70-73, 296, 307

McLoughlin, Kate, 269

McLuhan, Marshall, 66

McRobbie, Angela, 257

media, 9, 10, 13, 33, 65, 69, 70, $72,74,111,122,132,135$,

$137,139,140,144,191$, 196, 203, 208, 224, 234, 235, 239-241, 243, 247, 252-256, 263, 268-271, 273, 274, 276, 282, 287, 292, 294, 297-299, 305-308

social media, 2, 6, 55, 57, 59, 62, 66-68, 73, 140, 183, 186, $188,189,224,229,231,233$, 242,296

melodrama, 132, 137, 140, 141, 302, 307,310

Men vi har ju nästan allting [But We Have Almost Everything] (TV film), 139

Messner, Michael A., 51

Metarmofos (Periodical publication), 132

\#Metoo campaign, 29, 68, 74

migration, $1,2,34,82,83,90,174$, 298, 300-302

Millenium Trilogy (Novels), 127, 153

Millroth, Thomas, 231, 232

Mills, Melinda C., 105, 110

Miss (YA novel), 11, 174, 175, 177, $178,180,189,191$

Mitchell, David T., 155, 169

Moby Dick (Novel), 156

Moeller, Susan D., 38

Mohr, Sebastian, 105, 111, 112, 114, $115,122,123$

Møller, Per Stig, 276
Moss, Elisabeth, 28

'Muhammed drawings', 276

Mukhtar-Landgren, Dalia, 257

Mulgan, Geoff, 252

Munoz, José, 202, 203

Munster, Anna, 56, 70

Munthe, Margrethe, 40

murder, 6, 7, 13, 104, 114, 120, 127, 129, 159, 168, 292, 293, 295, 297-299, 301-311

Murray, Robin, 252

Museum Hours (Film), 26

Musikhjülpen [Music Aid] (TV

programme), 253, 254

$\mathbf{N}$

Nåde [Grace] (Novel), 154

Nasiri, Marall, 114

nation, 33-35, 38, 40, 48, 49, 64, $104,108,109,112,121,122$, $261,269,279,301,302,310$

Nichols, Bill, 132, 294, 303

Nordicness, 283

Nordic noir, 5, 103, 127, 129, 130, $138,142,143,308,309$

normalcy, 91, 154, 155, 160, 168, 169

Norway, 3, 6, 8, 35, 36, 38, 40, 41, $43-51,58-60,63,67,72,73$, $75,90,92,110,112,122,123$, $163,173,223,226,227,243$

migration, 34

nostalgia, 141-143

Notary, Terry, 27

Noujaim, Jehane, 26

Nussbaum, Martha C., 82, 85, 86, 92, 94-97

O

Oksanen, Sofi, 11, 153, 154, 158-161, 163, 169 
Olausson, Sara, 12, 224-229,

$$
\text { 234-242 }
$$

Olin, Margreth, 8, 9, 34-42, 44, $46-50,81-83,85,87,90,94,97$

Orbach, Susie, 184

Øresund, 103, 104, 108-110, $113-115,119,121$

Oslo, 39, 187, 189, 226, 227

Oslo Massacres, 8, 34, 36-38

Östlund, Ruben, 8, 20, 22-27, 29

Other (the), 4, 8, 12, 13, 27, 34, $36,40,44,47,48,227,268$, $272-274,278,279,281,282$, $285,286,288$

Ozu, Yasujirō, 25

$\mathbf{P}$

P3 Documentar [P3 Documentary]

(Radio programme), 13, 291, 296-298, 302, 303, 305, 308-311

Palm, Göran, 138, 139, 141

Pålsson, Adam, 104

Paradise Hotel (TV programme), 7, 11, 196-198, 200-206, 208-215 Parekh, Serena, 84, 93, 97

Parsberg, Cecilia, 224

participation, 11, 12, 88, 227, 229, 230, 247, 248, 250, 252, 253, $255,256,258-263,269,275$

participatory design, $4,6,12$, 247-252, 254, 256, 258-261, 263

part-taking, 248, 262

paternalism, 9

Peckinpah, Sam, 23

Pedersen, Lars Nørgaard, 270

perfectionism, 174

societies of perfection, 190

performance, $10,12,25,27,73,224$, $228-230,232,233,242,243$

performative documentary, 42
Persson, Leif G.W., 308

Persson, Yngve, 131

Petersen, Alan, 51

Petherbridge, Danielle, 86, 87

Pichel, Beatriz, 280, 281

Play (Film), 20, 22, 23

The Poetics of Fragility (Art project), 29

political art, 223, 242

politics of emotion, 243, 292, 293, 310

postnationalism, $8,35,47,49$

power, $2,4,8,12,28,41,61-64,69$, $73,75,85,118,130,132,133$, $135,137,138,140,141,167$, $169,177,178,180,181,186$, 199, 200, 210, 224, 225, 239, 248, 249, 251, 259-261, 263, 275-277, 287, 294

Präg, Patrick, 105, 110

precariousness, 20,21, 34, 36, 48, 272

Presserom [Press Room] (Art project), 224

privilege, $3,4,7,8,20-23,25-27$, 29, 106-108, 113, 118, 121, $160,224,241$

projective city, 258, 259

prolonged waiting, 9, 81, 84, 85, 89, 90, 92-97

Puar, Jasbir K., 152

public service radio, $6,7,252,291$, 292

public sphere, $252,254,255,258$

quasi, 307

Q

Quayson, Ato, 155, 156, 158-161

queer

and feminist activism, 7, 11, 196, $197,200,212,215$ 
$\mathbf{R}$

Răducanu, Georghe, 232, 233

RAMT series (Art project), 12, 267, 268, 275, 281, 284

Rasmussen, Lars Løkke, 269, 270, 278, 286

reality TV show, 200

refugees, 4, 8, 33-38, 40-49, 90, 91, 94

child refugees, 9, 81-85, 87-93, 95-97

Reich, Wilhelm, 64

reproductive health services, 105

resistance, $2,10-12,21,108,174$, $177,178,181-183,185,186$, $190,191,213,225,262$

Resnais, Alain, 25

responsiveness, 10, 103, 107, 111, 272, 311

Rettberg, Jill Walker, 186, 189

revenge porn, 67,74

Rezai, Abbas, 300

Ridderstedt, Maria, 239

Rogers, Wendy, 21

Rohde, Martin, 104, 138

Romania, 12, 223, 224, 226, 228-230, 232, 234-236, 239-243

Rosenberg, Tiina, 213, 214

Rosenfeldt, Hans, 103

Ryberg, Ingrid, 2, 3, 7, 197, 199

Rydström, Jens, 3, 152, 158

\section{$S$}

The Sacred Art of Dying (Novel), 179, 183

Sahindal, Fadime, 297-299, 308

Sandgren, Gustav, 136

Scandinavia

Scandi crime, 5, 128

Scandinavian contemporary art, 2
Scandinavian welfare state, $4-7,10$, $55,63,64,72,107,121,129$, 178

scar, 13, 38, 39, 270, 282, 286

Schäffer, Anne, 192

Schlingensief, Christoph, 224

school dropout, 4, 177, 182, 191

Scully, Jackie Leach, 157, 162, 163, 165

Second World War/World War II, 63 Sedgwick, Eve Kosofsky, 200, 213

Shakespeare, Tom, 154

sharing, $8,9,55-57,60,61,65-69$, $72,74,75,248,260,262$

Shildrick, Margrit, 157, 200 signal, 57, 118, 208

Silbersky, Leif, 308

Silver, Anna, 235

Sjöwall, Per, 120, 308, 309

SKAM , 9, 56-58, 63, 70, 71, 73, 189

Skärgairdsdoktorn [The Archipelago Doctor] (TV series), 137

Skeggs, Beverly, 197-199, 202, 204, 206, 296, 302, 306

Snyder, Sharon L., 155, 169

social commitment, 128, 130, 132, 133

Söder, Björn, 225-227, 235, 240, 242

Söderman, Jackie, 136, 138

Sørensen, Birgitte Refslund, 268, 269, $273,274,282$

Sourander, Andre, 82, 83, 89

space

common, 212, 252, 253

imagined, 104, 121

public, $65,76,304$

safe, 138, 203, 209, 212, 213, 215

urban, 109

Spinoza, Baruch, 61, 73

The Square (Film), 8, 20, 24-26, 29 
Stangertz, Göran, 138

Stein, Björn, 103

stereotypes, 35, 50, 213, 215, 233

Stoenescu, Arina, 235, 236, 239, 241

Straume, Anne Cathrine, 180

Straw Dogs (Film), 23

suffering, $21,22,44,47,60,83-86$, $120,137,141,162,168,187$, 232, 268, 272, 273, 278, 279, 281, 282, 284-286

surrogacy, 10, 106, 112, 113, $115-120,123$

surveillance, 72, 199, 301

Sweden artificial reproductive technology, 6 , 111

folkhemmet, 130, 141, 144

migration, 298, 301

public service radio, $6,7,252,291$, 292

public service television, 133

welfare state, 5, 7, 10, 104, 120, $130,131,134,309$

Systrar, 141, 143

T

Tarkovsky, Andrei, 25

Thain, Alanna, 57, 65

Thorning-Schmidt, Helle, 275, 278, 286

Toleranshuvan Reloaded (Art project), 224, 225, 227, 229, 231-234, 241,242

Traavik, Morten, 224

trade unions, 12, 250, 251

trauma, $8,34,36-38,44,49,83,84$, $89,118,120,152,179,200$, 203, 270, 297

Tretton dagar [Thirteen Days] (TV film), 138, 139

Trier, Lars von, 58
Turist (Force Majeure) (Film), 20, $22-25,27$

TV

reality $\mathrm{TV}, 4,7,10,11,196,197$, $199,200,203,205,296,302$, 303,306

TV drama, 5, 6, 10, 128-130, $133-137,139,142-144$

TV series, 2, 6, 8-10, 56-58, 152, 208

$\mathrm{U}$

Ullmann, Linn, 11, 154, 163-167

UN Child Convention, 36, 82, 97

Uncle Tom's Cabin (Novel), 156

UNHCR, 81, 82, 87, 90, 93, 94, 96

Uppdrag granskning [Mission:

Investigate] (TV programme), 130

Utøya, 36, 37

V

Vår tid är nu [Our Time Is Now]

(TV series), 141

Vermot, Cécile, 51

veterans, 13, 120, 268-271, 273, $274,279-282,285,287$

victim, $10,13,27,35,36,42,67$, $104,114,117,119,120,122$, $139,144,268,272-274,282$, 284, 292, 293, 295, 303-308, 310,311

viewer positions, 196, 200, 212, 215 violence, $8,22,23,28,33,72,127$, $267,268,270-274,276-278$, 280, 281, 286, 301, 303, 304, 310

vulnerability

conditional, 8, 21, 23, 28, 29

corporeal, 22, 29, 177, 225, 234

linguistic, 177, 225, 234, 242 
ontological, 3, 85, 157, 165, 167, 260,307

and power, 2, 4, 167, 186, 199, 200

productive, $28,87,109,256$

relational, $2,168,178$

tactics of, 12, 224, 225, 228, 229

vulnerable child, $45,47,84,85$, 90-92, 95-97

vulnerable subject, $9,10,21,25,26$, $104,107,111,271$

W

Wahlöö, Maj, 120, 308, 309

Waldahl, Ragnhild Holmen, 173, 174, 182

War Problems (Art project), 279, 280

Wednesday Play (series of British television plays), 133

Weiland, Colin, 140 welfare state

health care, 10, 110, 117, 131, $142,190,309$

migration, 174

school, 120, 131, 134, 142, 182

Wendel Rosenberg, Eva, 113

Werner, Wouter G., 294, 295, 299, 308

Westh, Asger, 270

What Ever Happened to Baby Jane? (Film), 159, 161, 162

Wilke, Hannah, 29

Wojnarowicz, David, 29

Wood, Helen, 197-199, 202, 206

wounds, 13, 67, 267-271, 273-275, $277-283,286,287,292$

Z
Žižek, Slavoj, 143
Zylinska, Joanna, 29, 69, 70 